Universidade de São Paulo

Faculdade de Filosofia, Ciências e Letras de Ribeirão Preto Departamento de Química

Programa de Pós-Graduação em Química

\title{
"Aplicação da teoria ac de eletrodos porosos na investigação da cinética de dispositivos eletrocatalíticos"
}

\section{LILIANE APARECIDA DE CARVALHO}

Tese apresentada à Faculdade de Filosofia Ciências e Letras de Ribeirão Preto da Universidade de São Paulo, como parte das exigências para a obtenção do Título de Doutor em Ciências, Área: Química

RIBEIRÃO PRETO - SP 


\section{FICHA CATALOGRÁFICA}

\section{Carvalho, Liliane Aparecida}

Aplicação da teoria $a c$ de eletrodos porosos na investigação da cinética de dispositivos eletrocatalíticos. Ribeirão Preto - 2008.

175 p. : il. ; $30 \mathrm{~cm}$

Tese apresentada à Faculdade de Filosofia Ciências e Letras de Ribeirão Preto da Universidade de São Paulo, como parte das exigências para a obtenção do Título de Doutor em Ciências, Área: Química

Orientadora: De Andrade, Adalgisa Rodrigues

1. Impedância. 2. Modelo de Poros. 3. ADE. 4. Célula a Combustível. 
Universidade de São Paulo

Faculdade de Filosofia, Ciências e Letras de Ribeirão Preto Departamento de Química

Programa de Pós-Graduação em Química

"Aplicação da teoria ac de eletrodos porosos na investigação da cinética de dispositivos eletrocatalíticos"

Liliane Aparecida de Carvalho Orientadora: Prof ${ }^{a}$ Dr $^{a}$ Adalgisa Rodrigues de Andrade

RIBEIRÃO PRETO - SP

2008 
"Les grands accamplissements sant réussis nan par la farce, mais par la persévérance." 


\section{AGRADECIMENTOS}

\section{$\grave{A}$ Deus.}

Aos meus pais Luzia e Pedro que sempre acreditaram em mim, as minhas irmãs Luciana e Luzia e meu irmão Adalberto pelo apoio sempre. Aos meus cunhados, sobrinhos e familiares em geral pelos momentos de alegria em família. 
À Prof $^{a}{ }^{2} r^{a}$ Adalgisa Rodrigues de Andrade por me dar a oportunidade de trabalhar no Laboratório de Eletrocatálise e Eletroquímica Ambiental de Ribeirão Preto, por acreditar em mim e nunca me deixar desistir mesmo nos momentos mais difíceis. Obrigada pela paciência e o incentivo. Pelas discussões e mesmo as broncas muitas vezes necessárias, mas que me ajudaram a chegar até o fim. Obrigada especialmente pela amizade e os emails de apoio mesmo a distância. 
Aos Profs. Drs. Paulo Olivi e Herenilton pelas discussões, a convivência e a amizade.

Ao Prof. Dr. Paulo Roberto Bueno pela co-orientação.

Ao Prof. Dr. Antonio Carlos Dias Ângelo da UNESP de Bauru pela atenção e amizade.

Ao Prof. Dr Fritz Cavalcante Huguenin pela atenção e discussões.

A CAPES pelas bolsas de doutorado e PDEE (sanduíche).

À minha amiga em especial Dr $^{\mathrm{a}}$ Juliane Forti pelas discussões experimentais, as palavras de apoio longe ou perto, os cafézinhos e principalmente a amizade.

Ao Prof. Dr. Josimar Ribeiro pelas discussões sobre impedância ao longo de tantos anos de trabalho juntos, as ajudas no laboratório e a amizade.

A amiga Dr ${ }^{a}$ Fabiana Purgato pelas discussões sobre células a combustível, a ajuda nos testes experimentais, as conversas, o apoio e a amizade.

Aos amigos do Laboratório de Eletrocatálise e Eletroquímica Ambiental de Ribeirão Preto: Fernando, Talita, Tiaguinho, Carô, Élen, Franciane, Isabel.

Ao Sidney Neto, Thiagão, Aristeu e o Rodrigo (Xyz) pela amizade e por manter sempre o bom humor presente no laboratório.

Ao Ângelo pela imensa ajuda na fase final do trabalho, a ajuda na preparação dos materiais, pelas discussões nos estudos de célula a combustível e pela bela amizade que acabou surgindo.

Aos técnicos Luiza e Valdir. E a secretária Lâmia pela ajuda nas burocracias, documentos, sempre com muito bom humor e simpatia.

Ao Bruno Gonçalves pela presença em todos os momentos bons ou ruins, pelos emails e telefonemas quando distante, pelas risadas, baladinhas, broncas e pela amizade sempre.

E aos amigos que sempre proporcionaram os momentos de diversão para descansar a mente: Marina Ness e Jamanta, Renata Neres, Luxaxa, Wagninho, Dri, Bruna, Paula e Pito, Carol Rigos, Quê, Fer Paschoalin. E os amigos de Sherbrooke: João, Fernando, Imaculada, Danusa, Carla, Gegê, Carol, Filipe e Caro, Camila e Marlon, Yves, Etienne e Sarah. 


\section{REMERCIEMENTS}

Je remercie Prof. Dr. Andrzej Lasia de m'avoir permis d'intégrer son équipe de recherche à l'Université de Sherbrooke et pour son attention, ses conseils, sa patience et son amitié.

Je tiens aussi à remercier les étudiants de l'Équipe d'Électrochimie de l'Université de Sherbrooke, Manuel Martin, Hugues Duncan et Marie-Lise Tremblay, pour leur aide, leur patience et nos discussions sur l'impédance.

Merci aussi à la famille de Louise Provencher et de Claude Courtemanche, ma deuxième famille, qui m'a accueillie à Sherbrooke et m'a gratifiée de beaux moments de bonheur et d'amour en famille. 
Je voudrais terminer en remerciant mon mari Sébastien Côté pour sa confiance en moi, pour ses mots d'encouragement prodigués sans arrêt, pour sa présence constante autant dans les moments de stress que dans les moments de bonheur, pour son amitié et son soutien en faisant tout le temps le maximum possible pour m'aider. Merci Sébastien pour tout ce que tu m'as apporté et tout ce que tu m'apportes au quotidien. 


\section{SUMÁRIO}

Abreviações e Símbolos............................................................................... i

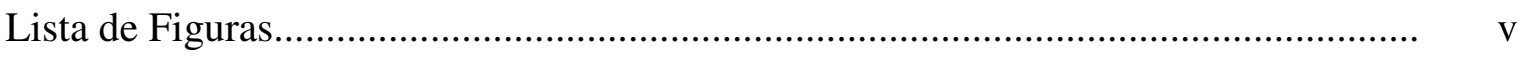

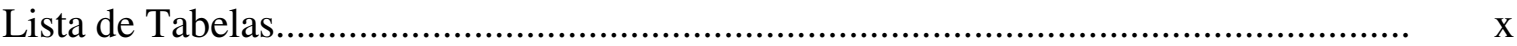

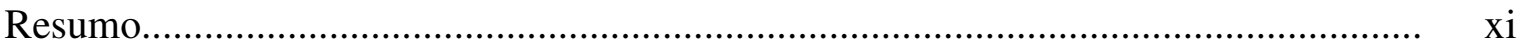

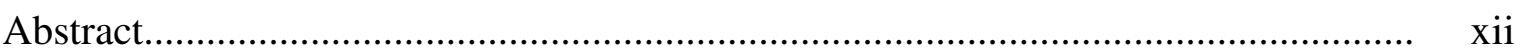

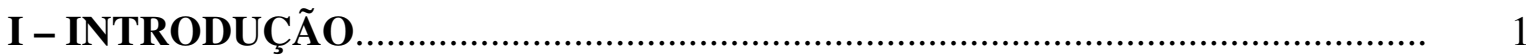

I.1 Espectroscopia de Impedância Eletroquímica (EIE)............................... 1

I.1.1 Modelo para eletrodos porosos................................................ 5

I.1.2 A EIE na presença de reações eletroquímicas............................. 14

I.2 Voltametria $a c$ ( Espectroscopia de Impedância Eletrodinâmica)................ 18

I.3 EIE e Voltametria $a c$ aplicadas a eletrocatalisadores............................... 20

I.3.1 Ânodos Dimensionalmente Estáveis (ADEs)............................ 20

I.3.1.1 EIE aplicada a ADEs................................................. 22

I.3.2 Células a combustível.......................................................... 25

I.3.2.1 Células a combustível de etanol (DEFCs)..................... 30

I.3.2.2 Catalisadores utilizados em DEFCs............................. 34

I.3.2.3 EIE e voltametria ac aplicadas a células a combustível de etanol

II- OBJETIVO

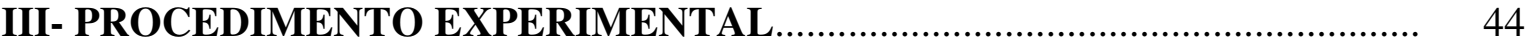

III.1 Preparação dos precursores poliméricos................................................ 44

III.1.1 Preparação da resina precursora de Titânio................................. 44

III.1.2 Preparação da resina precursora de Rutênio............................... 44

III.1.3 Preparação da resina precursora de Estanho............................. 45

III.1.4 Preparação da resina precursora de Platina................................ 46

III.2 Preparação dos eletrodos de trabalho e célula eletroquímica.................... 47 
III.3 Procedimento experimental utilizado nos estudos dos ADEs de

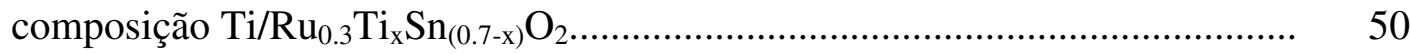

III.3.1 Eletrodos e eletrólito de suporte........................................... 50

III.3.2 Equipamentos e condições experimentais.................................. 51

III.4 Procedimento experimental utilizado no estudo dos eletrodos de

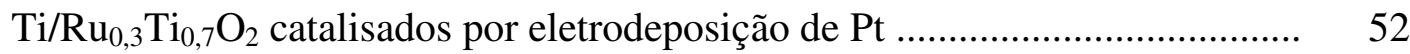

III.4.1 Eletrodos e eletrólito de suporte............................................. 52

III.4.2 Equipamentos e condições experimentais................................. 53

III.5 Procedimento experimental dos ânodos de Pt, Pt:Sn, Pt:Ru e Pt:Ru:Sn para oxidação de etanol............................................................................. 53

III.5.1 Eletrodos e eletrólito de suporte ............................................ 53

III.5.2 Equipamentos e condições experimentais................................ 55

III.5.3 Procedimento experimental utilizado para os testes de células a combustível de etanol (DEFCs).................................................... 58

III.5.3.1 Ativação do carbono Vulcan XC 72.......................... 58

III.5.3.2 Preparação do MEA (Membrane Electrode Assembled) ................................................................. 58

III.5.3.3 Equipamentos e condições experimentais................... 59

III.5.4 Microscopia Eletrônica de Varredura (MEV), Espectrometria de Energia Dispersiva de Raios-X (EDX)...................................... 61

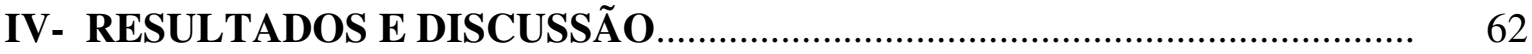

IV.1 Investigação dos ADEs de composição $\mathrm{Ti} / \mathrm{Ru}_{0,3} \mathrm{Ti}_{(0,7-\mathrm{x})} \mathrm{Sn}_{\mathrm{x}} \mathrm{O}_{2}$ em meio ácido.

IV.1.1 Voltametria $d c$ e diagramas de EIE.................................... 62

IV.1.2 Aplicação do modelo de poros de EIE..................................... 66

IV.1.3 EIE e Tafel para eletrodos de composição Ti/ $\mathrm{Ru}_{0,3} \mathrm{Sn}_{0,7} \mathrm{O}_{2} \ldots \ldots . . \quad 78$

IV 1.4 Conclusões........................................................................ 84 
IV.2 Efeito da adição de Pt por eletrodeposição sobre eletrodos de composição $\mathrm{Ti} / \mathrm{Ru}_{0,3} \mathrm{Ti}_{0,7} \mathrm{O}_{2}$ em meio ácido................................................. $\quad 85$

IV.2.1 Efeito da composição eletródica............................................ 85

IV.2.2 Uma análise do modelo de poros aplicando-se um circuito equivalente (CE) e uma linha de transmissão (LT) ........................................ 93

IV.2.3- EIE e Tafel para o eletrodo de $\mathrm{Ti} / \mathrm{Ru}_{0,3} \mathrm{Ti}_{0,7} \mathrm{O}_{2}+100 \mu \mathrm{g} \mathrm{cm}$ de Pt eletrodepositada...................................................................... 95

IV.2.4 Conclusões........................................................................... 99

IV.3 Investigação dos eletrodos de composição Pt, Pt:Sn (80:20), Pt:Ru (80:20) e Pt:Ru:Sn (80:10:10) na presença de etanol.................................. 100

IV.3.1 MEV e EDX.................................................................... 100

IV.3.2 Voltametria $d c$ e capacitância da dupla camada elétrica.......

IV.3.2.1 Determinação da capacitância da dupla camada elétrica em eletrólito de suporte $\left(\mathrm{H}_{2} \mathrm{SO}_{4} 0,5\right.$ moldm $\left.^{-3}\right)$

IV.3.2.2 Determinação da capacitância da dupla camada elétrica na presença de etanol $\left(1 \mathrm{~mol} \mathrm{dm}^{-3}\right)$.

IV.3.3 Cronoamperometria e EIE na presença de etanol..................... 116

IV.3.4 Voltametria $a c$ na presença de etanol.................................... 132

IV.3.5 Testes de células a combustível de etanol............................... 141

IV .3.6 Conclusões....................................................................... 144

V- CONCLUSÕES FINAIS........................................................... 146

VI- REFERÊNCIAS BIBLIOGRÁFICAS........................................... 147 


\section{ABREVIAÇÕES E SÍMBOLOS}

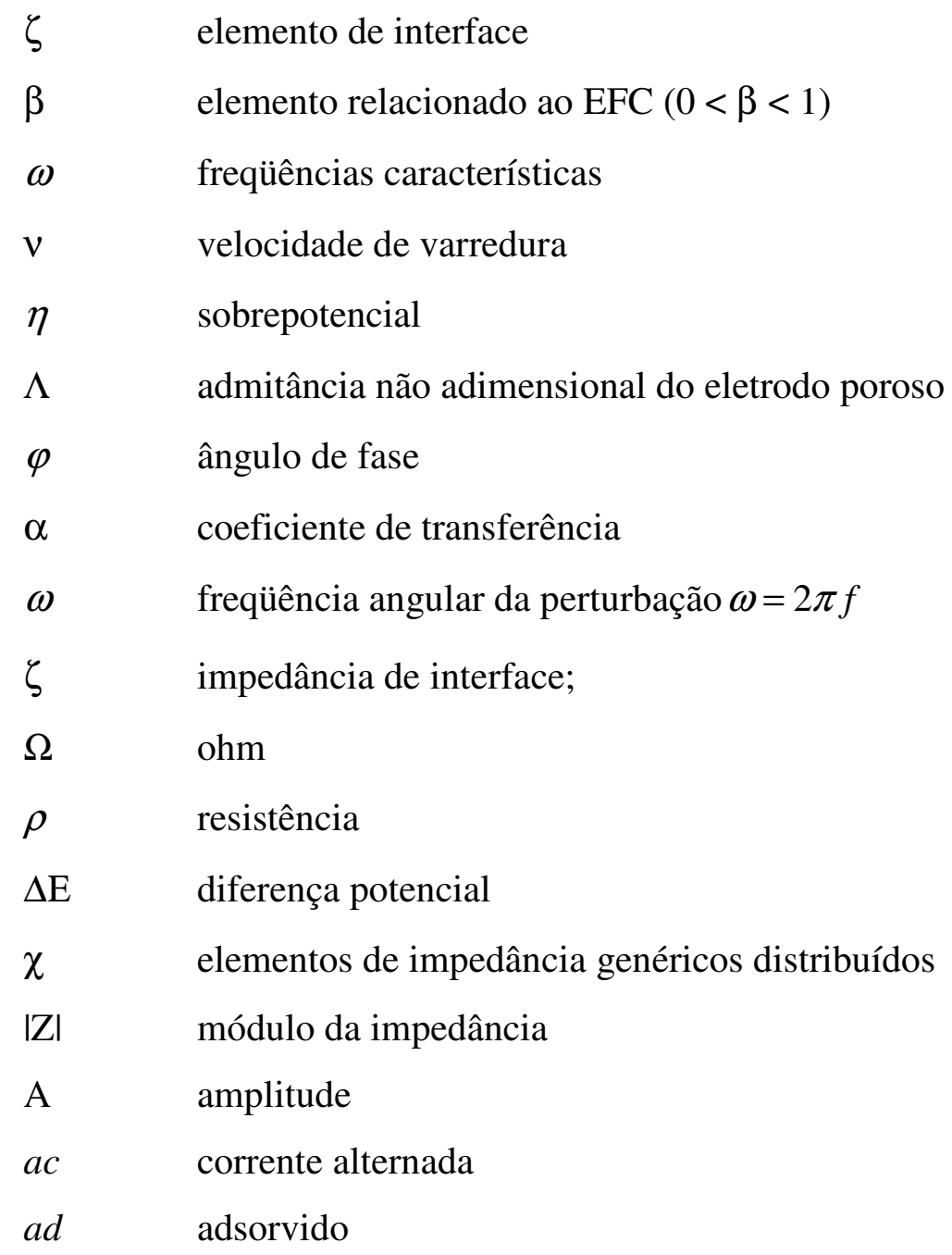

ADE-T Ânodos Dimensionalmente estáveis preparados pela metodologida tradicional AFC Células a Combustível Alcalinas

$b \quad$ coeficiente angular de Tafel

C capacitância

c capacitância em série

CC Células a combustível 
$\mathrm{C}_{\mathrm{dc}} \quad$ capacitância da dupla camada elétrica

CE circuito equivalente

$C_{o} \quad$ concentração das espécies oxidadas

$C_{R} \quad$ oncentração das espécies reduzidas

D o coeficiente de difusão do íon no eletrólito

dc corrente contínua

DCE dupla camada elétrica

DEFCs Células diretas de etanol

DEMS Espectrometria de Massas Eletroquímica Diferencial

DMFCs Células diretas de metanol

$\tilde{E} \quad$ potencial $a c$

EDX Espectrometria de Energia Dispersiva de Raios X

EFC Elemento de Fase Constante

EIE Espectroscopia de Impedância Eletroquímica

ERH eletrodo reversível de hidrogênio

F $\quad$ Faraday

$f \quad$ frequiência

$f_{c} \quad$ freqüência de relaxação característica

FTIRS Espectrometria de infravermelho por transformada de Fourier in situ

g grama

h hora

$\mathrm{Hz} \quad$ Hertz

$\tilde{I} \quad$ corrente de troca

$i \quad$ corrente

$k \quad$ constantes de velocidade

L comprimento da camada de óxidos

$l \quad$ comprimento do poro

LT linha de transmissão

M metal

MCFCs Célula de Combustível de Carbonato 
MEA (Membrane Electrode Assembled) conjunto ânodo/ membrana/ cátodo

MEV Microscopia Eletrônica de Varredura

min. minutos

n número de elétrons

$\mathrm{n} \quad$ número de poros

O espécie oxidada

oxi oxidação

$\mathrm{p} / \mathrm{p} \quad$ pico a pico

PAFCs Célula de combustível de ácido fosfórico

PEMFCs Célula de Combustível com Membrana para Troca de Próton

$Q_{d c} \quad$ CPE referente a capacitância da dupla camada elétrica

$q_{d c} \quad$ CPE distribuído, referente a capcitância da dupla camada elétrica

r raio do poro

$r \quad$ resistência distribuída em série

$R_{\Omega} \quad$ resistência ôhmica

$\mathrm{RDCl}$ reações de oxidação de cloro

RDH reação de desprendimento de hidrogênio

RDO reação de oxidação de oxigênio

red redução

$r_{f} \quad$ resistência distribuída, relacionada ao filme de óxidos

$R_{f} \quad$ resistência total do filme de óxidos

$R_{L} \quad$ resistência limite determinada pela intersecção com o eixo real no circuito de Randles

rms amplitude rms (root mean square, raíz média quadrada)

$R_{\text {sol }} \quad$ resistência da solução

$R_{t c} \quad$ resistência de transferência de carga

$r_{t c} \quad$ resistência de transferência de carga distribuída

$s \quad$ segundos

SOFC Célula de Combustível de Óxido Sólido

$\mathrm{T}_{\text {calc } \quad \text { temperatura de calcinação }}$ 


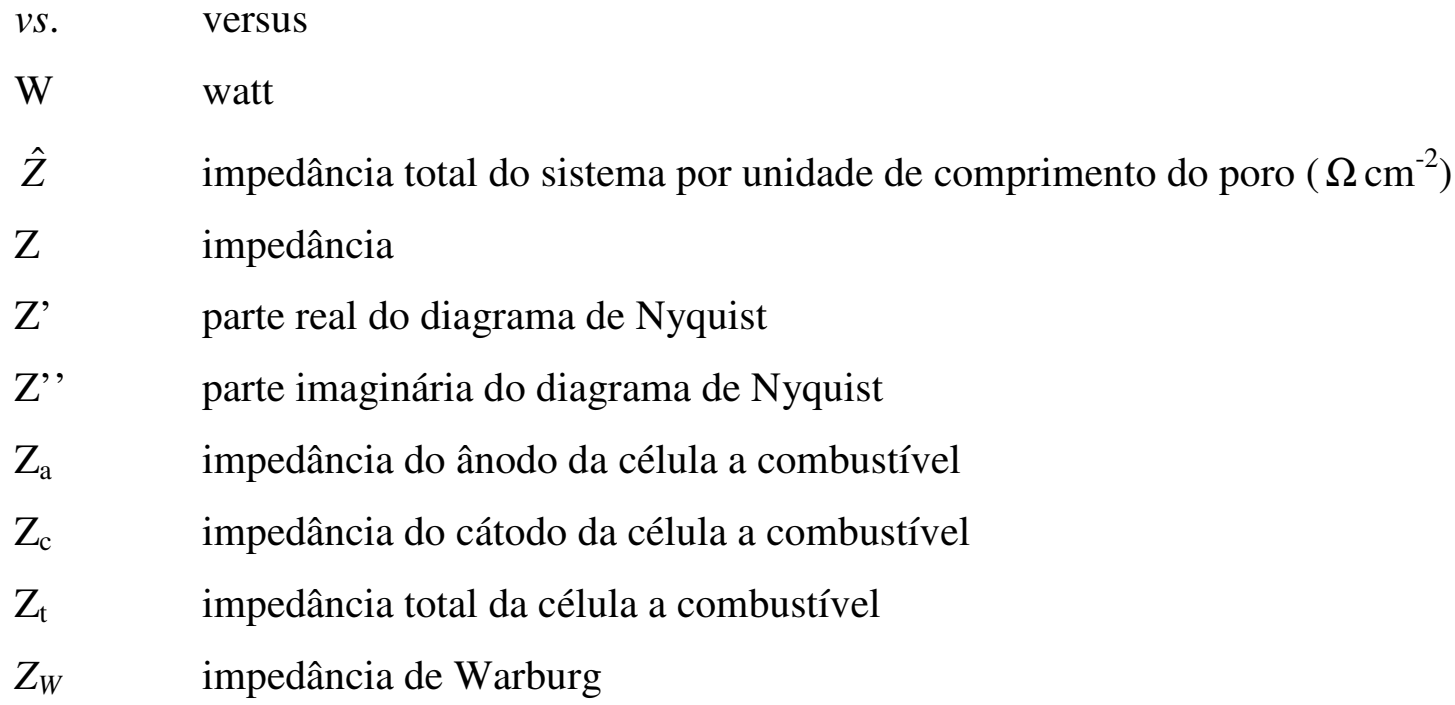




\section{LISTA DE FIGURAS}

Figura 1: Exemplos de: (a) um circuito elétrico e (b) seu diagrama de Nyquist representativo [21].

Figura 2: Diagrama de BODE, representativos para um sistema com comportamento como o apresentado na Figura 1. (a) Z e (b) $\varphi$ em função de $\log f$ [21]

Figura 3: Modelo de eletrodo poroso cilíndrico. A área cinza é não-condutora [21]

Figura 4: Diagrama de Nyquist representativo de um eletrodo poroso, com $n$ poros cilíndricos proposto por Levie [21].

Figura 5: Linha de transmissão representativa de um sistema de eletrodo poroso idealmente polarizado, onde $\mathrm{r}$ representa a resistência da solução e $c$ a capacitância da dupla camada elétrica, distribuídas ao longo do comprimento do poro [21]

Figura 6: Linha de transmissão generalizada. (a) generalização para dois canais e (b) generalização para um canal. $\chi_{1}, \chi_{2}$ e $\zeta$ são elementos de impedância generalizados. $\chi_{1}$ e $\chi_{2}$ são as impedâncias generalizadas para os canais 1 e 2 , respectivamente, e $\zeta$ para a "interface" que os conecta....

Figura 7: Circuito do tipo Randles (no topo) e sua resposta idealizada no plano de impedância complexa.

Figura 8: Esquema representativo do potencial aplicado em função do tempo em medidas de: - Voltametria Cíclica $a c$ e-Voltametria Cíclica $d c$

Figura 9: Esquema de uma célula a combustível de etanol [111]

Figura 10: Proposta mecanística da oxidação do etanol de acordo com referência [113]

Figura 11: Proposta mecanística da oxidação do etanol de acordo com referência [117]....

Figura 12: Esquema do processo de deposição das soluções precursoras no suporte de Ti metálico para preparação dos eletrodos de trabalho.

Figura 13: Eletrodo de trabalho de em suporte de titânio pronto para uso

Figura 14: eletrodo de referência de $\mathrm{Hg}-\mathrm{Hg}_{2} \mathrm{SO}_{4}$ e célula eletroquímica utilizados em todos os experimentos.....

Figura 15: Fluxograma representativo dos experimentos de cronoamperometria na presença de etanol realizados com eletrodos de todas as composições. Esse procedimento foi realizado no sentido positivo e negativo de potencial de cada eletrodo

Figura 16: Esquema representativo da célula utilizada para os estudos de DEFCs.

Figura 17: Voltamogramas cíclicos registrados durante os intervalos dos experimentos de EIE, para o eletrodo de composição Ti/ $\mathrm{Ru}_{0,3} \mathrm{Sn}_{0,7} \mathrm{O}_{2}, v=20 \mathrm{mV}$ $\mathrm{s}^{-1}$, em meio ácido $\left(1 \mathrm{HClO}_{4} \mathrm{~mol} \mathrm{\textrm {dm } ^ { - 3 }}\right)$. Espessura nominal $=1 \mu \mathrm{m}$. $\mathrm{T}_{\text {calc. }}=400^{\circ} \mathrm{C}$.

Figura 18: Diagramas de Nyquist em diferentes potenciais para o eletrodo 
$\mathrm{Ti} / \mathrm{Ru}_{0,3} \mathrm{Sn}_{0,7} \mathrm{O}_{2} \quad$ em $\quad \mathrm{HClO}_{4} \quad 1$ mol $\mathrm{dm}^{-3}, \quad \mathrm{~T}=25^{\circ} \mathrm{C}, \quad \mathrm{A}=5 \mathrm{mV}$, $1 \mathrm{~m} \mathrm{~Hz}<f<100 \mathrm{kHz}$.

Figura 19: Diagramas de BODE em diferentes potenciais para o eletrodo $\mathrm{Ti} / \mathrm{Ru}_{0,3} \mathrm{Sn}_{0,7} \mathrm{O}_{2}$ em $\mathrm{HClO}_{4} 1 \mathrm{~mol} \mathrm{dm}{ }^{-3}, \quad \mathrm{~T}=25{ }^{\circ} \mathrm{C}, \quad \mathrm{A}=5 \mathrm{mV}$, $1 \mathrm{~m} \mathrm{~Hz}<f<100 \mathrm{kHz}$. (A) $\log \mid \mathrm{ZI}$ e (B) ângulo de fase em função de $\log f / \mathrm{Hz} . . . . .$.

Figura 20: Diagrama de Nyquist com a curva teórica e a experimental, para o eletrodo Ti/ $\mathrm{Ru}_{0,3} \mathrm{Sn}_{0,7} \mathrm{O}_{2}$ em $\mathrm{HClO}_{4} 1 \mathrm{~mol} \mathrm{dm}^{-3}$, $\mathrm{T}=25{ }^{\circ} \mathrm{C}, \mathrm{E}=1,50 \mathrm{~V}$ vs. ERH...

Figura 21: Linha de transmissão que representa fisicamente os dados experimentais dos eletrodos $\mathrm{Ti} / \mathrm{Ru}_{0,3} \mathrm{Ti}_{(0,7-\mathrm{x})} \mathrm{Sn}_{\mathrm{x}} \mathrm{O}_{2}$ (x = 0; 0,3 e 0,7), no intervalo de potencial de 0,20 a $1,60 \mathrm{~V} v s . \mathrm{ERH}$

Figura 22: Diagrama de Nyquist em diferentes potenciais do eletrodo de composição Ti/ $\mathrm{Ru}_{0,3} \mathrm{Sn}_{0,7} \mathrm{O}_{2}$ em meio de $\mathrm{HClO}_{4}\left(1 \mathrm{~mol} \mathrm{dm}{ }^{-3}\right), 1 \mathrm{~m} \leq f \leq 100 \mathrm{k} \mathrm{Hz}$, Amplitude $=5 \mathrm{mV}$ p/p. (羊) valores teóricos, (O) valores experimentais

Figura 23: Valores de $R_{\Omega}$ em função do potencial para as diferentes composições investigadas. Sendo: - - - $\mathrm{Ti}^{-} \mathrm{Ru}_{0,3} \mathrm{Ti}_{0,7} \mathrm{O}_{2}, \quad-\bullet-$ $\mathrm{Ti} / \mathrm{Ru}_{0,3} \mathrm{Ti}_{0,4} \mathrm{Sn}_{0,3} \mathrm{O}_{2}$ e $\longrightarrow-\mathrm{Ti} / \mathrm{Ru}_{0,3} \mathrm{Sn}_{0,7} \mathrm{O}_{2}$.

Figura 24: (- $\boldsymbol{\Delta}_{-}$) Valores de $Q_{d c}$ (obtidos por LT) em função do potencial e (一) curva $\mathrm{i} v s$. E (obtida por voltametria cíclica), do eletrodo $\mathrm{Ti} / \mathrm{Ru}_{0,3} \mathrm{Ti}_{0,7} \mathrm{O}_{2}$, velocidade de varredura de $20 \mathrm{mV} \mathrm{s}^{-1}$, em meio ácido $\left(\mathrm{HClO}_{4} 1 \mathrm{~mol} \mathrm{dm}^{-3}\right)$...........

Figura 25: Valores da resistência do filme, $R_{f}$ em função do potencial (V vs. ERH), obtidos do ajuste dos dados experimentais do eletrodo de composição $\mathrm{Ti} / \mathrm{Ru}_{0,3} \mathrm{Sn}_{0,7} \mathrm{O}_{2}$

Figura 26: Diagramas de Nyquist para as diferentes composições investigadas. Sendo: $\square \mathrm{Ti} / \mathrm{Ru}_{0,3} \mathrm{Ti}_{0,7} \mathrm{O}_{2}, \bigcirc \mathrm{Ti} / \mathrm{Ru}_{0,3} \mathrm{Ti}_{0,4} \mathrm{Sn}_{0,3} \mathrm{O}_{2}$ e $\diamond \mathrm{Ti} / \mathrm{Ru}_{0,3} \mathrm{Sn}_{0,7} \mathrm{O}_{2}$. (A) na região da $\mathrm{DCE}, \mathrm{E}=0,85 \mathrm{~V}$ vs. $\mathrm{ERH}$ (b) na região da $\mathrm{RDO}, \mathrm{E}=1,525 \mathrm{~V} v s$. ERH

Figura 27: Valores de $R_{t c}$ em função do potencial para as diferentes composições investigadas. Sendo: - $-\mathrm{Ti} / \mathrm{Ru}_{0,3} \mathrm{Ti}_{0,7} \mathrm{O}_{2}, \quad-\bullet-$ $\mathrm{Ti} / \mathrm{Ru}_{0,3} \mathrm{Ti}_{0,4} \mathrm{Sn}_{0,3} \mathrm{O}_{2}$ e $\longrightarrow-\mathrm{Ti} / \mathrm{Ru}_{0,3} \mathrm{Sn}_{0,7} \mathrm{O}_{2}$.

Figura 28: Resistência de transferência de carga, $R_{t c}\left(\Omega \mathrm{cm}^{2}\right)$ em função do potencial (V vs. ERH), para a composição $\mathrm{Ti} / \mathrm{Ru}_{0,3} \mathrm{Sn}_{0,7} \mathrm{O}_{2}$.

Figura 29: Curva de Tafel (E vs. Log i), (一) sem correção e (一) com correção para queda ôhmica, do eletrodo de composição Ti/ $\mathrm{Ru}_{0,3} \mathrm{Sn}_{0,7} \mathrm{O}_{2}$....

Figura 30: Curva de $R_{t c}$ em função do potencial: (O) valores obtidos por EIE e $(\bullet)$ valores obtidos a partir dos valores de $i$ obtido na curva de Tafel do eletrodo de composição $\mathrm{Ti} / \mathrm{Ru}_{0,3} \mathrm{Sn}_{0,7} \mathrm{O}_{2}$.

Figura 31: Voltamogramas cíclicos característicos dos eletrodos sendo: $-\mathrm{Ti} / \mathrm{Ru}_{0,3} \mathrm{Ti}_{0,7} \mathrm{O}_{2} \mathrm{e}-\mathrm{Ti} / \mathrm{Ru}_{0,3} \mathrm{Ti}_{0,7}+\mathrm{Pt} 100 \mu \mathrm{g} \mathrm{cm}^{-2} . \mathrm{v}=50 \mathrm{mV} \mathrm{cm}{ }^{-2}$, em meio de $\mathrm{H}_{2} \mathrm{SO}_{4} 0,5 \mathrm{~mol} \mathrm{dm}^{-3}, \mathrm{~T}=25^{\circ} \mathrm{C}$. 
Figura 32: Diagramas de Nyquist em diferentes composições eletródicas. Sendo: $\square \mathrm{Ti} / \mathrm{Ru}_{0,3} \mathrm{Ti}_{0,7} \mathrm{O}_{2}, \quad \bigcirc \mathrm{Ti} / \mathrm{Ru}_{0,3} \mathrm{Ti}_{0,7}+\mathrm{Pt} 100 \mu \mathrm{g} \mathrm{cm}{ }^{-2}$. (A) Região da DCE, E $=0,15 \mathrm{~V} v s$. ERH e (B) Região da RDO, E = 1,54 V vs. ERH.

Figura 33: (A) Valores de $R_{\Omega}$ e (B) $r_{f}$ em função do potencial para: $-\mathbf{-}-\mathrm{Ti} / \mathrm{Ru}_{0,3} \mathrm{Ti}_{0,7} \mathrm{O}_{2} \mathrm{e}-\longrightarrow-\mathrm{Ti} / \mathrm{Ru}_{0,3} \mathrm{Ti}_{0,7}+\mathrm{Pt} 100 \mu \mathrm{g} \mathrm{cm}{ }^{-2}$.

Figura 34: (A) Valores de $Q_{d c}$ e (B) $\beta$ em função do potencial para as diferentes composições investigadas. Sendo: - - - $\mathrm{Ti} / \mathrm{Ru}_{0,3} \mathrm{Ti}_{0,7} \mathrm{O}_{2}$, $-\bullet-$ $\mathrm{Ti} / \mathrm{Ru}_{0,3} \mathrm{Ti}_{0,7}+\mathrm{Pt} 100 \mu \mathrm{g} \mathrm{cm} \mathrm{cm}^{-2}$

Figura 35: Valores de $R_{t c}$ em função do potencial para as diferentes composições investigadas. Sendo: - - - $\mathrm{Ti}^{2} \mathrm{Ru}_{0,3} \mathrm{Ti}_{0,7} \mathrm{O}_{2}, \quad-\bullet-$ $\mathrm{Ti} / \mathrm{Ru}_{0,3} \mathrm{Ti}_{0,7}+\mathrm{Pt} 100 \mu \mathrm{g} \mathrm{cm}{ }^{-2}$

Figura 36: Circuito equivalente utilizado no ajuste dos dados experimentais do eletrodo de composição Ti/ $\mathrm{Ru}_{0,3} \mathrm{Ti}_{0,7}$ com $100 \mu \mathrm{gcm}^{-2}$ de Pt eletrodepositada, na região da RDO (entre 1,4 a 1,6 V vs. ERH).

Figura 37: Diagrama de Nyquist do eletrodo de composição Ti/ $\mathrm{Ru}_{0,3} \mathrm{Ti}_{0,7}+\mathrm{Pt}$ $100 \mu \mathrm{gcm}^{-2}$ em E $=1,50 \mathrm{~V}$ vs. ERH. Sendo: $\bigcirc$ dados experimentais, — ajuste de acordo com o CE da Figura 37 e — ajuste de acordo com a LT da Figura 22.

Figura 38: Valores de $R_{t c}$ em função do potencial para o eletrodo de composição Ti/ $\mathrm{Ru}_{0,3} \mathrm{Ti}_{0,7}+\mathrm{Pt} 100 \mu \mathrm{gcm}^{-2}$ em E = 1,50 V vs. ERH. Sendo: $\triangle$ valores obtido a partir do ajuste com o $\mathrm{CE}$ e $\nabla$ valores obtido a partir do ajuste com a LT.

Figura 39: Curvas de polarização de Tafel do eletrodo de composição $\mathrm{Ti} / \mathrm{Ru}_{0,3} \mathrm{Ti}_{0,7} \mathrm{O}_{2}+\mathrm{Pt}\left(100 \mu \mathrm{g} \mathrm{cm}{ }^{-2}\right) \mathrm{com} v=56 \mu \mathrm{V} \mathrm{s}^{-1}$. Sendo: $b_{1}=40 \mathrm{~m} / \mathrm{vdec}^{-1} \mathrm{e}$ $b_{2}=114 \mathrm{mVdec}^{-1}$.

Figura 40: Curva de polarização de Tafel do eletrodo de composição

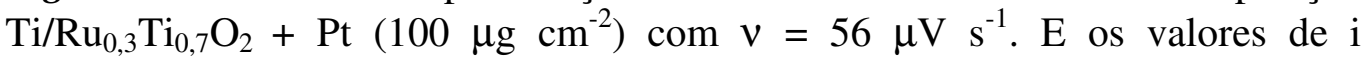
calculados a partir dos valores de $R_{t c}$, que foram obtidos por EIE.

Figura 41a: Micrografias representativas dos eletrodos de composição Ti/Pt e Ti/Pt:Ru (80:20). Mag = 1000 e 5000 vezes. EHT $=15000 \mathrm{~V}$

Figura 41b: Micrografias representativas dos eletrodos de composição Ti/Pt:Sn (80:20) e Ti/Pt:Ru:Sn (80:10:10). Mag = 1000 e 5000 vezes. EHT = $15000 \mathrm{~V}$

Figura 42: Micrografia do eletrodo de composição Ti/Pt:Ru:Sn (80:10:10), com a análise de EDX em linha.

Figura 43: Voltamogramas cíclicos representativos dos eletrodos Ti/PtRuSn em eletrólito suporte: $\left(\mathrm{H}_{2} \mathrm{SO}_{4} 0,5 \mathrm{~mol} \mathrm{dm}{ }^{-3}\right)$. (a) Ti/Pt; (b) Ti/Pt:Ru (80:20); (c) Ti/Pt:Sn:Ru (80:10:10) e (d) Ti/Pt:Sn (80:20); v =10mVs ${ }^{-1}$

Figura 44: Voltamogramas cíclicos representativos do eletrodo de composição $\mathrm{Ti} / \mathrm{Pt}$ em diferentes velocidades de varredura em $\mathrm{H}_{2} \mathrm{SO}_{4} 0,5 \mathrm{~mol} \mathrm{dm}^{-3}$..... 
Figura 45: Diagramas de Nyquist em $\mathrm{H}_{2} \mathrm{SO}_{4} 0,5 \mathrm{~mol} \mathrm{dm}^{-3}$, de 1 a $10 \mathrm{kHz}$ e $5 \mathrm{mV}$ de amplitude. (a) $\mathrm{Ti} / \mathrm{Pt}$ em diferentes potenciais (b) Diferentes composições eletródicas em $0,5 \mathrm{~V} v s$. ERH.

Figura 46: (a) Valores de $Q_{d c}$ calculados em função do potencial para as diferentes composições eletródicas investigadas em $\mathrm{H}_{2} \mathrm{SO}_{4} \quad 0,5 \mathrm{~mol} \mathrm{dm}^{-3}$. (b) Circuito elétrico utilizado para ajustar os dados experimentais e extrair os valores de $Q_{d c}$

Figura 47: Voltamogramas (curvas anódicas) representativos dos eletrodos Ti/PtRuSn na presença de etanol $\left(1 \mathrm{~mol} \mathrm{dm}^{-3}\right)$. ES $=\mathrm{H}_{2} \mathrm{SO}_{4} 0,5 \mathrm{~mol} \mathrm{dm}^{-3}$, $\mathrm{v}=10 \mathrm{mVs}^{-1}$

Figura 48: Voltamogramas cíclicos representativos dos eletrodos Ti/PtRuSn na presença de etanol $\left(1 \mathrm{~mol} \mathrm{dm}{ }^{-3}\right)$. ES $=\mathrm{H}_{2} \mathrm{SO}_{4} 0,5 \mathrm{~mol} \mathrm{dm}^{-3}, \mathrm{v}=10 \mathrm{mVs}^{-1}$ : (a) Ti/Pt (b) Ti/Pt:Ru (80:20) (c) Ti/Pt:Sn (80:20) e (d) Ti/Pt:Sn:Ru (80:10:10).... Figura 49: Diagramas de Nyquist em $\mathrm{H}_{2} \mathrm{SO}_{4} 0,5 \mathrm{~mol} \mathrm{dm}^{-3}+$ etanol $1 \mathrm{~mol} \mathrm{dm}^{-3}$, de 1 a $10 \mathrm{kHz}$ e $5 \mathrm{mV}$ de amplitude. (a) $\mathrm{Ti} / \mathrm{Pt}$ em diferentes potenciais (b) Diferentes composições eletródicas em $0.2 \mathrm{~V} v s$. ERH.

Figura 50: Os valores de $\mathrm{Q}_{\mathrm{dc}}$ calculados em função do potencial para as diferentes composições eletródicas investigadas (a ) em $\mathrm{H}_{2} \mathrm{SO}_{4} 0,5 \mathrm{~mol} \mathrm{dm}^{-3}$ (b) em $\mathrm{H}_{2} \mathrm{SO}_{4} 0,5 \mathrm{~mol} \mathrm{dm}^{-3}+$ etanol $1 \mathrm{~mol} \mathrm{dm}^{-3}$....

Figura 51: (a) Programa representativo de perturbação aplicada (E vs. tempo) no registro das curvas cronoamperométricas. (b) Curvas cronoamperométricas representativas (i vs. tempo).

Figura 52: Curva de corrente estacionária em função do potencial para a as diferentes composições eletródicas em $\mathrm{H}_{2} \mathrm{SO}_{4} 0,5 \mathrm{~mol} \mathrm{dm}^{-3}+$ etanol $1 \mathrm{~mol} \mathrm{dm}^{-3}$..

Figura 53: Voltamogramas cíclicos medidos (-) antes e (-) após os testes de cronoamperometria e EIE, em $\mathrm{H}_{2} \mathrm{SO}_{4} 0,5 \mathrm{~mol} \mathrm{dm}^{-3}$ e etanol $1 \mathrm{~mol} \mathrm{dm}^{-3} \mathrm{e}$ $\mathrm{v}=10 \mathrm{mVs}^{-1}$ para todas as composições investigadas.....

Figura 54: Voltamogramas cíclicos medidos (-) antes e $(-)$ após os testes cronoamperométricos, em $\mathrm{H}_{2} \mathrm{SO}_{4} 0,5 \mathrm{~mol} \mathrm{dm}^{-3}$ e etanol $1 \mathrm{~mol} \mathrm{dm}^{-3} \mathrm{e}$ $v=10 \mathrm{mVs}^{-1}$, do eletrodo de composição Au/Pt:Sn (80:20).

Figura 55: Diagramas de Nyquist em $\mathrm{H}_{2} \mathrm{SO}_{4} 0,5 \mathrm{~mol} \mathrm{dm}^{-3}+$ etanol $1 \mathrm{~mol} \mathrm{dm}^{-3}$, de 1 a $10 \mathrm{kHz}$ e $5 \mathrm{mV}$ de amplitude, realizados após as curvas cronoamperométricas, do eletrodo de $\mathrm{Ti} / \mathrm{Pt}$ em diferentes potenciais no sentido positivo de potencial.

Figura 56: Curva de corrente estacionária em função do potencial para o eletrodo de composição Ti/ Pt: (a) sentido positivo; (b) sentido negativo de potencial. Em meio de $\mathrm{H}_{2} \mathrm{SO}_{4} 0,5 \mathrm{~mol} \mathrm{dm}^{-3}+$ etanol $1 \mathrm{~mol} \mathrm{dm}^{-3}$. Em ênfase os diagramas de Nyquist característicos para cada região de potencial.

Figura 57: Circuitos elétricos utilizados para o ajuste dos dados experimentais de EIE para o eletrodo de composição Ti/Pt.

Figura 58:Valores de $R_{\Omega}\left(\Omega \mathrm{cm}^{2}\right)$ em função do potencial para o eletrodo de $\mathrm{Ti} / \mathrm{Pt}$, obtidos através do ajuste do circuito elétrico da Figura 58a para a região de carregamento da dupla camada elétrica. 
Figura 59: (a) $Q_{d c}$ e (b) $\beta$ em função do potencial, obtidos por EIE durante as análises de curva cronoamperométrica seguida de EIE. Eletrodo de Ti/Pt em $\mathrm{H}_{2} \mathrm{SO}_{4} 0,5 \mathrm{~mol} \mathrm{dm}^{-3}$ e etanol $1 \mathrm{~mol} \mathrm{dm}^{-3}$.....

Figura 60: $Q_{d c}$ em função do potencial obtida por EIE, com e sem estabilização cronoamperométrica. Eletrodo de $\mathrm{Ti} / \mathrm{Pt}$ em $\mathrm{H}_{2} \mathrm{SO}_{4}$ 0,5 mol dm${ }^{-3}$ e etanol $1 \mathrm{~mol} \mathrm{dm}^{-3}$

Figura 61: Valores de $R_{t c}$ obtidos a partir do ajuste dos dados experimentais utilizando-se o circuito da Figura 58b, em função do potencial. Eletrodo de Ti/Pt em $\mathrm{H}_{2} \mathrm{SO}_{4} 0,5 \mathrm{~mol} \mathrm{dm}^{-3}$ e etanol $1 \mathrm{~mol} \mathrm{dm}^{-3}$

Figura 62: Voltamogramas cíclicos $d c$, obtidos durante o registro dos voltamogramas $a c$ em todas as composições eletródicas, $v=50 \mathrm{mv} / \mathrm{s}$ em $\mathrm{H}_{2} \mathrm{SO}_{4}$ $0,5 \mathrm{~mol} \mathrm{dm}^{-3}$ e etanol $1 \mathrm{~mol} \mathrm{dm}^{-3}$......

Figura 63: Diagramas de Nyquist obtidos para o eletrodo de Ti/ Pt:Ru:Sn (80:10:10) por voltametria $a c$ : (a) sentido positivo e (b) sentido negativo de potencial. Em meio de $\mathrm{H}_{2} \mathrm{SO}_{4} 0,5 \mathrm{~mol} \mathrm{dm}^{-3}$ e etanol $1 \mathrm{~mol} \mathrm{dm}^{-3}, \mathrm{v}=5 \mathrm{mVs}^{-1} \ldots \ldots$.

Figura 64: Z' e Z' em função do potencial em diferentes valores de freqüência para o eletrodo de Ti/Pt, em $\mathrm{H}_{2} \mathrm{SO}_{4} 0,5 \mathrm{~mol} \mathrm{dm}-3$ + etanol $1 \mathrm{~mol} \mathrm{dm}{ }^{-3}$, $\mathrm{A}=5 \mathrm{mV}, \mathrm{v}=5 \mathrm{mV} / \mathrm{s}$.

Figura 65: $R_{\Omega}$ em função do potencial para as diferentes composições eletródicas investigadas em $\mathrm{H}_{2} \mathrm{SO}_{4} 0,5 \mathrm{~mol} \mathrm{dm}^{-3}+$ etanol $1 \mathrm{~mol} \mathrm{dm}^{-3}, \mathrm{f}=200 \mathrm{~Hz}$. Figura 66: Os valores de $Q_{d c}$ calculados a partir da voltametria $a c$, em função do potencial: para o eletrodo de $\mathrm{Ti} / \mathrm{Pt}$ nos sentidos positivo e negativo de potencial e (b) para as diferentes composições eletródicas investigadas no sentido positivo de potencial. $\mathrm{Em} \mathrm{H}_{2} \mathrm{SO}_{4} 0,5 \mathrm{~mol} \mathrm{dm}^{-3}+$ etanol $1 \mathrm{~mol} \mathrm{dm}{ }^{-3}$......

Figura 67: Os valores de $Q_{d c}$ em função do potencial, calculados a partir das medidas de EIE registras após estabilização cronoamperométrica e também obtidos a partir dos resultados de voltametria ac. Eletrodo de Ti/Pt, em $\mathrm{H}_{2} \mathrm{SO}_{4}$ $0,5 \mathrm{~mol} \mathrm{dm}^{-3}+$ etanol $1 \mathrm{~mol} \mathrm{dm}{ }^{-3}$.

Figura 68: Os valores de $R_{t c}$ em função do potencial (a) nos sentidos anódico e catódico para o eletrodo de $\mathrm{Ti} / \mathrm{Pt}$ e (b) no sentido positivo para todas composições eletródicas investigadas em $\mathrm{H}_{2} \mathrm{SO}_{4} 0,5 \mathrm{~mol} \mathrm{dm}^{-3}+$ etanol $1 \mathrm{~mol} \mathrm{dm}^{-3}$.

Figura 69: Valores de tensão $(\mathrm{E} / \mathrm{mV})$ e densidade de potência $\left(\mathrm{P} / \mathrm{mWcm}^{-2}\right)$ em função da densidade de corrente (i/ $\mathrm{mAcm}^{-2}$ ) para todas as composições investigadas. Medidas realizadas com etanol $2 \mathrm{M}$, a $80^{\circ} \mathrm{C}, p \mathrm{O}_{2}=1$ bar e $p_{\text {etanol }}=1$ bar, fluxo de $\mathrm{O}_{2}=150 \mathrm{mLmin}^{-1}$ e fluxo de etanol $=2 \mathrm{mlmin}^{-1}$. Cátodo de Nafion ${ }^{\circledR} 117$. Ânodo com $25 \mathrm{~cm}^{2}$ e $2 \mathrm{mg}$ de Platina na composição.

Figura 70: Valores de tensão $(\mathrm{E} / \mathrm{mV})$ e densidade de potência $\left(\mathrm{P} / \mathrm{mWcm}^{-2}\right) \mathrm{em}$ função da densidade de corrente $\left(\mathrm{i} / \mathrm{mAcm}^{-2}\right.$ ) para os eletrodos $\mathrm{C} / \mathrm{Pt}: \mathrm{Sn}(75: 25)$ E-TEK e C/ Pt:Sn (80:20). Etanol $2 \mathrm{M}$, a $80^{\circ} \mathrm{C}, p \mathrm{O}_{2}=1$ bar e $p_{\text {Etanol }}=1$ bar, fluxo de $\mathrm{O}_{2}=150 \mathrm{mLmin}^{-1}$ e fluxo de etanol $=2 \mathrm{mlmin}^{-1}$. Cátodo de Nafion ${ }^{\circledR} 117$. Ânodo com $25 \mathrm{~cm}^{2}$. 


\section{LISTA DE TABELAS}

Tabela I. Classificação de células a combustível

Tabela II: Potenciais investigados por EIE para os eletrodos de composição $\mathrm{T}$ i/ $\mathrm{Ru}_{0,3} \mathrm{Ti}_{(0,7-\mathrm{x})} \mathrm{Sn}_{\mathrm{x}} \mathrm{O}_{2}$

Tabela III: Valores dos elementos da linha de transmissão utilizados para ajustar os dados experimentais, do eletrodo de composição $\mathrm{Ti} / \mathrm{Ru}_{0,3} \mathrm{Sn}_{0,7} \mathrm{O}_{2}$.

Tabela IV. Mecanismos propostos na literatura para a RDO em meio ácido [36,190] Tabela V. Composições nominais e experimentais (\% atômica ) obtidas na análise de EDX dos eletrodos de composição Ti/Pt, Ti/Pt:Ru, Ti/Pt:Sn e Ti/Pt:Ru:Sn. $\mathrm{T}_{\text {calc }} \cdot 450^{\circ} \mathrm{C}$, espessura nominal $=1 \mu \mathrm{m}$

Tabela VI. Valores de $R_{t c}$ no sentido positivo e negativo de potencial obtidos por EIE, após estabilização cronoamperométrica 


\section{RESUMO}

Este trabalho consiste em utilizar a técnica de Espectroscopia de Impedância Eletroquímica (EIE) na investigação da cinética de diferentes materiais eletrocatalíticos. O modelo de eletrodos porosos se apresenta como uma forma bastante promissora no tratamento das respostas em frequiência dos ADEs. Uma vez estabelecida a aplicação do modelo, pode-se chegar à obtenção de informações cinéticas importantes durante a análise de vários fatores que ocorrem no sistema em questão, sendo possível então, confirmar resultados obtidos por outras técnicas.

Foram investigados eletrodos do tipo ADEs de composição $\mathrm{Ti} / \mathrm{Ru}_{0,3} \mathrm{Ti}_{(0,7-\mathrm{x})} \mathrm{Sn}_{\mathrm{x}} \mathrm{O}_{2}(\mathrm{x}=$ 0; 0,3 e 0,7), investigando o efeito da eletrodeposição de Pt na superfície do ADE de $\mathrm{Ti} / \mathrm{Ru}_{0,3} \mathrm{Ti}_{0,7} \mathrm{O}_{2}$, a fim de comparar os resultados obtidos por EIE (ac) com o estudo cinético realizado por curvas de polarização de Tafel $(d c)$ em meio ácido. $\mathrm{E}$ também, a investigação dos ânodos, aplicáveis a células a combutível de etanol (DEFCs), de composição: Ti/Pt, Ti/Pt:Ru (80:20), Ti/Pt:Sn (80:20) e Ti/Pt:Ru:Sn (80:10:10) em meio ácido e também de etanol, utilizando-se a EIE como elemento de diagnóstico da atividade da composição do ânodo.

Os resultados de EIE confirmam que, o aumento da concentração de $\mathrm{SnO}_{2}$ na composição dos eletrodos, favorecem a formação de oxigênio, como o apresentado na literatura, por outras técnicas eletroquímicas. A linha de transmissão de um canal, apresentou valores satisfatórios dos seus elementos, coerentes com os valores apresentados na literatura, quanto utilizada a técnica da EIE.

Foi observado também que adição de Pt na composição do $\mathrm{ADE} T \mathrm{Ti} / \mathrm{Ru}_{0,3} \mathrm{Ti}_{0,7} \mathrm{O}_{2}$ melhorou a eficiência do material, apresentando menores valores de resistência à transferência de carga,

A resistência de transferência de carga $\left(r_{t c}\right)$ diminui a medida que aumenta-se o potencial, no sentido da RDO. Analisando-se aos valores de potencial em função do logaritmo da corrente obtidos pelas diferentes técnicas: (i) curvas de polarização de Tafel, (ii) EIE, tem-se o mesmo comportamento tanto em baixo, quanto em alto sobrepotenciais, pode-se concluir então que existe um relação entre o comportamento $a c$ e $d c$ do sistema.

Nos estudos de materiais aplicados a DEFCs, o eletrodo de composição Ti/Pt:Ru:Sn (80:10:10) apresentou os melhores resultados para a oxidação do etanol nos testes de voltametria cíclica $d c$, porém, o ânodo de composição Ti/Pt:Sn(80:20) apresentou os melhores resultados de EIE, obtendo-se valores menores de resistência a transferência de carga, concordando com os resultados obtidos no estudo de célula a combustível de etanol com ânodos de mesma composição. 


\begin{abstract}
This work consists in using Electrochemical Impedance Spectroscopy (EIS) in the research of various electrocatalytic materials. The porous electrode model is a very promising approach to treat the frequency responses of Dimensionally Stable Anodes $\left(\mathrm{DSA}^{\circledR}\right)$. Once the application of the model is established, it is possible to obtain important kinetic information while various factors occurring in the system are analyzed. This allows confirmation results obtained by other techniques.

Electrodes of the $\mathrm{DSA}^{\circledR}$ type with composition $\mathrm{Ti} / \mathrm{Ru}{ }_{0,3} \mathrm{Ti}_{(0,7-\mathrm{x})} \mathrm{Sn}_{\mathrm{x}} \mathrm{O}_{2}(\mathrm{x}=0 ; 0,3$ e 0,7$)$ were investigated. In order to compare the results obtained for $\mathrm{DSA}^{\circledR} \mathrm{Ti} / \mathrm{Ru}{ }_{0,3} \mathrm{Ti}_{0,7} \mathrm{O}_{2}$ electrodes by EIS $(a c)$ with the kinetic studies by Tafel $(d c)$ polarization curves performed in acid environment. Additionally, an investigation of the anodes, applicable to Direct Oxidation of Ethanol Fuel Cells (DEFCs), with composition Ti/Pt, Ti/Pt:Ru (80:20), Ti/Pt:Sn (80:20) and Ti/Pt:Ru:Sn (80:10:10) in acid environment and also in ethanol was carried out, using EIS as a diagnosis element for the activity of the anode composition.

The EIS results confirmed that increasing concentration of $\mathrm{SnO}_{2}$ in the DSA ${ }^{\circledR}$ composition enhances oxygen formation, as reported in the literature, for other electrochemical techniques. The EIS technique revealed that the transmission line of one canal provided satisfactory data for its elements, in agreement with literature data. $\mathrm{Pt}$ addition to the $\mathrm{DSA}^{\circledR} \mathrm{Ti} / \mathrm{Ru}{ }_{0,3} \mathrm{Ti}_{0,7} \mathrm{O}_{2}$ improved the material efficiency, giving smaller resistance values for charge transfer.

The resistance of the charge transfer $\left(R_{t c}\right)$ lowered with increasing potential, in the direction of RDO. Analysing the potential values as a function of the Tafel polarization curves and EIS, it is possible to conclude that there is a relationship between the $a c$ and $d c$ behaviors of the system.

In the studies of materials applicable to DEFCs it was confirmed that Sn improves the activity for ethanol oxidation. The composition Ti/Pt:Sn (80:20) led to the best results in EIS tests, revealing lower resistance values in the charge transfer, in agreement with results obtained in the study of fuel cells.
\end{abstract}




\section{I- INTRODUÇÃO}

\section{I.1 Espectroscopia de Impedância Eletroquímica (EIE)}

A técnica de Espectroscopia de Impedância Eletroquímica (EIE) é uma técnica que fornece uma discussão completa e detalhada das características elétricas da interface eletrodo/solução [1-4], permitindo um estudo do comportamento geral de um sistema quando um número grande de processos intercorrelacionados ocorrem em diferentes velocidades.

Basicamente a EIE mede a habilidade de um sistema de impedir o fluxo de corrente elétrica, sendo assim, é uma técnica de grande interesse na eletroquímica aplicada ou básica, sendo utilizada em uma ampla gama de estudos, abrangendo desde o transporte eletrônico em dispositivos semicondutores até o estudo de processos cinéticos eletroquímicos das mais diferentes naturezas, tais como: processos que ocorrem em baterias de íons lítio [5], células fotovoltaicas [6-9], sistemas de corrosão e/ou processos eletrocatalíticos [10-14], bem como no estudo de células a combustível [15]. A EIE pode caracterizar o transporte e as perdas por difusão, avaliar as propriedades da resistência ôhmica, da resistência de transferência de carga e da capacitância da dupla camada elétrica, fornecendo resultados para a melhora do conjunto experimental. Em particular, a EIE é uma excelente ferramenta para se caracterizar filmes finos, sejam eles porosos ou lisos [16].

Em geral, as técnicas de varredura de potencial perturbam o sistema fora do equilíbrio, a EIE ao contrário, é aplicada para sistemas em equilíbrio. A resposta da aplicação de um pequeno sinal $a c$ (de corrente ou potencial), feita em uma ampla faixa de 
freqüências, possibilita diferenciar processos com tempos característicos distintos, que na maioria das técnicas tradicionais eletroquímicas seriam vistos como contribuições simultâneas à resposta total. Em geral, sinais de pequena amplitude $(\Delta \mathrm{E}=5 \mathrm{mV})$ devem ser utilizados para facilitar a linearização das respostas obtidas e as expressões matemáticas de tais respostas em função da freqüência permitem analisar os resultados experimentais para a obtenção dos parâmetros cinéticos desejados.

No desenvolvimento de modelos baseados em métodos de EIE, a resposta $a c$ da célula eletroquímica é convencionalmente descrita por um circuito equivalente (CE) ou por equações cinéticas que levam às funções de impedância [16, 17]. De maneira geral, os modelos de impedância consistem em estabelecer equações que incluem a Equação de Nernst-Plank e de Poisson, além de condições de contorno apropriadas ao sistema [2-4, 6, 18, 19]. O modelo deve possuir uma solução analítica, e estes podem ser expressos em termos de análogos de circuito elétrico, neste caso, um CE fornece uma representação total da distribuição de potencial elétrico no sistema e o analista atribuir o modelo físico relacionado ao CE proposto.

Uma vez escolhido o CE que melhor descreve o processo, pode-se relacionar as propriedades físicas ou químicas com elementos do circuito e extrair valores numéricos de todos estes elementos, através de simulações dos dados experimentais. Para tal, geralmente utiliza-se o método de mínimos quadrados não-linear, com o auxílio de um programa de computador adequado [20].

Os resultados de EIE são geralmente representados pelos diagramas de Nyquist e Bode (Figuras 1 e 2). O diagrama de Nyquist apresenta a parte imaginária (Z') em função 
da parte real (Z'). O ajuste dos dados experimentais com circuitos elétricos pré-definidos fornece as informações sobre o sistema como, por exemplo, as resistências presentes e a capacitância da dupla camada elétrica. O diagrama de Bode representa a impedância total do sistema e o ângulo de fase, ambos em função da freqüência. Por exemplo, um determinado sistema que apresente um diagrama de Nyquist como o apresentado na Figura 1b, partindo-se dos valores de freqüência, impedância e ângulo de fase podemos obter o digrama de BODE apresentado na Figura 2. Tal sistema pode ser representado pelo circuito equivalente da Figura 1a, formado pela resistência $\left(R_{\Omega}\right)$ em série com uma segunda resistência $\left(R_{t c}\right)$ em paralelo com uma capacitância $\left(C_{d c}\right)$.

(a)
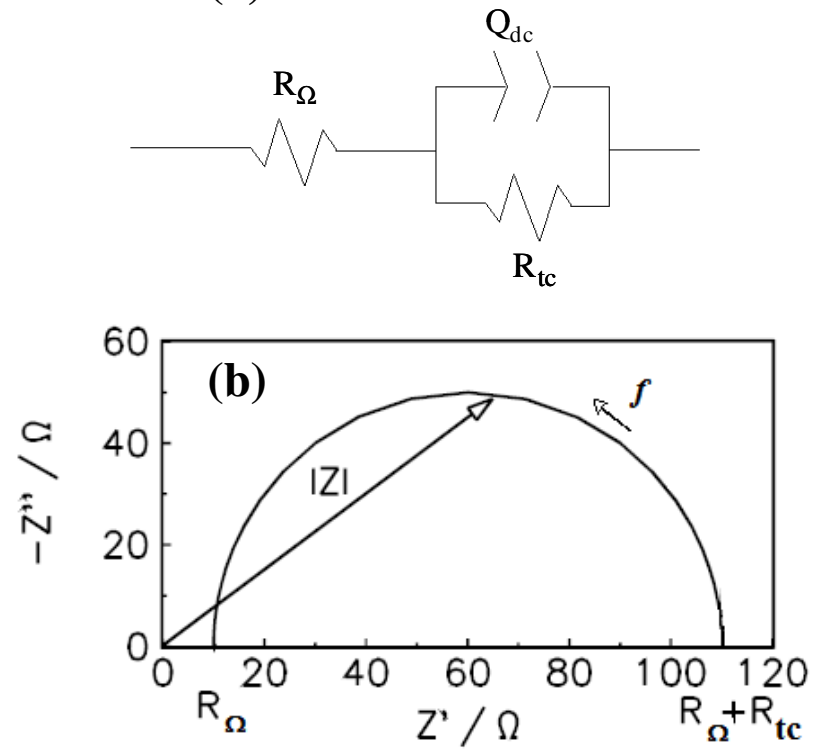

Figura 1: Exemplos de: (a) um circuito elétrico e (b) seu diagrama de Nyquist representativo [21]. 

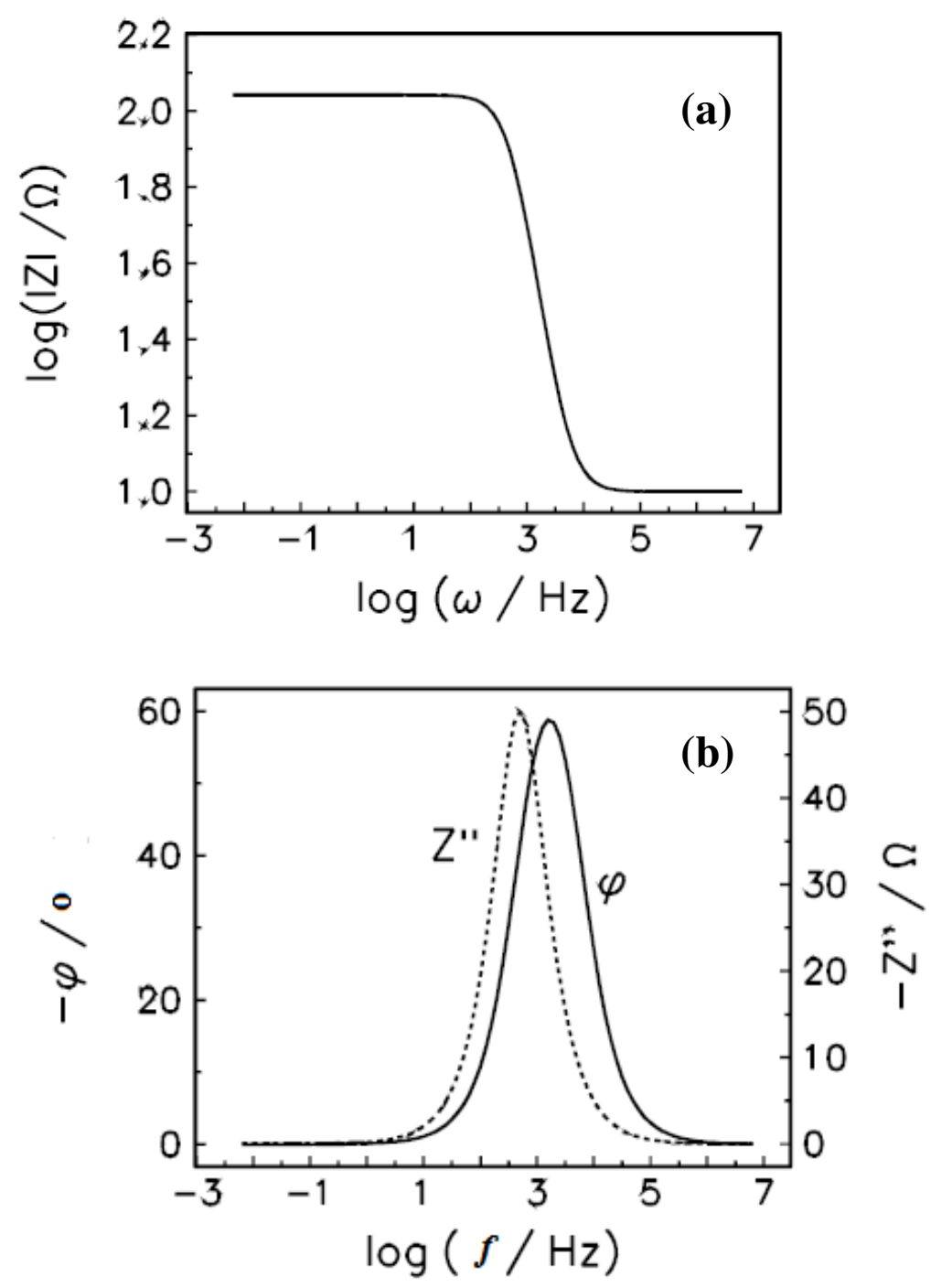

Figura 2: Diagrama de BODE, representativos para um sistema com comportamento como o apresentado na Figura 1. (a) Z e (b) $\varphi$ em função de $\log f$ [21].

Embora existam diferenças na complexidade e na estratégia de modelagem (e ocasionalmente há pontos que são conflitantes) entre as diversas teorias, estas apresentam similaridades estruturais importantes, sendo que em muitos aspectos são equivalentes [16, 17]. Para discutir as teorias aplicadas neste trabalho, será apresentado a seguir o modelo para eletrodos pororos. 


\section{I.1.1 Modelo para eletrodos porosos}

Para exemplificar o modelo para eletrodos porosos proposto por Levie [22], vamos considerar um eletrodo cilíndrico simples idealmente polarizado, de comprimento $l$ e raio $r$, onde apenas as paredes dos poros são condutoras e a superfície externa não-condutora, com fluxo de corrente alternada (ac), como apresentado na Figura 3 [21].

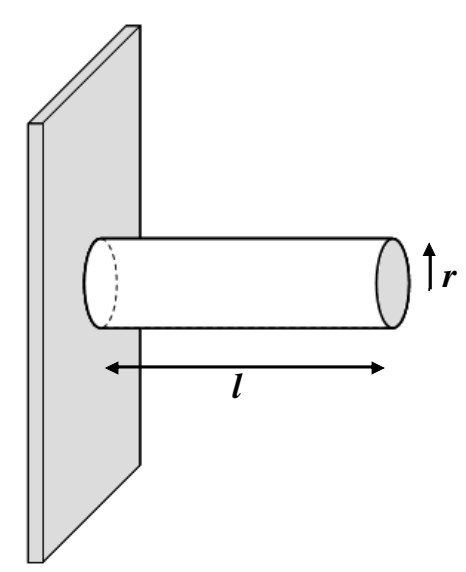

Figura 3: Modelo de eletrodo poroso cilíndrico. A área cinza é não-condutora [21].

A equação de impedância para um eletrodo poroso cilíndrico definida por Levie considera que [21]:

- O poro é cilíndrico;

- Somente as paredes do poro são condutoras e a resistência do material eletródico é igual a zero,

- O poro é totalmente preenchido pelo eletrólito caracterizado por uma resistência $\rho$. 
A impedância específica das paredes do poro é dada por [1]:

$$
\hat{Z}_{e l}=\frac{1}{j \omega C_{d c}}, \text { em } \Omega \mathrm{cm}^{-2}
$$

Onde: $C_{d c}=$ capacitância específica da parede do poro dada em $F \mathrm{~cm}^{-2}$;

$$
\begin{aligned}
& \omega=\text { freqüência angular da perturbação } a c(\omega=2 \pi f \text { onde } f \text { é a freqüêencia em } \mathrm{Hz}), \\
& j=\sqrt{-1}
\end{aligned}
$$

Considerando que o potencial $a c, \tilde{E}$, diminue com a profundidade do poro, podemos considerar que $\tilde{E}=\tilde{E}_{0}$, ou seja, dado pelo valor inicial na superfície do poro. E a corrente de troca, $\tilde{I}$, diminue com o fluxo na parede do poro. O sistema pode ser descrito por duas equações diferenciais [1]:

$$
\begin{aligned}
& \frac{d \tilde{I}}{d x}=-\frac{\tilde{E}}{\hat{Z} l} \\
& \frac{d \tilde{E}}{d x}=-R \tilde{I}
\end{aligned}
$$

Onde: $\hat{Z}=$ impedância por unidade de comprimento do poro $\left(\Omega \mathrm{cm}^{-2}\right)$;

A segunda derivada de $\tilde{E}$ de acordo com a Equação 3 é dada por:

$$
\frac{d^{2} \tilde{E}}{d x^{2}}=-R \frac{d \tilde{I}}{d x}=\frac{R}{\hat{Z}} \tilde{E}
$$

Com as seguintes condições de contorno:

$$
\begin{aligned}
& x=0 \\
& x=l \\
& \tilde{E}=\tilde{E}_{0} \\
& \frac{d \tilde{E}}{d x}=0
\end{aligned}
$$


A solução da Equação 4 é:

$$
\tilde{E}=\tilde{E}_{0} \frac{\cosh \left[\sqrt{\frac{R}{\hat{Z}}}(1-x)\right]}{\cosh \left[\sqrt{\frac{R}{\hat{Z}} l}\right]}
$$

Na superfície superior do poro:

$$
\left.\frac{d \tilde{E}}{d x}\right|_{x=0}=-\tilde{E}_{0} \sqrt{\frac{R}{\hat{Z}}} \tanh \left(\sqrt{\frac{R}{\hat{Z}}} l\right)=-\tilde{I}_{0} R
$$

E a impedância é definida como a relação entre potencial e corrente:

$$
\hat{Z}_{\text {poro }}=\frac{\tilde{E}_{0}}{\tilde{I}_{0}} \sqrt{R \hat{Z}} \operatorname{coth}\left(\sqrt{\frac{R}{\hat{Z}}} l\right)
$$

Esta equação pode ser escrita de forma simplificada por:

$$
\hat{Z}_{\text {poro }}=\frac{R_{\Omega, p}}{\Lambda^{1 / 2}} \operatorname{coth}\left(\Lambda^{1 / 2}\right)
$$

onde $R_{\Omega, p}=\frac{\rho l}{\pi r^{2}}$ é a resistência do eletrólito no poro e $\Lambda=\frac{\left(2 \rho l^{2} / r\right)}{\hat{Z}_{s}}$ é a admitância não adimensional do eletrodo poroso. No caso de um eletrodo contendo $n$ poros e a resistência da solução é $R_{\text {sol }}$, a impedância total do sistema é dada por:

$$
\hat{Z}=R_{\text {sol }}+\frac{\hat{Z}_{\text {poro }}}{n}
$$

Na Figura 4 é apresentado o diagrama de Nyquist descrito pela Equação 9. Em altas freqüências, tem-se um ângulo de $45^{\circ}$ em relação aos dois eixos (real e imaginário), do plano complexo. Tal equação pode ser representada por uma série semi-infinita, chamada linha de transmissão (LT), representada na Figura 5, onde a $R_{\text {sol }}$ é dada por uma linha de 
resistências $(r)$ em série, e o elemento $\hat{Z}_{\text {poro }} / n$ é representado por uma segunda linha de capacitâncias $(c)[6,21]$. A principal vantagem desta abordagem está relacionada à sua capacidade de representar fases com diferentes condutividades (eletrodo e eletrólito) que podem ser interconectadas por elementos dentro da própria linha de transmissão, ou mesmo representar o transporte iônico ou eletrônico no interior do eletrodo. Esta característica do modelo é chamada de macro-homogeneidade e pode ser favoravelmente utilizada para representar as características devido aos poros de um eletrodo óxido por exemplo.

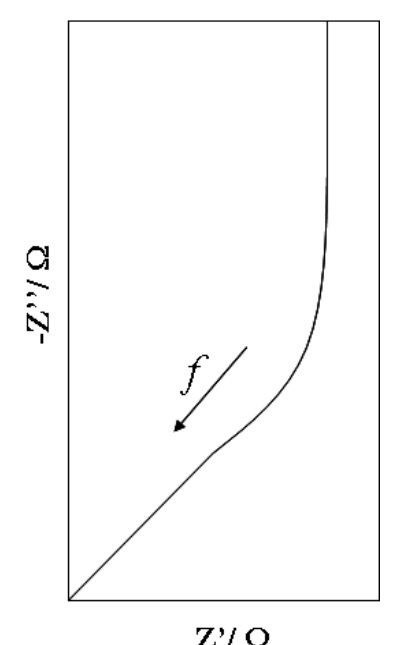

Figura 4: Diagrama de Nyquist representativo de um eletrodo poroso, com $n$ poros cilíndricos proposto por Levie [21].

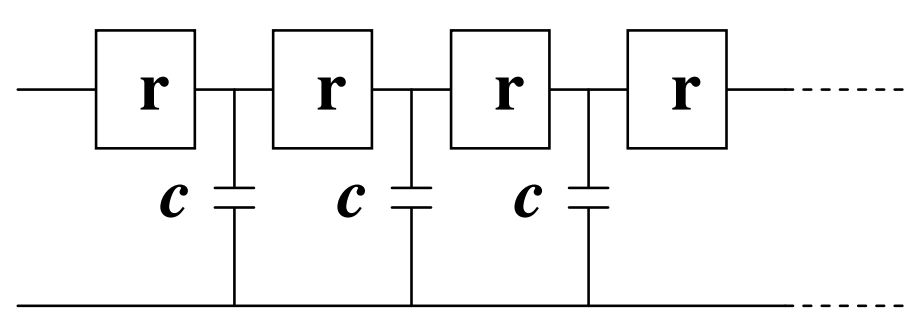

Figura 5: Linha de transmissão representativa de um sistema de eletrodo poroso idealmente polarizado, onde $\mathrm{r}$ representa a resistência da solução e $c$ a capacitância da dupla camada elétrica, distribuídas ao longo do comprimento do poro [21]. 
A Figura 6 apresenta um esquema genérico das linhas de transmissão freqüentemente empregadas para descrever os sistemas eletroquímicos. Estas podem ser compostas de um ou dois canais, com elementos de impedância genéricos distribuídos, $\chi_{1} \mathrm{e}$ $\chi_{2}$, conectados por um elemento de interface, $\zeta$. Na Figura $6 a$, os canais representam dois meios e/ou fases distintas. Propõe-se que estes sejam efetivamente homogêneos e continuamente conectados. As características essenciais do transporte elétrico ao longo de cada fase, bem como através da "interface" que os conecta, são descritas empregando-se elementos de impedância generalizados.

(a)

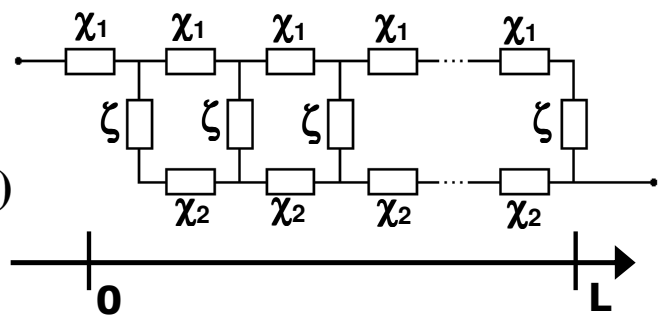

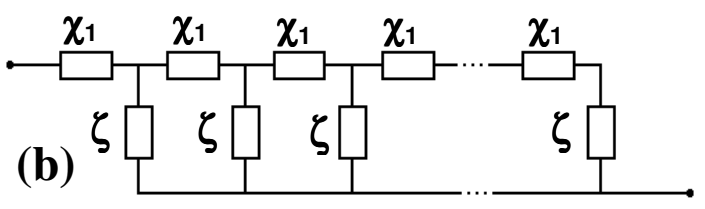

Figura 6: Linha de transmissão generalizada. (a) generalização para dois canais e (b) generalização para um canal. $\chi_{1}, \chi_{2}$ e $\zeta$ são elementos de impedância generalizados. $\chi_{1}$ e $\chi_{2}$ são as impedâncias generalizadas para os canais 1 e 2 , respectivamente, e $\zeta$ para a "interface" que os conecta.

Em cada meio (eletrodo/eletrólito) o circuito equivalente ramifica-se em uma dada posição $x$, em um elemento que se propaga no mesmo meio, $\chi_{1}$ ou $\chi_{2}$, interconectados pelo elemento $\zeta$ de "interface". Os elementos $\chi_{1}$ e $\chi_{2}$ descrevem a queda ôhmica em cada ponto $x$ dentro dos diferentes canais de transporte. Em sistemas eletroquímicos, $\chi_{1}$ e $\chi_{2}$ são utilizados para descrever a condutividade do meio. O elemento "interfacial”, $\zeta$, é utilizado 
para descrever processos de transferência de carga (associados aos processos faradaicos) e polarização. A ramificação dos elementos do circuito equivalente ocorre de forma contínua e por isso são descritos através de equações diferenciais.

Considerando que uma das fases é altamente condutora (na verdade, o que se assume é que a condutividade em um ramo ou fase é muito maior que condutividade no outro ramo ou fase), ou seja, que em uma das fases não há barreira ao transporte e, assumindo que esta fase altamente condutora é a fase 2 , então temos que $\chi_{2} \approx 0$. Neste caso, a fase 2 é um meio equipotencial e a linha de transmissão representada na Figura 6a está em curto-circuito nesta fase, enquanto que a fase 1 exibe uma resistência distribuída $\left(\chi_{1}=r_{1}\right)$ que depende da condutividade do eletrólito. Esta aproximação está representada na Figura 6b. Há várias condições eletroquímicas que podem utilizar esse modelo, dependendo do tipo de eletrodo, geometria e microestrutura [23, 24]. Pode-se chegar a esta configuração através de modelos cilíndricos perfeitos onde estes cilindros seriam os poros, cujos diâmetros são pequenos quando comparado com a profundidade, de acordo com o proposto por De Levie [19], poros rasos seriam tratados como rugosos. Outra aproximação, na qual o modelo de linha de transmissão pode ser empregado, é quando existe uma matriz de partículas semicondutoras interconectadas em contato com a solução ou eletrólito. Este modelo tem sido utilizado com sucesso para descrever a resposta de impedância eletroquímica de eletrodos com este tipo de configuração [23, 24].

Desta forma, considerando o caso em que uma das fases apresenta condutividade muito elevada $\left(\chi_{1}>>\chi_{2}\right)$, obtém-se a resposta de impedância de uma linha de transmissão de um único canal, tal como na Figura 6b. Esta atribuição depende das características do 
sistema, ou seja, da magnitude das condutividades das fases em estudo. Tomando-se então $\chi_{1} \gg \chi_{2}$ de maneira que $\chi_{2}$ pode ser aproximado a uma equipotencial $\left(\chi_{2}=0\right)$. A principal aproximação adotada nos modelos descritos, é que o transporte na fase mais resistiva é limitada pelo movimento iônico nos poros (a cinética é limitada pelo processo de difusão dos íons no poro). Ainda há na literatura discussão a respeito deste fato, de tal maneira que não se sabe se a diferença de potencial é limitada pela fase iônica ou eletrônica (eletrólito ou óxido) [25]. De qualquer forma, pode-se assegurar que quando uma fase é muito mais condutora do que a outra e o modelo com um único ramo pode ser adotado com segurança. Outra aproximação importante é considerar o sistema como sendo macro-homogêneo e, portanto, os termos $\chi_{1}, \chi_{2} \mathrm{e} \zeta$ são independentes da posição $x$, ou seja, estas quantidades são funções unicamente da freqüência.

A função de impedância da linha de transmissão de um canal está apresentada na equação abaixo [5]:

$$
Z=\left(\zeta / \chi_{1}\right)^{1 / 2} \operatorname{coth}(L / \lambda)
$$

em que $L$ é a espessura da camada de difusão ou do eletrodo e $\lambda$ é dado por:

$$
\lambda=\left(\zeta / \chi_{1}\right)^{1 / 2}
$$

Quando as magnitudes de condutividade iônica e eletrônica são comparáveis, não se pode utilizar a aproximação de um único canal, neste caso, a solução da linha de transmissão de dois canais é dada pela seguinte equação [5]:

$$
Z=\frac{\chi_{1} \chi_{2}}{\chi_{1}+\chi_{2}}\left(L+\frac{2 \lambda}{\operatorname{senh}(L / \lambda)}\right)+\lambda \frac{\chi_{1}^{2}+\chi_{2}^{2}}{\chi_{1}+\chi_{2}} \operatorname{coth}(L / \lambda)
$$

sendo que: 


$$
\lambda=\left(\frac{\zeta}{\chi_{1}+\chi_{2}}\right)^{1 / 2}
$$

A partir desta função, os elementos de impedância $\chi_{1}, \chi_{2}$ e $\zeta$ devem ser especificados de forma que, possibilitem a análise dos espectros de impedância, de acordo com um modelo físico apropriado. Isto pode ser realizado atribuindo-se elementos de circuito equivalentes aos termos $\chi_{1}, \chi_{2}$ e $\zeta$ para representar fisicamente o aspecto cinético observado.

Modelos de linha de transmissão de um único canal considerando, $\chi_{1}$ e $\zeta$ como elementos de circuito análogos aos fenômenos de transporte e aos processos interfaciais ocorrendo no sistema eletroquímico, são bastante úteis como já foi demonstrado anteriormente. Pode-se modelar a impedância do canal 1 utilizando-se uma resistência distribuída [5]:

$$
\chi_{1}=r_{1}
$$

sendo que a resistência total neste canal é dada por:

$$
R_{1}=r_{1} L
$$

A escolha do termo de impedância $\zeta$ leva a diferentes modelos, um destes modelos é obtido substituindo este elemento por um função do tipo [26]:

$$
\zeta=\frac{r_{3}}{1+j r_{3} c_{3} \omega}
$$

onde $r_{3}$ é uma resistência distribuída ao longo dos poros, e $\omega$ é a freqüência característica. Sendo a resistência total dada por:

$$
R_{3}=\frac{r_{3}}{L}
$$


Este modelo representa o caso de uma reação interfacial ocorrendo em um eletrodo poroso, ou seja, na qual o eletrólito penetra em pelo menos $90 \%$ da sua profundidade. Uma interface idealmente polarizável é descrita pela capacitância total, dada por $C_{3}$, sendo que $c_{3}$ é a capacitância distribuída a longo dos poros. Estes dois parâmetros, tal como o caso de $R_{3}$ e $r_{3}$, se relacionam também com a espessura do eletrodo (L):

$$
C_{3}=c_{3} L
$$

Neste caso, a função total de impedância adota a seguinte forma:

$$
Z=\left(\frac{R_{1} R_{3}}{1+j \omega / \omega_{3}}\right)^{1 / 2} \operatorname{coth}\left[\left(\omega_{3} / \omega_{L}\right)^{1 / 2}\left(1+j \omega / \omega_{3}\right)^{1 / 2}\right]
$$

sendo que $\omega_{L}$ e $\omega_{3}$ são as freqüências características do processo e estão relacionadas com os parâmetros $r_{1}, r_{3}$ e $c_{3}$ da seguinte forma:

$$
\begin{aligned}
& \omega_{L}=\frac{1}{L^{2} r_{1} c_{3}} \\
& \omega_{3}=\frac{1}{r_{1} c_{3}}
\end{aligned}
$$

Devido a porosidade geralmente é difícil a representação da capacitância da dupla camada elétrica por um elemento capacitivo puro, sendo-se que o Diagrama de Nyquist apresenta ângulos menores que $90^{\circ}$ nestes casos. Sendo assim, a impedância comporta-se como um Elemento de Fase Constante (EFC). Para considerar esta situação no modelo descrito acima, a capacitância $c_{3}$ deve ser substituída por um elemento cuja impedância é dada por: 


$$
Z=\frac{1}{q_{3}}(j \omega)^{-\beta}
$$

em que $q_{3}$ é uma constante e $0<\beta<1$.

Para este caso, em analogia com a Equação 16, tem-se que o elemento de interface toma a forma:

$$
\zeta=\frac{r_{3}}{1+r_{3} q_{3}(j \omega)^{\beta}}
$$

e por fim, a função de impedância total, ou a função de impedância da linha de transmissão, torna-se [26]:

$$
Z=\left[\frac{R_{1} R_{3}}{1+\left(j \omega / \omega_{3}\right)^{\beta}}\right]^{1 / 2} \operatorname{coth}\left(\left(\omega_{3} / \omega_{L}\right)^{\beta / 2}\left[1+\left(j \omega / \omega_{3}\right)^{\beta}\right]^{1 / 2}\right)
$$

\section{I.1.2 A EIE na presença de reações eletroquímicas}

Diversos fatores influenciam a impedância de um sistema eletroquímico, são eles: o eletrólito, a interface eletrodo solução e as reações eletroquímicas. Um eletrodo idealmente polarizado pode ser representado por um circuito simples, formado por uma resistência da solução $R_{\Omega}$ e a capacitância da dupla camada elétrica $C_{d c}$. Já por exemplo, no caso de um sistema onde ocorre um processo difusional semi-infinito:

$$
O x+n e^{-} \rightarrow \text { red },
$$

é necessário considerar as concentrações das espécies oxidadas $C_{O}$ e reduzidas $C_{R}$ :

$$
i=n F\left[k_{f} C_{O}(0)-k_{b} C_{R}(0)\right]
$$


Onde: $\mathrm{n}=$ número de elétrons;

$$
\begin{aligned}
& k_{f} \text { e } k_{b} \text { são as constantes de velocidade dadas por: } k_{f}=k_{0} \exp \left[-\alpha n f\left(E-E^{0}\right)\right] \text { e } \\
& k_{b}=k_{0} \exp \left[(1-\alpha) n f\left(E-E^{0}\right)\right] \\
& f=F / R T .
\end{aligned}
$$

Neste caso, o sistema é representado por um circuito elétrico um pouco mais complexo, onde tem-se uma nova resistência, chamada resistência de transferência de carga $\left(R_{t c}\right)$, que representa a reação redox. Para exemplificar um sistema deste tipo vamos considerar o circuito de Radles [27].

O circuito de Randles prevê que a corrente faradaica resultante das transferências eletrônicas na interface, estão sempre associadas ao componente capacitivo. Os componentes do circuito e as diferentes regiões de resposta em frequiência representam o processo eletroquímico global. A região de alta frequiência está associada com a resistência da solução eletrolítica, $R_{\Omega}$. A região de frequiências intermediárias está associada com a transferência de carga na interface, $R_{t c}$. O efeito de relaxação correspondente é apresentado no plano complexo ( $j Z^{\prime}$ - Z' ) com um semi-círculo, cuja constante de tempo é dada pelo produto $R_{t c} C_{d c}$ (Figura 7). 


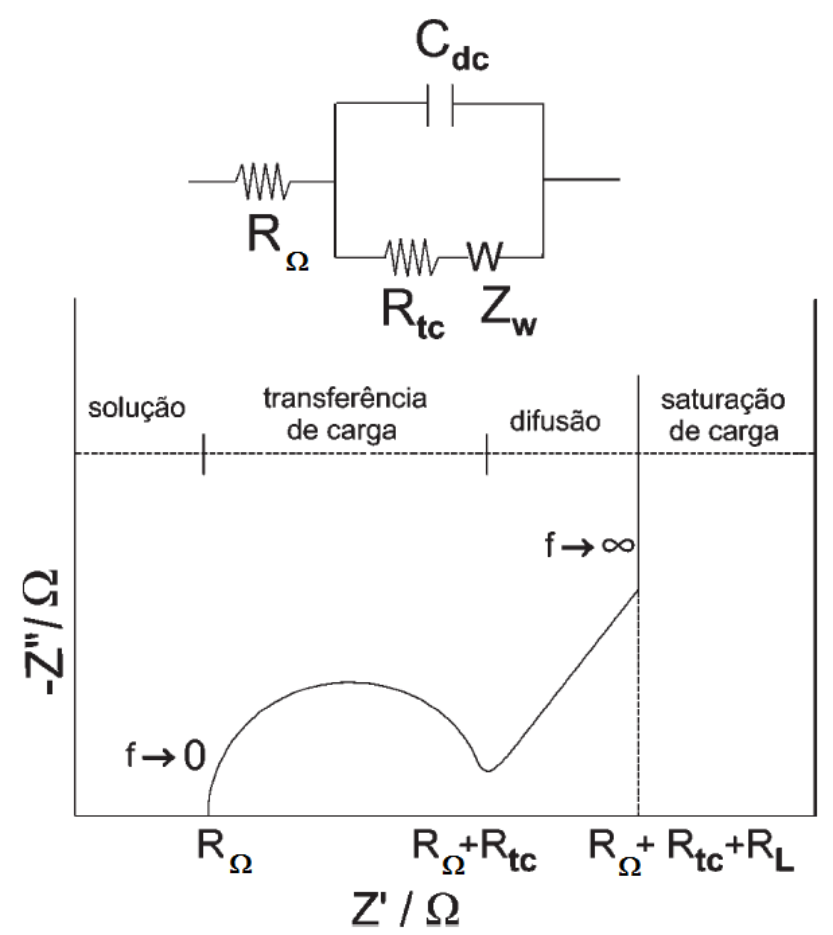

Figura 7: Circuito do tipo Randles (no topo) e sua resposta idealizada no plano de impedância complexa.

Dois parâmetros são obtidos da análise do semi-círculo: $R_{t c}$ que é a medida do diâmetro e a freqüência de relaxação característica, $f_{c}$, obtida no valor máximo do semicírculo. Em baixas frequiências a impedância é caracterizada por processos de transporte de massa por difusão. Duas regiões podem ser identificadas no plano de impedância complexa: uma região linear com ângulo de fase $\pi / 4$, correspondendo à difusão semiinfinita e representada pela impedância de Warburg, $Z_{W}$, e uma segunda região linear ainda em baixas freqüências com um ângulo de fase de $\pi / 2$, associada com uma resposta puramente capacitiva. Considerando uma reação de eletrodo onde a etapa mais lenta está 
relacionada ao transporte iônico em direção a interface, é razoável considerar que a cinética da reação é limitada por difusão. Nestas condições o processo de difusão é progressivamente limitado pela acumulação de carga eletrônica na interface do eletrodo, resultando em uma capacitância $C_{L}$, que é obtida através da equação [27]:

$$
C_{\mathrm{L}}=L^{2} / 3 D R_{L}
$$

sendo que $L$ é a espessura do eletrodo, $D$ o coeficiente de difusão do íon no eletrólito e $R_{L}$ é a resistência limite determinada pela intersecção com o eixo real.

O circuito de Randles descreve adequadamente os processos que ocorrem na região de altas freqüências. Contudo, na região de baixa freqüência, para eletrodos porosos, a análise é complexa e a interpretação física da $C_{L}$ não pode ser descrita como uma capacitância pura, sendo representada por um elemento de fase constante (EFC) [27].

Baseado no conceito do modelo de poros proposto por Levie [22], podemos escolher entre analisar um sistema eletroquímico, constituído por um eletrodo poroso, de acordo com diferentes abordagens. Por exemplo, empregando-se uma LT ou um CE. Cabe ao analista discutir qual a melhor abordagem para cada caso, bem como atribuir os elementos (da LT ou do CE) ao sistema, lembrando-se que ambas são equivalentes. 


\section{I.2 Voltametria ac ( Espectroscopia de Impedância Eletrodinâmica)}

O método consiste em registrar uma série de voltamogramas cíclicos em baixa velocidade de varredura $\left(v \leq 10 \mathrm{mVs}^{-1}\right)$ aplicando-se uma pequena perturbação $a c$ no potencial (Figura 8), em diferentes freqüências [28]. A baixa velocidade de varredura possibilita a medida em estado quase-estacionário, sendo assim, pode-se aplicar a metodologia de circuito equivalente de EIE para a análise dos dados experimentais. A diferença é que os valores dos elementos do circuito serão dependentes da velocidade de varredura [28].

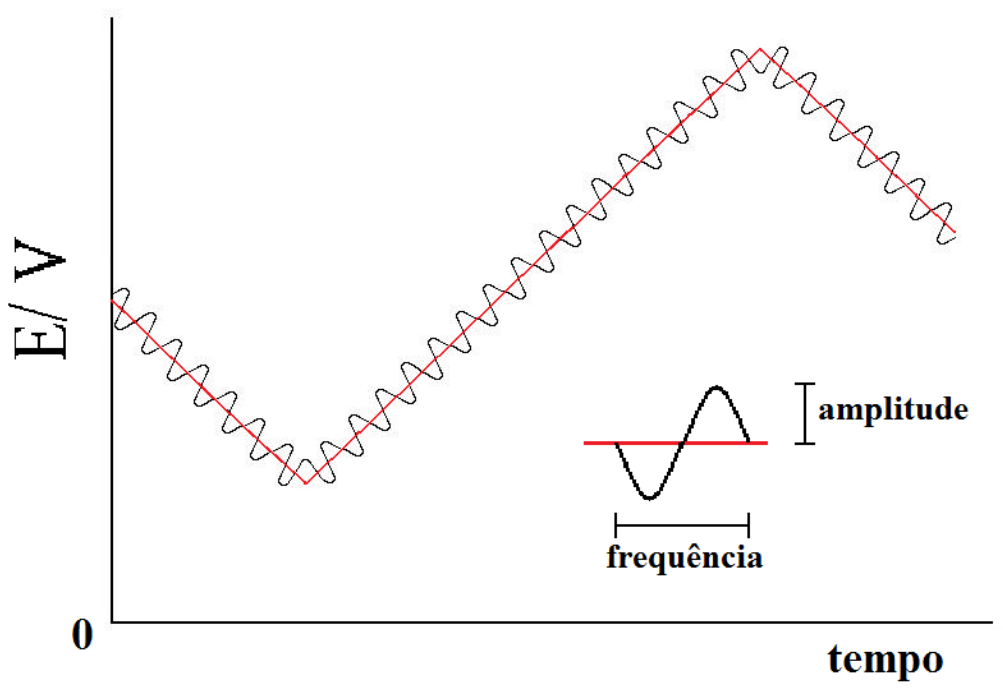

Figura 8: Esquema representativo do potencial aplicado em função do tempo em medidas de: —Voltametria Cíclica $a c$ e-Voltametria Cíclica $d c$.

Os resultados experimentais de voltametria $a c$ são obtidos como vários voltamogramas em diferentes freqüências, com o auxílio de programas adequados pode-se reorganizar os dados em forma de diagramas de Nyquist e BODE em uma faixa de 
potencial. Pode-se assim, analisar os resultados de voltametria ac com base nos fundamentos teóricos da técnica de EIE, utilizado-se um CE que representará o sistema em questão.

A voltametria $a c$ foi inicialmente usada para investigar reações de superfície. $\mathrm{O}$ primeiro trabalho encontrado na literatura foi realizado por Breiter [29], aplicados para sistemas com formação de óxido sobre platina. Posteriormente os trabalhos de Conway e colaboradoes, sobre a formação de óxido sobre Ag e Pt [30, 31]. Vários autores utilizam a voltametria $a c$ em análises qualitativas ou semi quantitativas sem extrair valores de constantes de velocidade.

Em alguns casos o método de estado estacionário da Voltametria $a c$ não pode ser aplicado, pois não favorece as condições reacionais. Por exemplo, reações que não apresentam um estado estacionário bem definido ou apresentam um estado estacionário apenas quando ocorre saturação da superfície. Lembrando-se que chamamos de estado estacionário aquele em que as condições da superfície não variam com o tempo.

Tais vantagens combinadas com a utilidade da análise por circuito equivalente no domínio de frequiência fazem da voltametria $a c$ uma técnica quantitativa útil no estudo de reações de superfície [28]. 


\section{I.3 EIE e Voltametria ac aplicadas a eletrocatalisadores}

Nesta seção será apresentado uma revisão bibliográfica das aplicações das técnicas de EIE e Voltametria $a c$ em materiais utilizados como eletrocatalizadores. Dois tipos de materiais serão apresentados: os Ânodos Dimensionalmente Estáveis (ADE) e eletrodos utilizados em células a combustível de etanol. Sendo ambos materiais porosos, utilizados como ânodos no sistema de interesse e que podem ser analisados pelo modelo de EIE para eletrodos porosos.

\section{I.3.1 Ânodos Dimensionamente Estáveis (ADEs)}

Os ADEs (DSA ${ }^{\circledR}$ patenteado pela Diamond Shamrock Technologies S. A., Genebra, Suíça) surgiram em meados do século XX e constituem uma classe de eletrodos extremamente importantes para a indústria eletroquímica de produção de cloro-soda [32]. Estes eletrodos possuem morfologia e microestrutura porosa [33, 34] e vêm sendo estudados desde a década de 60, quando surgiu o primeiro ADE comercial, em substituição aos eletrodos de grafite $[32,35]$. São inúmeras as aplicações tecnológicas destes materiais: produção de cloro e de oxigênio [32, 36], supercapacitores [37], medidores de $\mathrm{pH}$ [38], preparação de dispositivos de aquecimento [39], oxidação de substâncias orgânicas [40, $41]$.

Tais eletrodos consistem de uma base metálica, na maioria das vezes Ti $[32,36]$, sobre a qual uma camada de óxidos metálicos é aplicada. Esta camada é racionalizada misturando-se: óxidos com propriedades catalíticas $\left(\mathrm{RuO}_{2}[12,34,42-48]\right.$, $\mathrm{IrO}_{2}$ [49-57]); 
óxidos que fornecem estabilidade mecânica $\left(\mathrm{TiO}_{2}[34,48], \mathrm{Ta}_{2} \mathrm{O}_{5}[52,58-62]\right)$ necessários para melhorar a aderência da mistura no suporte e aumentar a estabilidade dimensional. Além disso, pode-se também utilizar aditivos moduladores das propriedades elétricas. Vários semicondutores, entre eles o óxidos de $\mathrm{SnO}_{2}[34,42,45,55], \mathrm{Co}_{3} \mathrm{O}_{4}[43,44], \mathrm{Nb}_{2} \mathrm{O}_{5}$ $[25,63,64], \mathrm{PtO}_{\mathrm{x}}[51,65], \mathrm{CeO}_{2}[12,49], \mathrm{ZrO}_{2}$ [66], são aplicados como aditivos, resultando em uma melhora na eficiência eletroquímica. Outra aplicação destes materiais é a utilização na oxidação eletroquímica de compostos orgânicos presentes em águas residuais, tais como: formaldeído [50], fenol [67], clorofenol [68], poluentes orgânicos [6972], lignina [73], álcool benzílico [74]. As propriedades mecânicas, elétricas e catalíticas dos ADEs são de grande interesse científico e muitas questões relacionadas aos mesmos requerem um entendimento mais aprofundando. Sendo assim, tem-se um número elevado de trabalhos abordando estudos cinéticos e as aplicações destes eletrodos em reações de oxidação de cloro (RDCl) [34, 44, 46], oxigênio (RDO) [42, 43, 45, 51, 53, 54, 57, 59, 75] e oxidação de moléculas orgânicas [50, 67, 73, 76-79].

Uma característica interessante destes eletrodos é seu comportamento pseudo capacitivo [75]. Na superfície eletródica dos ADEs, no intervalo de potencial que vai da reação de desprendimento de hidrogênio $(\mathrm{RDH})$ à reação de desprendimento de oxigênio (RDO), além do carregamento da dupla camada elétrica, ocorrem transições eletrônicas de estado sólido que envolvem a entrada e saída (intercalação/deinserção) de prótons entre grupos superficiais do óxido e a solução. Este processo pode ser representado por [36]:

$$
M O_{x}(\mathrm{OH})_{y}+\delta H^{+}+\delta e^{-} \rightarrow M O_{(x-\delta)}(O H)_{(y-\delta)}
$$


As reações de desprendimento de cloro e oxigênio nos ADEs, tanto em meio ácido como em meio básico, envolvem um grande número de etapas consecutivas [36]. A etapa determinante da velocidade da reação, contudo, é controlada pelas características específicas de cada material eletródico, tais como as propriedades eletrônicas, afinidade de adsorção dos intermediários da reação, arranjo geométrico dos átomos na superfície, dentre outras.

\section{I.3.1.1 EIE aplicada a ADEs}

A EIE se mostra uma ferramenta extremamente útil no estudo dos ADEs, possibilitando extrair informações sobre reações heterogêneas que ocorrem no eletrodo, capaz de representar fases com diferentes condutividades (eletrodo e eletrólito, por ex.), ou mesmo representar o transporte iônico ou eletrônico no interior do eletrodo $[6,25]$.

Vários trabalhos utilizam a EIE na caracterização de ADEs. Considerando alguns destes trabalhos temos, por exemplo, os que investigaram eletrodos contendo $30 \%$ de Ir, variando as concentrações de Ti, Ce e/ou Sn. Tais trabalhos utilizaram a EIE para investigar diferentes regiões de potencial, como a dupla camada elétrica, a região da reação de desprendimento de oxigênio ou mesmo estudos de tempo de vida útil dos materiais. Dependendo das condições experimentais e das características dos diagramas de EIE obtidos, diferentes circuitos elétricos foram propostos. A atribuição dos elementos do circuito ao sistema possibilitou a caracterização desses materiais, bem como a investigação dos mecanismos das reações $[11,53,55,80,81]$. 
Outros trabalhos também podem ser citados como, por exemplo: Borresen et al. [82] investigaram eletrodos de composição $\mathrm{Ti} / \mathrm{Ru}_{\mathrm{x}} \mathrm{Ti}_{(1-\mathrm{x})} \mathrm{O}_{2}$ para a reação de desprendimento de hidrogênio. Já Malpass et al. [83] utilizaram a EIE para discutir as diferenças entre os eletrodos comerciais de $\mathrm{Ti} / \mathrm{Ru}_{0,3} \mathrm{Ti}_{0,7} \mathrm{O}_{2}$ utilizados nas industrias de cloro-soda e eletrodos de mesma composição preparados em laboratório. Em estudos de tempo de vida útil de eletrodos do tipo $\mathrm{Ti} / \mathrm{RuO}_{2(\mathrm{x})}+\mathrm{Co}_{3} \mathrm{O}_{4(1-\mathrm{x})}$ [84] ou $\mathrm{Ti} / \mathrm{IrO}_{2}-\mathrm{Ta}_{2} \mathrm{O}_{5}$ [58] foi possível discutir o crescimento da camada de $\mathrm{TiO}_{2}$ proveniente do envenenamento do suporte de titânio utilizado na preparação dos eletrodos. O crescimento desta camada aumenta a resistência do filme resultando no aumento dos valores de $R(\mathrm{Ohm})$ nos estudos de EIE. O efeito de troca dos componentes dos óxidos tais como irídio e/ou tântalo como catalisador em substituição ao rutênio e titânio também foram investigados [60, 62, 85-87].

A maioria dos trabalhos que utilizam a EIE na investigação de ADEs, apresentam circuitos equivalentes simples para descrever diferentes regiões de potencial. Poucos trabalhos utilizam linhas de transmissão. Terezo et al. [25] investigaram eletrodos de composição $\mathrm{Ti} / \mathrm{IrO}_{2}$ e $\mathrm{Ti} / \mathrm{IrO}_{2} / \mathrm{Nb}_{2} \mathrm{O}_{5}$ em meio ácido simulando os dados com uma linha de transmissão de apenas um canal, em uma ampla faixa de potencial, desde o início da dupla camada elétrica até potenciais localizados na região de desprendimento de oxigênio. Panic et al. [88] utilizaram linhas de transmissão no estudo das propriedades capacitivas de eletrodos de $\mathrm{RuO}_{2}$ em meio de $\mathrm{H}_{2} \mathrm{SO}_{4}$ e $\mathrm{NaCl}$. Alguns outros trabalhos utilizaram linhas de transmissão no estudo de diferentes materiais porosos a base de níquel [3, 23, 89], zinco policristalino [90], filmes poliméricos [91].

Neste trabalho serão investigados diferentes tipos composições de ADEs aplicandose o modelo de poros. De acordo com o objetivo do estudo, aplicar uma LT torna-se mais 
interessante do que um CE simples, como por exemplo, em uma ampla faixa de potencial investigado, muitas vezes é necessário ajustar diferentes regiões de potencial com diferentes CE. Sendo que, uma mesma LT pode ser capaz de represetar toda a região de potencial de interesse. Mas, por outro lado, quando o objetivo do estudo é, por exemplo, investigar apenas a capacitância da dupla camada elétrica, pode-se utilizar um CE simples para extrair os valores dos dados experimentais, sem maiores problemas. É importante salientar que independente da abordagem utilizada, a EIE pode ser empregada para extrair valores numéricos importantes em relação a um determinado sistema eletroquímico. No caso dos ADEs, a EIE é uma técnica extremamente vantajosa, que possibilita investigar: reações redox, tempo de vida útil, reação de desprendimento de hidrogênio ou de oxigênio, influencia da composição eletródica ou do potencial aplicado [16] . 


\section{I.3.2 Células a combustível}

Atualmente, a preocupação com problemas ambientais é uma realidade em todo o mundo, o aumento progressivo da concentração de gases tóxicos, devido a queima de combustíveis fósseis, constitui um dos maiores problemas deste tipo, este quadro político e social levou a um maior interesse para a aplicação do conhecimento científico na geração de energia alternativa de forma limpa e eficiente. Uma opção promissora para a geração de energia elétrica, com reduzido impacto ambiental são as células (ou pilhas) a combustível, que realizam a transformação direta da energia química em energia elétrica.

Células a combustível (CC) são dispositivos que através da energia química proveniente da oxidação de um combustível, por exemplo: hidrogênio, metanol, etanol, ácido fórmico, e a redução do oxigênio do ar, produzem energia elétrica. Tais células apresentam várias vantagens em relação a dispositivos de combustão direta, como a alta eficiência e a baixa ou nenhuma emissão de poluentes.

As CCs foram descobertas ainda no século XIX, em 1839 por Willian Grove [9294]. A pilha de Grove era alimentada por gases hidrogênio e oxigênio em meio de ácido sulfúrico utilizando platina como ânodo e cátodo. Desde então os pesquisadores vem obtendo grandes avanços nos estudos de células a combustível em diversos países. O ressurgimento do interesse da CC para queima de combustíveis diferentes de derivados de petróleo aumentou com a crise energética de 1970.

Normalmente as células a combustível são classificadas de acordo com a temperatura em que operam e o eletrólito utilizado. Existem células de alta e baixa temperatura e os eletrólitos podem ser aquosos, fundidos ou sólidos. Os eletrólitos aquosos 
são utilizados em células que atuam em temperaturas mais baixas, podendo-se aumentar tais temperaturas a medida que se aumenta a pressão do sistema. Eletrólitos fundidos são empregados em células de altas temperaturas e eletrólitos sólidos (ou misturas de óxidos), são empregados em células com temperaturas ainda mais elevadas [95].

A Tabela I apresenta uma classificação contendo os diferentes tipos de células a combustível existentes, estas foram classificadas de acordo com as características gerais de cada uma:

- um primeiro grupo são as células que operam a baixas temperaturas:

- alcalinas (AFCs);

- com membrana de troca de prótons (PEMFCs):

- células diretas de metanol (DMFCs),

- células diretas de etanol (DEFCs).

- O segundo grupo são as células que operam a altas temperaturas:

- célula a combustível de ácido fosfórico (PAFCs).

- células de carbonato fundido (MCFCs) .

- células de óxido sólido (SOFCs) que operam em altas temperaturas, normalmente acima de $500^{\circ} \mathrm{C}$. 
Tabela I. Classificação de células a combustível $[95,96]$.

\begin{tabular}{|c|c|c|c|c|c|}
\hline Tipo* & a) $\mathrm{AFC}^{1}$ & b) PEMFC $^{2}$ & c) PAFC $^{3}$ & d) $\mathrm{MCFC}^{4}$ & e) $\mathrm{SOFC}^{5}$ \\
\hline Eletrólito & $\mathrm{NaOH} / \mathrm{KOH}$ & $\begin{array}{l}\text { Membrana } \\
\text { polimérica }\end{array}$ & $\overline{\mathrm{H}_{3} \mathrm{PO}_{4}}$ & $=\mathrm{LiCO}_{3}-\mathrm{K}_{2} \mathrm{CO}_{3}$ & $\begin{array}{c}\mathrm{ZrO}_{2} \text { com } \\
\mathrm{Y}_{2} \mathrm{O}_{3} \\
\end{array}$ \\
\hline $\begin{array}{c}\text { Material } \\
\text { eletródico }\end{array}$ & $\begin{array}{l}\text { Metal ou } \\
\text { carbono }\end{array}$ & $\begin{array}{c}\text { Platina sobre } \\
\text { carbono }\end{array}$ & $\begin{array}{c}\text { Platina sobre } \\
\text { carbono }\end{array}$ & $\mathrm{Ni}+\mathrm{Cr}$ & $\mathrm{Ni} / \mathrm{Y}_{2} \mathrm{O}_{3}-\mathrm{ZrO}_{2}$ \\
\hline Combustivel & $\mathrm{H}_{2}$ & $\begin{array}{c}\mathrm{H}_{2}, \mathrm{CH}_{3} \mathrm{OH} \text { ou } \\
\mathrm{CH}_{3} \mathrm{CH}_{2} \mathrm{OH}\end{array}$ & $\mathrm{H}_{2}$ & $\mathrm{H}_{2} / \mathrm{CO}$ & $\mathrm{H}_{2} / \mathrm{CO} / \mathrm{CH}_{4}$ \\
\hline Oxidante & $\mathrm{O}_{2} / \mathrm{ar}$ & $\mathrm{O}_{2} / \mathrm{ar}$ & $\mathrm{O}_{2} / \mathrm{ar}$ & $\mathrm{CO}_{2} / \mathrm{O}_{2} / \mathrm{ar}$ & $\mathrm{O}_{2} / \mathrm{ar}$ \\
\hline $\begin{array}{c}\text { Faixa de } \\
\text { temperatura }\end{array}$ & $60^{\circ} \mathrm{C}-90^{\circ} \mathrm{C}$ & $20^{\circ} \mathrm{C}-120^{\circ} \mathrm{C}$ & $160^{\circ} \mathrm{C}-200^{\circ} \mathrm{C}$ & $600^{\circ} \mathrm{C}-800^{\circ} \mathrm{C}$ & $\begin{array}{l}800^{\circ} \mathrm{C}- \\
1000^{\circ} \mathrm{C}\end{array}$ \\
\hline $\begin{array}{c}\text { Eficiência } \\
(\%)\end{array}$ & $50-60$ & $\begin{array}{l}50-60 \text { (PEFC) } \\
40-50 \text { (MEFC) }\end{array}$ & 55 & $60-65$ & $55-65$ \\
\hline Vantagens & $\begin{array}{l}\text { Produção de } \\
\text { água pura em } \\
\text { missões } \\
\text { espaciais }\end{array}$ & $\begin{array}{l}\text { alta densidade } \\
\text { de potência; } \\
\text { operação } \\
\text { flexível, } \\
\text { mobilidade. }\end{array}$ & $\begin{array}{c}\text { maior } \\
\text { desenvolvimen } \\
\text { to tecnológico } \\
\text { - tolerância a } \\
\text { CO }\end{array}$ & $\begin{array}{l}\text { tolerância a } \\
\text { monóxido e } \\
\text { dióxido de } \\
\text { carbono, } \\
\text { eletrodos de } \\
\text { níquel }\end{array}$ & $\begin{array}{c}\text { alta eficiência } \\
\text { (cinética } \\
\text { favorável) }\end{array}$ \\
\hline Desvantagens & $\begin{array}{l}\text { Limitada a } \\
\text { trabalhar em } \\
\text { ambientes } \\
\text { fechados }\end{array}$ & $\begin{array}{c}\text { custo da } \\
\text { membrana e } \\
\text { catalisador, } \\
\text { contaminação do } \\
\text { catalisador com } \\
\text { monóxido de } \\
\text { carbono. }\end{array}$ & $\begin{array}{c}\text { controle de } \\
\text { porosidade do } \\
\text { eletrodo, } \\
\text { eficiência } \\
\text { limitada pela } \\
\text { corrosão; }\end{array}$ & $\begin{array}{c}\text { corrosão do } \\
\text { cátodo, } \\
\text { interface } \\
\text { trifásica de } \\
\text { difícil controle; }\end{array}$ & $\begin{array}{l}\text { problemas de } \\
\text { materiais } \\
\text { expansão } \\
\text { térmica }\end{array}$ \\
\hline Aplicações & $\begin{array}{c}\text { Espaçonaves e } \\
\text { aparelhos } \\
\text { portáteis. }\end{array}$ & $\begin{array}{l}\text { veículos } \\
\text { automotores; } \\
\text { espaçonaves, } \\
\text { unidades } \\
\text { estacionárias. }\end{array}$ & $\begin{array}{c}\text { unidades } \\
\text { estacionárias, } \\
\text { geração de } \\
\text { calor. }\end{array}$ & $\begin{array}{c}\text { unidades } \\
\text { estacionárias, } \\
\text { cogeração de } \\
\text { eletricidade e } \\
\text { calor. }\end{array}$ & $\begin{array}{c}\text { unidades } \\
\text { estacionárias, } \\
\text { cogeração de } \\
\text { eletricidade e } \\
\text { calor }\end{array}$ \\
\hline
\end{tabular}

\footnotetext{
${ }^{1}$ Alcaline Fuel Cells - Células a Combustível Alcalinas;

${ }^{2}$ Proton Exchange Membran Fuel Cell - Célula de Combustível com Membrana para Troca de Próton;

${ }^{3}$ Phosphoric Acid Fuel Cell - Célula de Combustível de Ácido Fosfórico;

${ }^{4}$ Molten Carbonate Fuel Cell - Célula de Combustível de Carbonato,

${ }^{5}$ Solid Oxid Fuel Cell - Célula de Combustível de Óxido Sólido.
}

As PEMFCs apresentadas na Tabela I(b) operam em baixas temperaturas e vem sendo de grande interesse nas pesquisas devido a aplicação em veículos automotivos. Tais células utilizam uma membrana polimérica como meio condutor protônico. A membrana usada normalmente é a Nafion ${ }^{\circledR}$ (produzida pela Dupont ${ }^{\circledR}$ ), tem como principal desvantagem o alto custo. Além de o desempenho depender da retenção de água na matriz 
sólida que, em geral, não é limitada em temperaturas muito elevadas (acima de $110^{\circ} \mathrm{C}$ ). Como a faixa de operação dos protótipos de células a base de metanol e etanol é abaixo de $100{ }^{\circ} \mathrm{C}$, o Nafion ${ }^{\circledR}$ vem sendo usado de maneira satisfatória, pois apresenta uma boa condutividade e excelentes propriedades químicas e mecânicas nestas condições. Mesmo assim, alguns trabalhos começam a investigar outras opções para melhorar a eficiência da membrana, por exemplo adicionando zeólitas ao material [97]. Existem diferentes composições das membranas de Nafion, Le Ninivin C. et al. [98] realizaram um estudo com membranas de $\mathrm{Nafion}^{\circledR}$ 112, 115 e 117 (o número caracteriza a espessura da membrana) aplicadas a células a combustível de metanol e além de otimizarem as condições para uso das membranas na presença de álcoois, demonstraram que a membrana de Nafion ${ }^{\circledR} 117$ é, a mais adequada para o uso em DEFCs [98].

As PEMFCs utilizam álcool como combustível e oxigênio como oxidante. No ânodo tem-se a entrada de álcool, onde ocorre a oxidação do álcool, já no cátodo, tem-se a entrada de $\mathrm{O}_{2}$, onde ocorre a redução do oxigênio. Os alcoóis mais estudados são o metanol e etanol. Tais álcoois são vistos como possíveis combustíveis para diversas aplicações. Alimentar um ânodo por um combustível líquido permanente sem a presença de um reformador é o conceito ideal para aplicação em dispositivos pequenos (telefone, celulares, computadores, etc) [99]. O combustível encontrado para este tipo de aplicação foi o metanol (Direct Methanol Fuel Cell - DMFC), pois gera densidades da ordem de 20 a 50 $\mathrm{mW} \mathrm{cm} \mathrm{cm}^{-2}$ e apresenta algumas vantagens como, por exemplo: a facilidade de construção do sistema, peso e complexidade; facilidade de armazenamento do combustível e alta eficiência energética. Mas, o grande inconveniente da aplicação do metanol como combustível é a sua alta toxicidade tanto para ingestão como inalação. Assim, as DMFCs 
são vistas como uma alternativa ambientalmente de risco. Em vista disto a substituição do metanol por etanol (Direct Ethanol Fuel Cell - DEFC) tem despertado grande interesse científico, pois este pode ser produzido em grande quantidade por ser um insumo renovável e não poluidor.

Wang et al. [100] investigaram células a combustível utilizando Pt:Ru como ânodo e mostraram que o etanol é um alternativa promissora como combustível com uma atividade eletroquímica comparável ao metanol. Song et al. [101], mostraram que quando o álcool penetra através da membrana de $\mathrm{Nafion}^{\circledR}$, entrando em contato com o cátodo, ocorre um considerável decaimento da eficiência da célula de metanol. No caso do etanol essa contaminação apresenta efeitos menos drásticos, devido a menor permeabilidade através da membrana de Nafion ${ }^{\circledR}$ e da cinética de oxidação do etanol em Pt/C ser menor do que a do metanol.

Devido a isso, diversos estudos com etanol têm como foco identificar os intermediários e explicar o mecanismo da reação por diferentes técnicas como: a Espectrometria de Massas Eletroquímica Diferencial (DEMS) [102, 103] e a Espectrometria de infravermelho por transformada de Fourier in situ (FTIRS) [104-109].

Apesar de todos os avanços apresentados das PEMFCs, sérias dificuldades tecnológicas ainda devem ser resolvidas:

1. Para aplicação para meio de transporte, o tempo entre o início do funcionamento e reposta ainda é excessivamente lento. (A utilização em ambientes adversos: alta vibração, alteração de tração) ainda não é viável.

2. O problema da água necessária para humidificação da membrana e célula. 
3. Reservatório de hidrogênio (gás a alta pressão, criogênio para líquido ou processo de reforma para combustíveis).

4. Aplicação portátil, como fazer a minituarização.

5. Custo elevado (platina e demais co-catalisadores empregados; membrana polimérica, placas bipolares).

6. A contaminação do cátodo com etanol ou metanol pelo processo de transferência através da membrana.

\section{I.3.2.1 Células a combustível de etanol (DEFCs)}

O etanol é um combustível renovável, com ampla rede de distribuição no país tornase um candidato potencialmente interessante ao uso em células a combustível que empregam diretamente o etanol sem a necessidade de reforma. Em uma DEFC, o etanol age como fonte de produção de hidrogênio que irá reduzir o oxigênio e água no cátodo [99, 110]. Já no ânodo tem-se a oxidação do etanol como apresentado na Figura 9. A reação global é representada por:

$$
\mathrm{CH}_{3} \mathrm{CH}_{2} \mathrm{OH}+3 \mathrm{O}_{2} \rightarrow 2 \mathrm{CO}_{2}+3 \mathrm{H}_{2} \mathrm{O}
$$




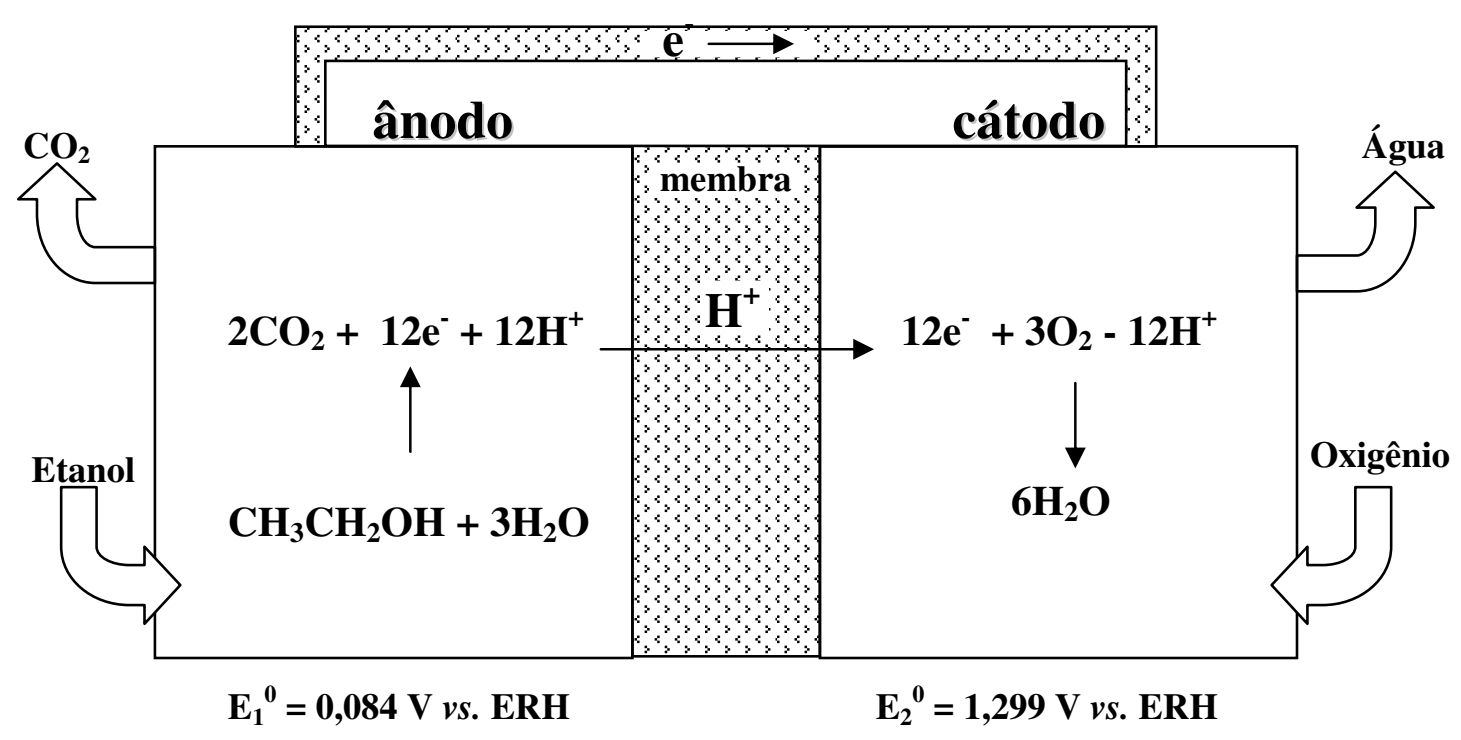

Figura 9: Esquema de uma célula a combustível de etanol [111].

Para uma geração de energia mais vantajosa o interessante nesta oxidação é a transformação completa do etanol em dióxido de carbono. Neste processo, 12 elétrons são transferidos (ver Figura 10). No entanto, a quebra da ligação C-C do etanol ocorre em escala muito pequena na maioria dos catalisadores conhecidos até o momento. A formação de $\mathrm{CO}_{2}$ é seriamente dificultada devido a grande competição entre a formação dos produtos menos oxidados, isto é, acetaldeído e ácido acético [107, 112]. Esta é uma séria limitação ao uso do etanol como combustível em dispositivos sem reforma.

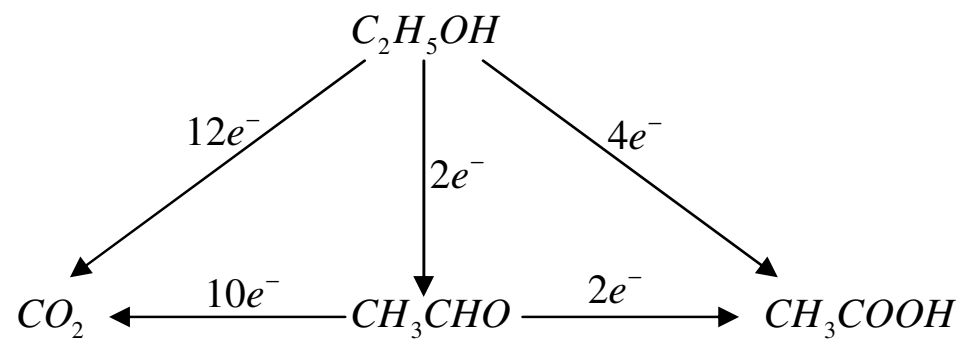

Figura 10: Proposta mecanística da oxidação do etanol de acordo com referência [113]. 
O mecanismo de oxidação do etanol é bastante complexo e envolve várias etapas de adsorção/desorção até a formação dos produtos finais. A adsorção do etanol na superfície da platina policristalina foi largamente estudada pelos mais diferentes métodos [114, 115]. Os produtos de reação formados $\mathrm{CO}_{2}$, acetaldeído e ácido acético foram claramente identificados [107, 112]. Dentre os mecanismos propostos na literatura tem-se o trabalho de Iwasita e colaboradores $[105,116]$, que estudaram o mecanismo de adsorção do etanol sobre platina utilizando as técnicas de DEMS e FTIRS e propuseram a seguinte seqüência reacional:

Ruptura da ligação O-H fazendo que um grupamento etoxi seja adsorvido:

$\mathrm{CH}_{3} \mathrm{CH}_{2} \mathrm{OH}+\mathrm{Pt} \rightarrow \mathrm{Pt}-\mathrm{OCH}_{2} \mathrm{CH}_{3}+\mathrm{e}^{-}$

A ruptura da ligação C-H ocorre a adsorção da carbonila $\alpha$ à hidroxila.

$\mathrm{CH}_{3} \mathrm{CH}_{2} \mathrm{OH}+\mathrm{Pt} \rightarrow \mathrm{Pt}-\mathrm{CHOHCH}_{3}+\mathrm{H}^{+}+\mathrm{e}^{-}$

Para os autores a espécie Pt- $\mathrm{CHOHCH}_{3}$ é a espécie precursora da formação de $\mathrm{CO}$ adsorvido linearmente na superfície:

$\mathrm{Pt}-\mathrm{CHOHCH}_{3} \rightarrow \mathrm{Pt}-\mathrm{CO}-\mathrm{CH}_{3}+2 \mathrm{H}++2 \mathrm{e}-\rightarrow \mathrm{Pt}-\mathrm{CO}+\mathrm{Pt}-\mathrm{CH}_{3}$

Já Hitmi et al. [117], utilizaram métodos eletroquímicos e voltametria cíclica e propuseram a existência de um mecanismo reacional paralelo e seqüencial:

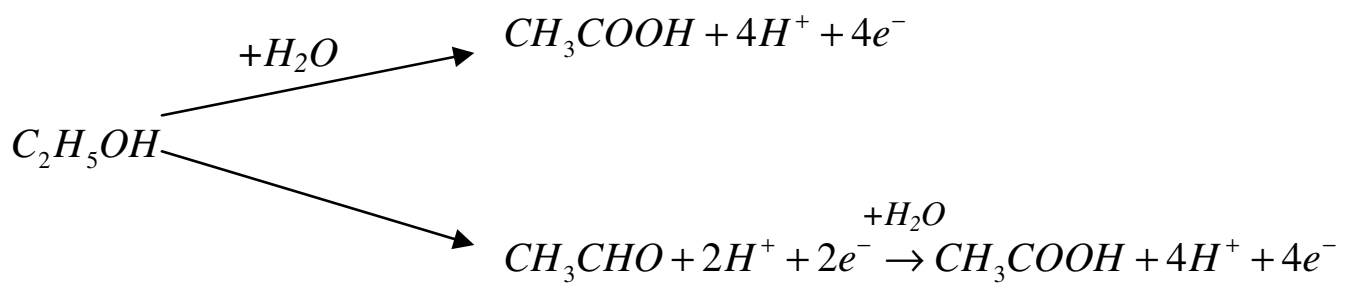

Figura 11: Proposta mecanística da oxidação do etanol de acordo com referência [117] . 
Em catalisadores de platina pura a reação acima se produz, principalmente, em altos valores de potencial ( $\mathrm{E}>0,8 \mathrm{~V}$ vs. ERH). No entanto, quando existem espécies doadoras de oxigênio na superfície da platina, tais como metais $\mathrm{Ru}, \mathrm{Sn}, \mathrm{Rh}$, a reação passa a ocorrer em potenciais mais baixos $(0,6 \mathrm{~V} v s$. ERH) [118].

Em potenciais intermediários ocorre a reação de dissociação da água:

$$
\mathrm{Pt}+\mathrm{H}_{2} \mathrm{O} \rightarrow \mathrm{Pt}-\mathrm{OH}_{\mathrm{ad}}+\mathrm{H}^{+}+\mathrm{e}^{-}
$$

Graças à formação de espécies oxigenadas na superfície do eletrodo forma-se, a partir do $\mathrm{CO}_{\mathrm{ad}} \mathrm{o} \mathrm{CO}_{2}$ e acetaldeído pode ser oxigenado à ácido acético $[113,117]$. A oxidação direta de ácido acético para $\mathrm{CO}_{2}$ é difícil de ocorrer sob condições de temperatura ambiente.

O grande interesse desta reação na produção de energia deve-se a quantidade de energia teórica que poderia ser obtida da combustão completa (12 elétrons): $8,01 \mathrm{kWhrKg}^{-1}$. Considerando a reação até a formação de ácido acético o rendimento corresponde a densidade de massa seria de $1,354 \mathrm{kWhrKg}^{-1}$. Embora este valor seja muitas vezes menor que o valor teórico para a formação de $\mathrm{CO}_{2}$ este, ainda é 10 vezes mais elevado do que o valor de um acumulador de lítio. Para melhorar o rendimento energético é possível agir sobre o rendimento faradáico da reação isto é, elaborar catalisadores eficientes capazes de diminuir os sobrepotenciais anódicos e catódicos, encontrar meio de transporte mais eficiente para diminuir a queda ôhmica da reação [50, 77, 119-121]. 


\section{I.3.2.2 Catalisadores utilizados em DEFCs}

A estrutura e distribuição eletrônica do material influência de maneira importante a eletrocatálise. A oxidação do etanol a baixa temperatura foi amplamente estudada em monocristais de platina $[122,123]$. A Pt pura, entretanto, não se mostra o melhor catalisador anódico para uma célula a combustível direta de etanol devido ao envenenamento rápido do material, ou seja, a adsorção de espécies que bloqueiam os sítios ativos da platina $[124,125]$. Portanto, alguns co-catalisadores vem sendo utilizados para evitar esse problema e melhorar a eficiência de ânodos contendo Pt, como por exemplo: Rh [126], Os [127], Ce [128]. Como catálise é um processo de superfície, o catalisador necessita de uma área eletroquimicamente ativa elevada, devido a isso, deposita-se o catalisador em uma base condutora composta por carbono.

O conhecimento atual mostra que a platina é um elemento essencial para a adsorção da molécula de etanol, no entanto, a ajuda de um segundo metal, que pode ter vários efeitos (catalítico, geométrico, eletrônico) permite que as espécies adsorvidas sejam rapidamente eliminadas da superfície do catalisador liberando o sítio ativo para prosseguir a reação. Portanto, no desenvolvimento dos catalisadores atuais utilizam-se materiais plurimetálicos (bi ou tri metálicos) sendo a platina um material base para o desempenho da reação. Neste caso, os materiais anódicos mais investigados em células a combustível de metanol ou etanol são as composições binárias PtRu e PtSn [102, 111], bem como composições ternárias: PtRuMo [129] ; PtRuOs [130]; PtRuW [129, 131], ou ainda, adicionando um novo metal como por exemplo: $\mathrm{Ni}$, Mo, W [125]. 
O catalisador PtRu foi intensamente investigado para oxidação de pequenas moléculas orgânicas [108, 132-135], notou-se que a reação de oxidação de etanol é fortemente dependente do conteúdo de Ru no catalisador [136]. Diversas composições e diferentes metodologias de preparação podem ser encontradas na literatura [137-139].

Schmith et al. [108] compararam a atividade de diferentes eletrodos Pt, Ru e PtRu na distribuição dos produtos de oxidação do etanol. Segundo os autores, as etapas de adsorção e redução são exclusivamente sobre os sítios de platina. $\mathrm{O}$ aumento da atividade do catalisador PtRu ocorre uma vez que a formação de espécies $\mathrm{OH}_{\mathrm{ad}}$ sobre a superfície do rutênio ocorre em potenciais mais baixos $(0,2 \mathrm{~V}$ vs. ERH) do que em platina $(0,7 \mathrm{~V} v s$. ERH). Portanto, sobre os sítios de platina as moléculas de etanol formam intermediários fortemente adsorvidos $\left(\mathrm{R}_{\mathrm{ad}}\right) \mathrm{e}$, portanto, a oxidação na presença de $\mathrm{Ru}$ ocorre em potenciais menores devido a oxidação das espécies adsorvidas pela hidroxila presente no sítio de Ru. Este efeito resulta de um mecanismo bifuncional estabelecido por Watanabe e Motoo [140]. Em função deste mecanismo a presença de Ru inibe a quimiosorção de espécies fortemente adsorvidas [141].

O dióxido de carbono forma-se exclusivamente devido a espécies adsorvidas, pois, independe da concentração inicial de etanol [108, 142]. Já Iwasita e colaboradores [113] demonstraram recentemente que em platina policristalina a contribuição das diferentes etapas para produção de $\mathrm{CO}_{2}$, ácido acético e acetaldeído é sim função da concentração do álcool. Altas concentrações de ácido acético são obtidas em baixas concentrações de etanol. $\mathrm{O}$ acetaldeído é o produto majoritário quando se utiliza concentrações superiores a $0,1 \mathrm{~mol}$ $\mathrm{dm}^{-3}$. Para catalisadores bimetálicos, PtRu, a reação de oxidação de etanol é fortemente dependente do conteúdo de Ru no catalisador. Composições contendo 1- $45 \%$ de Ru 
apresentaram maior atividade, sendo a composição PtRu (60-40) a mais ativa para oxidação do etanol [136].

Outro metal que tem sido objeto de diversos estudos, principalmente para a oxidação de metanol e CO, é o catalisador PtSn. A comparação das atividades dos eletrodos, Pt, PtSn e PtRu para a oxidação de pequenas moléculas orgânicas mostra que a composição PtRu apresenta uma melhor eficiência para oxidação de metanol. No entanto, Pt-Sn tem um efeito bastante acentuado na oxidação de CO [143-146]. Gonzalez et al. [147], estudaram a oxidação de álcoois e dióis sobre eletrodos de Pt modificados com Sn, preparados por co-depósito eletroquímico. Esta técnica permite a obtenção de partículas de 0,8 $\mu \mathrm{m}$ como produto final foi obtido ácido acético. Shibata e Motoo [148] demostraram que apesar de aumentar a atividade catalítica o estanho não é ativo para a quebra da ligação C-C. Sendo sempre o produto final o ácido acético.

Recentemente, no Laboratório de Eletrocatálise e Eletroquímica Ambiental de Ribeirão Preto foram realizados estudos com nanocatalisadores preparados por decomposição de precursores poliméricos (Pechini) de composição binária (C/PtSn) [120] e ternária (C/PtSnIr) [121]. A função do Estanho nestas ligas é fornecer espécies oxigenadas para auxiliar na remoção de CO durante a oxidação dissociativa do etanol sobre o sítio de platina. Dependendo do método empregado na preparação dos catalisadores pode-se obter diferentes respostas para a oxidação do etanol.

Zhao et al. [149] relataram que o comportamento das partículas de $\mathrm{PtSn}$ e $\mathrm{PtSnO}_{\mathrm{x}}$ preparadas pelo processo de polióis modificados. Os autores demonstraram que o láctice de Pt nas ligas PtSn são dilatados pela incorporação de Sn no retículo cristalino da Pt. Esta 
pequena diferença estrutural permite alterar de forma significativa a habilidade de $\mathrm{Sn}$ presente nas proximidades das nanopartículas de $\mathrm{Pt}$ em converter $\mathrm{CO}$ em $\mathrm{CO}_{2}$. Desta forma muitos metais de transição e seus respectivos óxidos foram investigados tais como $\mathrm{RuO}_{\mathrm{x}}$, $\mathrm{SnO}_{\mathrm{x}}, \mathrm{VO}_{\mathrm{x}}$ e $\mathrm{MoO}_{\mathrm{x}}$ como co-catalisadores para oxidação de álcoois [150-153]. Em um trabalho anterior verificamos que a oxidação do etanol ocorre em baixos sobrepotenciais $(<0,5 \mathrm{~V} v s . \mathrm{ERH})$ através de espécies acetil adsorvidas que levam à formação preferencial de acetaldeído e ácido acético. Uma pequena fração de $\mathrm{CO}_{2}$ e $\mathrm{CO}$ adsorvidos, também foram identificados através de análises espectroscópicas in situ (DEMS, FTIR) [105]. Apesar dos vários trabalhos na literatura investigando a oxidação de álcoois em catalisadores de Pt $[6,136,154]$, alguns aspectos importantes do mecanismo ainda precisam ser elucidados. De acordo com muitos trabalhos a quantidade apropriada de catalisador para um bom funcionamento da célula situou-se entre 10 a $40 \%$ de metal. Estes fatores dependem da temperatura de operação e da densidade de corrente desejada.

A comparação das atividades dos eletrodos, Pt, PtSn e PtRu para a oxidação de pequenas moléculas orgânicas mostra que a composição PtRu apresenta uma melhor eficiência para oxidação de metanol. No entanto, Pt-Sn tem um efeito bastante acentuado na oxidação de CO e etanol [147]. Antolini [125] apresenta uma revisão geral dos catalisadores testados como cátodos e ânodos para oxidação de etanol em meio ácido, dando ênfase as características físicas e químicas dos catalisadores e a atividade dos mesmos na reação de oxidação do etanol.

O entendimento dos mecanismos cinéticos reacionais, de transporte eletrônico e polarização, envolvidos em tais sistemas são ainda pouco conhecidos. Tal fato tem limitado a capacidade de monitorar as mudanças fundamentais que ocorrem quando da modificação 
das condições de síntese ou morfológicas de tais materiais. Sendo assim, no que se refere a um estudo básico de transporte eletrônico e polarização de tais eletrodos há ainda um grande desafio a ser enfrentado, o qual está diretamente relacionado com a identificação e caracterização dos principais mecanismos responsáveis por tais efeitos.

\section{I.3.2.3 EIE e voltametria $a c$ aplicadas a células a combustível de etanol}

A EIE quando aplicada ao estudo de células a base de alcoóis (metanol ou etanol) pode fornecer informações sobre perdas individuais, incluindo a cinética da reação de redução do oxigênio, transferência de massa e perdas na resistência da membrana eletrolítica, ou seja, respostas referentes ao mecanismo de oxidação, bem como aos intermediários. Muitos estudos vêm sendo realizados para determinar a impedância de células a combustível, sendo possível investigar e otimizar o funcionamento da célula.

Investigações realizadas com células de $\mathrm{H}_{2} / \mathrm{N}_{2}$ ou $\mathrm{H}_{2} / \mathrm{O}_{2}$ apresentaram bons resultados utilizando o modelo de poros e uma linha de transmissão para ajustar os dados experimentais. Parâmetros como a resistência ôhmica, a resistência da solução eletrolítica e a capacitância da dupla camada elétrica foram extraídos $[155,156]$. Ainda se tratando de estudos relacionados ao cátodo de uma PEMFC, os diagramas de Nyquist apresentam normalmente um segundo semi-círculo em baixas freqüências, atribuído as limitações difusionais do oxigênio [157].

A maioria dos trabalhos de EIE aplicada a PEMFCs investigam a oxidação do metanol, como Mueller \& Urban [157], que foi um dos primeiros grupos a utilizar a EIE 
para investigar células a combustível de metanol, obtendo sucesso ao realizar medidas de impedância em baixas, intermediárias e altas freqüências, com e sem as limitações de transporte de massa. E assim, foi possível utilizar um circuito elétrico simples com elementos representando os parâmetros cinéticos da reação.

Sen Gupta et al. [158] realizaram estudos de células a combustível diretas de alcoóis com eletrodo a base de PtRu depositados em ligas metálicas de Cu:Ni (70:30), as análises de EIE possibilitaram notar que na presença de Ru ocorreu um aumento da cinética da reação.

Wang et al. [159] compararam a impedância eletroquímica entre ânodos de PtRuNi e PtRu, e observaram uma melhora na eficiência com a adição do Ni. Seo \& Lee $[160,161]$ investigaram as características da impedância eletroquímica para DMFC em várias condições de operação. Variando a temperatura e/ou pressão, a velocidade do fluxo de metanol, a concentração de metanol e o tipo do gás oxidante. Como observado o uso da EIE em estudos de DMFCs vem apresentando resultados vantajosos, que ajudam na compreensão, do sistema, identificação das melhores condições operacionais.

No caso das DEFCs existem um número menor de trabalhos utilizando a EIE, devido ao envenenamento do $\mathrm{CO}$ no ânodos de platina, o que limita o desempenho devido à desativação do catalisador no ânodo de Pt. Muitos esforços foram feitos para compreender o mecanismo do envenenamento do CO. Alguns investigadores empregaram a técnica de EIE para estudar o envenenamento do CO do ânodo [162, 163]. Entretanto, alguns problemas ainda necessitam serem investigados. Um problema extremamente complexo consiste na separação das impedâncias do ânodo e do cátodo [15, 162]. Schiller et al. [164] 
utilizaram a EIE justamente para investigar a influencia do envenenamento de $\mathrm{CO}$ no ânodo de platina e Leng et al. [165] no estudo da tolerância ao CO de diferentes ligas de Pt.

Como já citado anteriormente, novos materiais adicionados a $\mathrm{Pt}$ vem sendo investigados. Bai et al. estudaram ânodos de $\mathrm{Pt}-\mathrm{ZrO}_{2} / \mathrm{C}$ [166] e PtSn/MCMB (Mesocarbon Microbeads) [167] em DEFCs e através da EIE notaram que a resistência de transferência de carga destes materiais era bem menor do que de ânodos de platina pura. Outros trabalhos investigando diferentes materiais como Pt:Rh [168]; Pt:Sn [169]; Pt-CeO $/$ /C [151], também utilizam a EIE no estudo de DEFCs.

Estudos relacionados a membrana de troca de prótons também podem ser encontrados na literatura, Song et al. [101] e Wiezell et al. [170, 171] por exemplo, realizaram estudos de EIE para avaliar o efeito do procedimento de preparação da membrana trocadora de prótons e os efeitos do Nafion em materiais contendo Pt:Ru aplicados a DMFC.

Wagner et al. [163] publicaram uma revisão da EIE utilizada na investigação de células a combustível com membrana de troca de prótons, onde apresentam as diferentes maneiras de usufruir dos resutados da EIE. Os autores constatam que a maior dificuldade ainda encontrada em análises de células a combustível por EIE é a separação da impedância do cátodo e do ânodo.

A impedância do cátodo é difícil de ser medida, devido a rápida velocidade da reação de redução do hidrogênio [15]. A resistência ôhmica, juntamente com a resistência da membrana polimérica e as resistências dos contatos elétricos são dadas por um único valor de resistência, presente no início do primeiro semi-circulo na parte real do diagrama [172, 173]. Diard et al. [174] relatam que nos estudos de células a combustível, a 
impedância do cátodo muitas vezes pode ser considerada muito menor que a do ânodo $\left(\mathrm{Z}_{\mathrm{c}} \ll<\mathrm{Z}_{\mathrm{a}}\right.$ ) portanto a impedância total do sistema, $\mathrm{Z}_{\mathrm{t}}=\mathrm{Z}_{\mathrm{c}}+\mathrm{Z}_{\mathrm{a}}$, pode ser dada como $\mathrm{Z}_{\mathrm{t}} \approx \mathrm{Z}_{\mathrm{a}}$. Os autores apresentam também a possibilidade da substituição do oxigênio do cátodo por hidrogênio, sendo assim a reação ocorrente no cátodo seria: $2 H^{+}+2 e^{-} \rightarrow H_{2}$. Diard et al. propuseram também uma outra opção para tentar medir a impedância do ânodo e do cátodo separadamente, realizando medidas diretas na célula e também medidas em uma dummy cell.

O foco deste trabalho, no entanto, refere-se a utilização da EIE para investigar a oxidação do etanol, para aplicação em célula a combustível. Portanto, a EIE será investigada em materiais a base de Pt, Ru e Sn depositados em suporte de Ti, sem a presença de carbono. As vantagens de se analisar estes materiais em um sistema externo, não diretamente na DEFC, é a facilidade de separação da impedância do ânodo. Além de que, a presença do suporte de carbono nas células a combustível contribui para um aumento nos valores de resistências $[163,175]$. Sem Gupta et al. utilizaram a EIE na investigação de materiais a base de PtRu e PtMo e Pt e PtRu suportados em um liga de CuNi (70:30) em meio de hidróxido de sódio na oxidação de etanol [158, 176, 177].

Pouco se encontra na literatura sobre a aplicação de Voltametria $a c$. O grupo de pesquisa de David A. Harrington da Universidade de Victoria no Canadá apresentaram alguns trabalhos na aplicação da técnica, como por exemplo, um trabalho que descreve o uso da Voltametria ac para medidas de cinética de superfície, onde o autor discute os parâmetros experimentais ideais para que se possa analisar os dados utilizando-se a teoria de impedância [28]. O mesmo grupo de autores investiga a aplicação da Voltametria $a c$ no 
estudo de platina policristalina em solução de ácido sulfúrico [178], na investigação da oxidação de metanol com eletrodos de platina [179] e na oxidação de ácido fórmico também com eletrodos de platina [180]. 


\section{II- OBJETIVO}

O objetivo deste trabalho consistiu em utilizar a técnica de EIE na investigação da cinética de diferentes materiais eletrocatalíticos. Para isso foram escolhidos para a investigação da $\mathrm{RDO}$, eletrodos do tipo ADEs de composição $\mathrm{Ti} / \mathrm{Ru}_{0,3} \operatorname{Ti}_{(0,7-\mathrm{x})} \mathrm{Sn}_{\mathrm{x}} \mathrm{O}_{2}$ $(x=0 ; 0,3$ e 0,7). Adicionalmente, o efeito da eletrodeposição de Pt na cinética da RDO do ADE também foi investigado. Os resultados obtidos por EIE (ac) com os estudos cinéticos, foram comparados com as curvas de polarização de Tafel $(d c)$ em meio ácido.

A investigação da cinética da oxidação de etanol utilizando a EIE, com ânodos aplicados a DEFCs de composição: Ti/Pt, Ti/Pt:Ru (80:20), Ti/Pt:Sn (80:20) e Ti/Pt:Ru:Sn (80:10:10), foi empregada para avaliar a eficiência eletrolítica. 


\section{III- PROCEDIMENTO EXPERIMENTAL}

\section{III.1 Preparação dos precursores poliméricos}

\section{III.1.1 Preparação da resina precursora de Titânio}

Para a preparação da resina de titânio, foi dissolvido ácido cítrico em etileno glicol em quantidades de 1:1 em massa a $65^{\circ} \mathrm{C}$. Após a dissolução do ácido a temperatura foi elevada para $85-90^{\circ} \mathrm{C}$ e adicionou-se o isopropóxido de titânio na proporção 1:4:16 em mol de isopropóxido de titânio, ácido cítrico e etileno glicol, respectivamente. A solução permaneceu sob aquecimento e agitação por aproximadamente 4 horas, até a dissolução completa do isopropóxido de titânio. A resina foi então estocada em ausência de luz.

A padronização gravimétrica foi realizada utilizando uma massa de $1 \mathrm{~g}$ de resina, e

calcinando durante 1 hora a $700^{\circ} \mathrm{C}$, sob fluxo de de $\mathrm{O}_{2}\left(5 \mathrm{dm}^{-3} \mathrm{~min}^{-1}\right)$. A concentração encontrada de titânio foi de $\left(3,0.10^{-4} \pm 0,00005\right) \mathrm{mol} \mathrm{Ti} / \mathrm{g}$ de resina.

\section{III.1.2 Preparação da resina precursora de Rutênio}

Uma massa de cloreto de rutênio $\left(\mathrm{RuCl}_{3} 3 \mathrm{H}_{2} \mathrm{O}\right.$ - Aldrich), foi dissolvida em um balão volumétrico de $100 \mathrm{~mL}$ contendo uma solução de $\mathrm{HCl} \mathrm{1:1} \mathrm{v/v.} \mathrm{A} \mathrm{resina} \mathrm{precursora} \mathrm{de}$ rutênio foi obtida através da dissolução de ácido cítrico em etilieno glicol (MERCK) em 
proporção de 4:16 em mol a $65{ }^{\circ} \mathrm{C}$. Após a dissolução do ácido, a temperatura foi elevada até aproximadamente $90-95{ }^{\circ} \mathrm{C}$ para que a solução de rutênio seja adicionada em uma proporção com o ácido cítrico de 1:4 em mol. Após a completa dissolução da solução, o volume foi resfriado até a temperatura ambiente.

A determinação da concentração de rutênio na resina precursora também foi realizada através de gravimetria. Uma massa conhecida da resina foi submetida à calcinação a $550{ }^{\circ} \mathrm{C}$ por 1 hora e a massa do óxido de rutênio obtido após este processo foi determinada. Pela relação do número de mols de rutênio no óxido obtido e a massa de resina utilizada pôde-se obter a concentração real de rutênio presente na resina. A concentração encontrada foi de $2,03 \cdot 10^{-4} \mathrm{~mol} \mathrm{RuO}_{2} / \mathrm{g}$ de resina.

\section{III.1.3 Preparação da resina precursora de Estanho}

A resina precursora de estanho foi preparada de acordo com Pechini \& Adams [181], utilizando-se o citrato de estanho $\mathrm{C}_{6} \mathrm{H}_{8} \mathrm{O}_{8} \mathrm{Sn}_{2}(\mathrm{M}=445,44 \mathrm{~g} / \mathrm{mol})$, como precursor, obtido a partir de ácido cítrico $\left(\mathrm{C}_{6} \mathrm{H}_{8} \mathrm{O}_{7} \cdot \mathrm{H}_{2} \mathrm{O}-\mathrm{MERCK}\right)$ e cloreto de estanho $\left(\mathrm{SnCl}_{2} \cdot 2 \mathrm{H}_{2} \mathrm{O}\right.$ - MERCK) na proporção de 1:2 em mol. A massa de cloreto de estanho (II) foi dissolvida na solução do ácido cítrico e, em seguida foi adicionado $\mathrm{NH}_{4} \mathrm{OH} 2,0 \mathrm{~mol} \mathrm{dm}^{-3}$ gota a gota com agitação e controle do $\mathrm{pH}$ até valores próximos de 3,0. A mistura foi centrifugada e obteve-se o citrato de estanho como precipitado, que foi lavado com água deionizada várias vezes, para que fosse retirado todo o excesso de cloreto. O citrato de estanho obtido foi colocado em estufa a $70^{\circ} \mathrm{C}$, por 24 horas, para a secagem completa do sal. 
Posteriormente, dissolveu-se ácido cítrico em etileno glicol (MERCK) nas quantidades de 3:10 em massa a $65^{\circ} \mathrm{C}$. Após a dissolução do ácido cítrico a temperatura foi elevada para $85-90^{\circ} \mathrm{C}$ e adicionou-se o citrato de estanho na proporção $1: 3$ de ácido cítrico em mol. Adicionou-se então o $\mathrm{HNO}_{3}$ (MERCK) concentrado gota a gota até a dissolução completa do sal obtendo-se a resina de estanho.

Foi realizada a padronização gravimétrica da resina de estanho, submetendo a mesma a uma calcinação gradual com uma programação pré-fixada em $300^{\circ} \mathrm{C}$, elevando-se $100^{\circ} \mathrm{C}$ a cada 20 minutos até atingir $700^{\circ} \mathrm{C}$, e mantendo por 1 hora sem fluxo de $\mathrm{O}_{2}$.

Após a calcinação, a massa de $\mathrm{SnO}_{2}$ obtida foi pesada determinando a concentração de estanho de mol de $\mathrm{Sn} / \mathrm{g}$ de resina. A concentração encontrada foi de $1,21.10^{-3} \mathrm{~mol}$ $\mathrm{SnO}_{2} / \mathrm{g}$ de resina.

\section{III.1.4 Preparação da resina precursora de Platina [182]}

Foram dissolvidos 5,0 g de ácido hexacloroplatínico $\left(\mathrm{H}_{2} \mathrm{PtCl}_{6}-\right.$ Aldrich), em um balão volumétrico de $100 \mathrm{~mL}$ contendo uma solução de $50 \%$ em volume $\mathrm{HCl}$. A resina precursora de platina foi obtida através da dissolução de ácido cítrico em etilieno glicol (MERCK) em proporção de 4:16 em mol a $65{ }^{\circ} \mathrm{C}$. Após a dissolução do ácido, a temperatura foi elevada aproximadamente a $90{ }^{\circ} \mathrm{C}$ para que a solução de platina fosse adicionada em uma proporção com o ácido cítrico de 1:4 em mol. Após a completa dissolução da solução, os volumes da mesma foram diminuídos e em seguida resfriados até a temperatura ambiente. 
A resina de platina foi padronizada pela técnica de espectrofotometria de chama (absorção atômica) pelo método de curva de calibração que foi construída com uma solução padrão de platina 1000 ppm (Aldrich) com a qual a concentração da resina foi determinada. $\mathrm{O}$ valor encontrado foi de $1,04.10^{-4} \mathrm{~mol} \mathrm{de} \mathrm{Pt/g} \mathrm{resina.}$

\section{III.2 Preparação dos eletrodos de trabalho e célula eletroquímica}

Após obtidas as resinas precursoras, foram preparadas misturas contendo as concentrações nominais de interesse. A espessura teórica desejada da camada de óxido foi de $1 \mu \mathrm{m}$, a qual foi preparada pelo controle da massa a ser depositada. Sendo a espessura nominal dos eletrodos de $1 \mu \mathrm{m}$ e a placa de Ti de $10 \times 10 \times 1 \mathrm{~mm}$, o volume total do óxido (volume $=$ área $\mathrm{x}$ espessura) depositado é de $2.10^{-4} \mathrm{~cm}^{3}$, considerando que ambos os lados do suporte foram revestidos pelo óxido.

Os suportes de titânio foram primeiramente colocados em água Milli-Q e levados a ebulição durante 30 minutos. Em seguida, levados ao ultra-som em isopropanol (MERCK) durante 30 minutos para eliminação de gordura e impurezas orgânicas. Por fim, foram colocados em uma solução de $\mathrm{HCl}$ (MERCK) 20\% em volume durante 5 minutos em ebulição. Os suportes foram armazenados em isopropanol até o dia de uso. Antes de iniciar a deposição dos materiais, os suportes foram colocados em solução de ácido oxálico (Synth) $10 \%$ em massa e levados a ebulição durante 20 minutos para eliminação de $\mathrm{TiO}_{2}$.

Os suportes de titânio possuem uma área de $2 \mathrm{~cm}^{2}$, $\log$ após o tratamento de limpeza, iniciou-se a deposição a partir de soluções precursoras descritas anteriormente. 
Esta deposição ocorreu através do pincelamento das devidas misturas de sais precursores nas placas, que posteriormente foram submetidas a jatos de ar quente e depois ao forno (mufla) à $450^{\circ} \mathrm{C}$ por mais 5 minutos sob fluxo contínuo de $\mathrm{O}_{2}$ de $5 \mathrm{dm}^{3} \mathrm{~min}^{-1}$. Em seguida, os eletrodos foram resfriados e pesados. A atividade de pincelamento e calcinação foram repetidas até que a massa teórica desejada fosse alcançada (massa de aproximadamente $1 \mathrm{mg}$, referente a uma espessura nominal de $1 \mu \mathrm{m}$ ), de acordo com a Figura 12. Uma vez obtida a massa necessária, realizou-se a calcinação durante 1 hora à $450^{\circ} \mathrm{C}$ mantendo-se fluxo contínuo de $\mathrm{O}_{2}$ para garantir a formação dos óxidos.

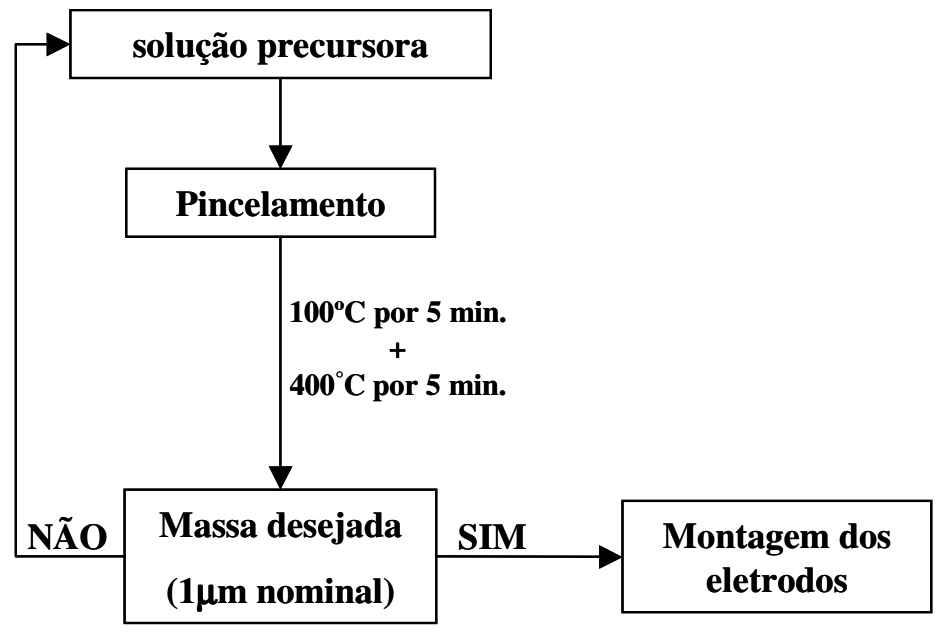

Figura 12: Esquema do processo de deposição das soluções precursoras no suporte de Ti metálico para preparação dos eletrodos de trabalho.

Depois de obtido o depósito contendo as composições de óxidos desejadas, foram montados os eletrodos. O contato elétrico foi realizado com fio de cobre, em torno da haste 
do suporte, previamente lixada, através de solda de ponta. Este sistema foi colocado num tubo de vidro Pirex vedado com cola epóxi (Figura 13).

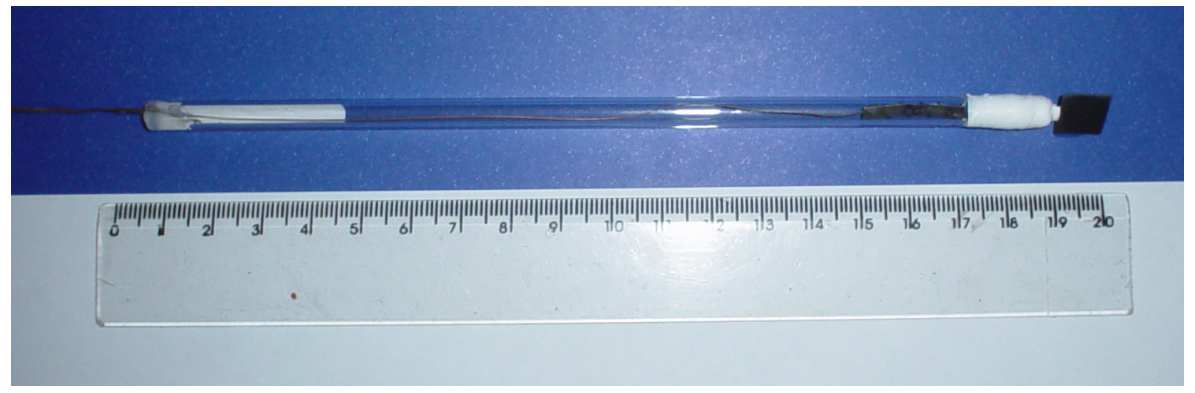

Figura 13: Eletrodo de trabalho de em suporte de titânio pronto para uso.

A célula utilizada possui capacidade de $300 \mathrm{~mL}$ e quatro compartimentos (Figura 14). As duas faces do eletrodo de trabalho, situado na parte central da célula, ficam expostas a dois eletrodos auxiliares situados em ambos os lados da célula, para que as duas faces do eletrodo possam ser utilizadas.

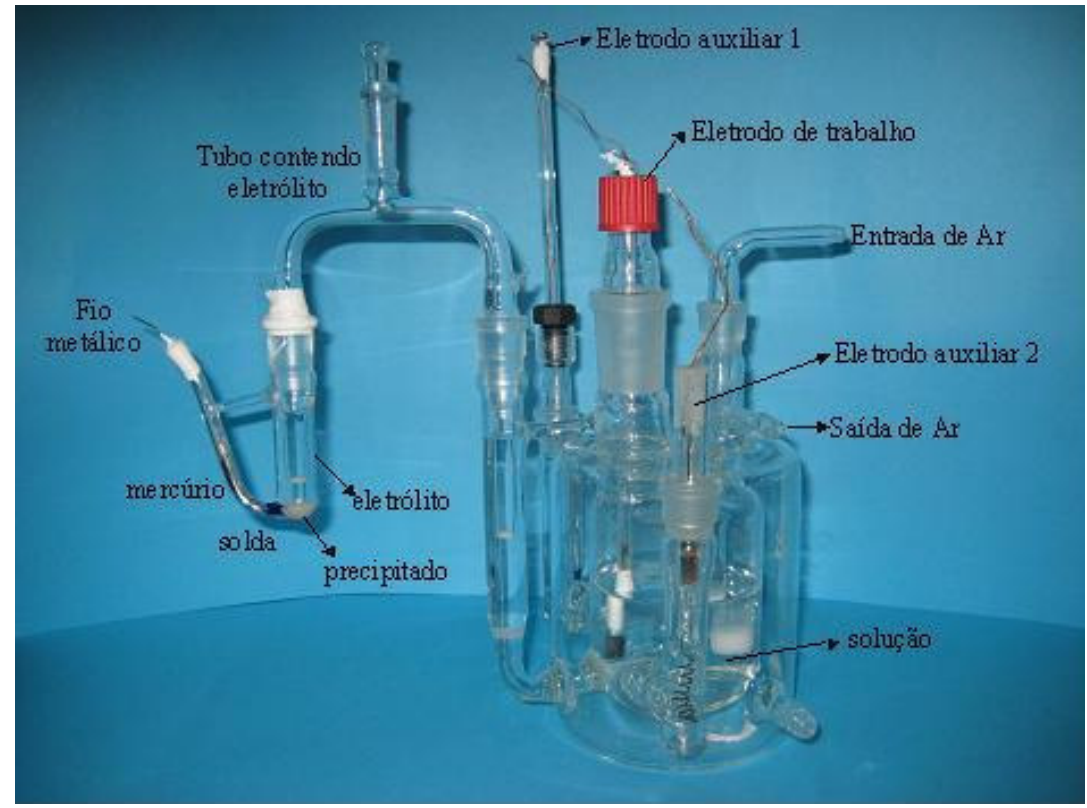

Figura 14: eletrodo de referência de $\mathrm{Hg}-\mathrm{Hg}_{2} \mathrm{SO}_{4}$ e célula eletroquímica utilizados em todos os experimentos. 


\section{III.3 Procedimento experimental utilizado no estudos dos ADEs de composição $\mathrm{Ti} / \mathbf{R u}_{\mathbf{0 , 3}} \mathbf{T i}_{(\mathbf{0}, 7-\mathrm{x})} \mathrm{Sn}_{\mathrm{x}} \mathrm{O}_{2}$}

\section{III.3.1 Eletrodos e eletrólito de suporte}

Os eletrodos de trabalho foram preparados pela metodologia de decomposição térmica de precursores poliméricos (Pechini) descrita acima e serão denominadas de ADE-P [181]. As composições nominais dos eletrodos de trabalho foram: Ti/ $\mathrm{Ru}_{0,3} \mathrm{Ti}_{(0,7-\mathrm{x})} \mathrm{Sn}_{\mathrm{x}} \mathrm{O}_{2}(\mathrm{x}=0 ; 0,3 ; 0,7)$. Os eletrodos auxiliares foram fios de platina platinizados enrolados em forma de espiral e o eletrodo de referência utilizado foi o eletrodo reversível de hidrogênio (ERH). Este eletrodo possui um fio de Pt platinizado num tubo de vidro, que o isola do resto da solução, essa parte do eletrodo foi preenchida com a solução do eletrólito de suporte, e em seguida colocada na célula, posteriormente, aplicouse galvanostaticamente, uma corrente catódica de $100 \mathrm{~mA}$ durante aproximadamente 20 segundos, para a formação do gás $\mathrm{H}_{2}$, sendo que este fica preso no invólucro de vidro, obtendo-se assim o ERH. A cada novo eletrodo a solução de eletrólito de suporte foi trocada e o ERH foi renovado.

O eletrólito de suporte foi $\mathrm{HClO}_{4}(C A R L O E R B A)$ 1,0 $\mathrm{mol} \mathrm{dm}$, , preparado com água destilada e purificada pelo sistema Milli-Q (Millipore Ind. Com. Ltda., SP).

Durante todas as medidas eletroquímicas a solução de trabalho foi mantida sob constante borbulhamento de gás nitrogênio (AIR LIQUIDE BRASIL S.A.). 


\section{III.3.2 Equipamentos e condições experimentais}

Os experimentos de VC, Tafel e EIE foram realizados em um Potenciostato/Galvanostato Autolab modelo PGSTAT 30, acoplado a um micro computador e controlado pelos programas: FRA- Frequency Response Analyser (EIE) e GPES- General Purpose Electrochemical System (VC e Tafel).

Os eletrodos recém-preparados foram hidratados registrando-se 50 voltamogramas cíclicos com velocidade de varredura de (v) $20 \mathrm{mV} \mathrm{s}^{-1}$, na região de carregamento da dupla camada $(\mathrm{E}=0,2-1,4 \mathrm{~V}$ vs. $\mathrm{ERH})$, antes do início dos experimentos. As curvas de polarização de Tafel foram medidas com $v=56 \mu \mathrm{V} \mathrm{s}^{-1}$.

Os espectros de EIE foram registrados em 60 pontos de freqüências, entre $1 \mathrm{mHz}$ e $100 \mathrm{kHz}$, utilizando-se uma amplitude de perturbação de $5 \mathrm{mV}$ pico a pico (p/p). Foram registrados para eletrodos recém-preparados nos potenciais descritos na Tabela II.

Tabela II: Potenciais investigados por EIE para os eletrodos de composição $\mathrm{T}$ i/ $\mathrm{Ru}_{0,3} \operatorname{Ti}_{(0,7-\mathrm{x})} \mathrm{Sn}_{\mathrm{x}} \mathrm{O}_{2}$.

\begin{tabular}{|c|c|c|}
\hline \multirow{2}{*}{ Eletrodos } & \multicolumn{2}{|c|}{ Potenciais ivestigados por EIE $(\mathrm{V} v \boldsymbol{s} . \mathrm{ERH})$} \\
\cline { 2 - 3 } & $\mathbf{D C E}$ & RDO \\
\hline $\mathrm{Ti} / \mathrm{Ru}_{0,3} \mathrm{Ti}_{(0,7-\mathrm{x})} \mathrm{Sn}_{\mathrm{x}} \mathrm{O}_{2}$ & 0,$20 ; 0,45 ; 0,70 ; 0,85 \mathrm{e} 1,00$ & 1,$500 ; 1,525 \mathrm{e} 1,550$ \\
$(\mathrm{x}=0 ; 0,3 ; 0,7)$ & & 1,$40 ; 1,45 ; 1,50 ; 1,55 \mathrm{e}$ \\
\hline $\mathrm{Ti} / \mathrm{Ru}_{0,3} \mathrm{Sn}_{0,7} \mathrm{O}_{2}$ & 0,$20 ; 0,40 ; 0,60 ; 0,8 ; 1,00 ; 1,20 ; 1,25 ; 1,30 \mathrm{e}$ & 1,60 \\
\hline
\end{tabular}

Os resultados experimentais de EIE foram analisados com a utilização do programa Sigma Plot 6.0 (Copyright 1986-2000, SPSS Inc.). 
III.4 Procedimento experimental utilizado no estudo dos eletrodos de $\mathbf{T i} / \mathbf{R} \mathbf{u}_{0,3} \mathbf{T i}_{0,7} \mathbf{O}_{2}$ catalisados por eletrodeposição de $\mathbf{P t}$.

\section{III.4.1 Eletrodos e eletrólito de suporte.}

$\mathrm{O}$ eletrodo de trabalho de $\mathrm{Ti} / \mathrm{Ru}_{0,3} \mathrm{Ti}_{0,7} \mathrm{O}_{2}$ foi preparado pela metodologia tradicional e, neste trabalho, será denominado de ADE-T. A partir de misturas contendo as concentrações nominais desejadas de: $\mathrm{RuCl}_{3} \cdot \mathrm{nH}_{2} \mathrm{O}$ (Aldrich) e $\mathrm{TiCl}_{4}$ (Vectron) em $\mathrm{HCl} / \mathrm{H}_{2} \mathrm{O}$ 1:1 (v/v) e submetidos ao tratamento térmico, como já descrito anteriormente na seção III.2. A Pt foi eletrodepositada na superfície do ADE [183], as composições nominais investigadas foram: $\mathrm{Ti} / \mathrm{Ru}_{0,3} \mathrm{Ti}_{0,7} \mathrm{O}_{2} \mathrm{e} \mathrm{Ti} / \mathrm{Ru}_{0,3} \mathrm{Ti}_{0,7} \mathrm{O}_{2}+\mathrm{Pt}\left(100 \mu \mathrm{g} \mathrm{cm}{ }^{-2}\right)$.

A partir da solução estoque de $\operatorname{Pt}(6368 \mu \mathrm{g} / \mathrm{mL})$ foi preparada a solução de $0,01 \%$ em massa de Pt em $\mathrm{H}_{2} \mathrm{SO}_{4} 0,5 \mathrm{~mol} \mathrm{dm}^{-3}$. Para realizar a eletrodeposição foi aplicado um potencial constante de $0,2 \mathrm{~V}$ vs. ERH até atingir uma carga de $100 \mathrm{mC}$. Esta carga corresponde a uma massa nominal de $25 \mu \mathrm{g}$ de metal $\mathrm{cm}^{-2}$. O procedimento foi acompanhado por voltametria cíclica nos potenciais 0,05 a $1,4 \mathrm{~V} v$ s. ERH $\operatorname{com} v=50 \mathrm{mV}$ $\mathrm{cm}^{-2}$.

Os eletrodos auxiliares foram fios de platina platinizados e o eletrodo de referência utilizado foi o eletrodo reversível de hidrogênio (ERH). Os experimentos foram registrados em $\mathrm{H}_{2} \mathrm{SO}_{4} 0,5 \mathrm{~mol} \mathrm{dm}^{-3}$. 


\section{III.4.2 Equipamentos e condições experimentais}

Os experimentos foram realizados em um Potenciostato/Galvanostato AUTOLAB modelo PGSTAT30 acoplado a um microcomputador. Os programas utilizados foram o FRA- Frequency Response Analyser (EIE) e o GPES- General Purpose Electrochemical System (VC e Tafel).

A EIE foi medida em 60 pontos de freqüência distribuídos entre $1 \mathrm{mHz}$ e $100 \mathrm{k} \mathrm{Hz}$. Na região da DCE, potenciais entre 0 e 1,4 V vs. ERH $(0,15 ; 0,30 ; 0,50 ; 0,70 ; 0,90 ; 1,10$; 1,30 V vs. ERH) e na região da RDO, potenciais acima de 1,50 V vs. ERH $(1,50 ; 1,54$ e 1,58 V vs. ERH). O eletrodos de composição $\mathrm{Ti} / \mathrm{Ru}_{0,3} \mathrm{Ti}_{0,7} \mathrm{O}_{2}+\mathrm{Pt}\left(100 \mu \mathrm{g} \mathrm{cm}{ }^{-2}\right)$ foi submetido a testes adicionais na região da $\mathrm{RDO}$, em intervalos menores de potencial: 1,$400 ; 1,425 ; 1,450 ; 1,475 ; 1,500 ; 1,525 ; 1,550 ; 1,575 ; 1,600 \mathrm{~V} v s$. ERH. A temperatura foi mantida a $25^{\circ} \mathrm{C}$ sob atmosfera constante de nitrogênio. As curvas de polarização de Tafel foram registradas variando-se o potencial até a corrente atingir um valor próximo a $100 \mathrm{~mA}$ $\mathrm{cm}^{-2}$. Todas as análises foram realizadas em duplicata, se necessário em triplicata.

\section{III.5 Procedimento experimental dos ânodos de Pt, Pt:Sn, Pt:Ru e Pt:Ru:Sn para oxidação de etanol}

\section{III.5.1 Eletrodos e eletrólito de suporte}

As composições nominais investigadas foram Ti/Pt, Ti/Pt:Ru (80:20), Ti/Pt:Sn (80:20) e Ti/Pt:Ru:Sn (80:10:10). Os eletrodos auxiliares foram fios de platina platinizados 
e o eletrodo de referência de $\mathrm{Hg}-\mathrm{Hg}_{2} \mathrm{SO}_{4}$ foi adaptado na quarta parte da célula eletroquímica, em um capilar de Luggin-Harber, para diminuir ao máximo a distância entre eletrodo de trabalho e o de referência. Para preparar o eletrodo de referência foi realizado o seguinte processo:

- Primeiramente foi preparada a suspensão de $\mathrm{Hg}_{2} \mathrm{SO}_{4}$ : adicionou-se lentamente nitrato de mercúrio (em pó) em água juntamente com uma gota de ácido nítrico para solubilizar, esse procedimento foi realizado em um frasco imerso em banho de gelo. Posteriormente, adicionou-se a solução de eletrólito $\left(\mathrm{H}_{2} \mathrm{SO}_{4} 0,5 \mathrm{~mol} \mathrm{dm}^{-3}\right)$.

- Montagem do eletrodo: o eletrodo consiste de dois compartimentos de vidro (que podem ser observados juntamente com a célula eletroquímica na Figura 15): no primeiro compartimento tem-se um fio metálico para contato elétrico, imerso em mercúrio, este compartimento é soldado no compartimento 2, que contém a semi-célula $\mathrm{Hg} / \mathrm{Hg}_{2} \mathrm{SO}_{4}$, o precipitado descrito acima juntamente com solução de eletrólito. Este sistema é encaixado em um tubo em formato de U, preenchido com eletrólito e este é adaptado à célula eletroquímica.

- Calibração do eletrodo: foi montada uma célula eletroquímica com um eletrodo reversível de hidrogênio, uma ponte salina, o eletrodo a calibrar (contra eletrodo) e $\mathrm{H}_{2} \mathrm{SO}_{4}$ $0,5 \mathrm{~mol} \mathrm{dm}^{-3}$ como eletrólito. Borbulhou-se hidrogênio sobre o eletrodo de Pt platinizada para ativar o mesmo, após ativado foi realizada uma galvanosplatia com a seguinte programação:

- Corrente de $0,5 \mathrm{~mA}$ durante 30 segundos,

a Corrente de $-0,5 \mathrm{~mA}$ durante 30 segundos. 
Foram repetidos de 5 a 6 ciclos e sempre terminando em -0,5 mA por 30 segundos. Com o auxílio de um voltímetro foi medido o potencial de circuito aberto entre o eletrodo de Pt platinizada e o eletrodo de mercúrio, o valor de potencial medido foi de $-0,687 \mathrm{~V} v s$. ERH, este valor foi utilizado para corrigir o valor de potencial registrado em todos os experimentos para que possamos apresentar os resultados de potencial em relação a um eletrodo de hidrogênio (ERH).

O eletrólito de suporte foi $\mathrm{H}_{2} \mathrm{SO}_{4}$ (Merck, $99.999 \%$ ) $0,5 \mathrm{~mol} \mathrm{dm}^{-3}$, preparado com água destilada e purificada pelo sistema Milli-Q (Millipore, Gradient, Q-Gard ${ }^{\circledR}$ ) e o etanol $1 \mathrm{~mol} \mathrm{dm}^{-3}$ (Les Alcools de Commerce In, Brampton, Ontario L6T 3Y4).

\section{III.5.2 Equipamentos e condiçõos experimentais}

Os experimentos de Voltametria Cíclica $d c$, Cronoamperometria e EIE foram realizados em um Potenciostato/Galvanostato modelo PAR273A e 5210, acoplados a um micro computador e controlado pelos programas: Power Suite 2.58 e Power CV 2.47.

Os eletrodos recém-preparados foram hidratados registrando-se voltamogramas cíclicos até a estabilização, em diferentes velocidades de varredura de (v) 50; 20 e $10 \mathrm{mV} \mathrm{s}^{-1}$, na região de carregamento da dupla camada.

Foram realizadas análises seguindo a variação da corrente com o tempo (cronoamperometria) em diferentes potenciais acoplado aos estudos de EIE. Foram registradas curvas cronoamperométricas na presença de etanol, em intervalos de potencial 
de $50 \mathrm{mV}$, por toda a região de potencial apresentada nos voltamogramas cíclicos de cada composição eletródica, seguindo o esquema apresentado na Figura 15.

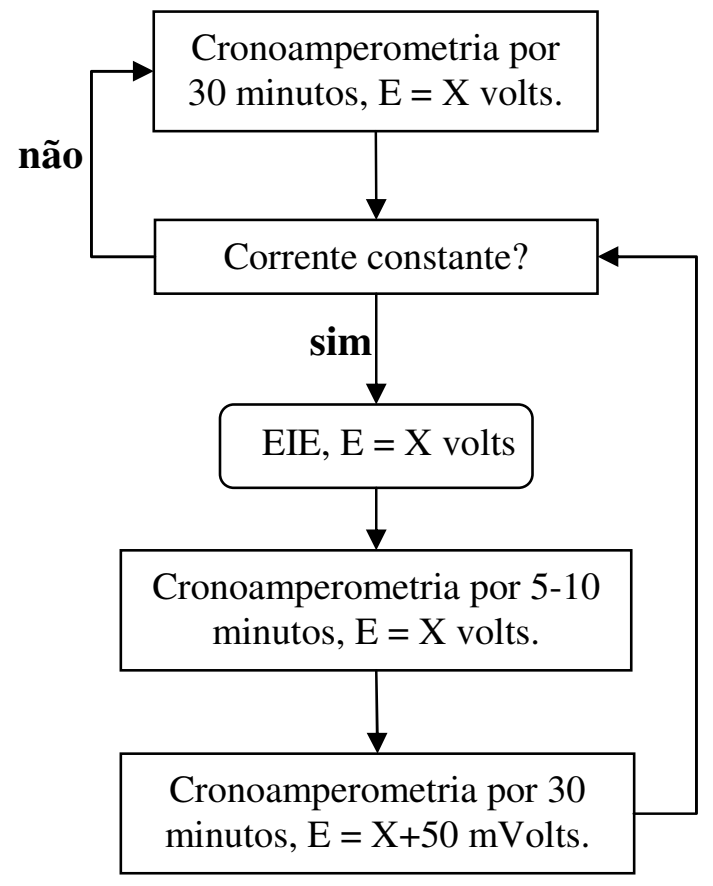

Figura 15: Fluxograma representativo dos experimentos de cronoamperometria na presença de etanol realizados com eletrodos de todas as composições. Esse procedimento foi realizado no sentido positivo e negativo de potencial de cada eletrodo.

Os espectros de impedância foram registrados no modo single-sine em aproximadamente 40 pontos de frequiências, entre $1 \mathrm{~Hz}$ e $10 \mathrm{kHz}$ e no multi-sine em aproximadamente 20 pontos de $0,01 \mathrm{~Hz}$ a $1 \mathrm{~Hz}$, com uma amplitude de perturbação de $5 \mathrm{mV}$ rms. Os resultados experimentais de EIE foram analisados com a utilização dos programas TR398/ DOS e ZView 1990-2007, versão 3.0. Todos os experimentos foram realizados em duplicata e, se necessário, em triplicata. $\mathrm{O}$ oxigênio foi removido da solução utilizando-se Argônio ultra puro (Ar UHP 5.0, Praxair). 
Os experimentos de Voltametria cíclica ac foram realizados em um Solartron 1296. Sempre antes e após o término das medidas de Voltametria $a c$, eram registrados 2 voltamogramas cíclicos $d c$ na mesma velocidade de varredura de interesse (2 ou $5 \mathrm{mVs}^{-1}$ ). Entre cada Voltamograma $a c$ foram registrados 2 Voltamogramas $d c$ a $50 \mathrm{mVs}^{-1}$, para verificar a estabilidade do material durante as análises. A amplitude utilizada foi de $5 \mathrm{mVs}^{-1}$ e foram registrados 20 voltamogramas em 20 valores de freqüências entre $1-200 \mathrm{~Hz}$. O intervalo de potencial investigado variou dependendo da composição eletródica, por exemplo, eletrodos de Pt:Sn a faixa investigada foi de 0 a $0,7 \mathrm{~V} v s$. ERH, eletrodos de Pt:Ru variou-se entre 0 a $0,9 \mathrm{~V}$ vs. ERH.

As medidas de EIE foram realizadas a cada $5 \mathrm{mV}$ ou $4 \mathrm{mV}$ (dependendo da velocidade de varredura utilizada), por exemplo, no caso do eletrodo de Pt:Ru, foram registrados 20 voltamogramas com freqüências diferentes de 0 a $0,9 \mathrm{~V} v s$. ERH, obtendo-se em uma dada frequiência um diagrama com aproximadamente 300 potenciais. Com ajuda do programa adequado, os diagramas obtidos foram transformados em 300 diagramas de Nyquist, contendo 20 pontos de frequiência cada. Os diagramas foram ajustados ao circuito equivalente adequado com ajuda do programa Power Suite 2.58. 


\section{III.5.3 Procedimento experimental utilizado para os testes de células a combustível de etanol (DEFCs)}

\section{III.5.3.1 Ativação do carbono Vulcan XC 72}

O carbono em pó Vulcan XC 72 foi purificado e ativado por um tratamento térmico. Primeiramente foram pesados 5,192 $\mathrm{g}$ de carbono, dispersado em água deionizada e submetido ao ultra-som durante 30 minutos. Esta dispersão foi filtrada com $30 \mathrm{ml}$ de etanol e depois levado a estufa por 2 horas a $80{ }^{\circ} \mathrm{C}$. Após a obtenção do carbono seco, foi realizado o tratamento térmico para a ativação do mesmo, que constituiu em submeter ao aquecimento durante 4 horas sob atmosfera de $\mathrm{N}_{2}$ com fluxo contínuo de $5 \mathrm{~mL} \min ^{-1}$, elevando da temperatura a $10^{\circ} \mathrm{C}$ por minuto até atingir $400^{\circ} \mathrm{C}$.

\section{III.5.3.2 Preparação do MEA (Membrane Electrode Assembled)}

Os pós metálicos foram preparados misturando-se as proporções desejadas de Pt e dos catalisadores (Ru ou $\mathrm{Sn}$ ) de modo a obter as seguintes composições nominais: Pt:Ru (80:20), Pt:Sn (80:20) e Pt:Ru:Sn (80:10:10). A mistura catalisador/metal foi submetida ao ultrassom por 10 minutos juntamente com $3 \mathrm{~mL}$ de etanol e, em seguida foi adicionado o carbono na proporção de $60 \%$ de carbono e $40 \%$ de metais e mantido no ultra-som por mais 20 minutos. A mistura final carbono/metais foi submetida ao tratamento térmico com fluxo

contínuo de $\mathrm{N}_{2}$ de $5 \mathrm{~mL} \mathrm{~min}^{-1}$, elevando a temperatura gradativamente da seguinte forma: $1^{\circ} \mathrm{C} \min ^{-1}$ até atingir $250{ }^{\circ} \mathrm{C}$ e permanecendo 60 minutos nesta temperatura; 
$10{ }^{\circ} \mathrm{C} \min ^{-1}$ até $350{ }^{\circ} \mathrm{C}$, permanecendo $120 \mathrm{~min}$; por fim $5^{\circ} \mathrm{C} \min ^{-1}$ até $25^{\circ} \mathrm{C}$, permanecendo $1000 \mathrm{~min}$.

Posteriormente, foi pesada uma massa equivalente a $2 \mathrm{mg}$ de $\mathrm{Pt}$ por $\mathrm{cm}^{2}$, aproximadamente $170 \mathrm{mg}$ da mistura carbono/metais, na qual foi adicionado Nafion ${ }^{\circledR}$ e água e submetido ao ultrassom por 1 hora. Em seguida essa solução foi depositada sobre um tecido de carbono (P.O.070768 W.O. 0011988) com área geométrica de $25 \mathrm{~cm}^{2}$ e deixado em estufa a $70^{\circ} \mathrm{C}$ por no mínimo 3 horas.

O cátodo utilizado foi um eletrodo comercial E-TEK contendo $40 \%$ em massa de Platina e $60 \%$ de carbono Vulcan XC-72, também com uma área de $25 \mathrm{~cm}^{2}$ e massa de catalisador de $2 \mathrm{mgcm}^{-2}$. A membrana utilizada foi uma membrana de troca de prótons Nafion ${ }^{\circledR} 117$ previamente hidratada.

Para a preparação do MEA, o conjunto ânodo/membrana/cátodo foi prensado a $130^{\circ} \mathrm{C}$ por 3 minutos a $35 \mathrm{Kg} f \mathrm{~cm}^{-2}$.

\section{III.5.3.3 Equipamentos e condições experimentais}

A célula apresentada na Figura 16 é constituída por duas placas de cobre coletoras de corrente, no seu interior têm-se duas placas de grafite onde são distribuídos o $\mathrm{O}_{2}$ e o etanol. A temperatura é controlada por um termopar fixado nas placas de cobre. O sistema é controlado por um Eletrocell ${ }^{\circledR}$ modelo ECT-500M.

Os valores de corrente foram previamente programados no software de aquisição de dados ImpagLog Tech Cell, aplicados por 10 segundos cada valor. O programa nos fornece as curvas de tensão $(\mathrm{mV})$ e densidade de potência $\left(\mathrm{mWcm}^{-2}\right)$ em função da densidade de 
corrente $\left(\mathrm{mAcm}^{-2}\right)$. O ânodo é alimentado por uma solução de etanol 2 moldm $^{-3}$ e o cátodo por $\mathrm{O}_{2}$ umidificado.

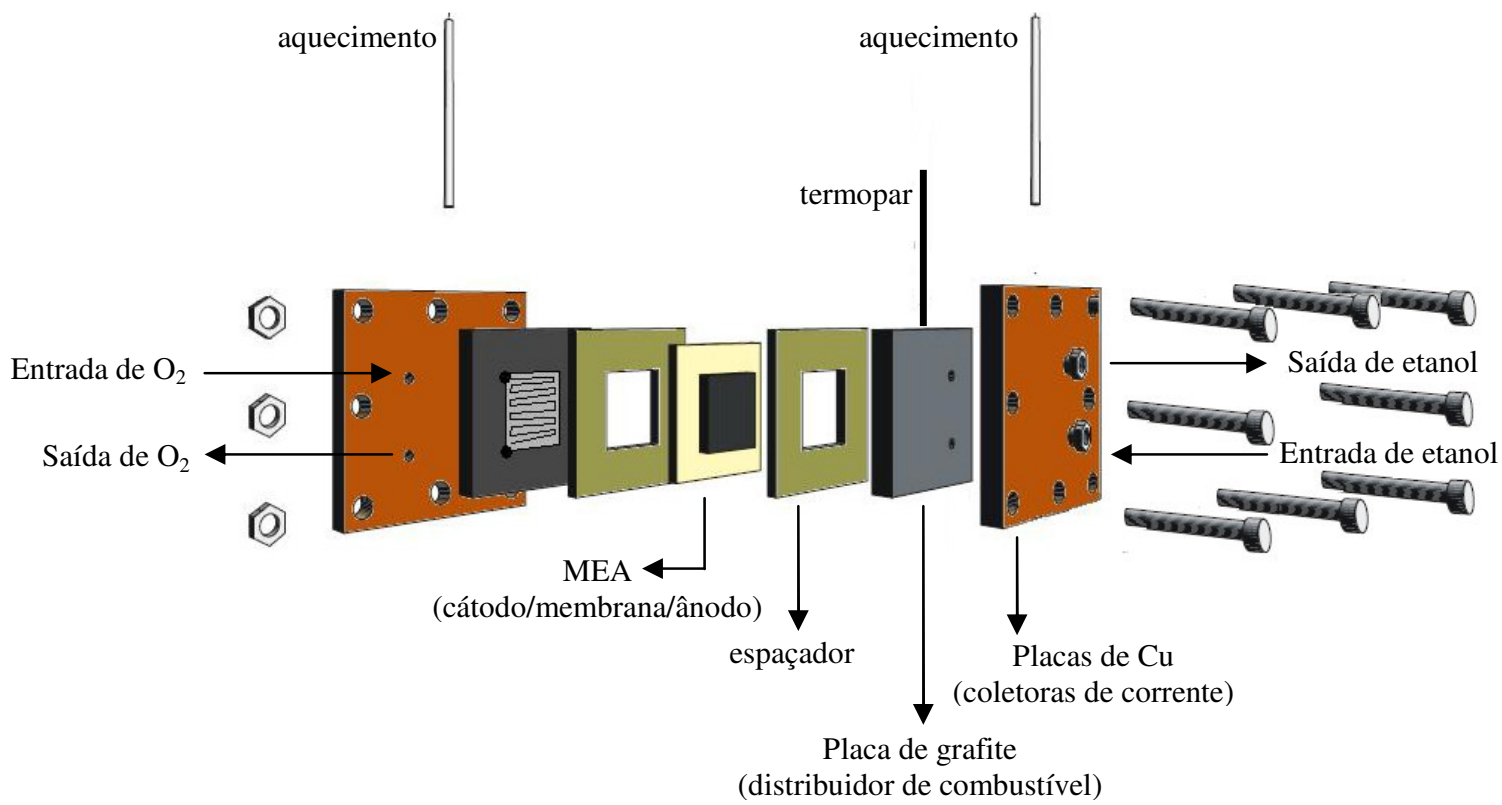

Figura 16: Esquema representativo da célula utilizada para os estudos de DEFCs.

As curvas foram obtidas a 50,70 e $80^{\circ} \mathrm{C}$. O fluxo de $\mathrm{O}_{2}$ mantido a $150 \mathrm{mLmin}^{-1}$ e de etanol em $2 \mathrm{mLmin}^{-1}$. As pressões de $\mathrm{O}_{2}$ e etanol foram mantidas a 1 bar durante todos os experimentos. 


\section{III.5.4 Microscopia Eletrônica de Varredura (MEV), Espectrometria de Energia Dispersiva de Raios X (EDX)}

A técnica de $\mathrm{MEV}$, foi utilizada para caracterizar a superfície dos eletrodos antes dos experimentos de EIE e a caracterização por análise de EDX foi utilizada, acoplada a MEV, para a determinação qualitativa e semi-quantitativa dos elementos constituintes das amostras. Os eletrodos foram fixados em porta amostras com uma tinta de prata condutora. As análises foram realizadas em um microscópio eletrônico Leica-Zeiss LEO modelo 440 SEM, acoplado a um analisador Oxford modelo 7060, com correção das interferências da matriz, com aumentos variando entre 1000 e 5000 vezes. 


\section{IV- RESULTADOS E DISCUSSÃO}

\section{IV.1 Investigação dos ADEs de composição $\left.\mathrm{Ti} / \mathbf{R u}_{0,3} \mathrm{Ti}_{(0,7-\mathrm{x})}\right) \mathrm{Sn}_{\mathrm{x}} \mathrm{O}_{2} \mathrm{em}$ meio ácido}

\section{IV.1.1 Voltametria dc e diagramas de EIE}

A voltametria cíclica foi utilizada com o objetivo de acompanhar o comportamento dos eletrodos antes, durante e após as análises de EIE. O comportamento voltamétrico típico de todas as composições eletródicas estão apresentados na Figura 17, onde pode-se observar o pico de transição $\mathrm{Ru}(\mathrm{III}) / \mathrm{Ru}(\mathrm{IV})$ entre os potenciais 0,6 e 0,9 vs. ERH [36]. Pode-se observar também que, o comportamento do eletrodo, ou seja, a carga eletródica não se altera significativamente com as análises de EIE. O potencial de início da RDO desloca cerca de $50 \mathrm{mV}$ do valor inicial com o tempo de análise de EIE. Este não deve ser atribuído a alterações na composição e/ou na estrutura do eletrodo de trabalho, mas sim a alterações no eletrodo de referência de hidrogênio, que sofre alterações (perda do gás) em função do longo tempo necessário para realizar-se o conjunto de medidas de EIE (2-4 horas).

A Figura 18, apresenta os diagramas de Nyquist representativos do sistema $\mathrm{Ti} / \mathrm{Ru}_{0,3} \mathrm{Ti}_{(0,7-\mathrm{x})} \mathrm{Sn}_{\mathrm{x}} \mathrm{O}_{2}$ em diferentes potenciais. Nota-se que em potenciais localizados na $\operatorname{DCE}(E=0,80 \mathrm{~V} v s . \mathrm{ERH})$ tem-se uma reta com um ângulo de fase menor que $90^{\circ}$ e com o aumento do potencial, a partir de $1,40 \mathrm{~V} v$ s. ERH para o eletrodo $\mathrm{Ti} / \mathrm{Ru}_{0,3} \mathrm{Sn}_{0,7} \mathrm{O}_{2}$, surge um semi-círculo que indica a existência de uma resistência associada ao início da RDO. 


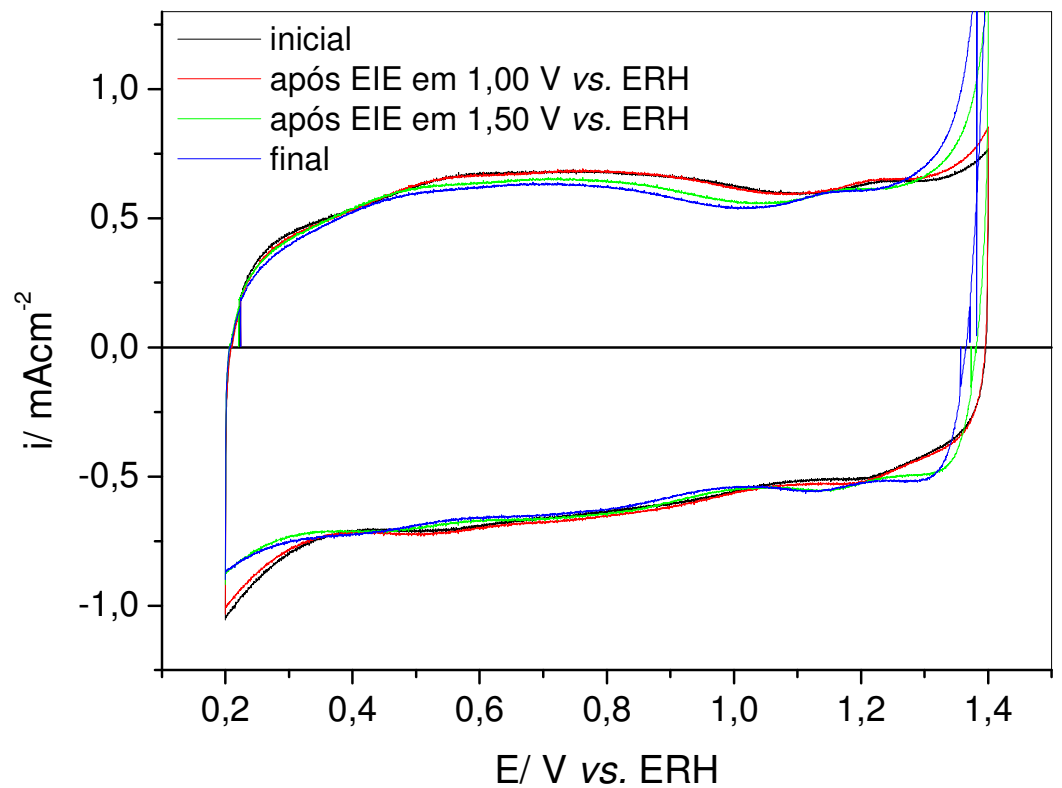

Figura 17: Voltamogramas cíclicos registrados durante os intervalos dos experimentos de EIE, para o eletrodo de composição $\mathrm{Ti} / \mathrm{Ru}_{0,3} \mathrm{Sn}_{0,7} \mathrm{O}_{2}, v=20 \mathrm{mV} \mathrm{s}{ }^{-1}$, em meio ácido (1 $\mathrm{HClO}_{4} \mathrm{~mol} \mathrm{dm}^{-3}$ ). Espessura nominal $=1 \mu \mathrm{m} . \mathrm{T}_{\text {calc. }}=400^{\circ} \mathrm{C}$.
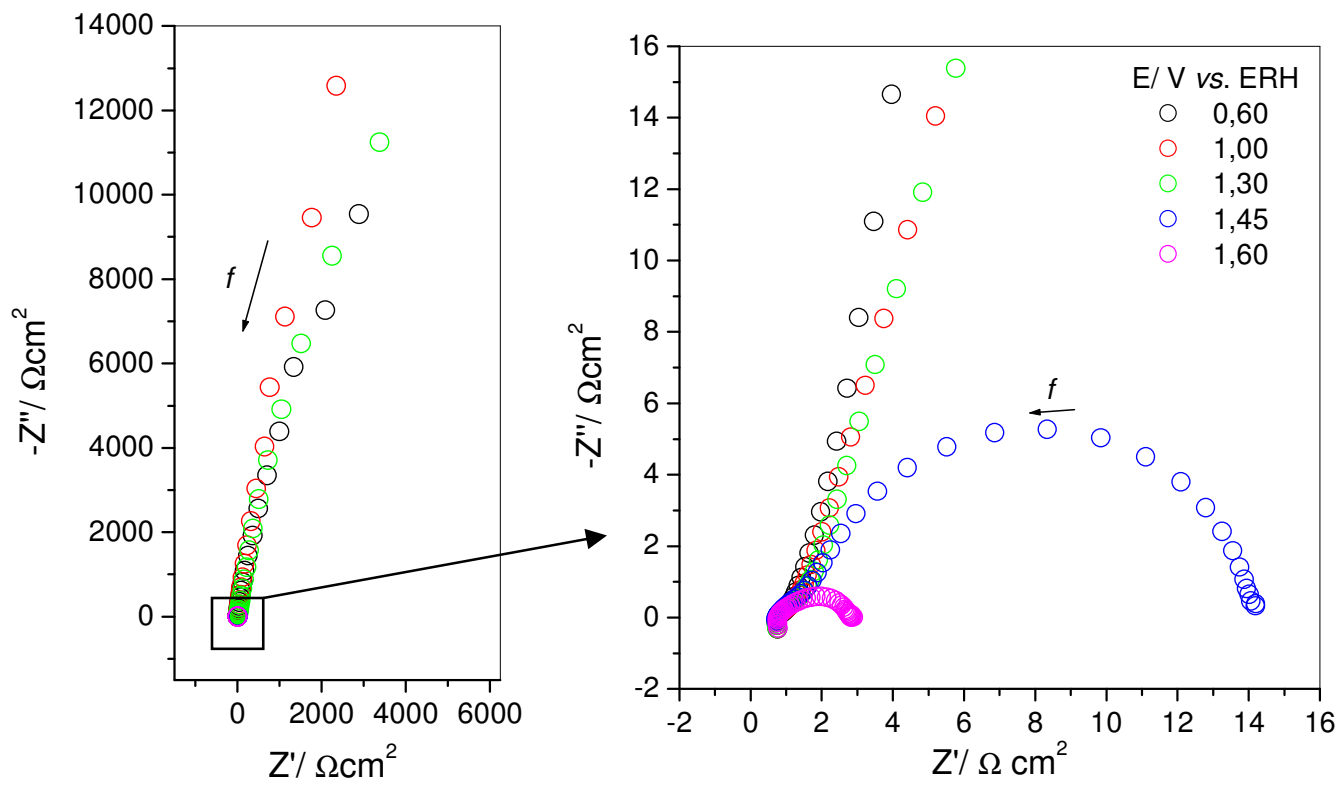

Figura 18: Diagramas de Nyquist em diferentes potenciais para o eletrodo $\mathrm{Ti} / \mathrm{Ru}_{0,3} \mathrm{Sn}_{0,7} \mathrm{O}_{2}$ em $\mathrm{HClO}_{4} 1 \mathrm{~mol} \mathrm{dm}^{-3}, \mathrm{~T}=25^{\circ} \mathrm{C}, \mathrm{A}=5 \mathrm{mV}, 1 \mathrm{~m} \mathrm{~Hz}<f<100 \mathrm{kHz}$. 
Os digramas de Bode representativos do sistema $\mathrm{Ti} / \mathrm{Ru}_{0,3} \mathrm{Ti}_{(0,7-\mathrm{x})} \mathrm{Sn}_{\mathrm{x}} \mathrm{O}_{2}$ em diferentes potenciais estão representados na Figura 19. Podemos observar alguns pontos em alta freqüência que indicam a presença de um elemento indutor, tais pontos serão desconsiderados nos ajustes dos dados experimentais, tendo em vista que são provenientes do equipamento, das conecções e fios, como já discutido por diversos autores $[53,80]$.

Potenciais inferiores a 1,30 V vs. ERH apresentam claramente um comportamento capacitivo, característico da região da dupla camada elétrica, como pode ser observado pelos valores de ângulo de fase próximos de $80^{\circ}$. Um comportamento capacitivo ideal apresenta um ângulo de fase de $90^{\circ}$, no caso de eletrodos porosos tem-se normalmente valores inferiores a $90^{\circ}$, devido as características porosas do material [184]. Neste caso, ao atribuir um elemento capacitivo ao sistema, faz-se necessário a utilização de um EFC (Elemento de Fase Constante) juntamente com o elemento $\beta(0<\beta<1)$. No caso de um capacitor ideal tem-se $\beta=1$, já uma resistência tem-se $\beta=0$, o elemento de Warburg também pode ser relacionado ao EFC, sendo $\beta=0,5$ e ainda, no caso de um elemento indutor $\beta=-1$ [185]. Para eletrodos do tipo ADEs, geralmente a capacitância da dupla camada elétrica é representada por um $\mathrm{EFC}$, sendo que os valores de $\beta$ se encontram entre 0,8 a 0,9 , dependendo a porosidade do material. 

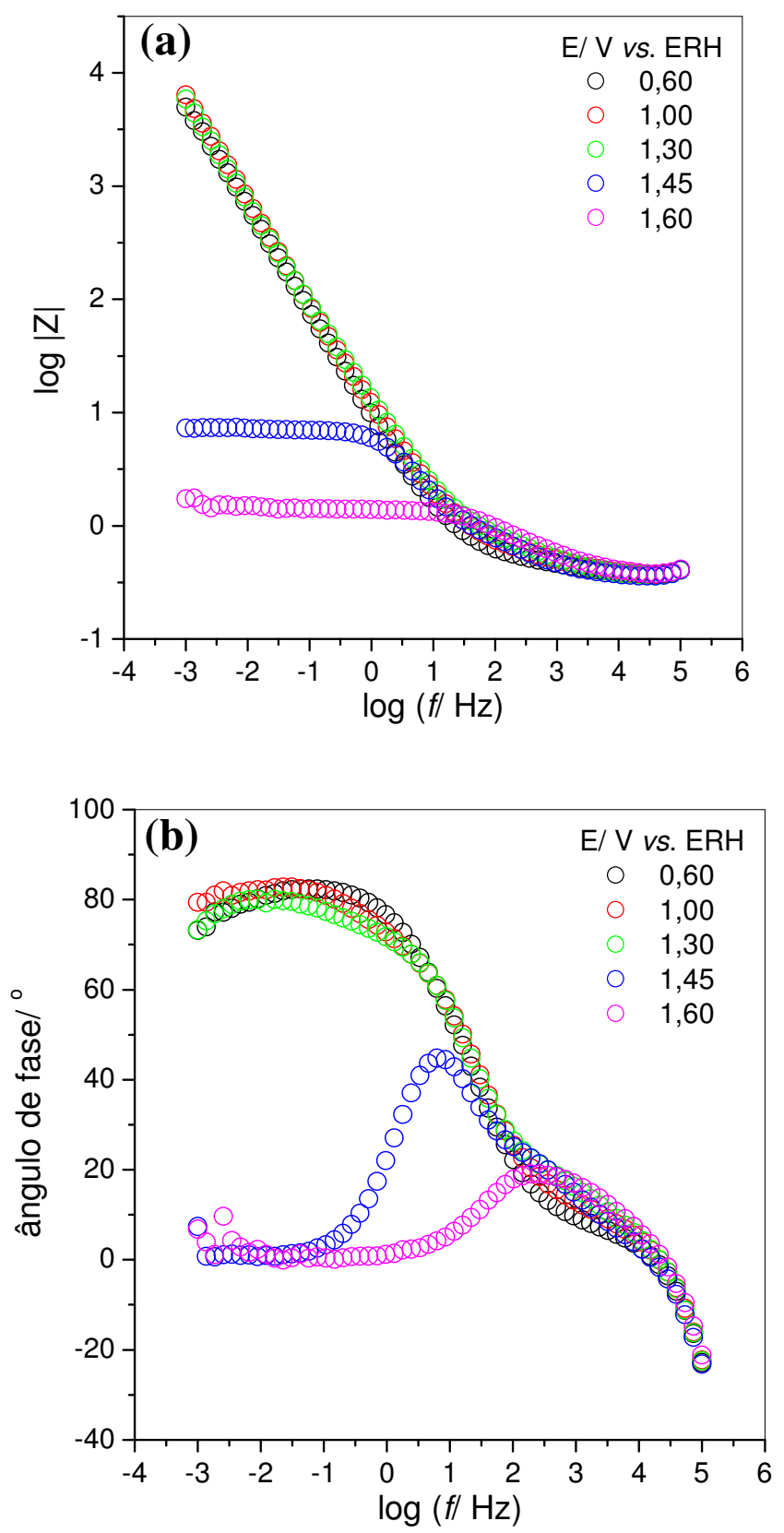

Figura 19: Diagramas de BODE em diferentes potenciais para o eletrodo $\mathrm{Ti} / \mathrm{Ru}_{0,3} \mathrm{Sn}_{0,7} \mathrm{O}_{2}$ em $\mathrm{HClO}_{4} 1 \mathrm{~mol} \mathrm{dm}^{-3}, \mathrm{~T}=25^{\circ} \mathrm{C}, \mathrm{A}=5 \mathrm{mV}, 1 \mathrm{~m} \mathrm{~Hz}<f<100 \mathrm{kHz}$. (A) log $\mathrm{ZZ} \mathrm{e} \mathrm{(B)} \mathrm{ângulo}$ de fase em função de $\log f / \mathrm{Hz}$. 


\section{IV.1.2 Aplicação do modelo de poros de EIE}

Com base no comportamento experimental obtido, iniciaram-se os ajustes dos dados experimentais, em busca da LT que melhor descreve o sistema nas regiões de potencial investigadas. Foram ajustados valores para cada elemento da LT com o objetivo de se obter o menor valor possível de porcentagem de erro da curva experimental em relação a curva teórica imposta para o sistema escolhido. Quanto menor o valor da porcentagem de erro, melhor é o ajuste dos resultados experimentais e teóricos. O ajuste dos dados experimentais pode ser observado na Figura 20, onde nota-se uma ótima sobreposição da curva teórica com a curva experimental.

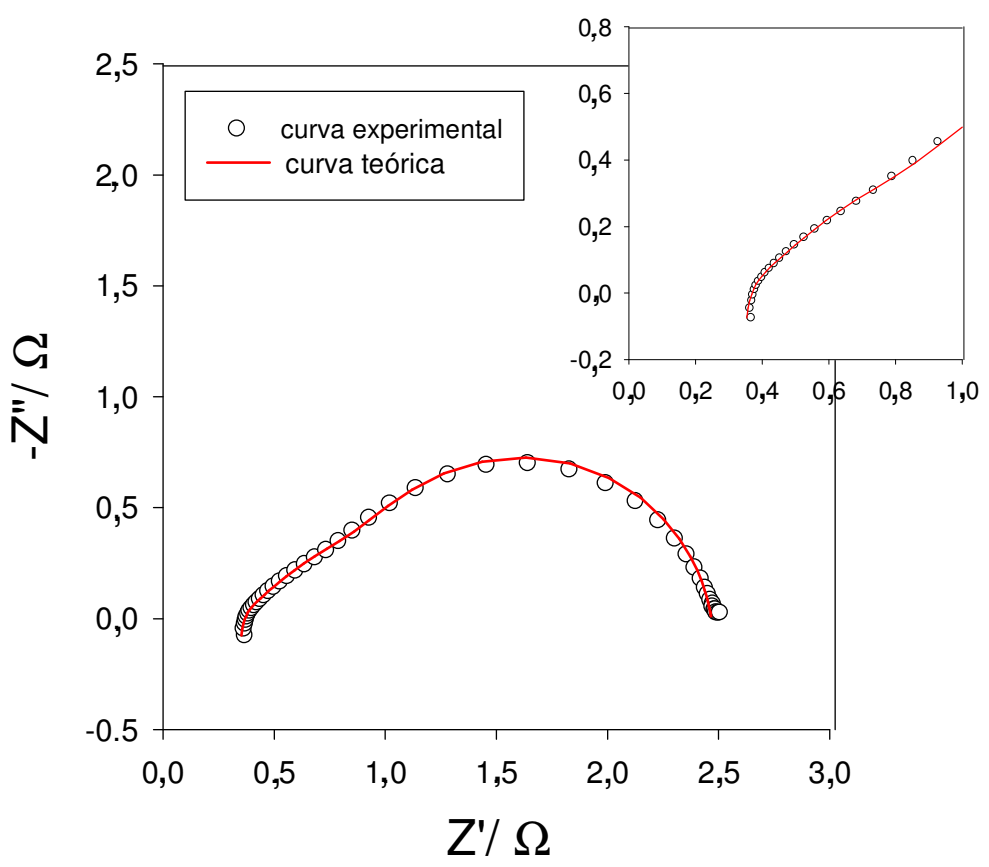

Figura 20: Diagrama de Nyquist com a curva teórica e a experimental, para o eletrodo $\mathrm{Ti} / \mathrm{Ru}_{0,3} \mathrm{Sn}_{0,7} \mathrm{O}_{2}$ em $\mathrm{HClO}_{4} 1 \mathrm{~mol} \mathrm{dm}{ }^{-3}, \mathrm{~T}=25^{\circ} \mathrm{C}, \mathrm{E}=1,50 \mathrm{~V}$ vs. ERH. 
A LT que melhor ajustou os dados experimentais obtidos para os eletrodos de composição $\mathrm{Ti} / \mathrm{Ru}_{0,3} \mathrm{Ti}_{(0,7-\mathrm{x})} \mathrm{Sn}_{\mathrm{x}} \mathrm{O}_{2}(\mathrm{x}=0 ; 0,3$ e 0,7$)$, foi escolhida com base no modelo de poros de Levie [22] discutido anteriormente. A LT utilizada no ajuste dos dados é formada por um único canal de condução e uma impedância de interface (ver Figura 6b, seção I.1). O canal de condução é formado por uma série de resistências $\left(r_{f}\right)$ e a impedância de interface $\zeta$ pelos elementos distribuídos $r_{t c}$ e $q_{d c}$ em paralelo, Figura 21. Tais elementos são relacionados pelas Equações 34 e 35.

$$
\begin{aligned}
& r_{f}=\frac{R_{f}}{L} \\
& \zeta=\frac{r_{t c}}{1+r_{t c} q_{d c}(j \omega)^{\beta}}
\end{aligned}
$$

Onde: $r_{f}$ é a resistência distribuída, relacionada ao filme de óxidos;

$R_{f}$ é a resistência total do filme de óxidos;

Lé o comprimento da camada de óxidos;

$\zeta$ é a impedância de interface;

$r_{t c}$ é a resistência de transferência de carga distribuída;

$q_{d c}$ é o CPE distribuído, referente a capcitância da dupla camada elétrica;

$j=\sqrt{-1}$

$\omega=2 \pi f$ 


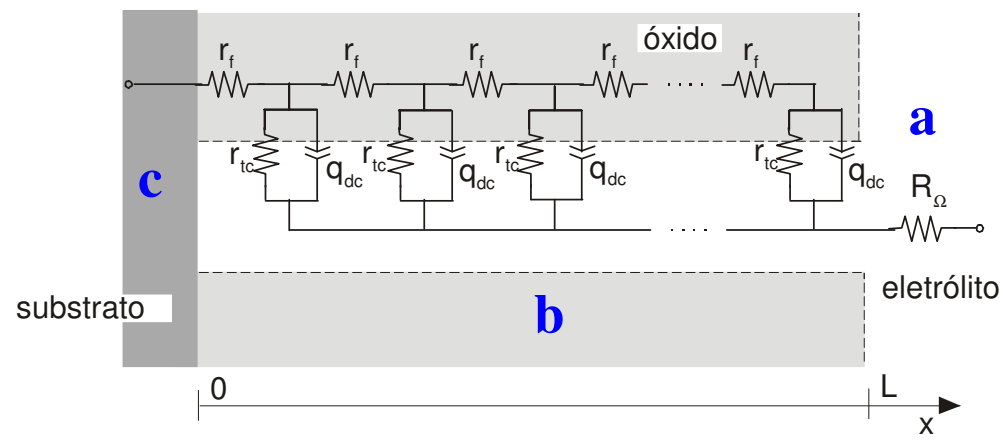

Figura 21: Linha de transmissão que representa fisicamente os dados experimentais dos eletrodos $\mathrm{Ti} / \mathrm{Ru}_{0,3} \mathrm{Ti}_{(0,7-\mathrm{x})} \mathrm{Sn}_{\mathrm{x}} \mathrm{O}_{2}(\mathrm{x}=0 ; 0,3$ e 0,7), no intervalo de potencial de 0,20 a 1,60 V vs. ERH.

É importante salientar que, neste caso temos que o elemento $q_{d c}$, que representa a capacitância da dupla camada elétrica, comporta-se como um EFC. Além disso, assume-se que a capacitância total $\left(Q_{d c}\right)$ está relacionada com a capacitância em série $\left(q_{d c}\right)$ pela seguinta relação: $Q_{d c}=q_{d c} L$, sendo $L$ o comprimento da camada de óxidos. Equivalentemente tem-se que $R_{t c}=r_{t c} / L$.

Portanto, a função de impedância total, apresentada anteriormente na Equação 24, torna-se neste caso específico:

$$
Z=\left[\frac{R_{f} R_{t c}}{1+\left(j \omega / \omega_{\varsigma}\right)^{\beta}}\right]^{1 / 2} \operatorname{coth}\left\{\left(\omega_{3} / \omega_{L}\right)^{\beta / 2}\left[1+\left(j \omega / \omega_{\varsigma}\right)^{\beta}\right]^{1 / 2}\right\}
$$

sendo que $\omega_{L}$ e $\omega_{3}$ são as freqüências características do processo e estão relacionadas com os parâmetros $r_{f}, r_{t c}$ e $q_{d c}$ da seguinte forma:

$$
\omega_{\varsigma}=\frac{1}{\left(r_{t c} q_{d c}\right)^{1 / \beta}}=\frac{1}{\left(R_{t c} Q_{d c}\right)^{1 / \beta}}
$$




$$
\frac{\omega_{\varsigma}}{\omega_{L}}=\left(\frac{R_{f}}{R_{t c}}\right)^{1 / \beta}
$$

Para facilitar a atribuição dos fenômenos eletroquímicos aos elementos da LT, podese representar a estrutura de um eletrodo de óxidos condutores de acordo com um modelo. Este é composto por três regiões distintas (regiões a, b e c da Figura 21) [55, 186]:

- Região $a \Rightarrow$ interface óxido/solução, acesso livre a superfície externa;

- Região $b \Rightarrow$ interface óxido/solução adjacente, parte interna poros;

- Região $c \Rightarrow$ interface suporte metálico $\left(\mathrm{Ti}^{\circ}\right) / o ́ x i d o$, nesta região ocorre formação de óxido de titânio dopado com óxido de rutênio [33].

Observando o comportamento dos diagramas de Nyquist (Figura 22) é possível fazer algumas considerações importantes para a simulação dos dados experimentais. De acordo com o modelo utilizado (Equação 36), tem-se três casos distintos que representam três regiões de potencias diferentes [6]: 

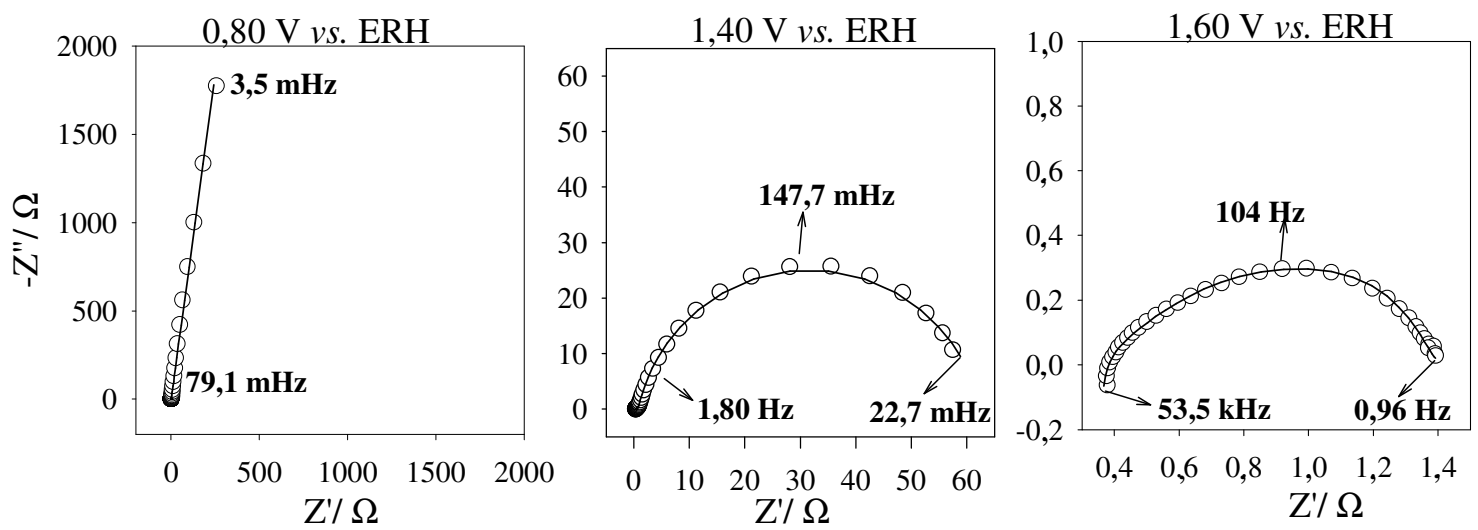

Figura 22: Diagrama de Nyquist em diferentes potenciais do eletrodo de composição $\mathrm{Ti} / \mathrm{Ru}_{0,3} \mathrm{Sn}_{0,7} \mathrm{O}_{2}$ em meio de $\mathrm{HClO}_{4}\left(1 \mathrm{~mol} \mathrm{dm}^{-3}\right), 1 \mathrm{~m} \leq f \leq 100 \mathrm{k} \mathrm{Hz}$, Amplitude $=5 \mathrm{mV} \mathrm{p} / \mathrm{p}$. $(\square)$ valores teóricos, (O) valores experimentais.

- O caso a (Figura 22a, E = 0,80 V vs. ERH) região de baixos sobrepotenciais, onde ocorre o carregamento/descarregamento da dupla camada elétrica, junto às transições eletrônicas do estado sólido $\mathrm{Ru}(\mathrm{III}) / \mathrm{Ru}(\mathrm{IV})$, ou seja, o ADE demonstra um comportamento pseudocapacitivo [36]. Neste caso, seria o mesmo que considerar que a resistência de transferência de carga distribuída nos poros tende a valores muito grandes. Nesta região, a impedância do eletrodo pode ser representada pela Equação 33, sendo que como esperado pelo modelo, os valores de $R_{t c} \rightarrow \infty$, portanto a Equação 35 pode ser simplificada:

$$
\zeta=\frac{1}{q_{d c}}(i \omega)^{-\beta}
$$

ou seja, obtêm-se o comportamento de uma interface idealmente polarizável que é o comportamento normalmente atribuído ao carregamento da dupla camada elétrica. 
- O caso b (Figura 22b, E = 1,40 V vs. ERH) descreve os potencias intermediários, onde ambos processos, carregamento da DCE e início da RDO, estão presentes. Neste caso, o diagrama de Nyquist já apresenta um componente resistivo visto pelo aparecimento de um semicírculo que corta o eixo real $Z^{\prime}$ e, portanto, $R_{t c}$ apresenta valores razoáveis comparados aos demais parâmetros do modelo, ainda que $R_{t c}>R_{f}$. Neste caso, observa-se que a freqüência característica $\omega_{\zeta}$, dada pela Equação 37 é menor que $\omega_{L}$.

- O caso $c$ (Figura 22c, $\mathrm{E}=1,60 \mathrm{~V}$ vs. ERH) descreve a região da RDO, onde ocorre transferência de carga, neste caso $R_{t c} \leq R_{f}$ (equivalentemente $\omega_{\zeta}>\omega_{L}$ ), ou seja, a resistência de transferência de carga não mais limita a cinética da reação. Nota-se que o semicírculo sofre uma deformação, tornando-se assimétrico. Este fato pode ser explicado pelo grande desprendimento de gás oxigênio observado nestes potenciais, estes bloqueiam os sítios ativos do material, interferindo na condutividade eletrônica da camada de óxidos [25]. De acordo com Lasia [1] devido ao aumento do potencial, tem-se o aumento da velocidade da reação de desprendimento de oxigênio, portanto em altas ferquências a solução eletródica não é capaz de penetrar todo o comprimento do poro, ocorrendo então uma queda de potencial no interior do poro. Este comportamento é observado no diagrama de Nyquist com a deformação do semicírculo em altas freqüências [1, 25].

A seguir então, serão analisados os elementos da LT. Primeiramente, a $R_{\Omega}$ que corresponde a resistência ôhmica, cuja contribuição vem da soma das resistências: da solução e dos contatos elétricos [186]. Os valores de $R_{\Omega}$, para uma mesma composição eletródica, são aproximadamente constantes em relação aos potenciais investigados 
(Figura 22), este comportamento pode ser explicado visto que, tanto o eletrólito $\left(\mathrm{HClO}_{4} 1 \mathrm{~mol} \mathrm{dm}{ }^{-3}\right)$, quanto a posição do eletrodo de trabalho, são mantidas constantes. A pequena variação de $R_{\Omega}$ em função da composição, entre 0,25 e $0,70 \Omega \mathrm{cm}^{-2}$, pode ser explicada em função da distância do eletrodo de trabalho e o capilar de Luggin-Harber do eletrodo de referência, que sofre uma pequena alteração cada vez que a célula eletroquímica é montada para uma nova medida $[55,81,84,187]$. Os valores obtidos são próximos aos valores observados por Da Silva et al. [80] para eletrodos de $\mathrm{IrO}_{2}+\mathrm{TiO}_{2}$ preparados por tratamento térmico a temperaturas entre 350 e $500^{\circ} \mathrm{C}$ em meio ácido. Os autores obtiveram valores de $R_{\Omega}$ na ordem de $0,6-0,7 \Omega \mathrm{cm}^{-2}$.

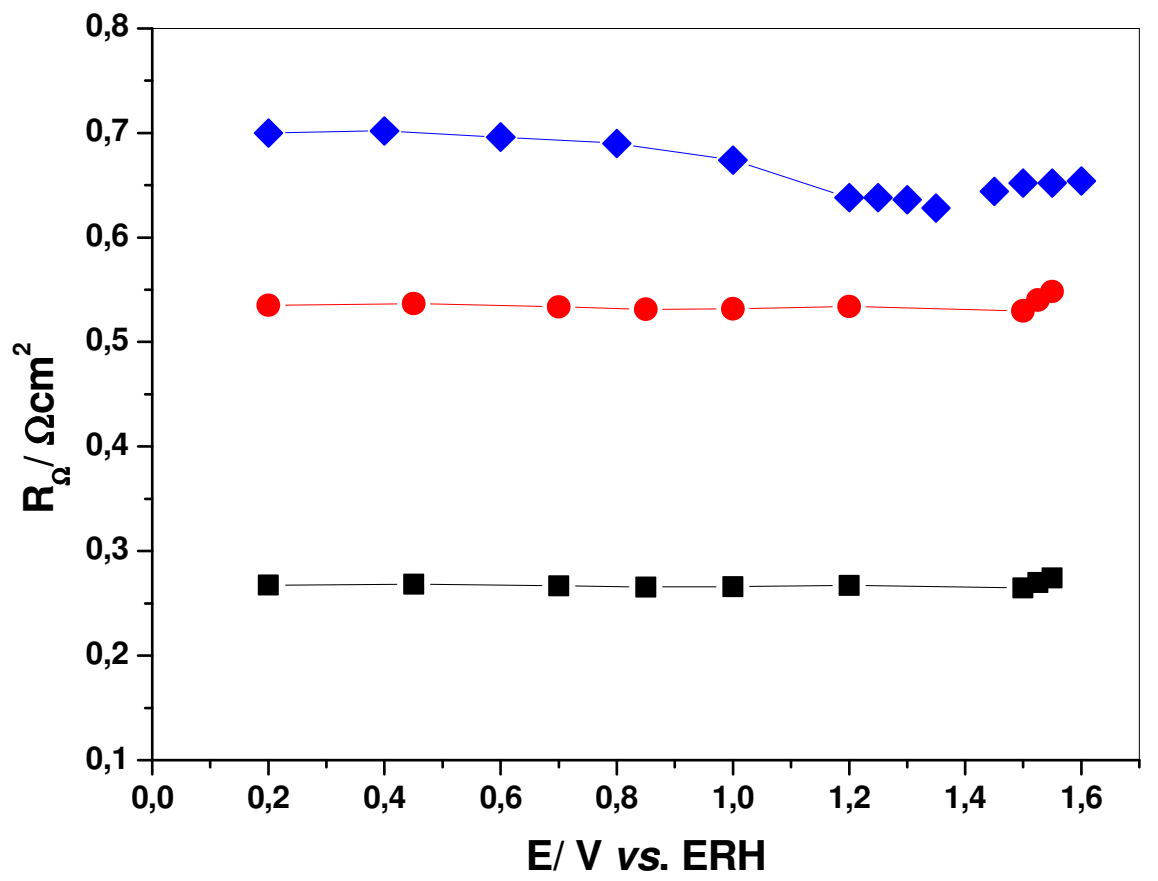

Figura 23: Valores de $R_{\Omega}$ em função do potencial para as diferentes composições investigadas. Sendo: - - $-\mathrm{Ti} / \mathrm{Ru}_{0,3} \mathrm{Ti}_{0,7} \mathrm{O}_{2},-\longrightarrow-\mathrm{Ti} / \mathrm{Ru}_{0,3} \mathrm{Ti}_{0,4} \mathrm{Sn}_{0,3} \mathrm{O}_{2} \quad \mathrm{e}-\longrightarrow-$ $\mathrm{Ti} / \mathrm{Ru}_{0,3} \mathrm{Sn}_{0,7} \mathrm{O}_{2}$. 
A análise da Figura 24 mostra que o comportamento observado nos valores da capacitância da dupla camada elétrica, $Q_{d c}$, em função dos potenciais é similar ao comportamento do voltamograma cíclico (entre 0,2 e 1,0 V vs. ERH), isso se reproduz para todas as composições investigadas. Este comportamento é a capacitância relacionada ao carregamento da dupla camada, somada a pseudocapacitância devido a transição redox no estado sólido, que inclui a soma da oxidação/redução dos sítios de rutênio e do processo de desprotonação/protonação [188, 189].

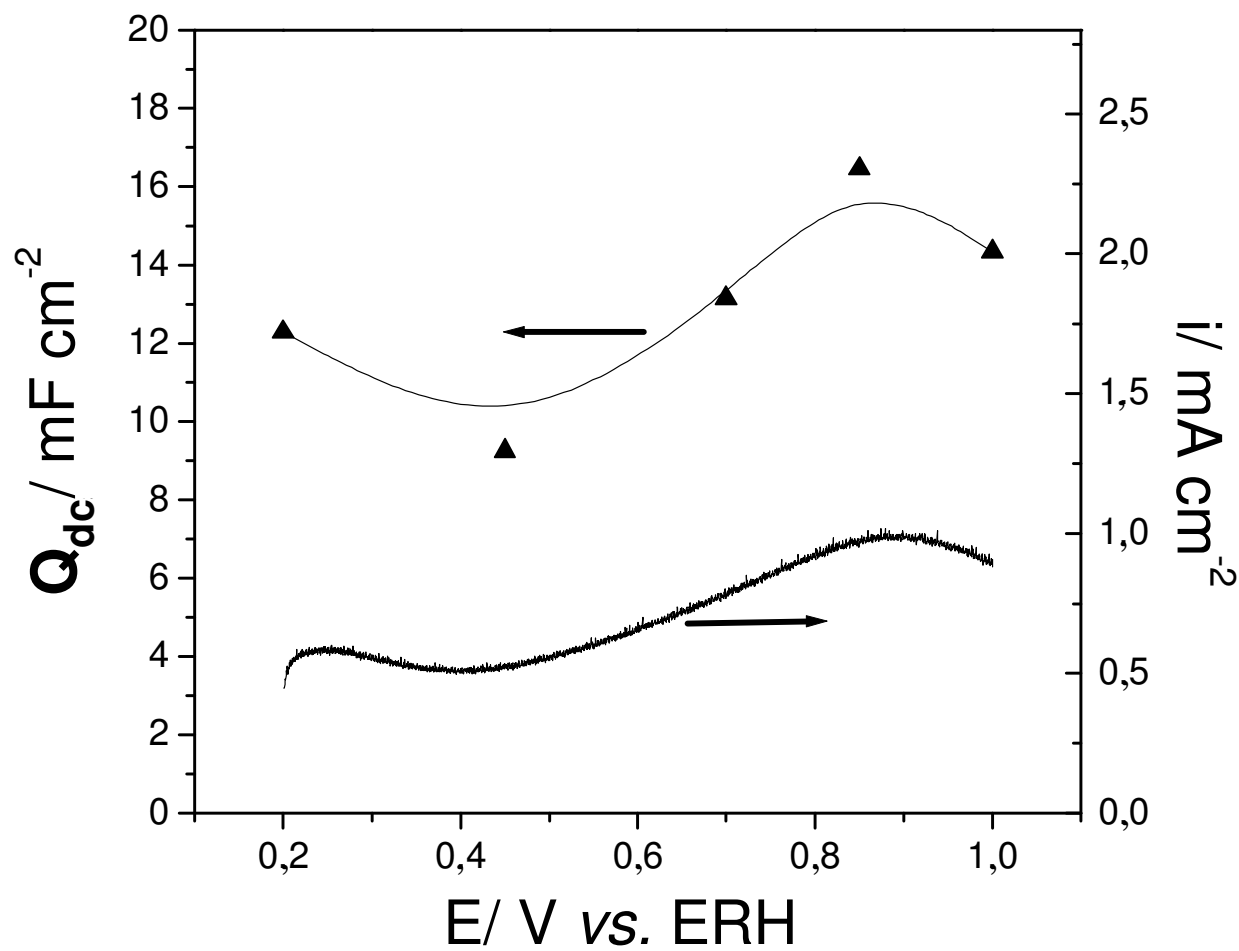

Figura 24: (- -) Valores de $Q_{d c}$ (obtidos por LT) em função do potencial e (一) curva i vs. E (obtida por voltametria cíclica), do eletrodo $\mathrm{Ti} / \mathrm{Ru}_{0,3} \mathrm{Ti}_{0,7} \mathrm{O}_{2}$, velocidade de varredura de $20 \mathrm{mV} \mathrm{s}^{-1}$, em meio ácido $\left(\mathrm{HClO}_{4} 1 \mathrm{~mol} \mathrm{dm}^{-3}\right)$. 
Os valores de $R_{f}$, estão relacionados com a atividade da camada de óxidos. Foi observado, para todas as composições, que com o aumento de potencial estes valores aumentam, estes dados estão representados na Figura 25 pelo eletrodo de $\mathrm{Ti} / \mathrm{Ru}_{0,3} \mathrm{Sn}_{0,7} \mathrm{O}_{2}$. Como discutido anteriormente (casos b e c da Figura 22), com o aumento do potencial a RDO é favorecida e a resistência à tranferência de carga tende a $R_{t c} \leq R_{f}$, sendo assim, $R_{t c}$ passa a não limitar mais a cinética da reação, que passa agora a ser limitada por fatores relacionados à camada de óxidos. Por exemplo, a porosidade e a capacitância da dupla camada. Tais fatores, influenciam na condutividade eletrônica do material óxido, que está diretamente relacionada aos valores de $R_{f}$. Como discutido anteriromente, em altos sobrepotenciais devido ao desprendimento de gás tem-se uma queda de potencial ao longo do comprimento do poro em altas freqüências, o que também influencia no aumento dos valores de $R_{f}$. 


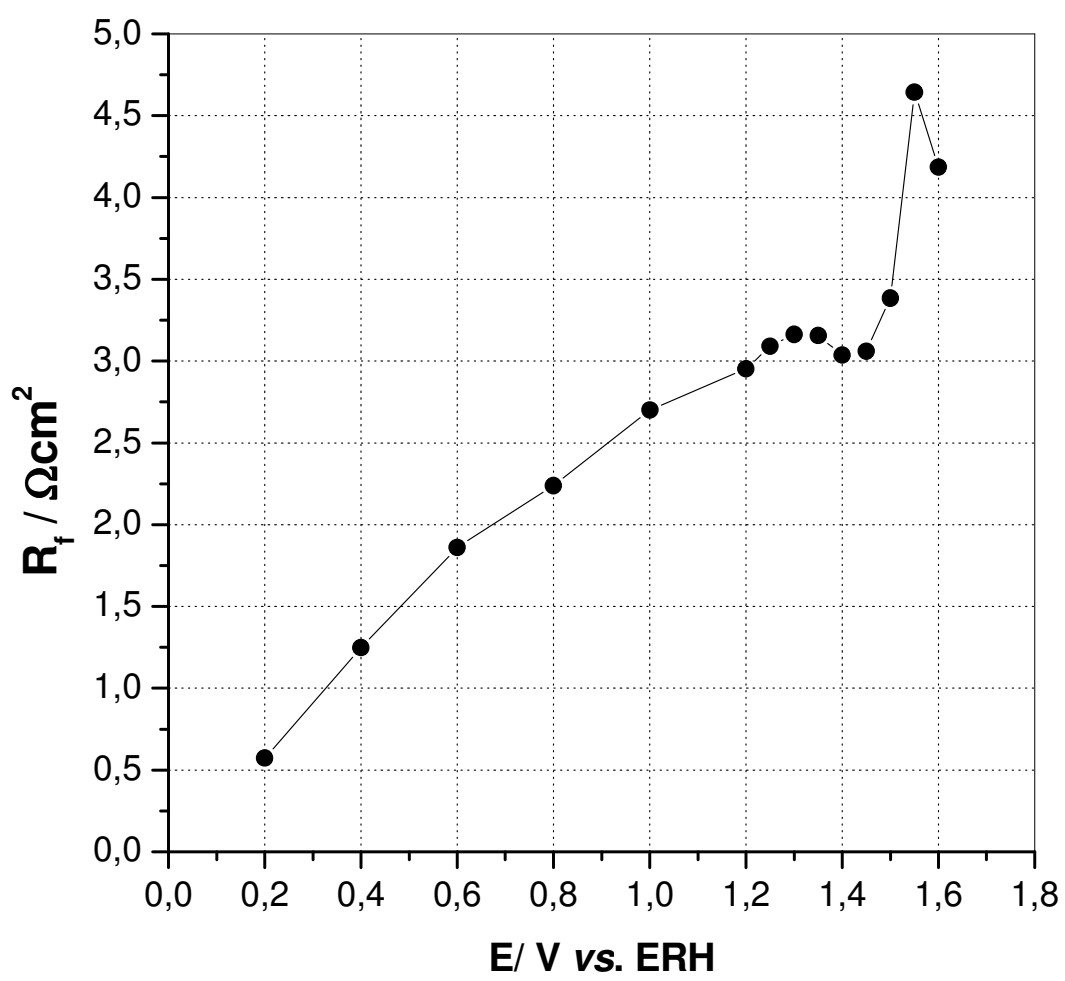

Figura 25: Valores da resistência do filme, $R_{f}$ em função do potencial (V vs. ERH), obtidos do ajuste dos dados experimentais do eletrodo de composição Ti/ $\mathrm{Ru}_{0,3} \mathrm{Sn}_{0,7} \mathrm{O}_{2}$.

O último elemento da LT a ser discutido é a resistência de tranferência de carga distribuída $R_{t c}$. No diagrama de Nyquist na Figura 26 pode-se observar que, na região da DCE $(\mathrm{E}=0,85 \mathrm{~V} v s . \mathrm{ERH})$ a troca de $\mathrm{TiO}_{2}$ por $\mathrm{SnO}_{2}$, não influencia no comportamento da impedância do sistema. Já na região da RDO, potenciais acima de $\mathrm{E}=1,525 \mathrm{~V} v s$. ERH, temos que o eletrodo com $70 \%$ de $\mathrm{SnO}_{2}$ apresentou melhores resultados, pois é visível no diagrama de Nyquist que esta composição apresenta menor resistência à transferência de carga. 

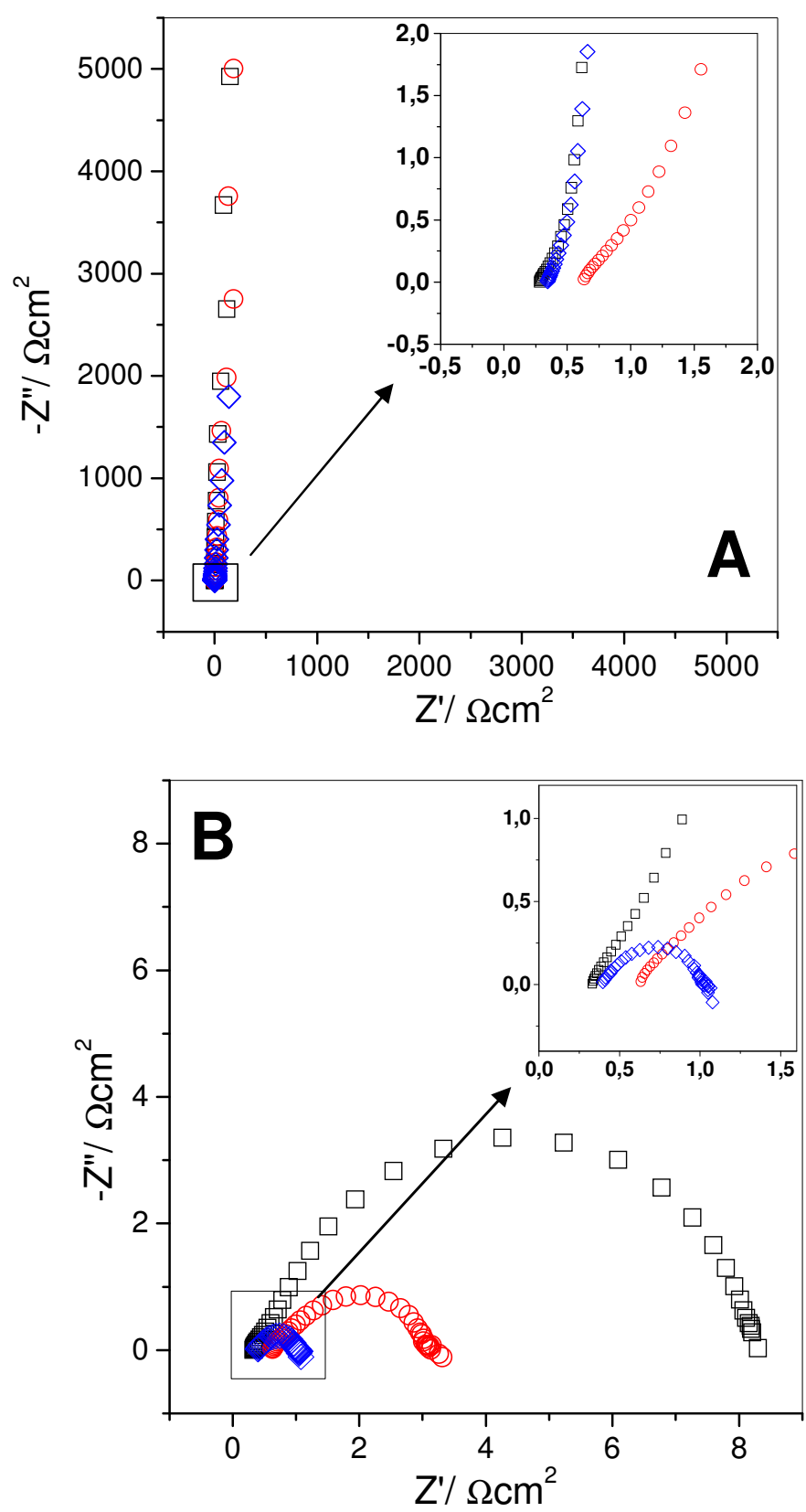

Figura 26: Diagramas de Nyquist para as diferentes composições investigadas. Sendo: $\square \mathrm{Ti} / \mathrm{Ru}_{0,3} \mathrm{Ti}_{0,7} \mathrm{O}_{2}, \bigcirc \mathrm{Ti} / \mathrm{Ru}_{0,3} \mathrm{Ti}_{0,4} \mathrm{Sn}_{0,3} \mathrm{O}_{2}$ e $\diamond \mathrm{Ti} / \mathrm{Ru}_{0,3} \mathrm{Sn}_{0,7} \mathrm{O}_{2}$. (A) na região da DCE, E $=0,85 \mathrm{~V} v s . \mathrm{ERH}(\mathrm{b})$ na região da $\mathrm{RDO}, \mathrm{E}=1,525 \mathrm{~V} v s . \mathrm{ERH}$. 
Os valores de $R_{t c}$ em função da composição eletródica na RDO estão apresentados na Figura 27. Estes resultados estão de acordo com o observado por Forti [190] em relação à atividade catalítica de eletrodos $\mathrm{Ti} / \mathrm{Ru}_{0,3} \mathrm{Sn}_{0,7} \mathrm{O}_{2}$ para a $\mathrm{RDO}$. De fato, Forti observou que a troca de $\mathrm{TiO}_{2}$ por $\mathrm{SnO}_{2}$ na composição aumenta a atividade eletrocatílica para a RDO. Os resultados de EIE confirmam os dados acima e permitem obter uma quantificação do ganho energético obtido com a troca desses óxidos.

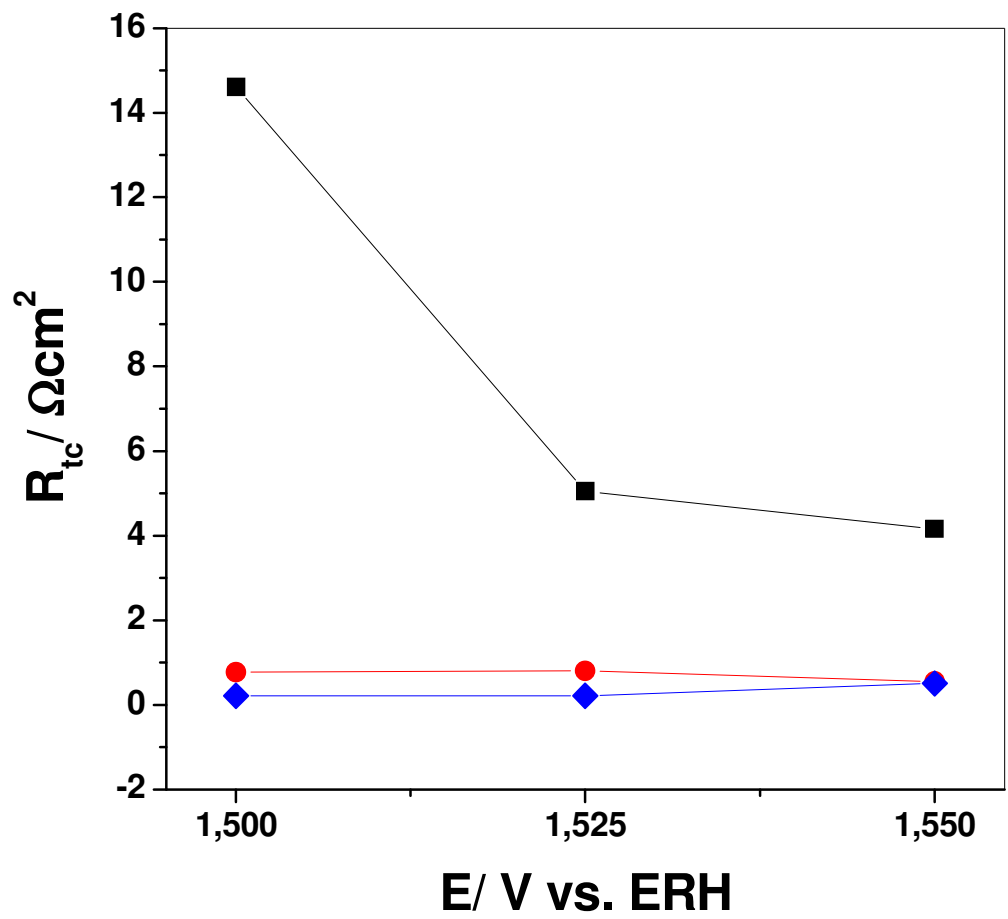

Figura 27: Valores de $R_{t c}$ em função do potencial para as diferentes composições investigadas. Sendo: - - $-\mathrm{Ti} / \mathrm{Ru}_{0,3} \mathrm{Ti}_{0,7} \mathrm{O}_{2},-\longrightarrow-\mathrm{Ti} / \mathrm{Ru}_{0,3} \mathrm{Ti}_{0,4} \mathrm{Sn}_{0,3} \mathrm{O}_{2} \quad$ e $-\longrightarrow-$ $\mathrm{Ti} / \mathrm{Ru}_{0,3} \mathrm{Sn}_{0,7} \mathrm{O}_{2}$. 


\section{IV.1.3 EIE e Tafel para eletrodos de composição $\mathrm{Ti} / \mathbf{R u}_{0,3} \mathrm{Sn}_{0,7} \mathrm{O}_{2}$}

Com o objetivo de refinar os resultados obtidos de EIE para os eletrodos do tipo ADEs. Foi realizada para a composição $\mathrm{Ti} / \mathrm{Ru}_{0,3} \mathrm{Sn}_{0,7} \mathrm{O}_{2}$, estudos em intervalos de potencial menores. Os valores de cada elemento da LT, obtidos para esta composição eletródica, em todos os potenciais investigados, são apresentados na Tabela III.

Tabela III: Valores dos elementos da linha de transmissão utilizados para ajustar os dados experimentais, do eletrodo de composição $\mathrm{Ti} / \mathrm{Ru}_{0,3} \mathrm{Sn}_{0,7} \mathrm{O}_{2}$.

\begin{tabular}{|c|c|c|c|c|c|}
\hline $\begin{array}{c}\mathrm{E} / \mathrm{V} v s . \\
\mathrm{ERH}\end{array}$ & $R_{f} / \Omega \mathrm{cm}^{2}$ & $R_{t c} / \Omega \mathrm{cm}^{2}$ & $Q_{d c} / \mathrm{mFcm}^{-2}$ & $\beta$ & $R_{\Omega} / \Omega \mathrm{cm}^{2}$ \\
\hline $\mathbf{0 , 2 0}$ & 0,572 & $4,8 \mathrm{k}$ & 35,0 & 0,87 & 0,70 \\
\hline $\mathbf{0 , 4 0}$ & 1,246 & $19 \mathrm{k}$ & 33,4 & 0,89 & 0,70 \\
\hline $\mathbf{0 , 6 0}$ & 1,860 & $71,8 \mathrm{k}$ & 38,2 & 0,90 & 0,70 \\
\hline $\mathbf{0 , 8 0}$ & 2,238 & $3,80 \mathrm{M}$ & 37,4 & 0,90 & 0,70 \\
\hline $\mathbf{1 , 0 0}$ & 2,702 & $4,98 \mathrm{M}$ & 32,0 & 0,88 & 0,67 \\
\hline $\mathbf{1 , 2 0}$ & 2,952 & $3,98 \mathrm{M}$ & 32,4 & 0,86 & 0,64 \\
\hline $\mathbf{1 , 2 5}$ & 3,090 & $5,02 \mathrm{M}$ & 31,6 & 0,86 & 0,64 \\
\hline $\mathbf{1 , 3 0}$ & 3,162 & $1,90 \mathrm{M}$ & 31,2 & 0,86 & 0,64 \\
\hline $\mathbf{1 , 3 5}$ & 3,154 & $5,56 \mathrm{k}$ & 34,4 & 0,86 & 0,63 \\
\hline $\mathbf{1 , 4 0}$ & 3,036 & 123,4 & 39,6 & 0,86 & 0,62 \\
\hline $\mathbf{1 , 4 5}$ & 3,060 & 12,68 & 33,0 & 0,89 & 0,64 \\
\hline $\mathbf{1 , 5 0}$ & 3,384 & 3,22 & 26,2 & 0,90 & 0,65 \\
\hline $\mathbf{1 , 5 5}$ & 4,642 & 1,34 & 36,0 & 0,87 & 0,65 \\
\hline $\mathbf{1 , 6 0}$ & 2,184 & 1,00 & 29,4 & 0,85 & 0,65 \\
\hline
\end{tabular}

Para melhor visualização dos valores de $R_{t c}$ estes estão apresentados na Figura 28, nota-se um decaimento exponencial dos valores com o aumento do potencial. Os valores de $R_{t c}$ estão associados com a RDO, ou seja, ao processo faradaico, portanto, apresentam valores extremamente elevados na região da DCE $\left(R_{t c}>>4,0 \mathrm{k} \Omega\right.$ ), onde não 
ocorre processo faradaico. Já com o aumento do potencial, observa-se que os valores de $R_{t c}$ diminuem, indicando um aumento da velocidade da reação de desprendimento de oxigênio.

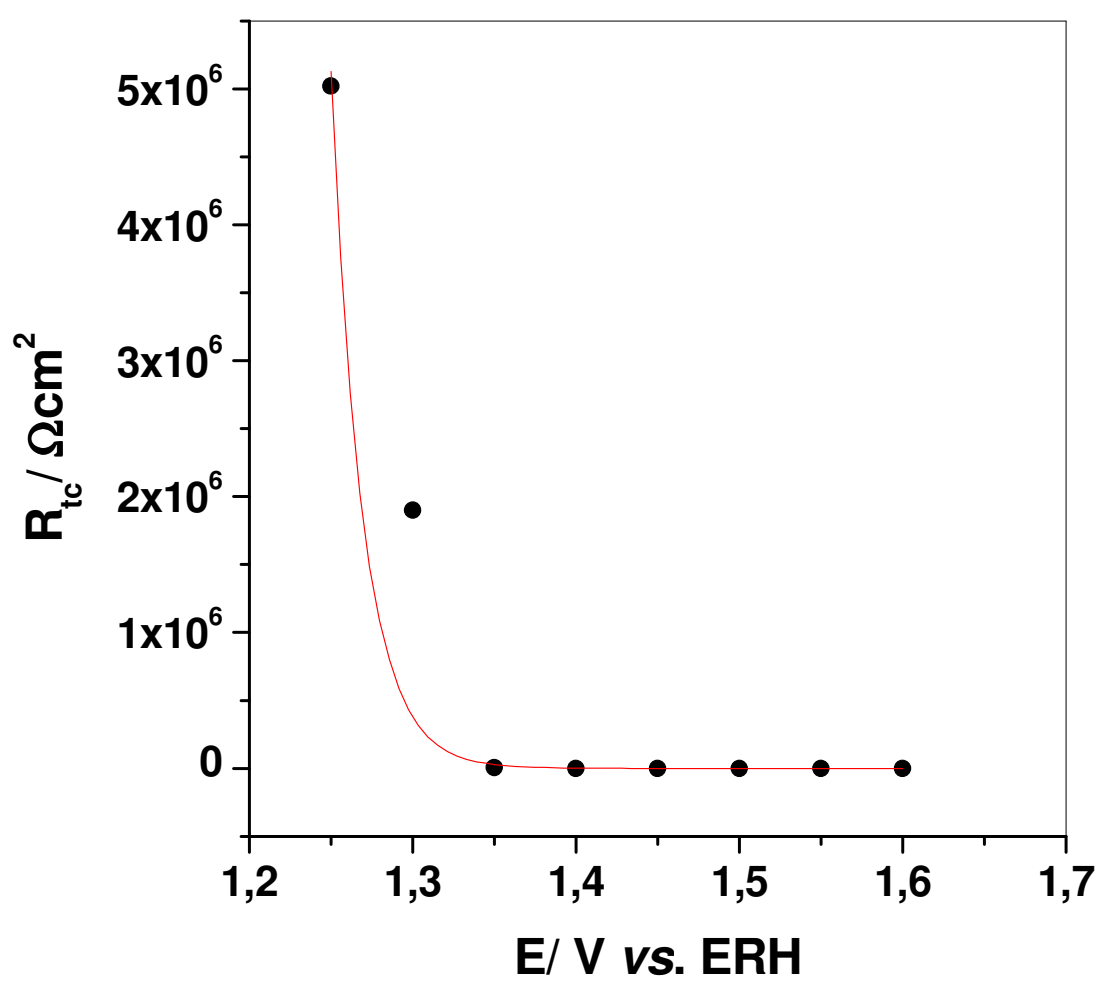

Figura 28: Resistência de transferência de carga, $R_{t c}\left(\Omega \mathrm{cm}^{2}\right)$ em função do potencial (V vs. ERH), para a composição $\mathrm{Ti} / \mathrm{Ru}_{0,3} \mathrm{Sn}_{0,7} \mathrm{O}_{2}$.

Foram também registradas curvas de polarização de Tafel do eletrodo de composição $\mathrm{Ti} / \mathrm{Ru}_{0,3} \mathrm{Sn}_{0,7} \mathrm{O}_{2}$, para que fosse possível comparar os resultados da teria $a c$ (EIE) e da teoria $d c$ (Tafel).

As curvas de polarização de Tafel foram registradas variando-se o potencial inicialmente na direção positiva até a corrente atingir um valor próximo a $100 \mathrm{~mA} \mathrm{~cm}{ }^{-2}$ e depois no sentido contrário. Foi realizada a correção para queda ôhmica de acordo com o 
método proposto por Shub \& Reznick [191], Figura 29. O mecanismo eletródico da RDO envolve várias etapas mecanísticas propostas na literatura [36]. Através do registro de curvas de Tafel pode-se extrair os valores do coeficiente angular de Tafel ( $b$ dado em $\mathrm{mVdec}^{-1}$ ) e, a partir deste valor, obter a etapa determinante da velocidade. A Tabela IV apresenta os valores teóricos do coeficiente angular de Tafel para definições mecanisticas propostas para a RDO, considerando-se todos os intermediários formados [190, 192].

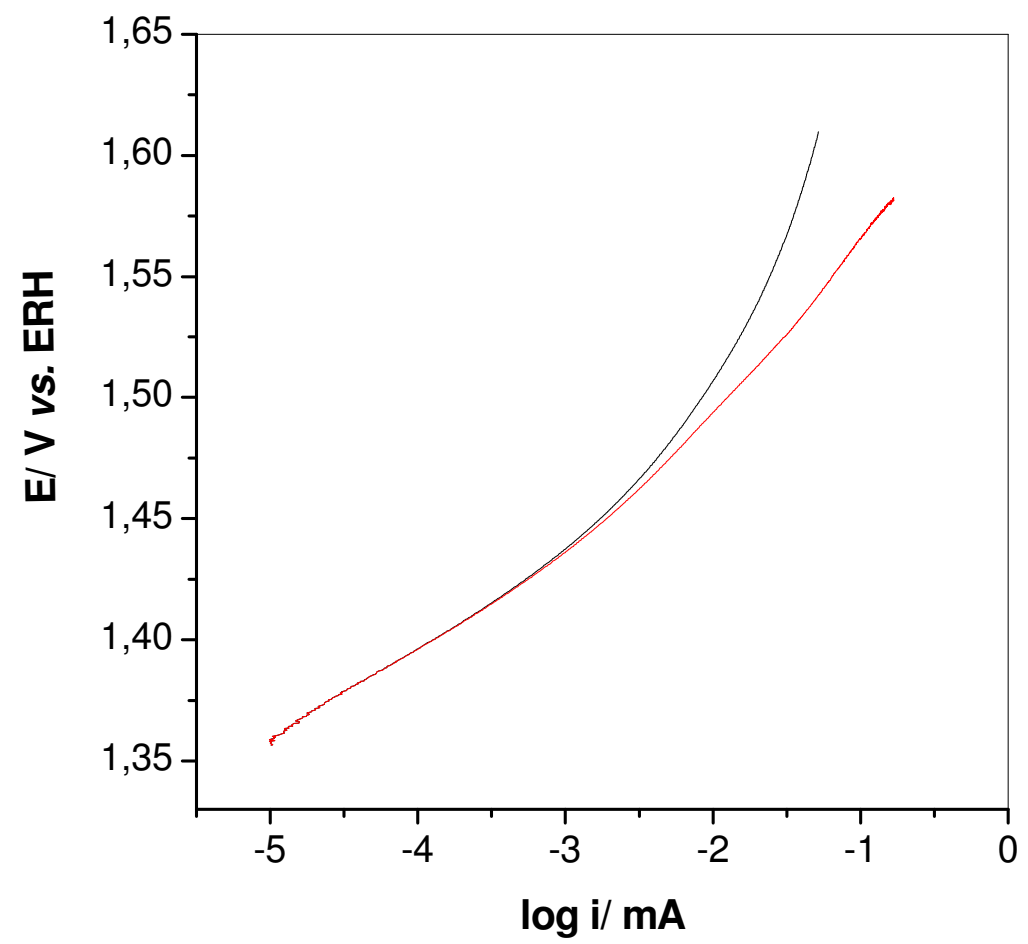

Figura 29: Curva de Tafel (E vs. Log i), (-) sem correção e (-) com correção para queda ôhmica, do eletrodo de composição $\mathrm{Ti} / \mathrm{Ru}_{0,3} \mathrm{Sn}_{0,7} \mathrm{O}_{2}$. 
Tabela IV. Mecanismos propostos na literatura para a RDO em meio ácido [36, 190].

\begin{tabular}{|l|c|}
\hline \multicolumn{1}{|c|}{ Mecanismo } & $b / \mathrm{mVdec}^{-1}$ \\
\hline (I) Mecanismo Eletroquímico & \\
$\equiv S+\mathrm{H}_{2} \mathrm{O} \rightarrow \equiv \mathrm{S}-\mathrm{OH}+\mathrm{H}^{+}+e^{-}$ & 120 \\
$\equiv \mathrm{S}-\mathrm{OH} \rightarrow \equiv \mathrm{S}-\mathrm{O}+\mathrm{H}^{+}+e^{-}$ & 40 \\
$2 \equiv \mathrm{S}-\mathrm{O} \rightarrow 2 \equiv \mathrm{S}+\mathrm{O}_{2}$ & 15 \\
& \\
\hline (II) Mecanismo Químico & 120 \\
$\equiv \mathrm{S}+\mathrm{H}_{2} \mathrm{O} \rightarrow \equiv \mathrm{S}-\mathrm{OH}+\mathrm{H}^{+}+e^{-}$ & 30 \\
$2 \equiv \mathrm{S}-\mathrm{OH} \rightarrow \equiv \mathrm{S}-\mathrm{O}+\equiv \mathrm{S}+\mathrm{H}_{2} \mathrm{O}$ & 15 \\
$2 \equiv \mathrm{S}-\mathrm{O} \rightarrow 2 \equiv \mathrm{S}+\mathrm{O}_{2}$ & \\
\hline
\end{tabular}

Frente aos valores teóricos apresentados na Tabela acima e, a análise do coeficiente de Tafel obtido neste trabalho $\left(b=42 \mathrm{mVdéc}^{-1}\right)$, observa-se que a etapa determinante da RDO na região de potencial investigada é a etapa 2 do modelo eletroquímico, dada por:

$$
\equiv S-O H \rightarrow \equiv S-O+H^{+}+e^{-}
$$

Sendo assim, a etapa determinante da velocidade é a perda do próton/elétron, formando a espécie $\equiv S-O$. Este resultado está de acordo com o observado por Boodts \& Trasatti [42] no estudo de eletrodos de $\mathrm{Ti} / \mathrm{Ru}_{0,3} \mathrm{Ti}_{(0,7-\mathrm{x})} \mathrm{Sn}_{\mathrm{x}} \mathrm{O}_{2}$ preparados pelo método de decomposição térmica de cloretos, onde foi observado duas inclinações para a curva de Tafel, sendo que em baixo sobrepotenciais o coeficiente de Tafel obtido foi $40 \mathrm{mVdéc}^{-1}$.

A resistência a tranferência de carga, obtida através da EIE (teoria $a c$ ), está relacionada com os valores de corrente obtidos por Tafel (teoria $d c$ ) de acordo com a Equação de Butler-Volmer [193]:

$$
i=i_{0}\left\lfloor e^{\alpha n f \eta}-e^{-(1-\alpha) n f \eta}\right\rfloor
$$

onde: $\quad \alpha=$ coeficiente de transferência

$$
\text { n = número de elétrons envolvidos na reação }
$$




$$
\begin{aligned}
& \eta=\text { sobrepotencial }\left(\eta=\mathrm{E}-\mathrm{E}_{0}\right) \\
& f=\mathrm{F} / \mathrm{RT}
\end{aligned}
$$

No caso da RDO, tem-se que a densidade de corrente e o sobrepotencial $(\eta)$ são controlados pelo processo de transferência de carga de acordo com a seguinte reação total:

$$
2 \mathrm{H}_{2} \mathrm{O} \rightarrow \mathrm{O}_{2}+4 \mathrm{H}^{+}+4 e^{-}
$$

De acordo com Elumalai et al. [193], podemos considerar que neste caso, do sobrepotencial afastado do equilíbrio $(\eta \rightarrow 0)$, a Equação 41 pode ser reescrita como:

$$
i=i_{0} e^{-(1-\alpha) n f \eta}
$$

Pode-se então, isolar o $\eta$ da seguinte forma:

$$
\eta=-\frac{\left(\ln i_{0}-\ln i\right)}{(1-\alpha) n f}
$$

Derivando-se a Equação 44, teremos que:

$$
\left(\frac{d n}{d i}\right)_{\eta \neq 0}=-\frac{1}{(1-\alpha) n f i}
$$

Por fim, a resistência de tranferência de carga pode ser dada como [85]:

$$
R_{t c}=\left(\frac{d n}{d i}\right)_{\eta \neq 0}
$$

Substituindo-se os valores de $R_{t c}$, obtidos através dos valores experimentais das medidas de EIE, o número de elétrons é dado pela reação total da RDO (Equação 42), portanto $\mathrm{n}=4$ e o valor de $\alpha=0,6$ foi obtido a partir do gráfico de ln i vs. E [193]. Utilizando-se as Equações 46 e 45 foram obtidos os valores de corrente provenientes dos valores experimentais de $R_{t c}$. A Figura 30 mostra o gráfico de $R_{t c}$ em função dos valores 
de potencial investigados em comparação com os valores de corrente obtidos pela curva de polarização de Tafel. Nota-se que, os valores de corrente obtidos através da aplicação do modelo de poros de EIE e Tafel seguem o mesmo comportamento, nos fornecendo uma análise comparativa das teorias $a c$ e $d c$.

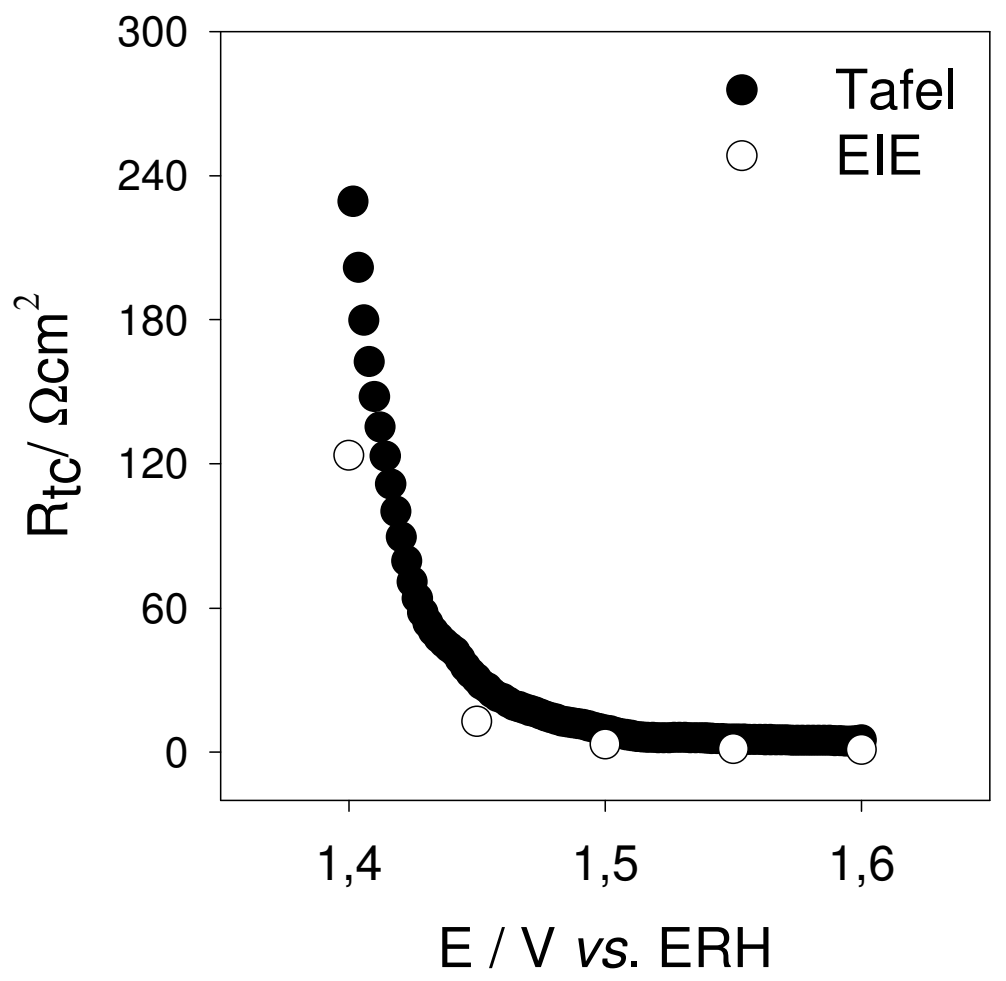

Figura 30: Curva de $R_{t c}$ em função do potencial: (०) valores obtidos por EIE e (•) valores obtidos a partir dos valores de $i$ obtido na curva de Tafel do eletrodo de composição $\mathrm{Ti} / \mathrm{Ru}_{0,3} \mathrm{Sn}_{0,7} \mathrm{O}_{2}$. 


\section{IV.1.4 Conclusões}

O modelo de eletrodos porosos se apresenta como uma forma bastante promissora no tratamento das respostas em frequiência dos ADEs. Uma vez estabelecida a aplicação do modelo, pode-se chegar à obtenção de informações cinéticas importantes durante a análise de vários fatores que ocorrem no sistema em questão, sendo possível então, confirmar resultados obtidos por outras técnicas. Neste trabalho pode-se observar que o modelo ajustou-se muito bem aos dados experimentais.

Os resultados de EIE confirmam que, o aumento da concentração de $\mathrm{SnO}_{2}$ na composição dos eletrodos, favorecem a formação de oxigênio, como o apresentado na literatura por outras técnicas eletroquímicas [77]. A linha de transmissão de um canal apresentou valores satisfatórios dos seus elementos, coerentes com os valores apresentados na literatura, quanto utilizada a técnica da EIE.

Os valores de coeficiente de Tafel observados para a RDO concordam com os valores da literatura para eletrodos de mesma composição [42]. A resistência de transferência de carga $\left(R_{t c}\right)$ diminui a medida que aumenta-se o potencial, no sentido da RDO. Analisando-se aos valores de potencial em função do logaritmo da corrente obtidos pelas diferentes técnicas: (i) curvas de polarização de Tafel, (ii) EIE, tem-se o mesmo comportamento, pode-se concluir então que existe um relação entre o comportamento $a c$ e $d c$ do sistema. 


\section{IV.2 Efeito da adição de Pt por eletrodeposição sobre eletrodos de composição $\mathrm{Ti} / \mathrm{Ru}_{0,3} \mathrm{Ti}_{0,7} \mathrm{O}_{2} \mathrm{em}$ meio ácido}

\section{IV.2.1 Efeito da composição eletródica}

De acordo com o aspecto voltamétrico obtido (Figura 31), pode-se observar que o eletrodo sem adição de platina $\mathrm{Ti} / \mathrm{Ru}_{0,3} \mathrm{Ti}_{0,7} \mathrm{O}_{2}$, apresenta um o comportamento característicos dos ADEs com o pico de transição $\mathrm{Ru}(\mathrm{III}) / \mathrm{Ru}(\mathrm{IV})$ $\left(2 \mathrm{RuO}_{2}+2 \mathrm{H}^{+}+2 \mathrm{e} \rightarrow \mathrm{Ru}_{2} \mathrm{O}_{3}+\mathrm{H}_{2} \mathrm{O}\right)$ entre os potenciais 0,6 e 0,9 vs. ERH, como discutido anteriormente na seção IV.1.1 [36]. Com a adição de platina na composição, os voltamogramas começam a apresentar um comportamento misto, com picos relativos as transições redox de rutênio e dos processos característicos da platina [194, 195].

Os processos característicos da platina podem ser observados em três regiões distintas de potenciais. Em potenciais inferiores a $0,3 \mathrm{~V}$ vs. ERH observa-se picos característicos da redução do $H^{+}\left(P t+H^{+}+e ́ P t-H_{a d}\right)$ e a oxidação do $H_{a d}$. Estes picos estão pouco definidos em função da quantidade de platina eletrodepositada e a rugosidade do suporte (ADE). Em potenciais entre 0,3 e 0,6 V vs. ERH observa-se a região de carregamento da dupla camada elétrica, onde ocorrem os processos não faradáicos, sem presença de espécies adsorvidas. Em potenciais acima de 0,6 V vs. ERH, tem-se a região de oxidação/redução dos óxidos de Pt, além das transições pseudocapacitivas $\mathrm{Ru}(\mathrm{III}) / \mathrm{Ru}(\mathrm{IV})$ definidas anteriormente $[65,194]$. 


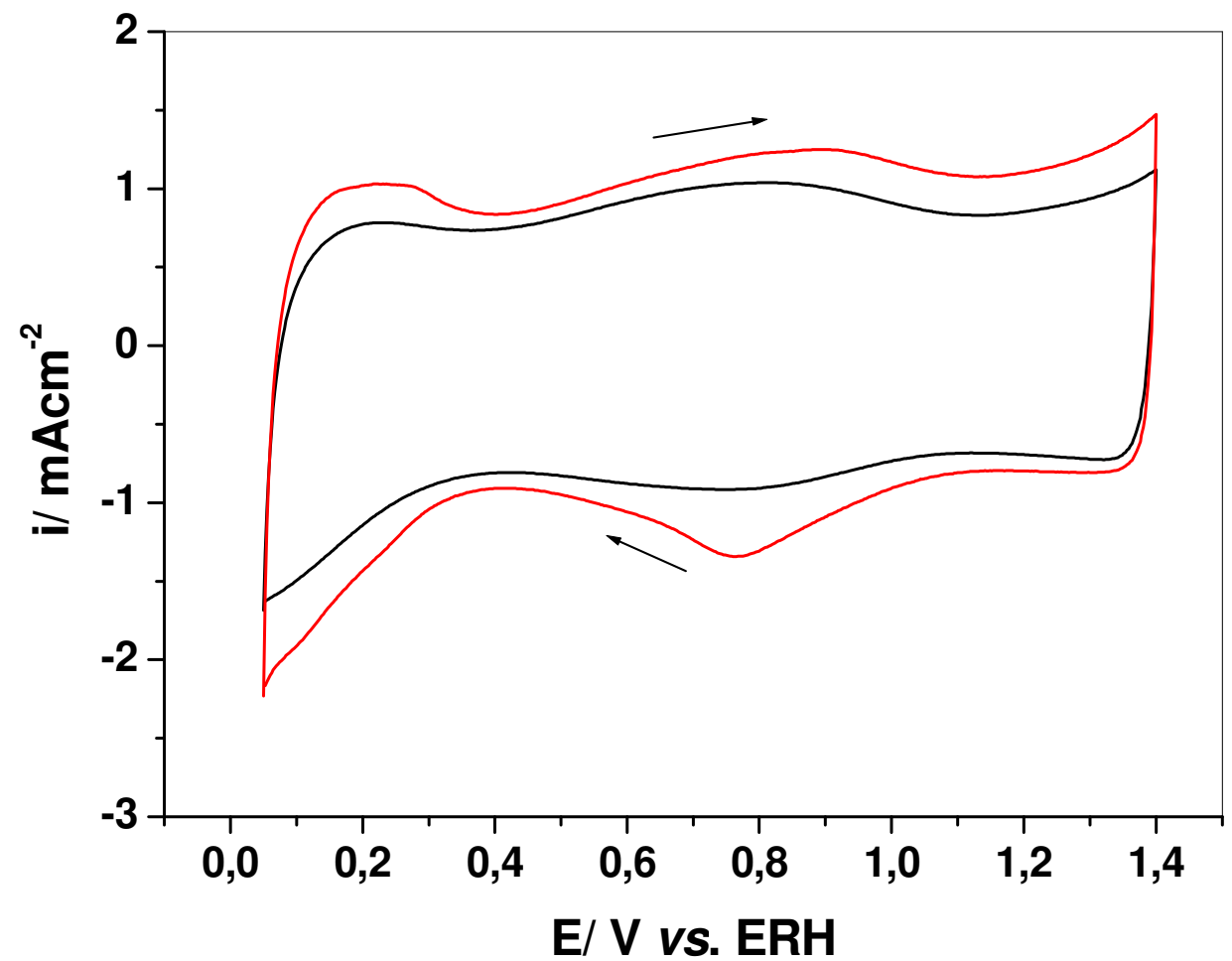

Figura 31: Voltamogramas cíclicos característicos dos eletrodos sendo: $-\mathrm{Ti} / \mathrm{Ru}_{0,3} \mathrm{Ti}_{0,7} \mathrm{O}_{2} \mathrm{e}-\mathrm{Ti} / \mathrm{Ru}_{0,3} \mathrm{Ti}_{0,7}+\mathrm{Pt} 100 \mu \mathrm{g} \mathrm{cm}^{-2} \cdot \mathrm{v}=50 \mathrm{mV} \mathrm{cm}{ }^{-2}$, em meio de $\mathrm{H}_{2} \mathrm{SO}_{4} 0,5 \mathrm{~mol} \mathrm{dm}^{-3}, \mathrm{~T}=25^{\circ} \mathrm{C}$.

Para os testes de EIE das duas composições investigadas, foram escolhidos potenciais na região da DCE, entre 0 a 1,4 V vs. ERH, como também potenciais referentes a RDO, 1,50 a 1,58 V vs. ERH. O formato típico dos diagramas de Nyquist obtidos para todos os eletrodos pode ser observado na Figura 32. Na região da dupla camada elétrica, Figura 32A, podemos observar que a composição não interfere na impedância do sistema. Já na região da RDO, Figura 32B, nota-se no eixo imaginário que a resistência ôhmica varia com a composição eletródica, isto pode ser explicado devido a troca de eletrodo para a realização dos experimentos, o que altera a distância entre o eletrodo de trabalho e o capilar de Luggin-Harber do eletrodo de referência de hidrogênio [53, 55, 80, 81]. 

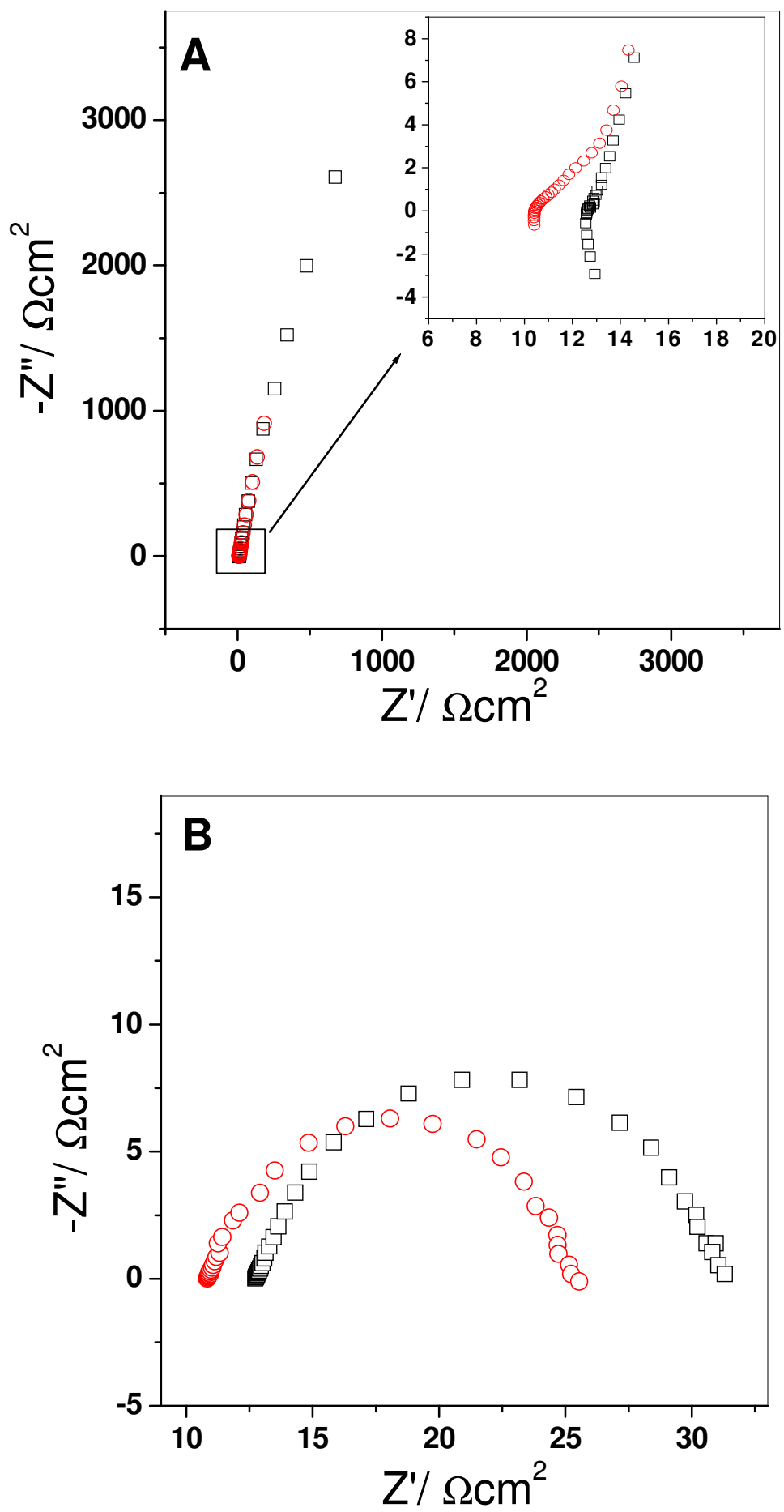

Figura 32: Diagramas de Nyquist em diferentes composições eletródicas. Sendo: $\mathrm{Ti} / \mathrm{Ru}_{0,3} \mathrm{Ti}_{0,7} \mathrm{O}_{2}$, $\bigcirc \mathrm{Ti} / \mathrm{Ru}_{0,3} \mathrm{Ti}_{0,7}+\mathrm{Pt} 100 \mu \mathrm{g} \mathrm{cm}{ }^{-2}$. (A) Região da DCE, $\mathrm{E}=0,15 \mathrm{~V} v s$. ERH e (B) Região da RDO, E = 1,54 V vs. ERH. 
Baseando-se nos diagramas de Nyquist (Figura 32), foi proposta uma LT para representar o sistema. A LT que melhor ajustou-se aos dados experimentais foi a mesma discutida anteriormente na seção IV.1.2, apresentada na Figura 21. Os resultados experimentais foram ajustados de acordo com as equações específicas da LT utilizada, para que fossem obtidos os valores dos diferentes elementos da LT. Verificando o efeito da composição eletródica, vamos analisar os valores obtidos a partir da simulação dos dados experimentais de cada elemento da LT.

Na Figura 33A, tem-se os valores obtidos de $R_{\Omega}$ (que corresponde a resistência total do sistema cuja contribuição vem da resistência da solução, do recobrimento óxido e dos contatos elétricos). Nota-se que os valores não variam com o potencial, a variação em relação a composição ocorre devido a distância do eletrodo de trabalho e o eletrodo de referência como discutido anteriormente [84].

A Figura 33B apresenta os valores da resistência do filme, $R_{f}$, em função do potencial para todas as composições investigadas, pode-se observar, para ambos materiais, um aumento significativo dos valores em potenciais acima de 1,40 V vs. ERH, ou seja, na região da RDO, caso onde $R_{t c} \leq R_{f}$. Como discutido anteriormente, com o aumento do potencial e favorecimento da reação de desprendimento de oxigênio, o aumento dos valores de $R_{f}$ já seria esperado $[6,25]$. 

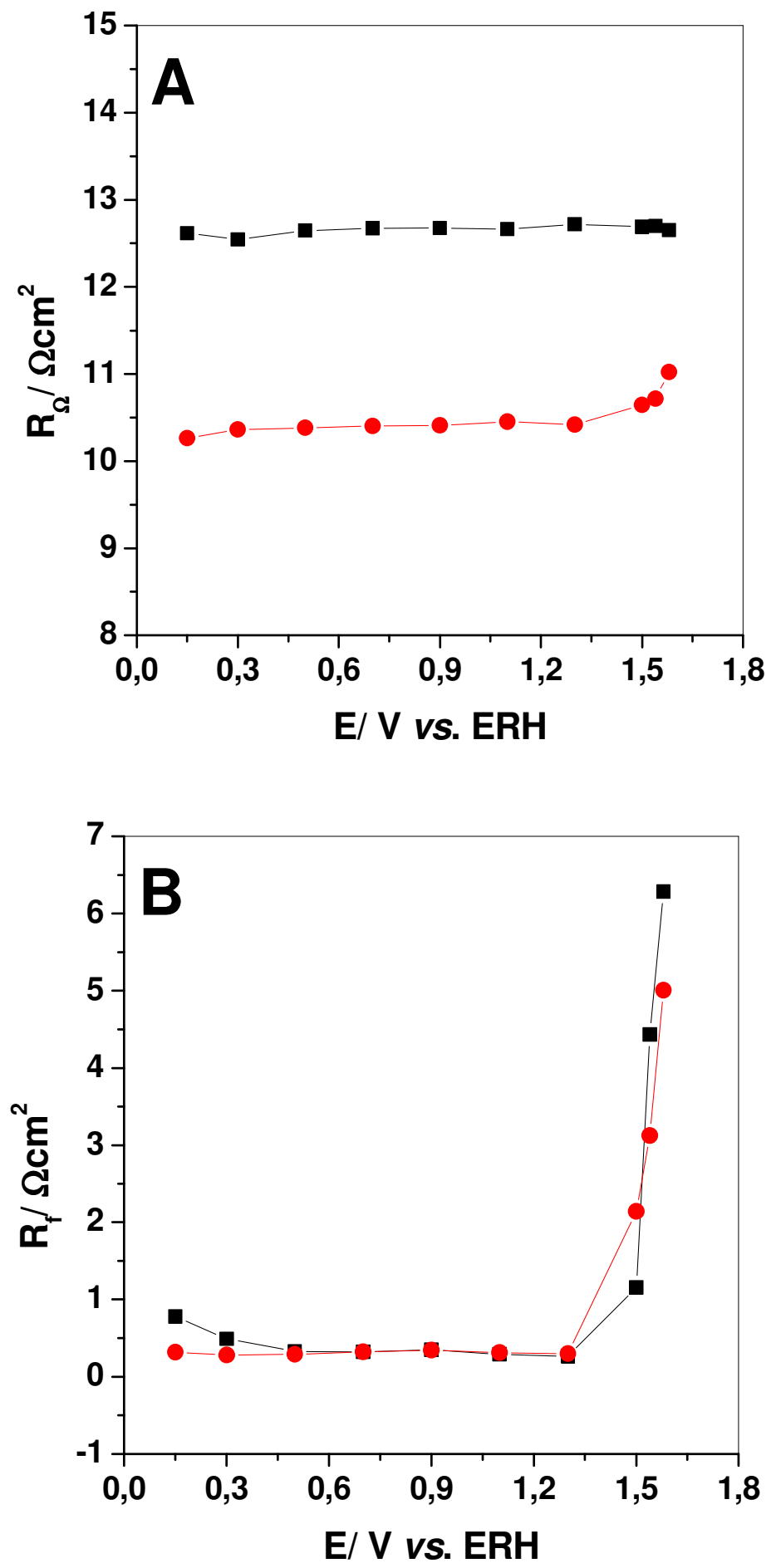

Figura 33: (A) Valores de $R_{\Omega}$ e $\quad$ (B) $r_{f}$ em função do potencial para: - $-\mathrm{Ti} / \mathrm{Ru}_{0,3} \mathrm{Ti}_{0,7} \mathrm{O}_{2} \mathrm{e}-\bullet-\mathrm{Ti} / \mathrm{Ru}_{0,3} \mathrm{Ti}_{0,7}+\mathrm{Pt} 100 \mu \mathrm{g} \mathrm{cm}{ }^{-2}$. 
Nas Figuras 34 estão apresentado os valores de capacitância da dupla camada elétrica $\left(Q_{d c}\right)$ para as duas composições investigadas. Nota-se que, o eletrodo com $100 \mu \mathrm{g}$ $\mathrm{cm}^{-2}$ de platina eletrodepositada apresentou os maiores valores de capacitância. Os valores de $\beta$ encontran-se entre 0,90 e 0,98 o que demonstra um comportamento próximo a uma capacitância ideal.
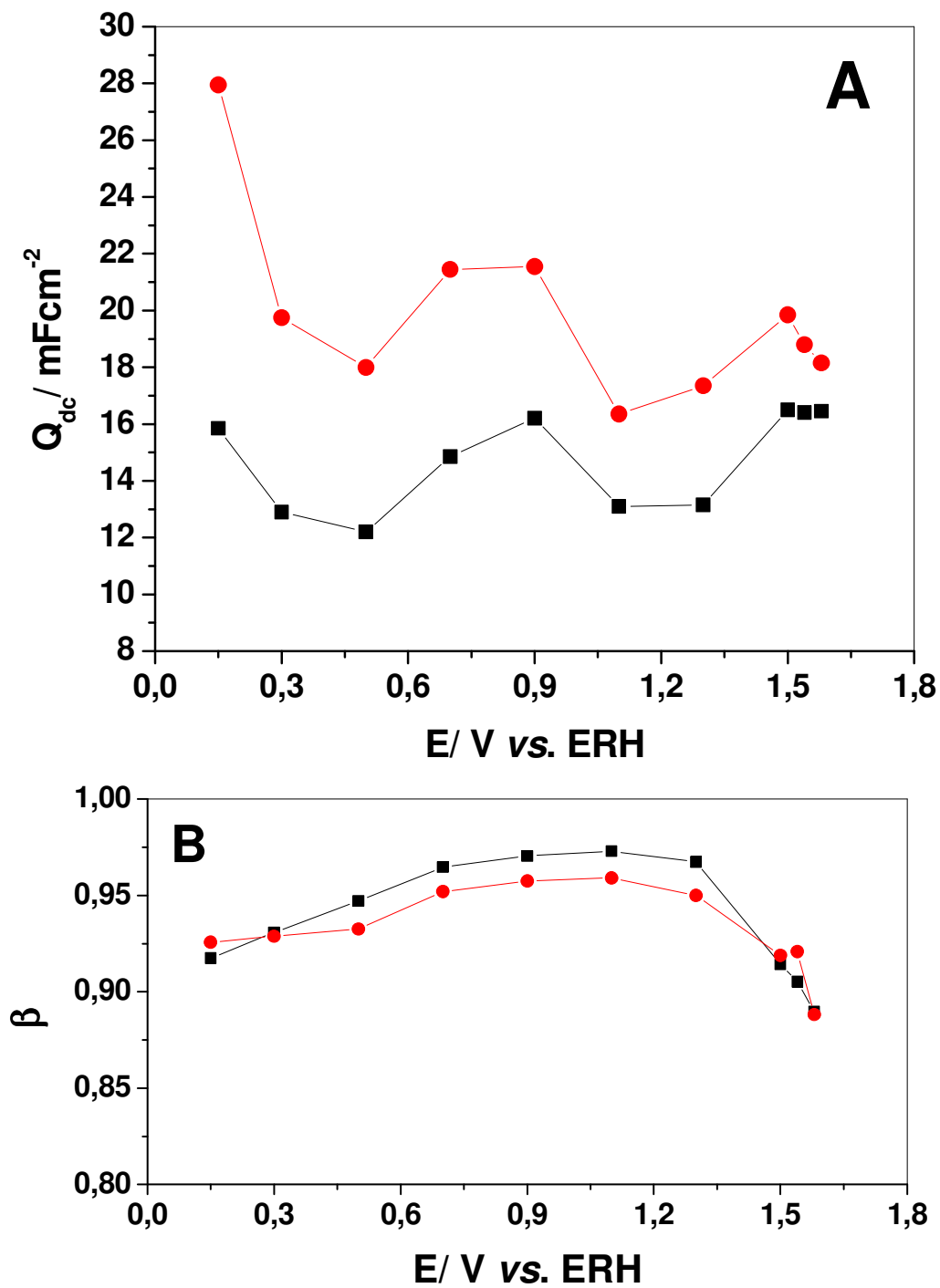

Figura 34: (A) Valores de $Q_{d c}$ e (B) $\beta$ em função do potencial para as diferentes composições investigadas. Sendo: $-\mathbf{-}-\mathrm{Ti} / \mathrm{Ru}_{0,3} \mathrm{Ti}_{0,7} \mathrm{O}_{2},-\longrightarrow-\mathrm{Ti} / \mathrm{Ru}_{0,3} \mathrm{Ti}_{0,7}+\mathrm{Pt} 100$ $\mu \mathrm{g} \mathrm{cm}^{-2}$. 
Na Figura 35 estão apresentados os valores da resitência à transferência de carga $\left(R_{t c}\right)$ para as duas composições eletródicas investigadas. Observa-se que, em valores menores de potencial (1,5 V vs. ERH), o ADE sem adição de platina é cerca de $15 \Omega \mathrm{cm}^{2}$ mais elevado que o ADE-Pt. Observa-se que a adição de platina na composição melhora ligeiramente a eficiência do eletrodo para a RDO. A medida que aumenta-se o potencial essa vantagem diminue, sendo que, em 1,575 $\mathrm{V}$ vs. ERH as atividades de ambas composições são equivalentes. Este resultado aparentemente está em desacordo com as análises de DEMS (Espectrometria de Massas Eletroquímica Diferencial) obtido por Forti et al. [65]. Estes autores calcularam a eficiênica de corrente para a RDO através da razão da corrente iônica $\left(i_{i}\right)$ e corrente faradáica $\left(i_{f}\right)$ e observaram que o ADE sem adição de platina apresentou maior atividade para a RDO. No entanto, deve-se salientar que a contribuição de efeito de área é um parâmetro crítico nesses estudos. Porém, os autores também observaram que, a adição de platina ao $\mathrm{ADE}$ de $\mathrm{Ti} / \mathrm{Ru}_{0,3} \mathrm{Ti}_{0,7} \mathrm{O}_{2}$ melhora sensivelmente sua eficiência na oxidação do acetaldeído e formação de $\mathrm{CO}_{2}$ [65].

Na seção IV.1.3 deste trabalho, foram apresentados os valores obtidos de $R_{t c}$ para o eletrodo de $\mathrm{Ti} / \mathrm{Ru}_{0,3} \mathrm{Sn}_{0,7} \mathrm{O}_{2}$, preparado pelo método de decomposição térmica de precursores poliméricos (ADE-P). De acordo com a Tabela 3, os valores de $R_{t c}$ para o ADE-P, acima de $1,5 \mathrm{~V}$ vs. ERH são menores que $3 \Omega \mathrm{cm}^{2}$. A Figura 35 mostra, claramente, que os valores de $R_{t c}$ obtidos para o eletrodo de $\mathrm{Ti}^{\mathrm{i}} / \mathrm{Ru}_{0,3} \mathrm{Ti}_{0,7} \mathrm{O}_{2}$ preparado por decomposição térmica tradicional (ADE-T), acima de $1,5 \mathrm{~V} v s$. ERH, são maiores que $10 \Omega \mathrm{cm}^{2}$. Este fato está de acordo com o observado anteriormente por Forti [190] e Ribeiro [196], na investigação de ADEs preparados por diferentes metodologias, onde foi 
observado que, os ADE-P apresentam melhor eficiência para a RDO se comparados a eletrodos de mesma composição preparados por decomposição térmica de cloretos. Novamente a EIE pode dar um valor mensurável, ou seja, uma análise quantitativa, para as observações qualitativas obtidas pela análise voltamétrica.

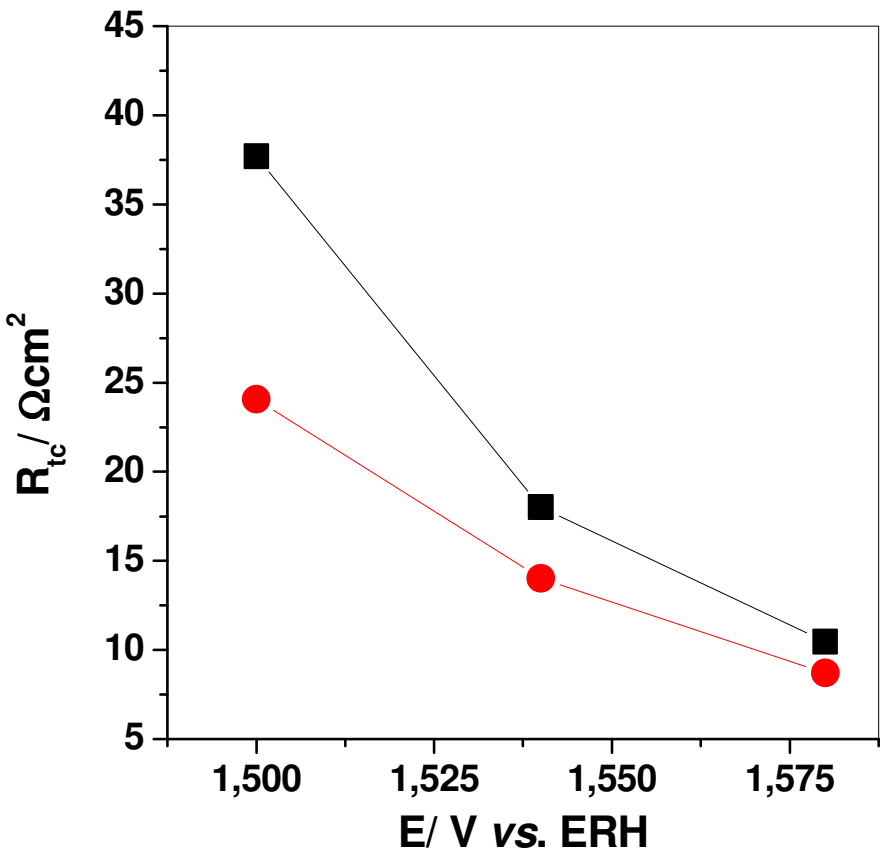

Figura 35: Valores de $R_{t c}$ em função do potencial para as diferentes composições investigadas. Sendo: - - $-\mathrm{Ti} / \mathrm{Ru}_{0,3} \mathrm{Ti}_{0,7} \mathrm{O}_{2},-\longrightarrow \mathrm{Ti} / \mathrm{Ru}_{0,3} \mathrm{Ti}_{0,7}+\mathrm{Pt} 100 \mu \mathrm{g} \mathrm{cm}{ }^{-2}$. 


\section{IV.2.2 Uma análise do modelo de poros aplicando-se um circuito equivalente (CE) e uma linha de transmissão (LT)}

Esta seção tem como objetivo apresentar os valores resistência a tranferência de carga obtidos para o eletrodo de $\mathrm{Ti} / \mathrm{Ru}_{0,3} \mathrm{Ti}_{0,7} \mathrm{O}_{2}$ com $100 \mu \mathrm{gcm}^{-2}$ de Pt eletrodepositada, na região da RDO. Os potenciais variam de 1,4 a 1,6 V vs. ERH e como apresentado na seção anterior os dados experimentais foram ajustados utilizando-se uma LT de acordo com a Figura 21. Posteriormente, os mesmo dados experimentais foram ajustados utilizando-se um circuito equivalente simples, apresentado na Figura 36. Este é formado por uma resistência ôhmica $\left(R_{\Omega}\right)$, a resistência de transferência de carga $\left(R_{t c}\right)$ e a capacitância da dupla camada elétrica representada por um $\operatorname{EFC}\left(Q_{d c}\right)$. Considerando que a região de interesse é a RDO, não foi adicionado ao circuito nenhum elemento referente a resistência do filme.

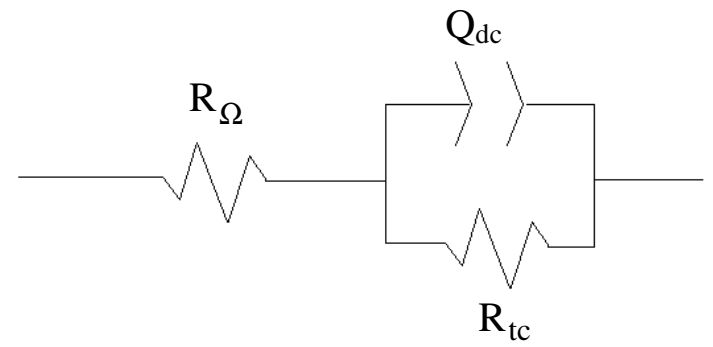

Figura 36: Circuito equivalente utilizado no ajuste dos dados experimentais do eletrodo de composição Ti/ $\mathrm{Ru}_{0,3} \mathrm{Ti}_{0,7}$ com $100 \mu \mathrm{gcm}^{-2}$ de Pt eletrodepositada, na região da RDO (entre $1,4$ a $1,6 \mathrm{~V} v s . \mathrm{ERH})$. 
Ambas análises apresentaram um ótimo ajuste para os dados experimentais, como pode ser observado tanto no digrama de Nyquist (Figura 37) como nos valores obtidos de $R_{t c}$ apresentados na Figura 38.

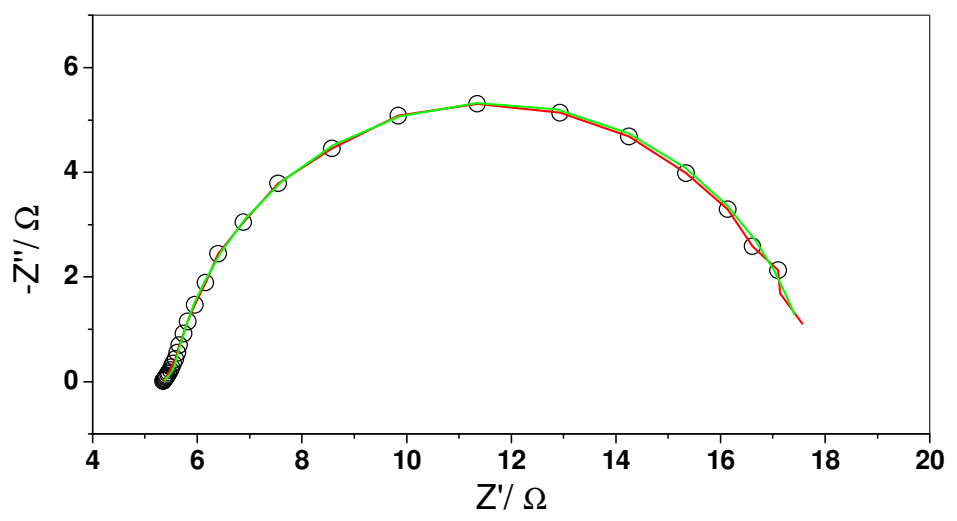

Figura 37: Diagrama de Nyquist do eletrodo de composição Ti/ $\mathrm{Ru}_{0,3} \mathrm{Ti}_{0,7}+\mathrm{Pt} 100 \mu \mathrm{gcm}^{-2}$ em $\mathrm{E}=1,50 \mathrm{~V}$ vs. ERH. Sendo: $\bigcirc$ dados experimentais, — ajuste de acordo com o CE da Figura 37 e ——ajuste de acordo com a LT da Figura 22.

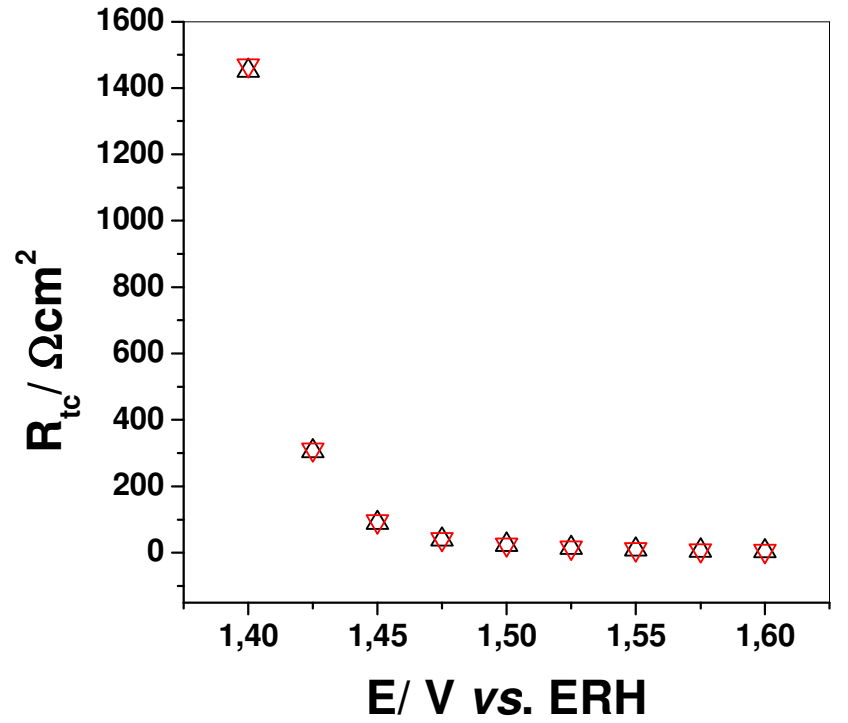

Figura 38: Valores de $R_{t c}$ em função do potencial para o eletrodo de composição $\mathrm{Ti} / \mathrm{Ru}_{0,3} \mathrm{Ti}_{0,7}+\mathrm{Pt} 100 \mu \mathrm{gcm}^{-2}$ em E = 1,50 V vs. ERH. Sendo: $\triangle$ valores obtido a partir do ajuste com o $\mathrm{CE}$ e $\nabla$ valores obtido a partir do ajuste com a LT. 
Como apresentado na introdução deste trabalho, o modelo de poros de Levie pode ser empregado de acordo com diferentes abordagens, por exemplo aplicando-se uma LT ou um CE no ajuste dos dados experimentais, sendo estas abordagens equivalentes. Fato esse comprovado nesta seção. A abordagem de LT possui a vantagem de ser capaz de representar o sistema em diferentes intervalos de potencial a partir de uma única linha contendo sempre os mesmo elementos [16, 25]. Por outro lado, dependo dos objetivos experimentais a abordagem de CE torna-se mais simples de ser utilizada, pois nos fornece valores gerais dos elementos de interesse, ou seja, não estão relacionados ao comprimento do poro como os elementos distribuídos na LT.

\section{IV.2.3- EIE e Tafel para o eletrodo de $T \mathbf{T i} / \mathrm{Ru}_{0,3} \mathrm{Ti}_{0,7} \mathrm{O}_{2}+100 \mu \mathrm{gcm}^{-2} \mathrm{de} \mathbf{P t}$ eletrodepositada}

O eletrodo de composição $\mathrm{Ti} / \mathrm{Ru}_{0,3} \mathrm{Ti}_{0,7} \mathrm{O}_{2}+\mathrm{Pt}\left(100 \mu \mathrm{gcm}^{-2}\right)$, apresentou os melhores valores de EIE na região da RDO, ou seja, os menores valores de $R_{t c}$. Este eletrodo foi então utilizado para o estudo das curvas de polarização de Tafel com o objetivo de comparar os valores das curvas i vs. E obtidas através das duas técnicas: $a c$ (EIE) e $d c$ (Tafel). O diagrama de Tafel com correção para queda ôhmica obtido, pode ser observado na Figura 39.

Os valores de coeficiente de Tafel obtidos foram: em baixos sobrepotenciais $b=40 \mathrm{~m} / \mathrm{vdec}^{-1}$ e em altos sobrepotenciais $b=114 \mathrm{mVdec}^{-1}$. De acordo com a 
Tabela 4, apresentada anteriormente, pode-se propor, de acordo com o modelo eletroquímica que as etapas determinantes da reação são dadas por:

- Em baixos sobrepotenciais $\left(b=40 \mathrm{~m} / \mathrm{vdec}^{-1}\right)$

$$
\equiv S-O H \rightarrow \equiv S-O+H^{+}+e^{-}
$$

- Em altos sobrepotenciais $\left(b=114 \mathrm{mVdec}^{-1}\right)$

$$
\equiv \mathrm{S}+\mathrm{H}_{2} \mathrm{O} \rightarrow \equiv \mathrm{S}-\mathrm{OH}+\mathrm{H}^{+}+e^{-}
$$

De acordo com o discutido anteriormente (seção IV.1.3), onde foi obtido o mesmo valor do coeficiente de Tafel para o ADE de composição Ti/ $\mathrm{Ru}_{0,3} \mathrm{Sn}_{0,7} \mathrm{O}_{2}$, comparando-se com o resultado obtido para o eletrodo de composição $\mathrm{Ti} / \mathrm{Ru}_{0,3} \mathrm{Ti}_{0,7} \mathrm{O}_{2}+\mathrm{Pt}\left(100 \mu \mathrm{gcm}^{-2}\right)$, pode-se concluir que, a adição de pequena quantidade de platina na composição do eletrodo, bem como a metodologia de preparação do eletrodo, não alteram o mecanismo de reação para a RDO. 


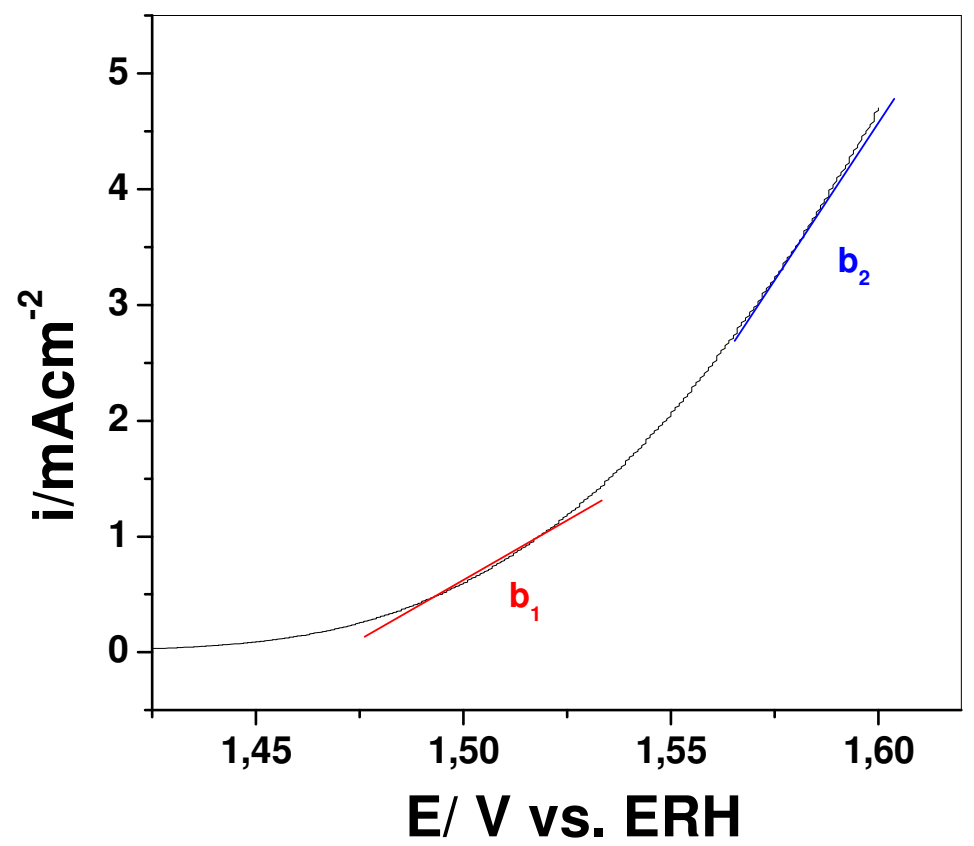

Figura 39: Curvas de polarização de Tafel do eletrodo de composição $T i / \mathrm{Ru}_{0,3} \operatorname{Ti}_{0,7} \mathrm{O}_{2}+\mathrm{Pt}$ $\left(100 \mu \mathrm{g} \mathrm{cm}^{-2}\right)$ com $v=56 \mu \mathrm{V} \mathrm{s}^{-1}$. Sendo: $b_{1}=40 \mathrm{~m} / \mathrm{vdec}^{-1} \mathrm{e} b_{2}=114 \mathrm{mVdec}^{-1}$.

Foram também realizadas novas medidas de EIE para o eletrodo $\mathrm{Ti} / \mathrm{Ru}_{0,3} \mathrm{Ti}_{0,7} \mathrm{O}_{2}+\mathrm{Pt}$ (100 $\left.\mu \mathrm{g} \mathrm{cm}^{-2}\right)$, em intervalos menores de potenciais localizados na região da RDO, entre 1,4 - 1,8 V vs. ERH. Aplicando a LT descrita na Figura 21, foram extraídos os valores de resistência de transferência de carga $\left(R_{t c}\right)$. Uma vez obtidos os valores de $R_{t c}$, foram calculados os valores de corrente correspondentes de acordo com a Equação de ButlerVolmer, discutida na seção IV.1.3 (Equações 41 e 45). Os valores de corrente obtidos através da aplicação do modelo de poros (EIE) e Tafel $(d c)$ seguem o mesmo comportamento, como pode ser observado na Figura 40 . 


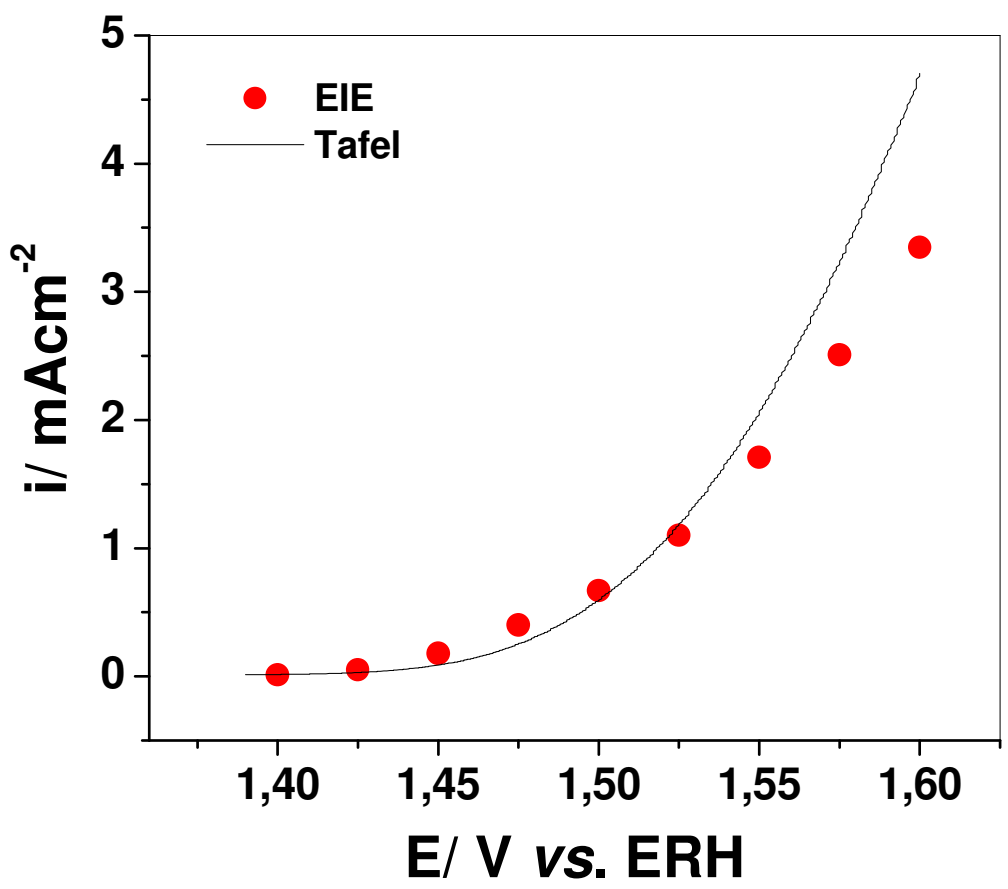

Figura 40: Curva de polarização de Tafel do eletrodo de composição $\mathrm{Ti} / \mathrm{Ru}_{0,3} \mathrm{Ti}_{0,7} \mathrm{O}_{2}+\mathrm{Pt}$ $\left(100 \mu \mathrm{g} \mathrm{cm}^{-2}\right)$ com $v=56 \mu \mathrm{V} \mathrm{s}^{-1}$. E os valores de i calculados a partir dos valores de $R_{t c}$, que foram obtidos por EIE.

Observa-se na Figura 40 que, com o aumento do potencial, acima de 1,55 V vs. ERH, os valores de $i$ obtidos a partir da $R_{t c}$, deslocam da curva de Tafel. Este fato pode ser explicado devido ao aumento de potencial favorecer a RDO, a forte liberação de gás (presença de bolhas), bloqueia os sítios ativos do material, de modo a interferir nos valores de $R_{t c}$ em altos sobrepotenciais [25]. 


\section{IV.2.4 Conclusões}

Foi observado nesta seção que, a análise dos resultados experimentais de EIE para eletrodos do tipo de ADEs, com ou sem adição de platina, pode ser realizada utilizado-se uma LT ou um CE para ajustar os valores experimentais, de acordo com o modelo de poros, pois ambas abordagens são equivalentes.

Quando comparados os valores obtidos de $R_{t c}$ para o eletrodo de $\mathrm{Ti} / \mathrm{Ru}_{0,3} \mathrm{Sn}_{0,7} \mathrm{O}_{2}$ (ADE-P) e o eletrodo de $\mathrm{Ti} / \mathrm{Ru}_{0,3} \mathrm{Ti}_{0,7} \mathrm{O}_{2}$ (ADE-T), foram confirmados os resultados já apresentados na literatura $[190,196]$, que demonstram que os ADE-P apresentam melhor eficiência para a RDO em relação a eletrodos de ADE-T.

O eletrodo De $\mathrm{Ti} / \mathrm{Ru}_{0,3} \mathrm{Ti}_{0,7} \mathrm{O}_{2}$ com $100 \mu \mathrm{g} \mathrm{cm}{ }^{-2}$ de platina eletrodepositada apresentou os maiores valores de capacitância, quando comparado ao ADE sem adição de platina. Conseqüentemente, obteve-se os menores de resistência à transferência de carga para esta composição. Foi observado que os valores de $R_{t c}$ diminuem a medida que aumenta-se o potencial no sentido da RDO. Os valores de corrente obtidos através da aplicação do modelo de poros (EIE) e Tafel $(d c)$ seguem o mesmo comportamento, exceto em altos sobrepotenciais, devido ao deprendimento de gás oxigênio que bloqueia os sítios ativos do material, concluindo então, a relação entre o comportamento $a c$ e $d c$ do sistema. 


\section{IV.3 Investigação dos eletrodos de composição Pt, Pt:Sn (80:20), Pt:Ru (80:20) e Pt:Ru:Sn (80:10:10) na presença de etanol}

\section{IV.3.1 MEV e EDX}

A técnica de Microscopia Eletrônica de Varredura (MEV) foi utilizada para verificar variações na morfologia com a composição. A caracterização por análise de Espectrometria de Energia Dispersiva de Raios-X (EDX), Tabela V, foi utilizada, acoplada à $\mathrm{MEV}$, para a determinação qualitativa e semi-quantitativa dos elementos constituintes das amostras. De acorco com a Figura 41, todas as composições eletródicas apresentaram superfície relativamente homogênea, sem grandes fendas ou rachaduras. A estrutura barrorachado é características do tratamento térmico adotado na preparação dos eletrodos. O eletrodo de Ti/Pt:Ru apresenta regiões com a típica estrutura de barro-rachado características de ânodos contendo Ru na composição [36].

TABELA V: Composições nominais e experimentais (\% atômica ) obtidas na análise de EDX dos eletrodos de composição Ti/Pt, Ti/Pt:Ru, Ti/Pt:Sn e Ti/Pt:Ru:Sn. $\quad \mathrm{T}_{\text {calc. }} \quad 450^{\circ} \mathrm{C}$, espessura nominal $=1 \mu \mathrm{m}$.

\begin{tabular}{|c|c||c|c||c|c||}
\hline $\begin{array}{c}\mathrm{Pt} \\
\text { nominal }\end{array}$ & $\begin{array}{c}\mathrm{Pt} \\
\text { exp. }\end{array}$ & $\begin{array}{c}\mathrm{Ru} \\
\text { nominal }\end{array}$ & $\begin{array}{c}\mathrm{Ru} \\
\text { exp. }\end{array}$ & $\begin{array}{c}\mathrm{Sn} \\
\text { nominal }\end{array}$ & $\begin{array}{c}\mathrm{Sn} \\
\text { exp. }\end{array}$ \\
\hline \hline 80 & 78,9 & 20 & 21,1 & - & - \\
\hline 80 & 81,1 & - & - & 20 & 18,9 \\
\hline 80 & 74,5 & 10 & 12,2 & 10 & 13,3 \\
\hline
\end{tabular}


(a)

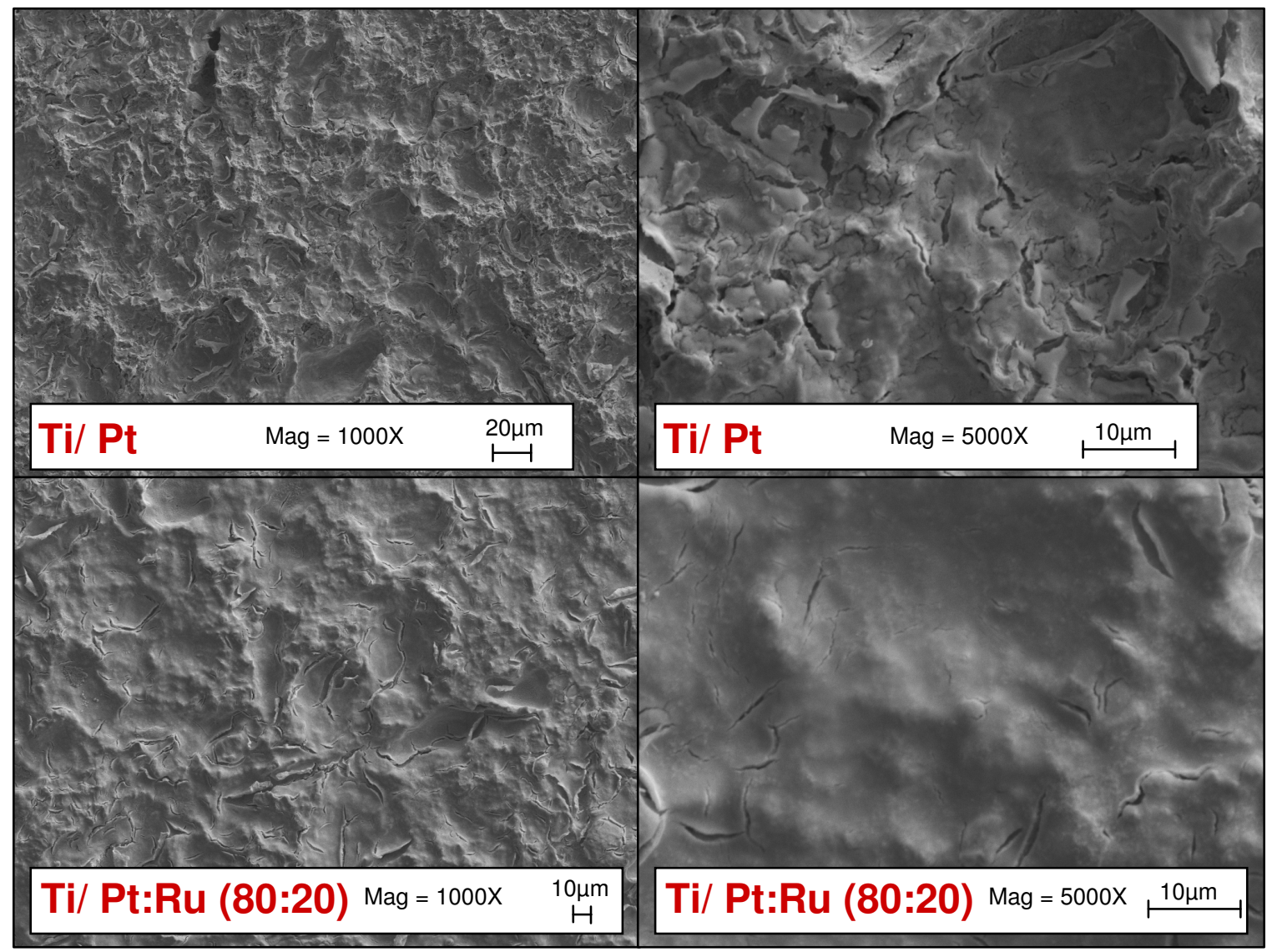

Figura 41a: Micrografias representativas dos eletrodos de composição Ti/Pt e Ti/Pt:Ru $(80: 20)$. Mag $=1000$ e 5000 vezes. EHT $=15000 \mathrm{~V}$. 
(b)

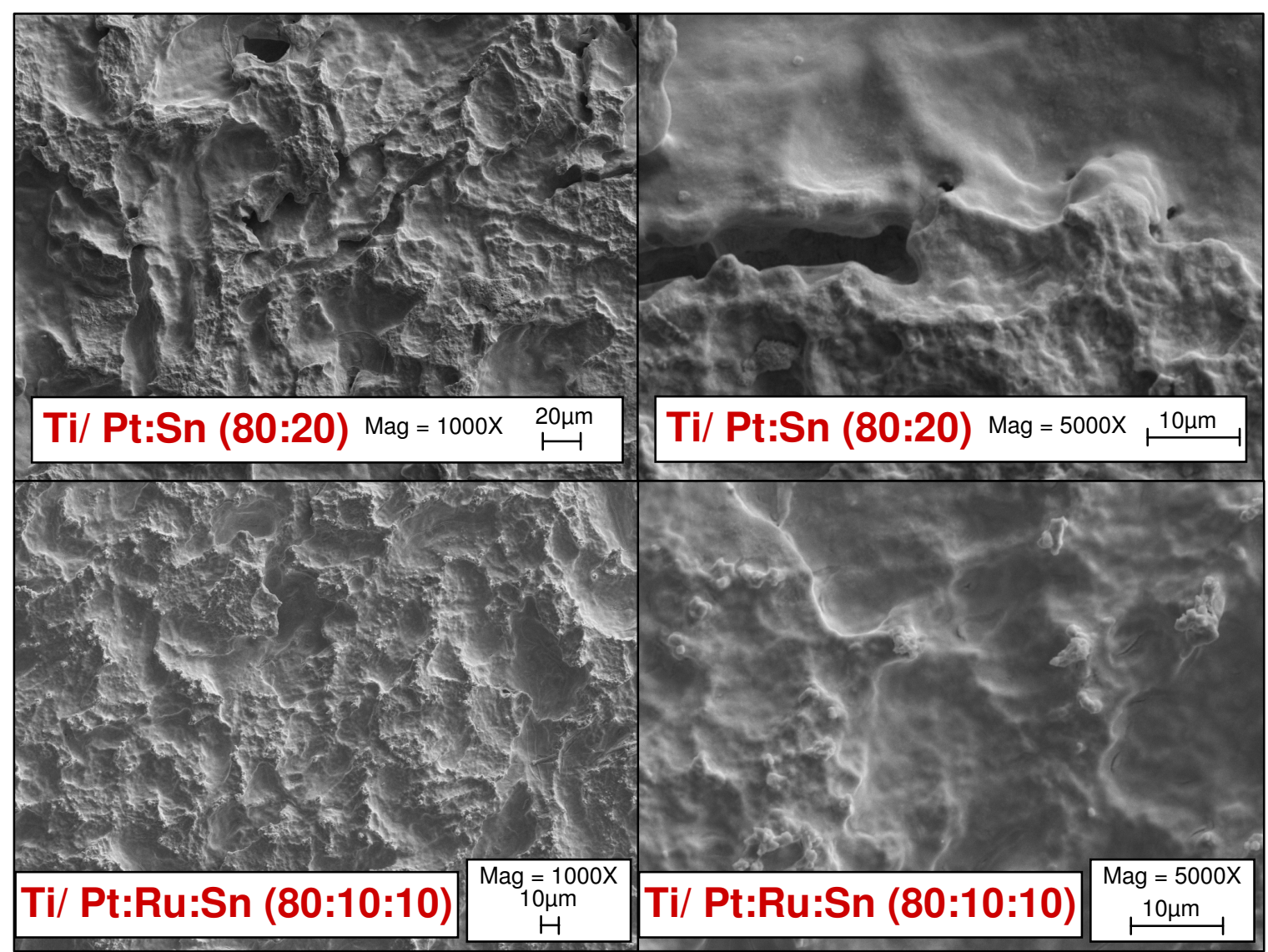

Figura 41b: Micrografias representativas dos eletrodos de composição Ti/Pt:Sn (80:20) e Ti/Pt:Ru:Sn (80:10:10). Mag = 1000 e 5000 vezes. EHT = $15000 \mathrm{~V}$. 
A análise da Tabela 5 mostra, para todas as composições eletródicas preparadas, que a composição nominal e experimental apresenta valores concordantes, demonstrando que a metodologia de decomposição térmica dos precursores poliméricos é adequada para a preparação desses materiais, ou seja, não se verifica perda relacionada à evaporação dos constituintes durante o processo de calcinação $\left(T=450^{\circ} \mathrm{C}\right)$. Principalmente em relação ao conteúdo de estanho que, dependendo do método térmico empregado, o sal precursor apresenta evaporação acentuada acima de $114{ }^{\circ} \mathrm{C}$ [197, 198]. Resultados similares já haviam sido obtidos quando se preparou eletrodos óxidos de PtSn [120] e PtSnIr [121], onde foram observadas a presença de concentrações de Pt e Sn bem próximas as nominais.

Na Figura 42 é apresentado a análise de EDX em linha do eletrodo de composição Ti/Pt:Ru:Sn (80:10:10), podemos observar que toda a superfície do eletrodo analisada, contêm platina distribuída uniformemente. As regiões mais escuras da micrografia apresentam uma concentração maior de estanho, já as regiões mais claras apresentam maior concentração de rutênio. O titânio presente no suporte, pode ser observado nas regiões onde existem fendas mais profundas capazes de atingir o substrato de titânio. 
a) $\mathrm{Ti}$
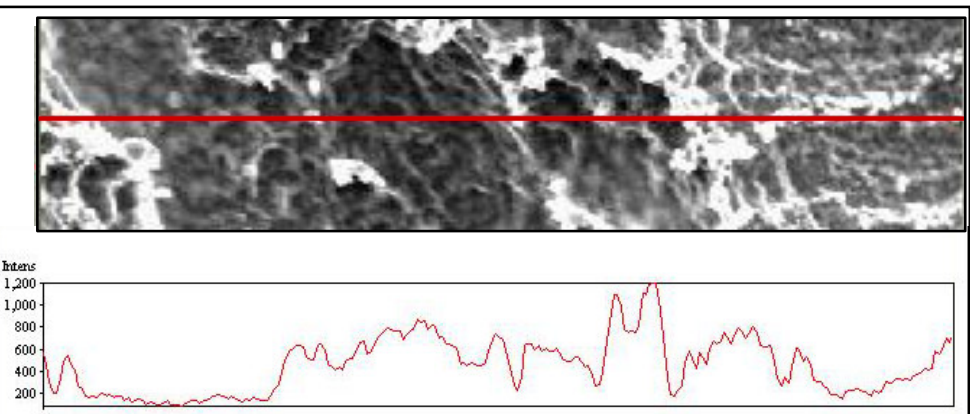

b) $\mathrm{Ru}$

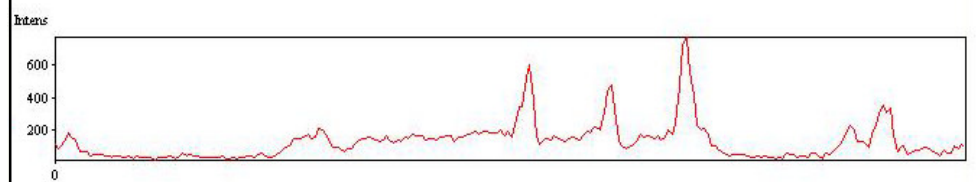

c) $\mathrm{Sn}$

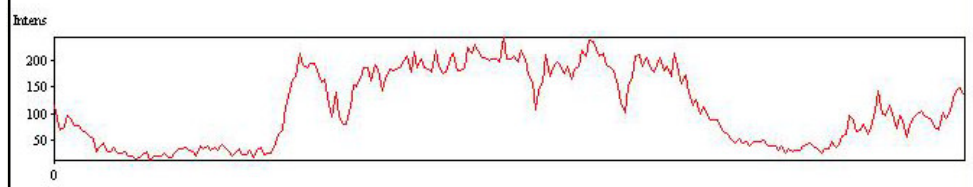

d) $\mathrm{Pt}$

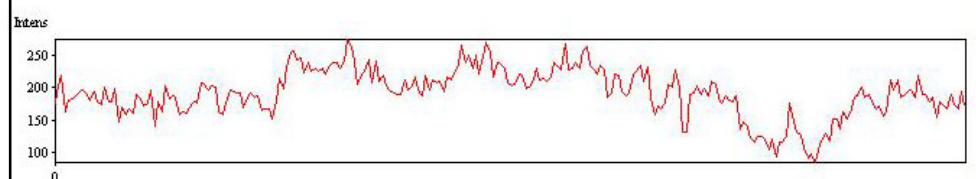

Figura 42: Micrografia do eletrodo de composição Ti/Pt:Ru:Sn (80:10:10), com a análise de EDX em linha. 


\section{IV.3.2 Voltametria $d c$ e capacitância da dupla camada elétrica}

A Figura 43 apresenta os voltamogramas cíclicos registrados em eletrólito de $\mathrm{H}_{2} \mathrm{SO}_{4}$ $0,5 \mathrm{~mol} \mathrm{dm}^{-3}$. É importante salientar que, o intervalo de potencial utilizado para os estudos variou com a composição do material investigado. Assim, eletrodos contendo Sn na composição a faixa de potencial investigada foi de 0 a $0,7 \mathrm{~V} v s$. ERH, e para o eletrodo contendo Ru o potencial foi varrido entre 0 e 0,9 V vs. ERH [199]. Esta precaução deve-se ao cuidado da formação de óxido de estanho em potenciais mais positivos e possível dissolução do recobrimento.

Na Figura 43a, podemos observar o comportamento característico da platina e seus picos bem definidos, devido a presença de uma maior concentração de platina na composição, ao contrário do apresentado anteriormente ao adicionarmos platina por eletrodeposição na superfície do ADE. Neste caso, pode-se observar claramente a região do hidrogênio ( 0 a $0,3 \mathrm{~V} v s$. ERH), a região da dupla camada elétrica (entre 0,3 e $0,7 \mathrm{~V} v s$. ERH) e por fim a região de oxidação e redução dos óxidos de platina (acima de $0,7 \mathrm{~V} v s$. ERH) [200].

A Figura 43b apresenta os voltamogramas das demais composições investigadas, nestes casos, mesmo na presença de platina, esse comportamento sofre alterações devido a presença de Ru e/ou Sn. Os picos da região de adsorção/dessorção de hidrogênio perdem a definição devido aos picos de transição redox destes materiais.

Em relação a carga capacitiva, podemos observar uma diminuição com a adição de estanho: Ti/Pt:Ru (80:20) > Ti/ Pt:Ru:Sn(80:10:10) > Ti/ Pt:Sn (80:20), este resultado está em desacordo com dados obtidos para eletrodos de mesma composição, depositado sobre 
partículas de carbono Vulcan, onde foram observadas maiores cargas capacitivas para os eletrodos trimetálicos (Pt:Ru:Sn) [201].
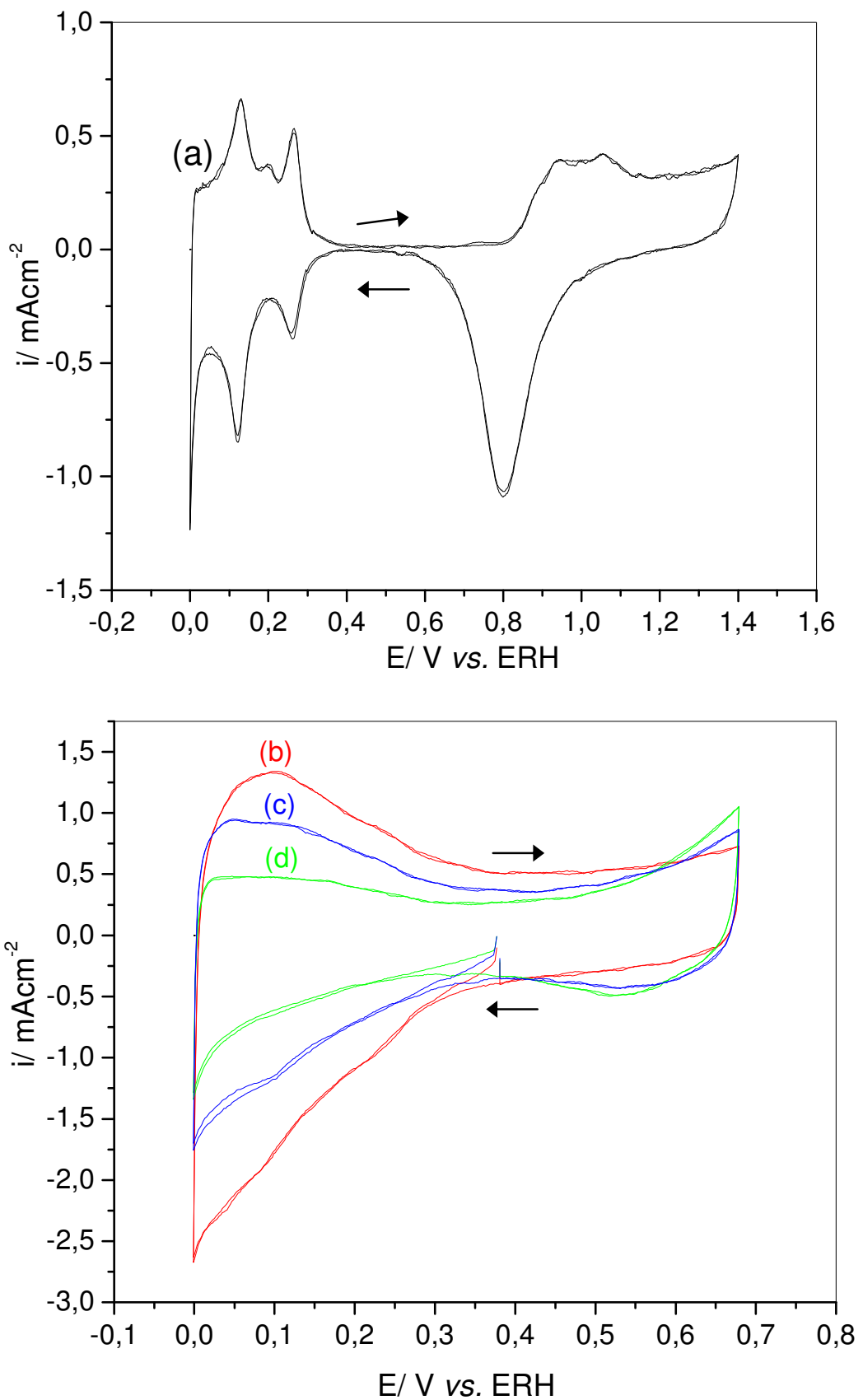

Figura 43: Voltamogramas cíclicos representativos dos eletrodos Ti/PtRuSn em eletrólito suporte: $\left(\mathrm{H}_{2} \mathrm{SO}_{4}\right.$ 0,5 mol dm$\left.{ }^{-3}\right)$. (a) Ti/Pt; (b) Ti/Pt:Ru (80:20); (c) Ti/Pt:Sn:Ru (80:10:10) e (d) Ti/Pt:Sn (80:20); $v=10 \mathrm{mVs}^{-1}$ 


\section{IV.3.2.1 Determinação da capacitância da dupla camada elétrica em eletrólito de suporte $\left(\mathrm{H}_{2} \mathrm{SO}_{4} 0,5 \mathrm{~mol} \mathrm{dm}^{-3}\right)$}

Primeiramente, os eletrodos foram hidratados por voltametria cíclica em solução de $\mathrm{H}_{2} \mathrm{SO}_{4} 0,5 \mathrm{~mol} \mathrm{dm}{ }^{-3}$, em diferentes velocidades de varredura: $50 ; 20$ e $10 \mathrm{mVs}^{-1}$, no intervalo de potencial referente ao carregamento da dupla camada elétrica de acordo com a composição em questão (Figura 44).

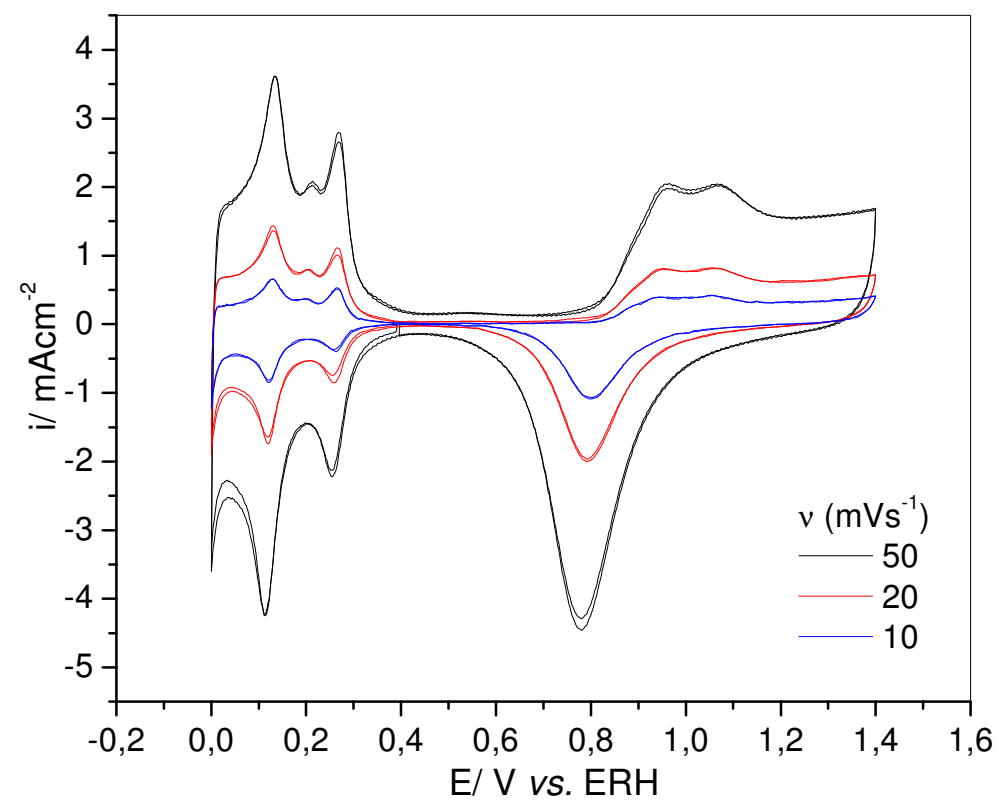

Figura 44: Voltamogramas cíclicos representativos do eletrodo de composição Ti/Pt em diferentes velocidades de varredura em $\mathrm{H}_{2} \mathrm{SO}_{4} 0,5 \mathrm{~mol} \mathrm{dm}^{-3}$.

Após o registro dos voltamogramas cíclicos, foram realizadas medidas de EIE em potenciais referentes a região de carregamento da dupla camada elétrica $(0,25-0,65 \mathrm{~V} v s$. ERH). Nota-se pelo diagrama de Nyquist que, as curvas não variam de acordo com o potencial (Figura 45a) ou a composição (Figura 45b). Apenas pode-se observar uma 
pequena inclinação na reta, ou seja, um ângulo de fase inferior a $90^{\circ}$, que ocorre devido a porosidade destes materiais [202]. Nestes diagramas pode-se observar 2 regiões distintas de frequências:

(i) em regiões de altas frequiências: pode-se constatar a presença de um elemento indutor (que será desconsiderado na análise dos resultados apresentada posteriormente);

(ii) região de frequências intermediárias: pode-se extrair a capacitância da dupla camada elétrica;
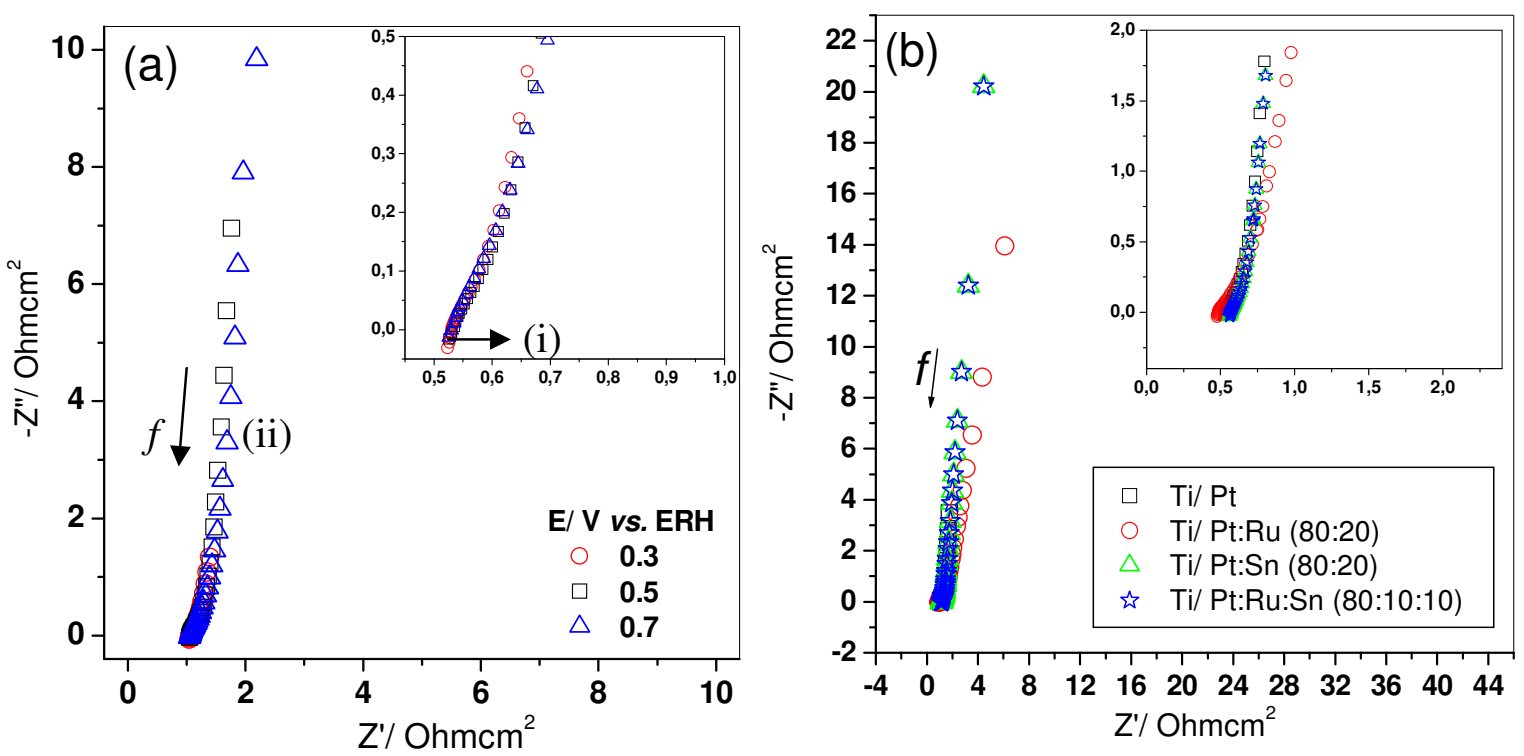

Figura 45: Diagramas de Nyquist em $\mathrm{H}_{2} \mathrm{SO}_{4} 0,5 \mathrm{~mol} \mathrm{dm}^{-3}$, de 1 a $10 \mathrm{kHz}$ e $5 \mathrm{mV}$ de amplitude. (a) Ti/Pt em diferentes potenciais (b) Diferentes composições eletródicas em 0,5 V vs. ERH.

Os espectros de EIE registrados nos potenciais entre 0,30 e 0,65 V vs. ERH em meio de eletrólito de suporte $\left(\mathrm{H}_{2} \mathrm{SO}_{4} 0,5 \mathrm{~mol} \mathrm{dm}^{-3}\right)$ foram empregados para o cálculo da capacitância da dupla camada elétrica, $Q_{d c}$. No ajuste das curvas experimentais foram utilizadas apenas as regiões de frequências intermediárias $(\sim 10-100 \mathrm{~Hz})$ onde se observa o 
comportamento capacitivo do sistema. Utilizou-se um circuito equivalente simples, formado apenas por uma resistência e a capacitância da dupla camada elétrica $\left(Q_{d c}\right)$ em série, apresentado na Figura 46b.

Os valores obtidos de $Q_{d c}$ são mostados na Figura 46a. Nota-se que, os eletrodos de Ti/Pt, Ti/Pt:Ru (80:20) e Ti/Pt:Ru:Sn (80:10:10) apresentam valores similares de $Q_{d c}$, já o eletrodo contendo Ti/Pt:Sn (80:20) na sua composição apresenta os menores valores de $Q_{d c}$. Este resultado é coerente com o observado na voltametria cíclica (Figura 43b), onde o eletrodo de Ti/Pt:Sn (80:20) apresentou o menor valor de carga, portanto, menor valor de capacitância.

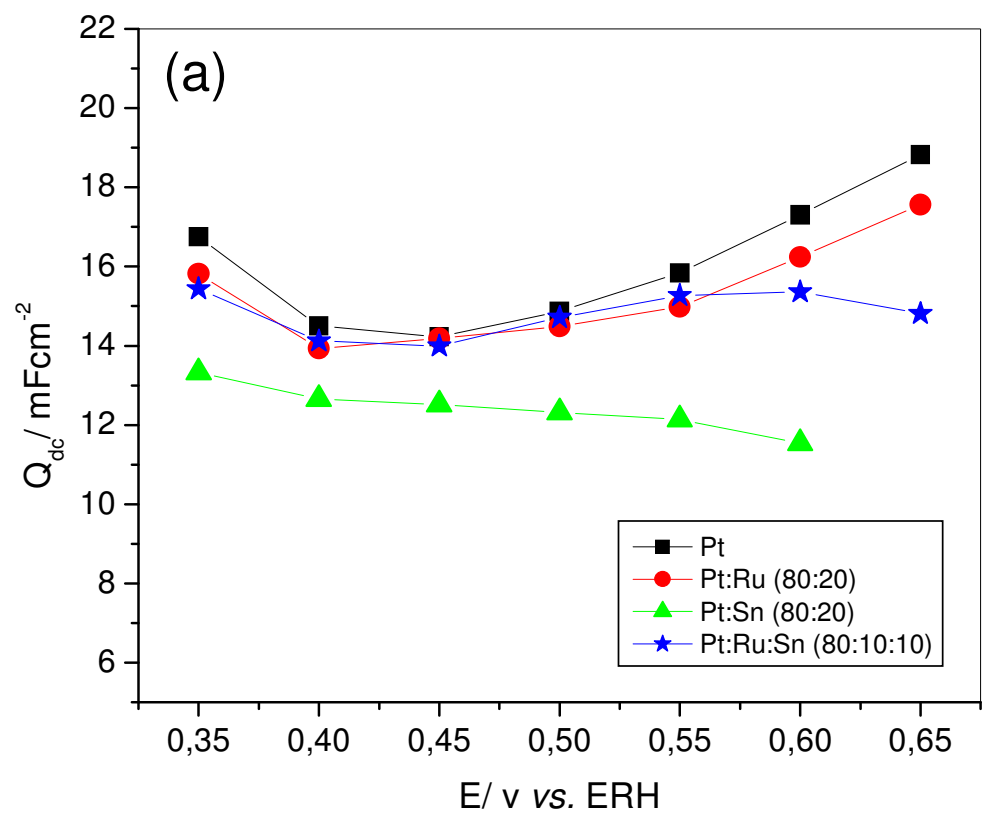

(b)

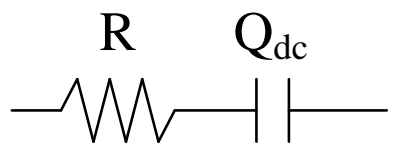

Figura 46: (a) Valores de $Q_{d c}$ calculados em função do potencial para as diferentes composições eletródicas investigadas em $\mathrm{H}_{2} \mathrm{SO}_{4} 0,5 \mathrm{~mol} \mathrm{dm}^{-3}$. (b) Circuito elétrico utilizado para ajustar os dados experimentais e extrair os valores de $Q_{d c}$. 


\section{IV.3.2.2 Determinação da capacitância da dupla camada elétrica na presença de etanol (1 mol dm $\left.\mathbf{~ d m}^{-3}\right)$}

Foram registrados voltamogramas cíclios na presença de etanol $\left(1 \mathrm{~mol} \mathrm{dm}^{-3}\right) \mathrm{em}$ $\mathrm{H}_{2} \mathrm{SO}_{4}$ 0,5 mol dm${ }^{-3}$, apresentados na Figura 47. Podemos observar que o potencial de início da oxidação do etanol varia com a composição eletródica. No caso do eletrodo de Pt, Figura 47a, observa-se os picos bem definidos. A oxidação do etanol se inicia em aproximadamente $0,65 \mathrm{~V} v s$. ERH. Na varredura no sentido positivo de potencial, observase um pico de oxidação em $0,9 \mathrm{~V} v s$. ERH, decorrente da adsorção do etanol na superfície da platina. Já na varredura no sentido negativo, observa-se o pico em aproximadamente $0,75 \mathrm{~V}$ vs. ERH decorente do processo que reativa a superfície do metal, resultando em um pico anódico que indica a reação de re-oxidação de etanol. O processo é chamado de reativação da superfície ou corrente de re-adsorção e ocorre com a maioria das pequenas moléculas orgânicas em eletrodos do grupo da Pt, onde há uma forte interação entre a molécula orgânica e o sítio ativo [203].

O segundo pico observado na varredura no sentido positivo de potencial, em 1,3 V vs. ERH, está relacionado com a oxidação de etanol a substâncias menos oxidadas, tais como o acetaldeído e ácido acético.

Nas demais composições eletródicas, contendo Sn e/ou Ru, Figuras 47b, c e d, não se observa picos definidos como no caso da Pt, mas pode-se observar o potencial de início da eletrooxidação do etanol é função do material eletródico. 

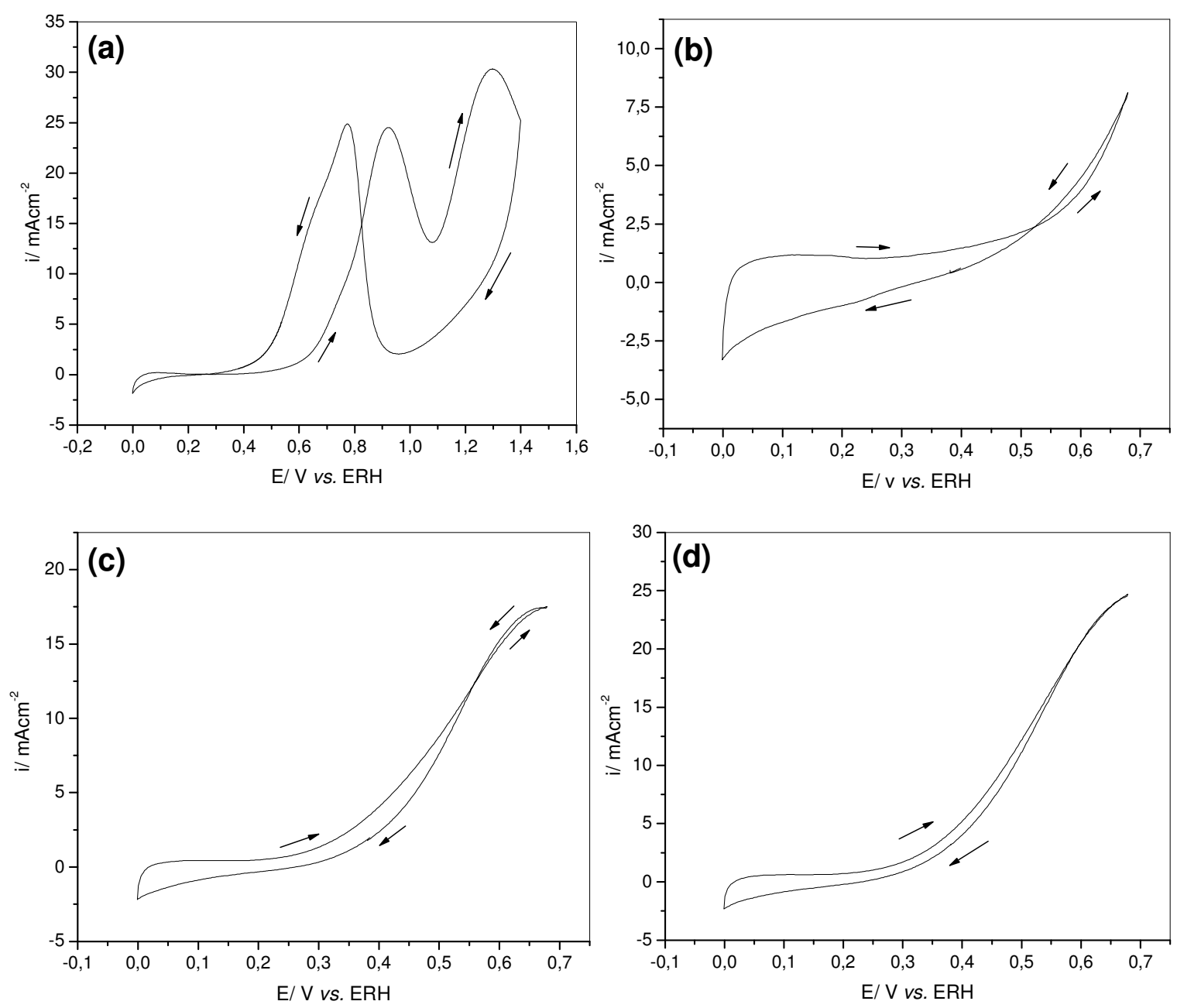

Figura 47: Voltamogramas (curvas anódicas) representativos dos eletrodos Ti/PtRuSn na presença de etanol $\left(1 \mathrm{~mol} \mathrm{dm}^{-3}\right)$. ES $=\mathrm{H}_{2} \mathrm{SO}_{4} 0,5 \mathrm{~mol} \mathrm{dm}^{-3}, v=10 \mathrm{mVs}^{-1}$.

Para melhor visualizar esse efeito da composição na eletrólise do etanol, é apresentada a Figura 48. Nota-se que, o eletrodo de Pt:Sn apresentou um melhor comportamento para eletrólise do etanol, pois tem-se o início da eletrooxidação em um potencial menor que os demais eletrodos. Sendo que, todos os eletrodos apresentaram comportamento melhor que o eletrodo de Pt. O mesmo comportamento foi observado para 
eletrodos com Pt:Sn:Ir [121]. Neste caso, a reação de oxidação do etanol ativada, para eletrodos binários e ternários, apresentaram melhores resultados que o eletrodo de Pt. No estudo de eletrodos de Pt:Sn em diferentes concentrações, na eletrólise de etanol, também foi observado um deslocamento do potencial de oxidação em função da composição, e o eletrodo com a mesma composição apresentada neste relatório Pt:Sn (80:20) apresentou resultados semelhantes aos apresentados aqui para a oxidação de etanol [120].

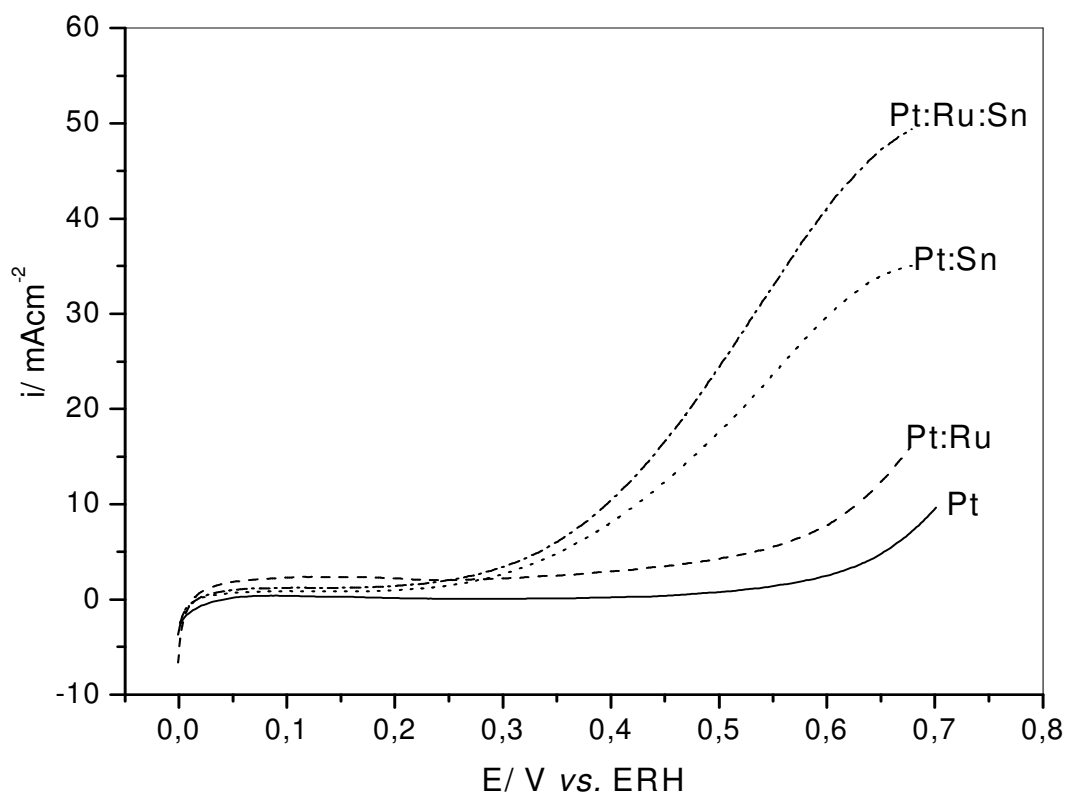

Figura 48: Voltamogramas cíclicos representativos dos eletrodos Ti/PtRuSn na presença de etanol $\left(1 \mathrm{~mol} \mathrm{dm}^{-3}\right)$. ES $=\mathrm{H}_{2} \mathrm{SO}_{4} 0,5 \mathrm{~mol} \mathrm{dm}^{-3}, v=10 \mathrm{mVs}^{-1}$ : (a) Ti/Pt (b) Ti/Pt:Ru (80:20) (c) Ti/Pt:Sn (80:20) e (d) Ti/Pt:Sn:Ru (80:10:10).

Para a obtenção dos valores de capacitância da dupla camada elétrica na presença de etanol, foi realizado o mesmo procedimento de EIE, os diagramas de Nyquist obtidos estão apresentados na Figuras 49. Para calcular a $Q_{d c}$ foram considerados apenas os valores de frequiências intermediárias como na seção anterior. 

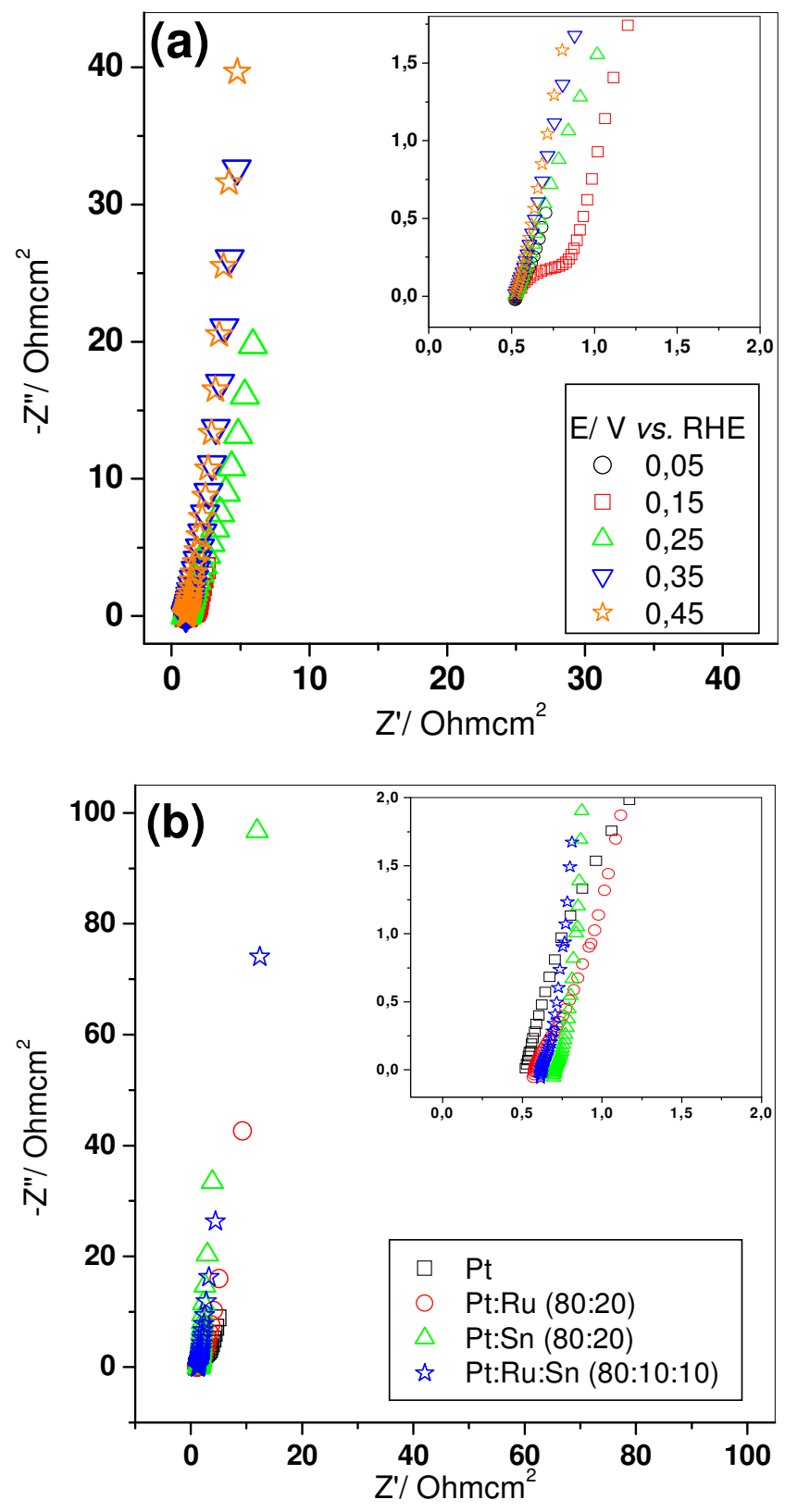

Figura 49: Diagramas de Nyquist em $\mathrm{H}_{2} \mathrm{SO}_{4} 0,5 \mathrm{~mol} \mathrm{dm}^{-3}+$ etanol $1 \mathrm{~mol} \mathrm{dm}^{-3}$, de 1 a 10 $\mathrm{kHz}$ e $5 \mathrm{mV}$ de amplitude. (a) Ti/Pt em diferentes potenciais (b) Diferentes composições eletródicas em $0.2 \mathrm{~V} v s$. ERH. 
Os valores de $Q_{d c}$ na presença de etanol podem ser observados na Figura 50b. Para efeito de comparação, o gráfico de $Q_{d c}$ em eletrólito está novamente apresentado na Figura 50a. Na presença de etanol, a seguinte série foi obtida: Ti/Pt:Ru > Ti/Pt:Ru:Sn, > Ti/Pt:Sn, por fim, o eletrodo de Ti/Pt apresentou-se menos capacitivo. Nota-se então que, na presença de etanol os eletrodos contendo maior quantidade de material catalítico $(\mathrm{Ru})$, apresentaram os melhores resultados.

Nota-se que o eletrodo de composição Ti/Pt na presença de etanol apresentou menores valores de capacitância da dupla camada, este fato é explicado pela adsorção do etanol nos sítios ativos que inicialmente eram recobertos por moléculas de água, a adsorção de moléculas de CO na superfície eletródica aumenta a resistência da dupla camada e conseqüentemente diminuem a capacitância da mesma [204]. 

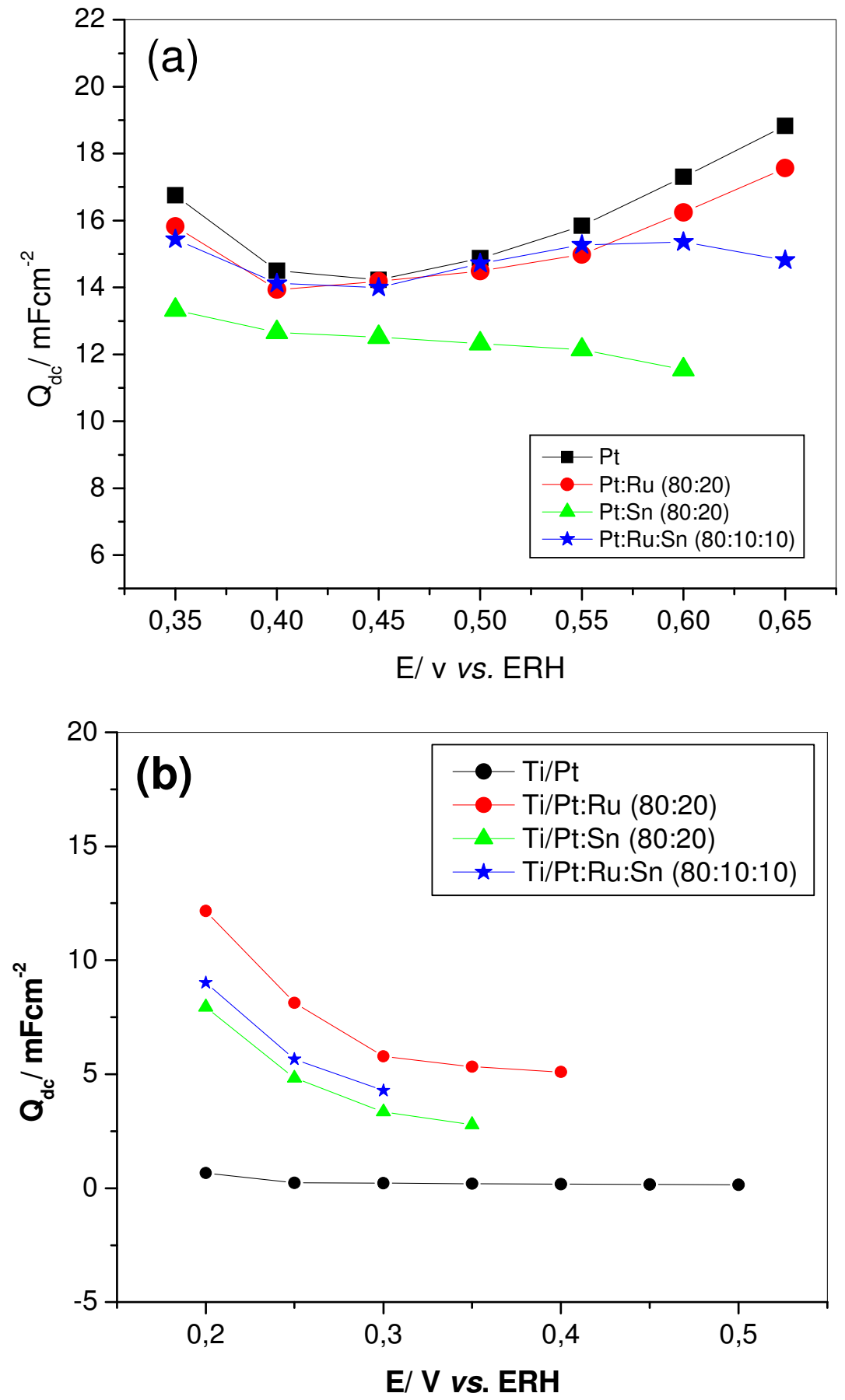

Figura 50: Os valores de $\mathrm{Q}_{\mathrm{dc}}$ calculados em função do potencial para as diferentes composições eletródicas investigadas (a ) em $\mathrm{H}_{2} \mathrm{SO}_{4} 0,5 \mathrm{~mol} \mathrm{dm}^{-3}$ (b) em $\mathrm{H}_{2} \mathrm{SO}_{4}$ 0,5 mol $\mathrm{dm}^{-3}+$ etanol $1 \mathrm{~mol} \mathrm{dm}^{-3}$. 


\section{IV.3.3 Cronoamperometria e EIE na presença de etanol}

Os testes de cronoamperometria apresentados a seguir foram realizados em potenciais entre 0 a $1,4 \mathrm{~V} v s$. ERH para o eletrodo de Ti/Pt, entre 0 a $0,9 \mathrm{~V} v s$. ERH para o eletrodo de Ti/ Pt:Ru e entre 0 a 0,7 V vs. ERH para os eletrodos contendo Sn na composição (Ti/ Pt:Ru:Sn e Ti/ Pt:Sn). As curvas cronoamperométricas foram realizadas a cada $50 \mathrm{mV}$ e após cada curva foi registrado um conjunto de medidas de EIE, no sentido positivo e negativo de potencial.

Na Figura 51, está apresentado o programa de perturbação aplicado nos testes cronoamperométricos. A Figura 51a, mostra o esquema do potencial aplicado em função do tempo, dando ênfase ao momento onde o experimento de cronoamperometria foi interrompido para o registro do conjunto de medidas de EIE, sendo que este constituiu de medidas de EIE no mesmo potencial de interesse e em diferentes freqüências.

Na Figura 51b, estão apresentadas as curvas cronoamperométricas registadas para os potenciais de 0,20 a $0,35 \mathrm{~V} v$ s. ERH no sentido positivo para o eletrodo de composição Ti/Pt:Sn. Pode-se observar que após a realização das medidas de impedância, ao manter o potencial aplicado durante 5 minutos adicionais, o eletrodo mantêm-se no estado estacionário até a aplicação de um novo potencial. Indicando que nessas condições, a superfície eletródica é suficientemente estável para os estudos de EIE. 

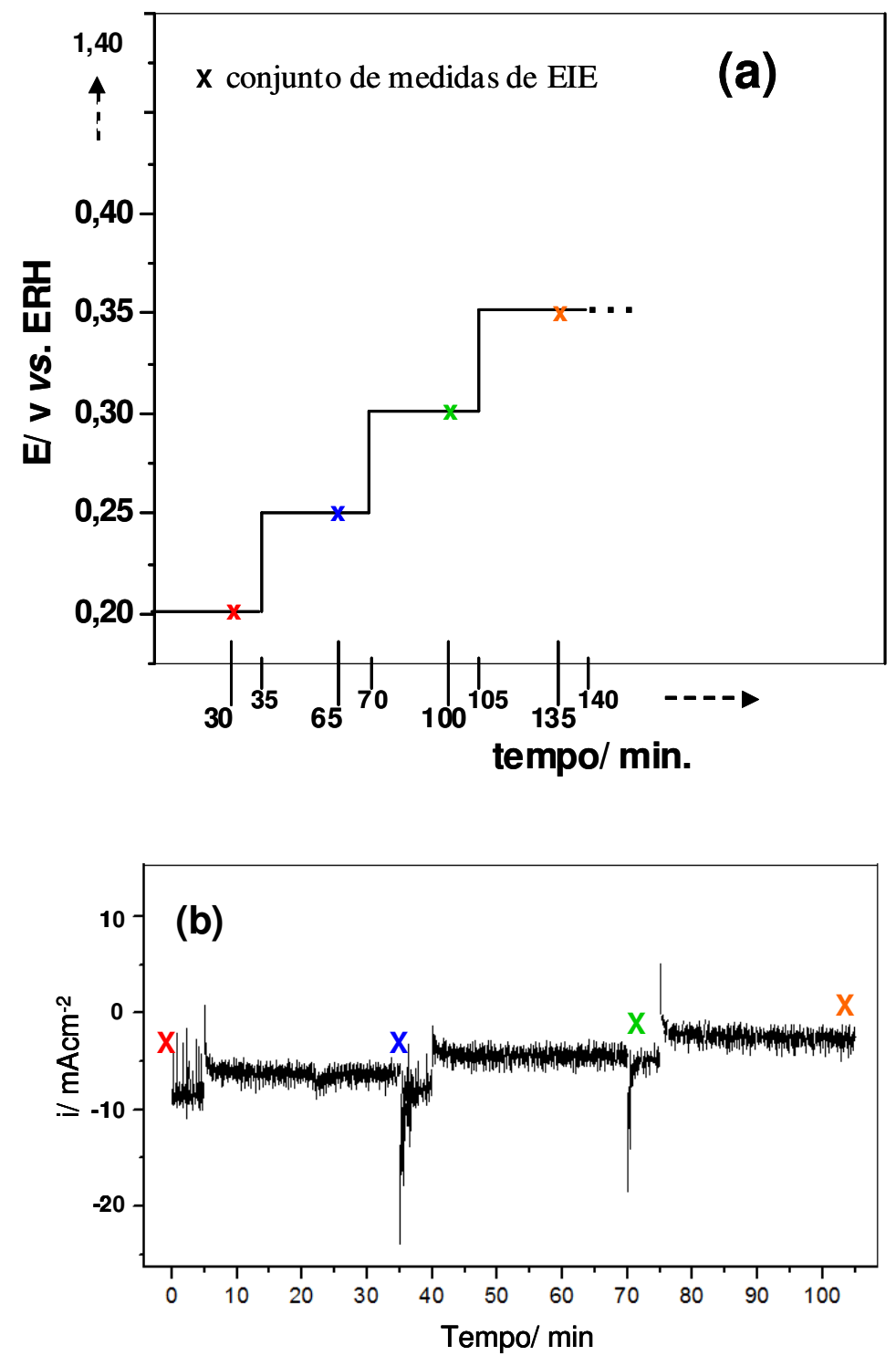

Figura 51: (a) Programa representativo de perturbação aplicada (E vs. tempo) no registro das curvas cronoamperométricas. (b) Curvas cronoamperométricas representativas (i vs. tempo).

A quantidade de tempo necessária para se obter uma corrente estacionária foi função do potencial e composição do material. Em potenciais referentes à região de carregamento da DCE, até aproximadamente $0,4 \mathrm{~V}$ vs. ERH, apenas 30 minutos foram suficientes para obter uma corrente estacionária. Já em potenciais, onde ocorre a oxidação de etanol (acima 
de $0,4 \mathrm{~V} v s$. ERH) foi necessário um tempo maior, podendo chegar até a 4 horas sem obter uma corrente constante. Uma análise da literatura, mostra que, eletrodos com PtRuIr, na região de potencilal da oxidação do etanol também apresentam decaimento lento da corrente em função do tempo [121]. Segundo os autores, esse decaimento é explicado pela adsorção de espécies como $\mathrm{CO}$ e $\mathrm{CH}_{\mathrm{x}}$ nos sítios ativos da platina. À formação de tais resíduos também é a responsável pelo decaimento da corrente e a dificuldade em se obter o estado estacionário [120, 121].

Após a realização de todas as medidas experimentais, pode-se construir o gráfico de corrente estacionária em função do potencial, Figura 52. Nota-se que os valores de corrente são praticamente nulos para as composições eletródicas contendo Ru e Sn, ou seja, não apresentam valores significativos de corrente estacionária. $\mathrm{O}$ fato da área eletroquimicamente ativa desses materiais diminuir acentuadamente, indica que ocorre uma grande perda de material com os estudos cronoamperométricos. Esse resultado está em desacordo com os dados obtidos para eletrodos de mesma composição, depositados sobre carbono [201]. Segundo vários resultados obtidos recentemente para eletrodo de C/PtSnX, composições binárias ou ternárias apresentam atividade catalítica muito superior à platina pura $[120,121,201]$. 


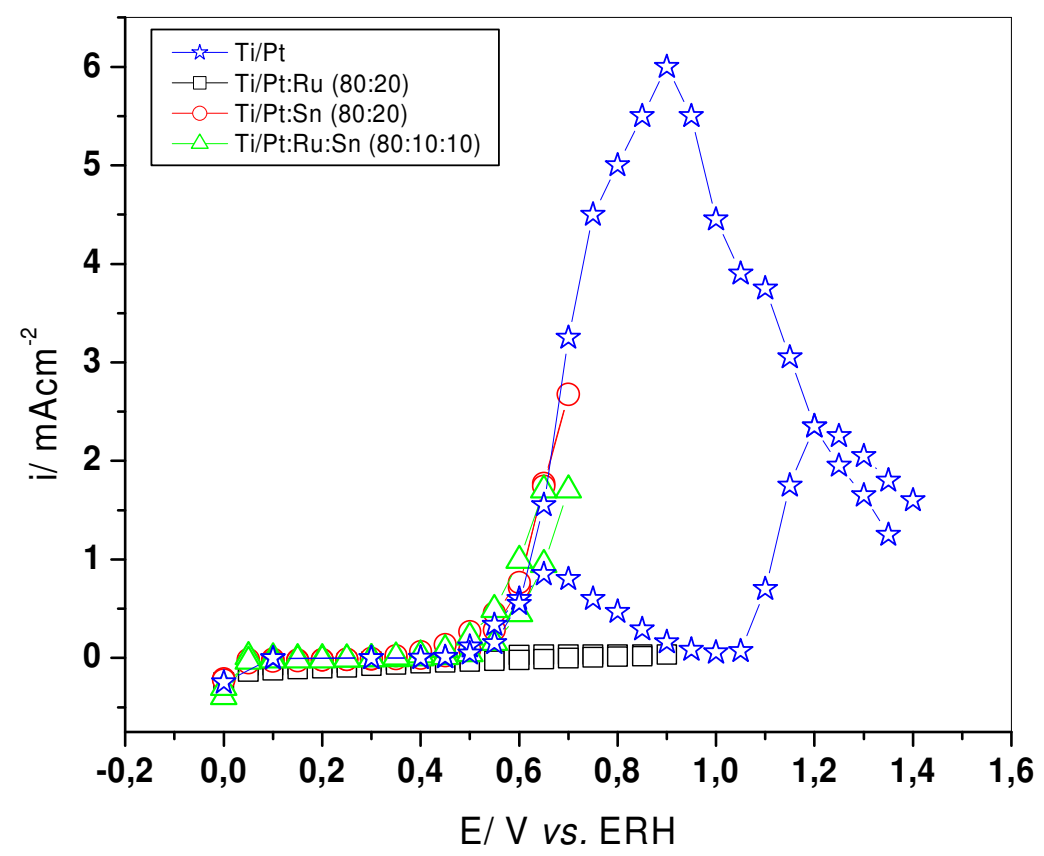

Figura 52: Curva de corrente estacionária em função do potencial para a as diferentes composições eletródicas em $\mathrm{H}_{2} \mathrm{SO}_{4} 0,5 \mathrm{~mol} \mathrm{dm}^{-3}+$ etanol $1 \mathrm{~mol} \mathrm{dm}^{-3}$.

Comparando-se os voltamogramas cíclicos, registrados antes e após os experimentos de cronoamperometria (Figura 53), comprovam-se as observações acima. De fato, observa-se que os valores de corrente encontrados após a cronoamperometria são significativamente menores do que os valores para eletrodos recém preparados, principalmente para as composições mistas. Na presença de etanol, os valores de corrente, de tais composições, passam de 10 a $30 \mathrm{mAcm}^{-2}$ para 4 a $0,2 \mathrm{mAcm}^{-2}$. O eletrodo de $\mathrm{Pt}$ também apresentou um decaimento da corrente, porém relativamente menor quando comparado às demais composições. Visto que esses materiais apresentam-se estáveis quando suportados em cabono [120], uma hipótese para a desativação acentuada, poderia ser atribuída à formação de um recobrimento isolante de $\mathrm{TiO}_{2}$ sobre o suporte de titânio metálico [81]. 

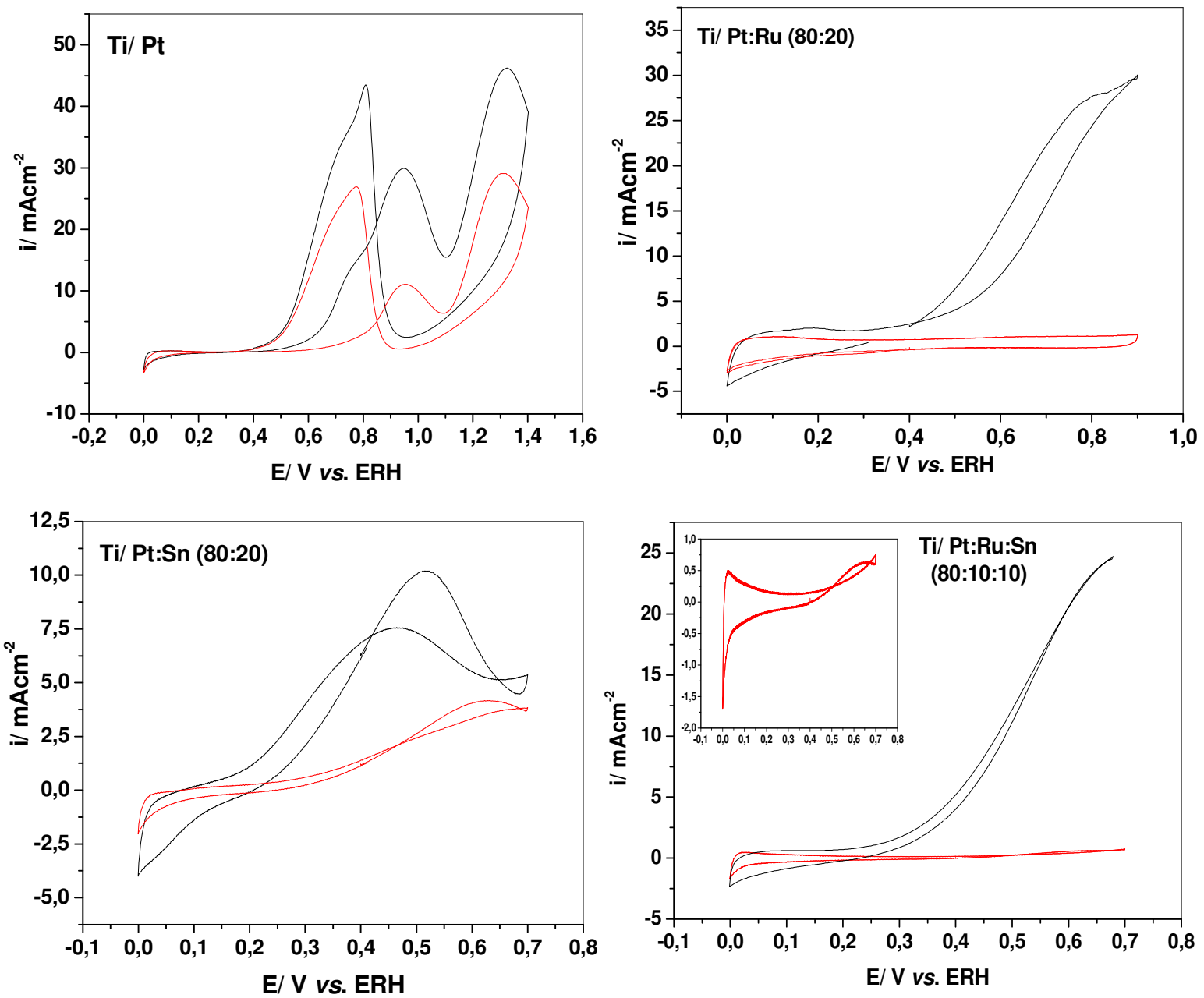

Figura 53: Voltamogramas cíclicos medidos (-) antes e $(-)$ após os testes de cronoamperometria e EIE, em $\mathrm{H}_{2} \mathrm{SO}_{4} 0,5 \mathrm{~mol} \mathrm{dm}{ }^{-3}$ e etanol $1 \mathrm{~mol} \mathrm{dm}^{-3}$ e $v=10 \mathrm{mVs}^{-1}$ para todas as composições investigadas.

Para verificar a hipótese acima, foram feitos recobrimentos da composição Pt:Sn (80:20) sobre suporte de Au. Foi utilizada uma placa de $0,5 \mathrm{~cm}^{2}$ de Au, onde foi depositada a mistura contendo $80 \%$ em Pt e $20 \%$ em Sn, proveniente das resinas descritas no procedimento experimental deste trabalho (seção III.1.3 e III.1.4). O eletrodo foi preparado 
exatamente como o eletrodo de Ti/Pt:Sn, por pincelamento, e submetido ao tratamento térmico a $450^{\circ} \mathrm{C}$. Após o preparo do eletrodo, este foi submetido ao mesmo procedimento de cronoamperometria/EIE descrito anteriormente. Os voltamogramas iniciais (antes das medidas cronoamperométricas) e finais (após as medidas cronoamperométricas) são apresentados na Figura 54. Nota-se que mesmo com a troca de substrato, subtraindo a possibilidade de formação de uma camada isolante de $\mathrm{TiO}_{2}$, ocorre a diminuição dos valores de corrente, o que nos faz concluir que a instabilidade da camada de óxidos não sofre influência do suporte metálico. Portanto, pode-se concluir que a queda da corrente é devido ao desgaste do catalisador (instabilidade mecânica) ou formação de um filme pela adsorção irreverssível de espécies orgânicas nos sítios ativos da platina [205].

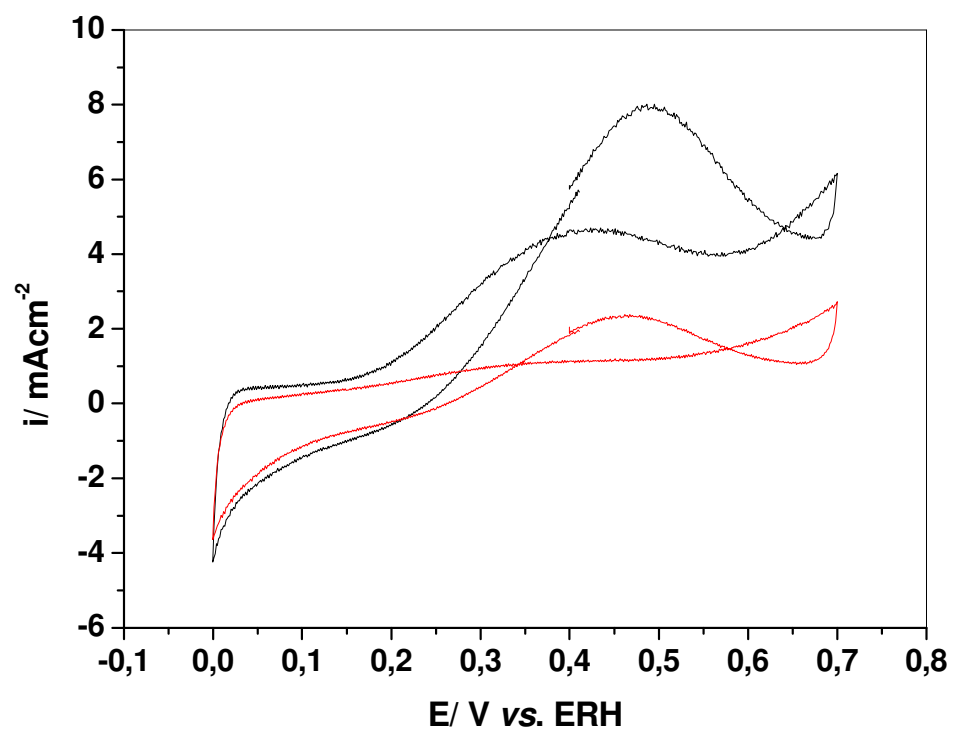

Figura 54: Voltamogramas cíclicos medidos (-) antes e (-) após os testes cronoamperométricos, em $\mathrm{H}_{2} \mathrm{SO}_{4} 0,5 \mathrm{~mol} \mathrm{dm}^{-3}$ e etanol $1 \mathrm{~mol} \mathrm{dm}^{-3}$ e $\mathrm{v}=10 \mathrm{mVs}^{-1}$, do eletrodo de composição Au/Pt:Sn (80:20). 
Devido ao eletrodo de Ti/ Pt ter sido o material mais estável, apenas os resultados obtidos para esse material serão analisados e discutidos a seguir. Dando início as análises dos resultados de EIE tem-se os diagramas de Nyquist para o eletrodo de Ti/Pt. Os potenciais investigados para o eletrodo de Ti/ Pt variam entre 0 e $1,4 \mathrm{~V} v s$. ERH, foram realizadas as medidas cronoamperométricas a cada $50 \mathrm{mV}$, primeiramente no sentido positivo e depois no sentido negativo de potencial.

Os diagramas de Nyquist descrevem claramente os processos que ocorrem nas diferentes regiões de potencial. A Figura 55 apresenta alguns dosdiagramas obtidos no sentido positivo de potencial.

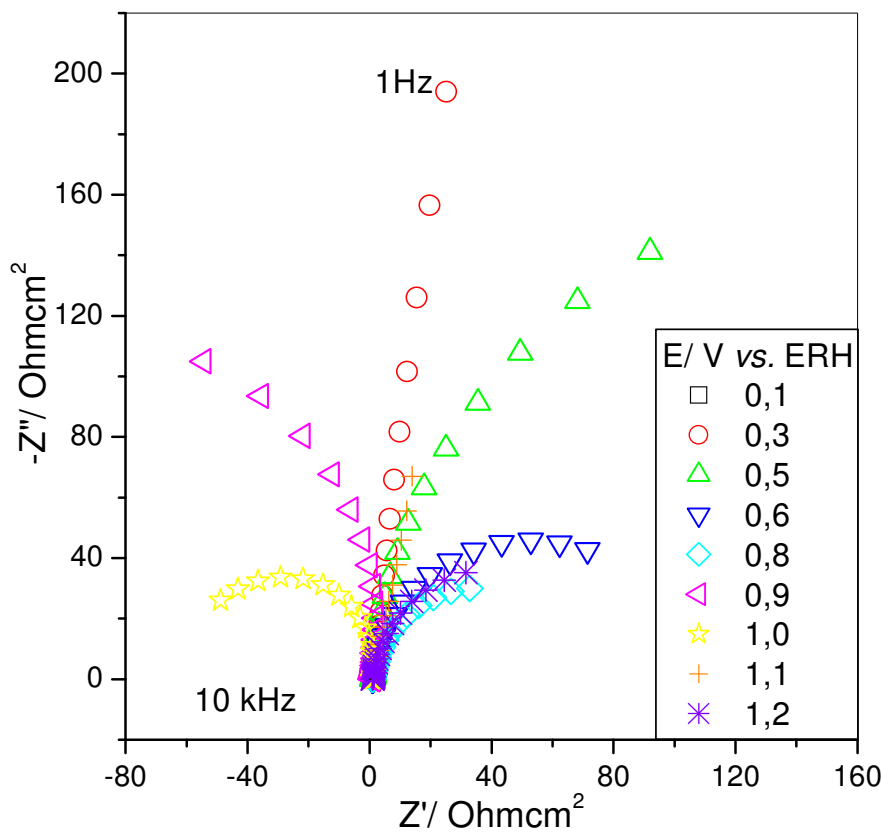

Figura 55: Diagramas de Nyquist em $\mathrm{H}_{2} \mathrm{SO}_{4} 0,5 \mathrm{~mol} \mathrm{dm}^{-3}+$ etanol $1 \mathrm{~mol} \mathrm{dm}^{-3}$, de 1 a 10 $\mathrm{kHz}$ e $5 \mathrm{mV}$ de amplitude, realizados após as curvas cronoamperométricas, do eletrodo de $\mathrm{Ti} / \mathrm{Pt}$ em diferentes potenciais no sentido positivo de potencial. 
A Figura 56, apresenta a curva de corrente estacionário em função do potencial e os diagramas de Nyquist correspondentes. Em potenciais inferiores a $0,3 \mathrm{~V} v s$. ERH, tanto no sentido positivo como negativo de potencial, os eletrodos apresentam os diagramas típicos da região de carregamento da dupla camada elétrica. O circuito elétrico utilizado para o ajuste dos dados experimentais é apresentado na Figura 57a, composto pela resistência ôhmica $\left(R_{\Omega}\right)$ e o elemento de fase constante que nos fornece informações sobre a capacitância da dupla camada elétrica $\left(Q_{d c}\right)$.

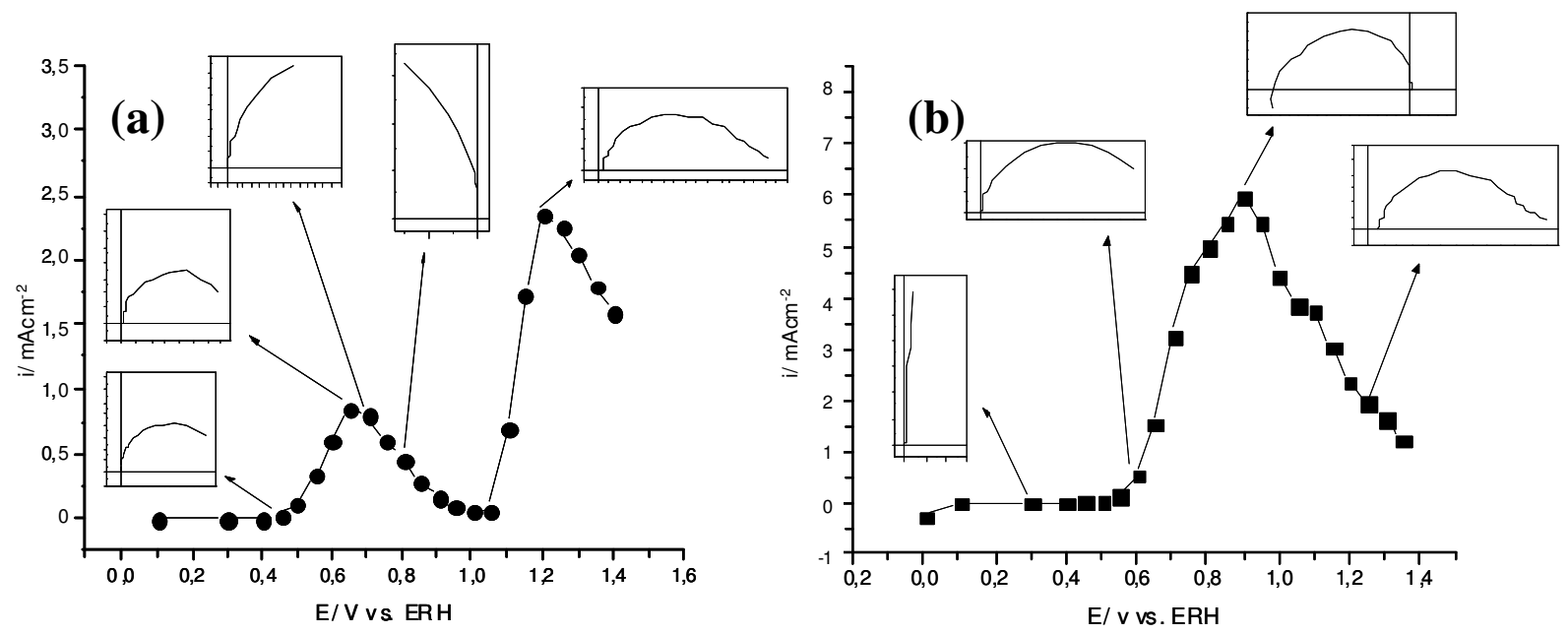

Figura 56: Curva de corrente estacionária em função do potencial para o eletrodo de composição Ti/ Pt: (a) sentido positivo; (b) sentido negativo de potencial. Em meio de $\mathrm{H}_{2} \mathrm{SO}_{4} 0,5 \mathrm{~mol} \mathrm{dm}^{-3}+$ etanol $1 \mathrm{~mol} \mathrm{dm}^{-3}$. Em ênfase os diagramas de Nyquist característicos para cada região de potencial. 
(a)

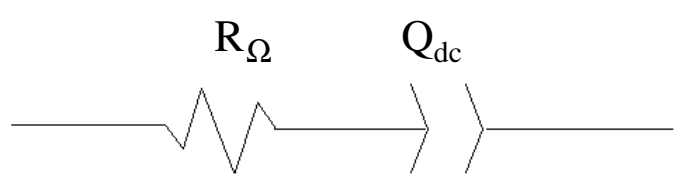

(b)

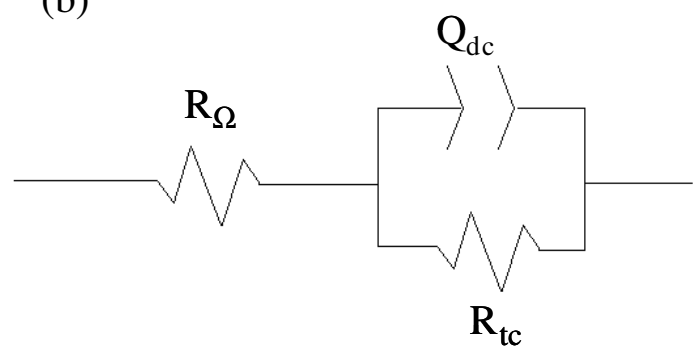

Figura 57: Circuitos elétricos utilizados para o ajuste dos dados experimentais de EIE para o eletrodo de composição Ti/Pt.

Os valores obtidos de $R_{\Omega}$, apresentados na Figura 58, encontram-se entre 1,0 e 1,5 $\Omega \mathrm{cm}^{2}$. Estes resultados são próximos aos valores obtidos no estudo de voltametria $a c$ de eletrodos óxidos de platina realizados por Van der Geest et al. [178], que foram da ordem de $1 \Omega \mathrm{cm}^{2}$.

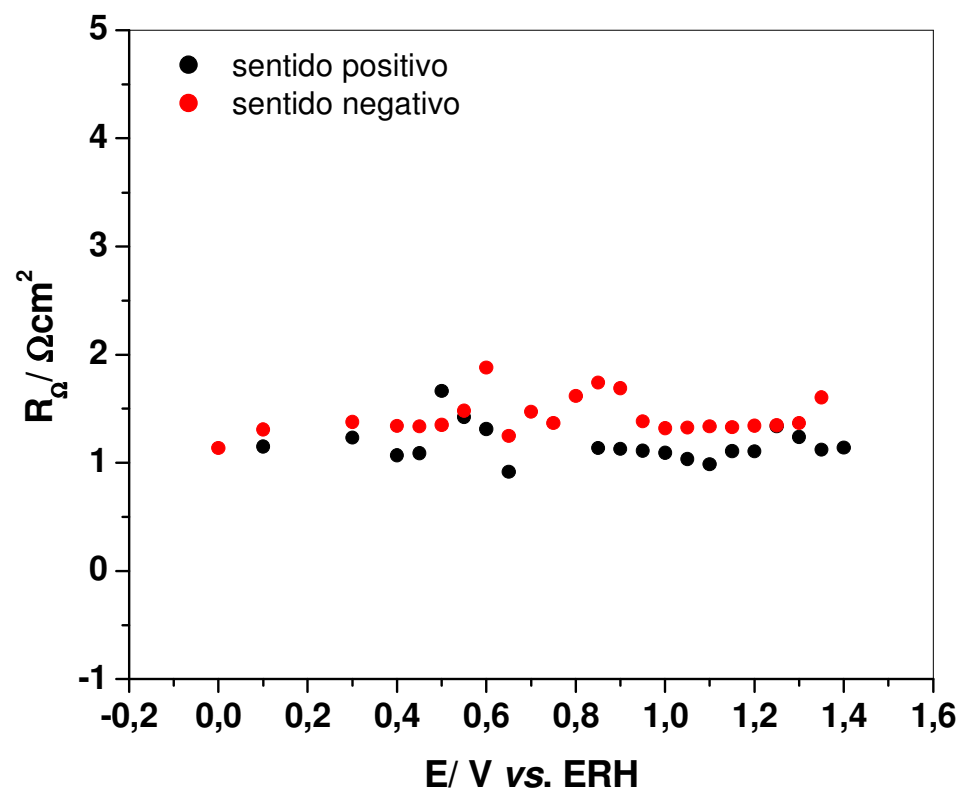

Figura 58:Valores de $R_{\Omega}\left(\Omega \mathrm{cm}^{2}\right)$ em função do potencial para o eletrodo de Ti/Pt, obtidos através do ajuste do circuito elétrico da Figura 58a para a região de carregamento da dupla camada elétrica. 
Os valores de $Q_{d c}$ são mostrados na Figura 59a, pode-se verificar que seguem o mesmo comportamento do voltamograma cíclico, na ausência de etanol, em meio de $\mathrm{H}_{2} \mathrm{SO}_{4}$ $0,5 \mathrm{~mol} \mathrm{dm}^{-3}$, apresentado anteriormente (Figura 43a). A capacitância da dupla camada elétrica está diretamente relacionada aos processos capacitivos e pseudo-capacitivos, sendo assim, nota-se que os valores de $Q_{d c}$ apresentam um ligeiro aumento a partir do potencial de $1,0 \mathrm{~V}$ vs. ERH, referente aos processos que ocorrem na superfície do catalisador (formação dos óxidos de platina). Os valores de $\beta$, mostrados na Figura 59b, encontram-se entre 0,8 e 1 , ou seja, o CPE $\left(Q_{d c}\right)$ pode ser considerado próximo a um elemento puramente capacitivo.

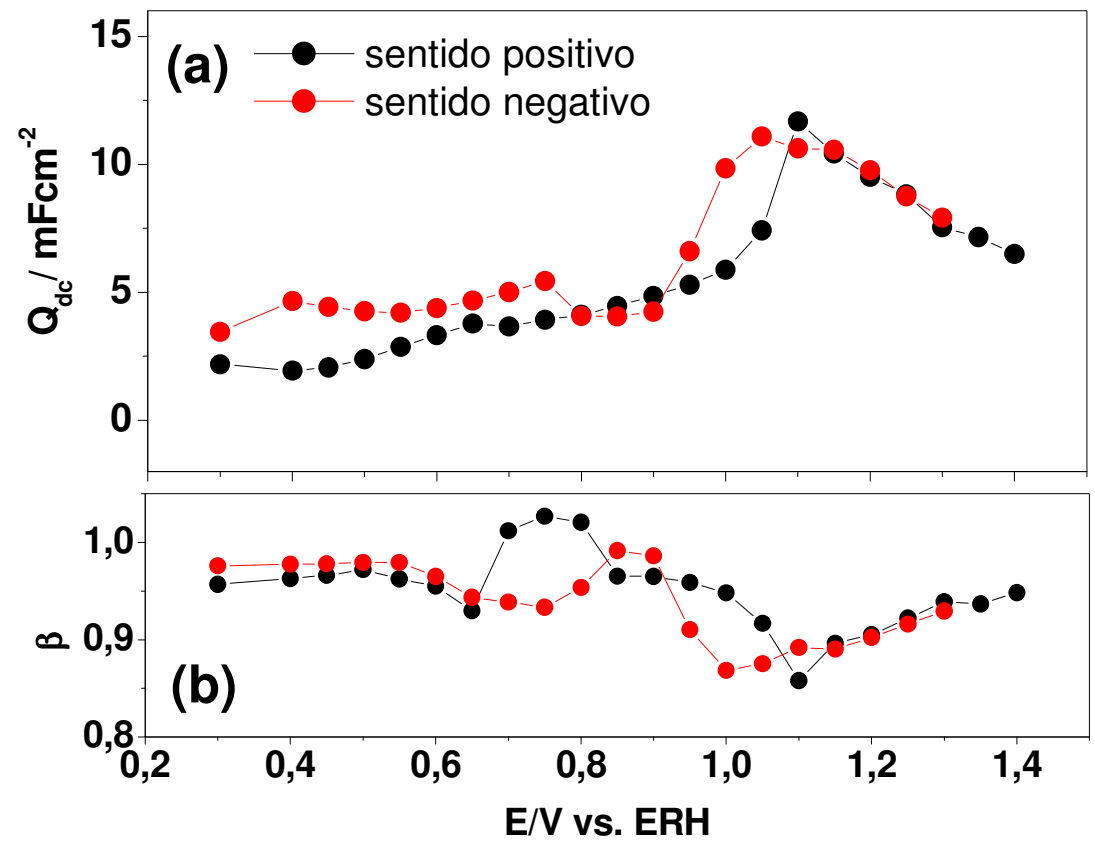

Figura 59: (a) $Q_{d c}$ e (b) $\beta$ em função do potencial, obtidos por EIE durante as análises de curva cronoamperométrica seguida de EIE. Eletrodo de Ti/Pt em $\mathrm{H}_{2} \mathrm{SO}_{4}$ 0,5 mol dm${ }^{-3} \mathrm{e}$ etanol $1 \mathrm{~mol} \mathrm{dm}^{-3}$. 
A Figura 60 compara os valores obtidos de $Q_{d c}$ em função do potencial, para as duas condições investigadas: valores da capacitância da dupla camada elétrica com e sem a estabilização cronoamperométrica. Pode-se observar que os valores de $Q_{d c}$ obtidos sem estabilização cronoamperométrica apresentam-se entre 0 e $1,0 \mathrm{mFcm}^{-2}$. Já os valores posteriores à cronoamperometria são mais elevados, acima de $2 \mathrm{mFcm}^{-2}$. Pode-se então concluir que, medidas cronoamperométricas possibilitam o aumento da área eletroquimicamente ativa dos catalisadores na região da dupla camada elétrica.

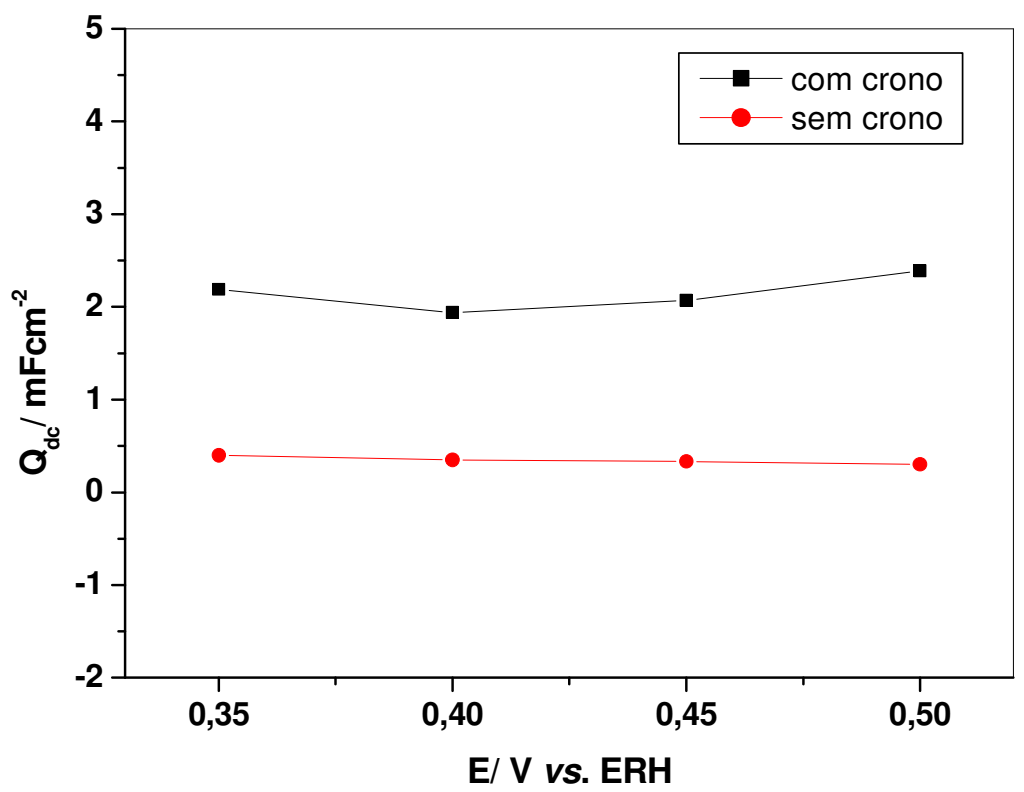

Figura 60: $Q_{d c}$ em função do potencial obtida por EIE, com e sem estabilização cronoamperométrica. Eletrodo de Ti/Pt em $\mathrm{H}_{2} \mathrm{SO}_{4} 0,5 \mathrm{~mol} \mathrm{dm}^{-3}$ e etanol $1 \mathrm{~mol} \mathrm{dm}^{-3}$.

Dando continuidade a discussão dos valores dos elementos do CE obtidos para o eletrodo de Ti/Pt, serão apresentados em seguida os valores de $R_{t c}$ (Figura 61 e Tabela VI). Nos diagramas de Nyquist obtidos no sentido positivo de potencial (Figura 56a), podemos observar que em potenciais acima de 0,45 V vs. ERH tem-se a presença de semicírculos no 
primeiro quadrante do gráfico, ou seja, valores positivos de $R_{t c}$ são obtidos até o potencial de $0,70 \mathrm{~V}$ vs. ERH. Em potenciais entre 0,7 e $1,1 \mathrm{~V}$ vs. ERH, onde observa-se uma diminuição acentuada da corrente estacionária, os diagramas tendem a atingir o segundo quadrante, valores negativos de resistência $\left(R_{t c}<0\right)$.

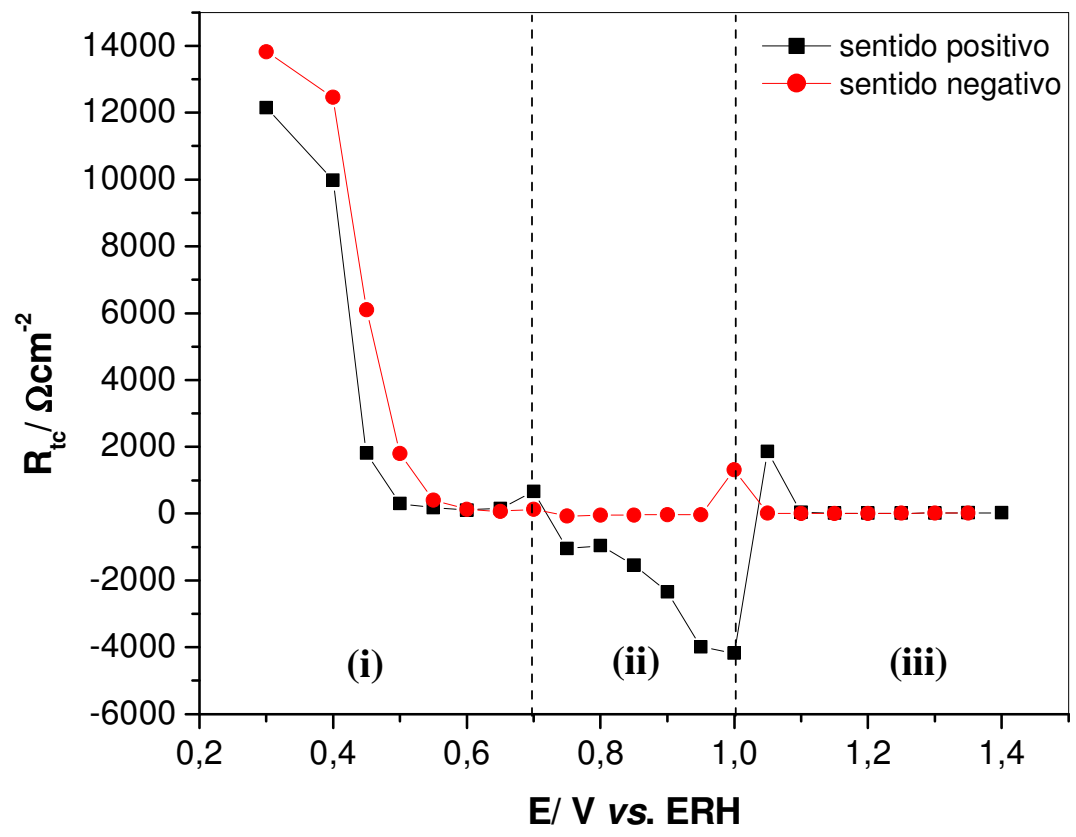

Figura 61: Valores de $R_{t c}$ obtidos a partir do ajuste dos dados experimentais utilizando-se o circuito da Figura 58b, em função do potencial. Eletrodo de Ti/Pt em $\mathrm{H}_{2} \mathrm{SO}_{4} 0,5 \mathrm{~mol} \mathrm{dm}^{-3}$ e etanol $1 \mathrm{~mol} \mathrm{dm}^{-3}$. 
Tabela VI. Valores de $R_{t c}$ no sentido positivo e negativo de potencial obtidos por EIE, após estabilização cronoamperométrica.

\begin{tabular}{|c|c|c|c|}
\hline \multirow{2}{*}{ Região } & \multirow[b]{2}{*}{$\begin{array}{c}E \\
V v s .(E R H)\end{array}$} & \multicolumn{2}{|c|}{$R_{t c}\left(\Omega c m^{2}\right)$} \\
\hline & & $\begin{array}{l}\text { Sentido } \\
\text { positivo }\end{array}$ & $\begin{array}{c}\text { Sentido } \\
\text { negativo }\end{array}$ \\
\hline \multirow{9}{*}{ (i) } & 0,10 & 6368,0 & 19,617 \\
\hline & 0,30 & 1214,6 & 16,926 \\
\hline & 0,40 & 9976,0 & 13,366 \\
\hline & 0,45 & 1810,0 & 10,176 \\
\hline & 0,50 & 299,27 & 8,6034 \\
\hline & 0,55 & 175,69 & 8,5719 \\
\hline & 0,60 & 109,55 & 15,760 \\
\hline & 0,65 & 159,43 & 1309,1 \\
\hline & 0,70 & 663,28 & $-36,562$ \\
\hline \multirow{6}{*}{ (ii) } & 0,75 & $-1051,2$ & $-30,353$ \\
\hline & 0,80 & $-958,45$ & $-39,822$ \\
\hline & 0,85 & $-1538,2$ & $-44,378$ \\
\hline & 0,90 & $-2339,5$ & $-74,485$ \\
\hline & 0,95 & $-3989,8$ & 135,25 \\
\hline & 1,00 & $-4166,4$ & 65,477 \\
\hline \multirow{8}{*}{ (iii) } & 1,05 & 1864,6 & 129,68 \\
\hline & 1,10 & 38,805 & 408,98 \\
\hline & 1,15 & 13,789 & 1794,7 \\
\hline & 1,20 & 13,439 & 6098,1 \\
\hline & 1,25 & 15,354 & 12467 \\
\hline & 1,30 & 21,184 & 13825 \\
\hline & 1,35 & 24,705 & 2047,3 \\
\hline & 1,40 & 28,057 & 35,816 \\
\hline
\end{tabular}

Na Figura 61, estão os valores obtidos de $R_{t c}$ em função do potencial aplicado para o eletrodo de Ti/Pt. Em função da complexidade obtida, faz-se necessário a análise da Figura 61 por intervalos e direção do potencial. Primeiramente, vamos discutir as três regiões distintas no sentido positivo de potencial: 
(i) Nota-se que, entre 0,2 e 0,4 V vs. ERH os valores de $R_{t c}$ apresentam um decaimento exponencial acentuado a medida de que aumenta o potencial, e coincide com o aumento da corrente na curva i vs. E estacionária. Já em potenciais entre 0,4 e 0,7 V vs. ERH, a resistência da transferência de carga diminui com o aumento do potencial, e a tranferência de elétrons controla a velocidade da reação. Os pontos referentes às baixas freqüências nos diagramas de Nyquist estão bem definidos neste intervalo de potencial. Este fato pode ser explicado assumindo que a reação de oxidação do etanol tende a atingir regiões mais profundas dos poros, portanto, os semicírculos positivos são bem definidos [180].

(ii) Acima de 0,7 V vs. ERH até aproximadamente 1,0 V vs. ERH observa-se valores negativos de $R_{t c}$. Este comportamento já foi observado no estudo da impedância da oxidação de ácido fórmico, com eletrodo de platina, realizada por Seland et al. [180]. Os autores obtiveram diagramas de Nyquist característicos para as diferentes regiões de potencial investigadas, similares ao apresentado na Figura 56 [179, 180]. Os autores observaram valores negativos de $R_{t c}$ na região de potencial logo após o pico de oxidação e denominaram esta região de "região de resistência negativa escondida". Nesta região, os valores de $R_{t c}$ negativos, apresentam grandes erros de ajuste, similarmente ao observado para os elevados valores positivos de $R_{t c}$ na região de carregamento da dupla camada elétrica, portanto, não apresentam um significado físico. Neste caso, a $R_{t c}$ não mais limita a velocidade da reação, e seus valores em baixas frenquencias sofrem uma distorção e tendem ao segundo quadrante do diagrama de Nyquist. Seland et al. [180] propuseram, para 
ajustar os dados experimentais nesta região de potencial, um circuito equivalente onde não está presente uma $R_{t c}$.

O mecanismo de oxidação do etanol, vem sendo muito investigado por diferentes autores, sendo propostas diferentes etapas mecanísticas, tais etapas especificam as espécies adsorvidas e os intermediários formados [105, 116, 117]. Algumas destas propostas mecanísticas foram apresentados na introdução deste trabalho (páginas 32-33). De acordo com Ribeiro et al. [205], este mecanismo pode ser descrito como:

$$
\begin{aligned}
& \mathrm{H}_{2} \mathrm{O}_{(\mathrm{M})} \rightarrow \mathrm{OH}_{\mathrm{ad}(\mathrm{M})}+\mathrm{H}^{+}+\mathrm{é} \\
& \mathrm{CH}_{3} \mathrm{CHO}_{\mathrm{ad}(\mathrm{Pt})}+\mathrm{OH}_{\mathrm{ad}(\mathrm{M})} \rightarrow \mathrm{CH}_{3} \mathrm{COOH}_{\mathrm{ad}(\mathrm{Pt})}+\mathrm{H}^{+}+\text {é } \\
& \mathrm{CH}_{3} \mathrm{COOH}_{\mathrm{ad}(\mathrm{Pt})} \rightarrow \mathrm{CH}_{3} \mathrm{COOH} \\
& \mathrm{CO}_{\mathrm{ad}(\mathrm{Pt})}+\mathrm{OH}_{\mathrm{ad}(\mathrm{M})} \rightarrow \mathrm{CO}_{2}+\mathrm{H}^{+}+\text {é }
\end{aligned}
$$

Cada etapa do mecanismo de oxidação do etanol decrito acima, pode ser discutida em estudos realizados por diferentes técnicas [105]. Porém, os resultados de EIE, obtidos neste trabalho, não demostram diferentes constantes de tempo, sendo assim, a obtenção de parâmetros cinéticos, quando se tem mecanismos complexos (várias etapas ocorrendo simultânemente com diferentes velocidades de reação) torna-se difícil neste caso.

(iii) Potenciais acima de 1,0 V vs. ERH, a $R_{t c}$ apresenta valores positivos (Tabela VI). Nesta região, tem-se a formação dos óxidos de Pt, no sentido positivo de potencial, portanto, observa-se semicírculos positivos nos diagramas de Nyquist, referentes a reação de formação de tais óxidos.

Em relação ao sentido negativo de potenciais, observa-se na Tavela VI, que na região (ii) os valores de $R_{t c}$ obtidos são novamente negativos. Este fato ocorre pois: 
primeiramente são atingidos valores mais positivos de potencial (região (iii)), onde ocorre a formação de óxidos de platina na superfície do catalisador, em seguida, inicia-se a varredura no sentido negativo de potencial, portanto, renova-se os sítios ativos, do material para dar início a redução do etanol. Os valores de $R_{t c}$ obtidos aqui, podem então ser atribuídos a nova reação de tranferência de carga que ocorre no sentido negativo de potencial (a redução do etanol). Após a oxidação do etanol, nota-se na Figura 56b, que ocorre uma queda nos valores de corrente estacionária, obtêm-se novamente então, uma região com resistências negativas. Seland et al. [117] observaram o mesmo comportamento porém, foram observados semicírculos cujas baixas freqüências, atingiram o quarto quadrante no diagrama de Nyquist (freqüências até $0,2 \mathrm{~Hz}$ ), os quais os autores atribuíram as espécies adsorvidas nos sítios da platina. Entretanto, neste trabalho foram obtidos apenas semicírculos simples, este fato pode ter ocorrido devido a não terem sido registradas medidas, em tão baixas freqüências $(f<1 \mathrm{~Hz})$, capazes de fornecer tais informações. 


\section{IV.3.4 Voltametria $a c$ na presença de etanol}

As medidas de voltametria $a c$ foram obtidas registrando-se voltamogramas cíclicos a velocidade de varredura de 2 ou $5 \mathrm{mV} / \mathrm{s}$ e aplicando-se uma amplitude de $5 \mathrm{mV} / \mathrm{s}$ (rms). Foram registrados 20 valores de frequiências entre $1-200 \mathrm{~Hz}$. As medidas de EIE foram registradas simultamente ao deslocamento do potencial, desta forma, a cada $5 \mathrm{mV}$ obteve-se um digrama de Nyquist.

Depois de obtidos os voltamogramas $a c$, os diagramas de Nyquist foram extraídos utilizando-se o programa adequado para a análise dos gráficos em função do potencial. Foram registrados voltamogramas cíclicos $d c$, iniciais, finais e também entre cada voltamograma $a c$ de frequiência diferente. Estes voltamogramas podem ser observados na Figura 62, todas as composições eletródicas apresentaram uma pequena diminuição da corrente, sendo que o eletrodo de composição Pt:Ru apresentou a diminuição mais acentuada.

Apesar deste resultado, os diagramas de Nyquist obtidos foram analisados, pois os eletrodos apresentam a carga final significativa. Comparando-se com os resultados apresentados anteriormente, verifica-se que a voltametria $a c$ é menos drástica e permite a análise de sistemas menos estáveis. 

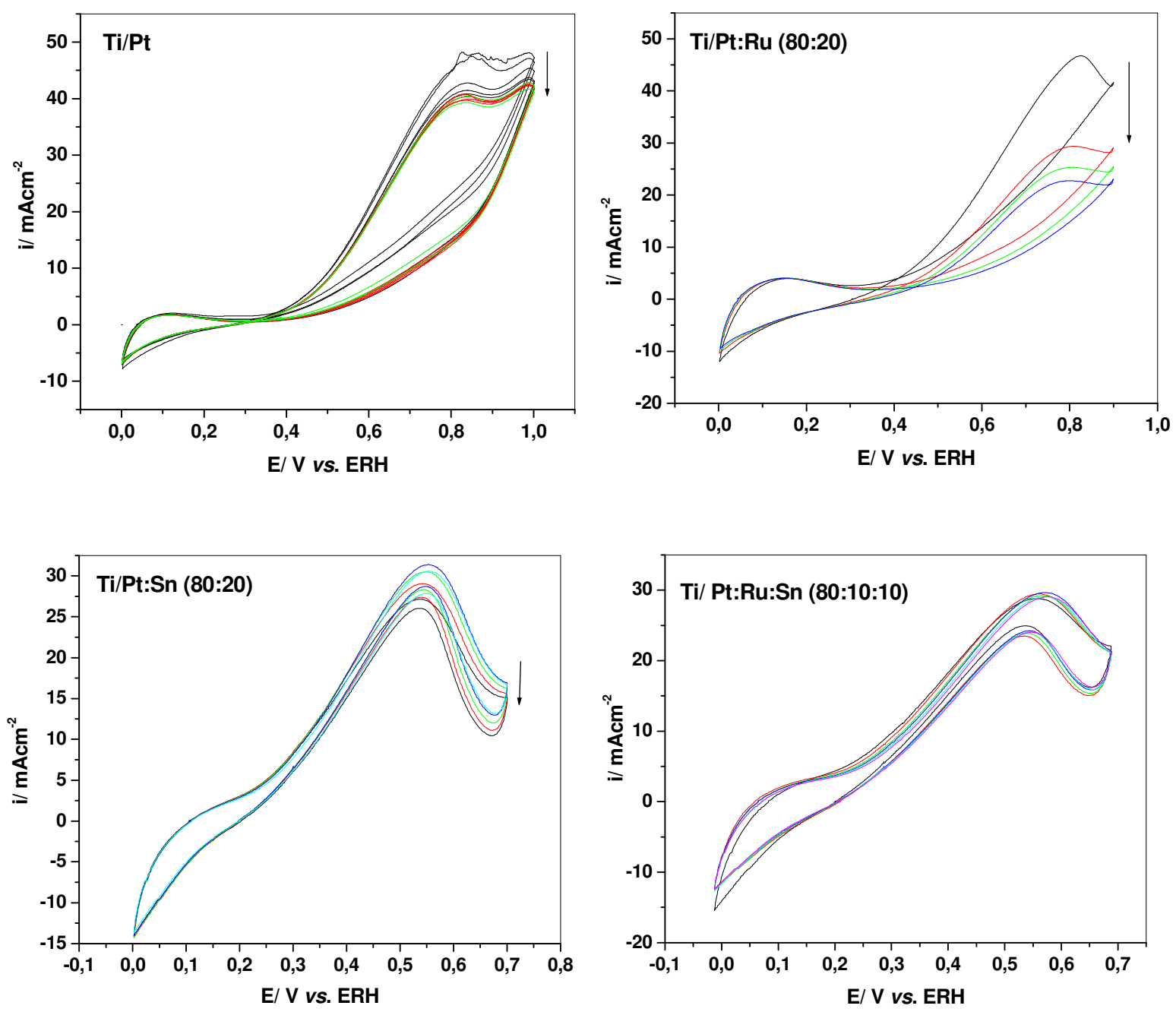

Figura 62: Voltamogramas cíclicos $d c$, obtidos durante o registro dos voltamogramas ac

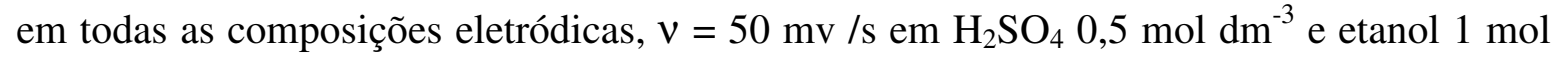
$\mathrm{dm}^{-3}$.

A Figura 63 apresenta os diagramas de Nyquist obtidos para o eletrodo de Ti/ Pt. Dependendo da composição eletródica foram obtidos de 280 a 360 diagramas, do sentido positivo e negativo de potencial. Os resultados experimentais de voltametria $a c$, foram ajustados utilizando-se os circuitos descritos anteriormente na Figura 57. 

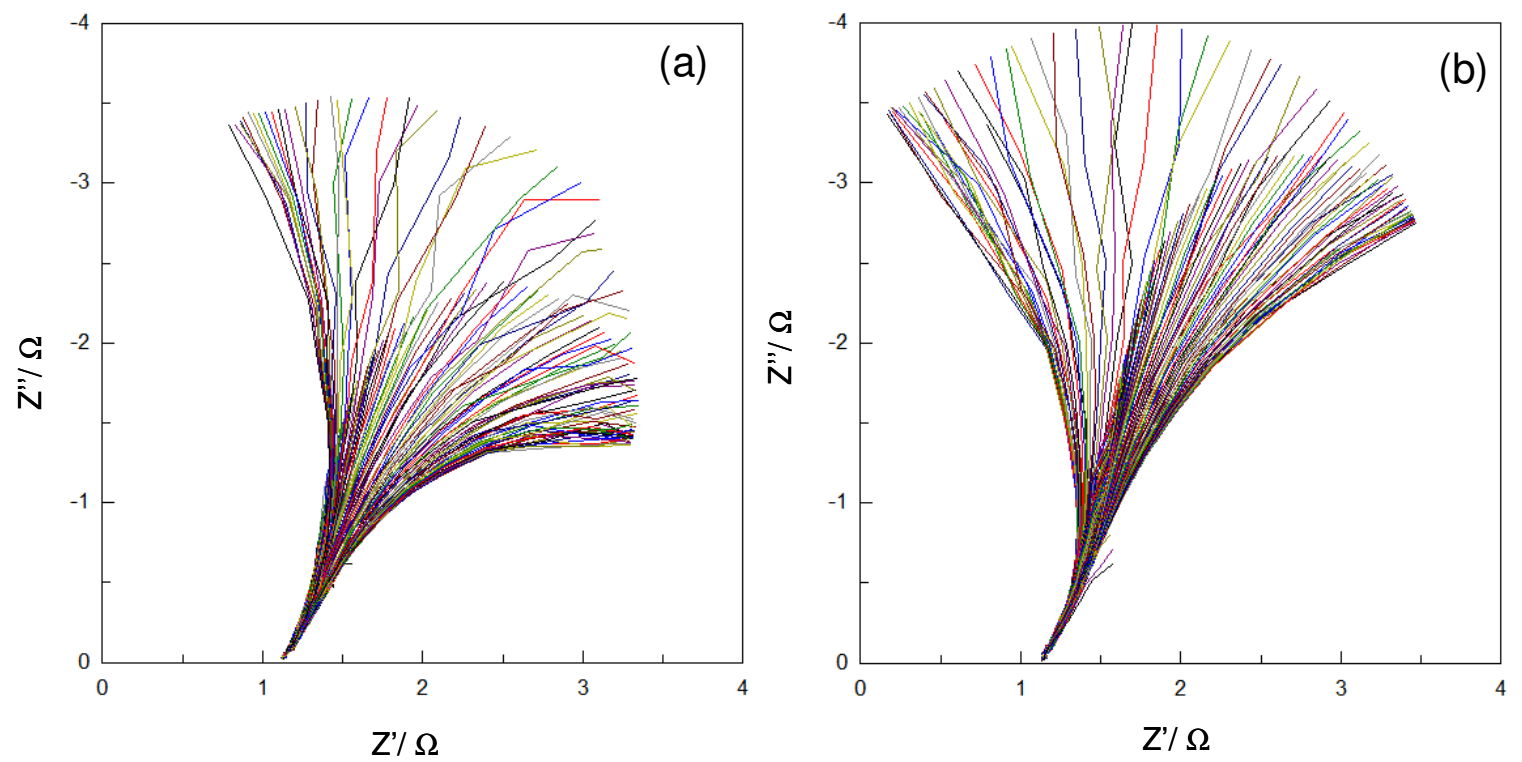

Figura 63: Diagramas de Nyquist obtidos para o eletrodo de Ti/ Pt:Ru:Sn (80:10:10) por voltametria $a c$ : (a) sentido positivo e (b) sentido negativo de potencial. Em meio de $\mathrm{H}_{2} \mathrm{SO}_{4}$ $0,5 \mathrm{~mol} \mathrm{dm}^{-3}$ e etanol $1 \mathrm{~mol} \mathrm{dm}^{-3}, \mathrm{v}=5 \mathrm{mVs}^{-1}$.

Na Figura 64, tem-se os diagramas característicos de Z' e Z’' em função do potencial, para o eletrodo de Ti/Pt, em diferentes freqüências investigadas. Nota-se que com o aumento da frequiência os diagramas apresentam-se picos mais definidos e diminue a presença de ruídos. Este fato pode ser explicado devido ao fato de que, em baixas freqüências, tem-se interferências na medida de EIE devido a ruídos do equipamento.

A parte imaginária em função do potencial demostra que, a medida que se aumenta a frequiência os valores de capacitância diminuem, o que pode ser explicado novamente pelo fato da adsorção de espécies nos sítios da platina. As medidas são registradas a partir das freqüências menores até as mais elevadas. No decorrer do registro das freqüências mais baixas, as espécies são adsorvidas com maior facilidade nos sítios ativos da platina, sendo que, em freqüências mais elevadas a quantidade de espécies adsorvidas se torna elevada, 
gerando uma resistência na superfície, que é claramente observada na diminuição dos valores de capacitância dados pela parte imaginária em função do potencial.
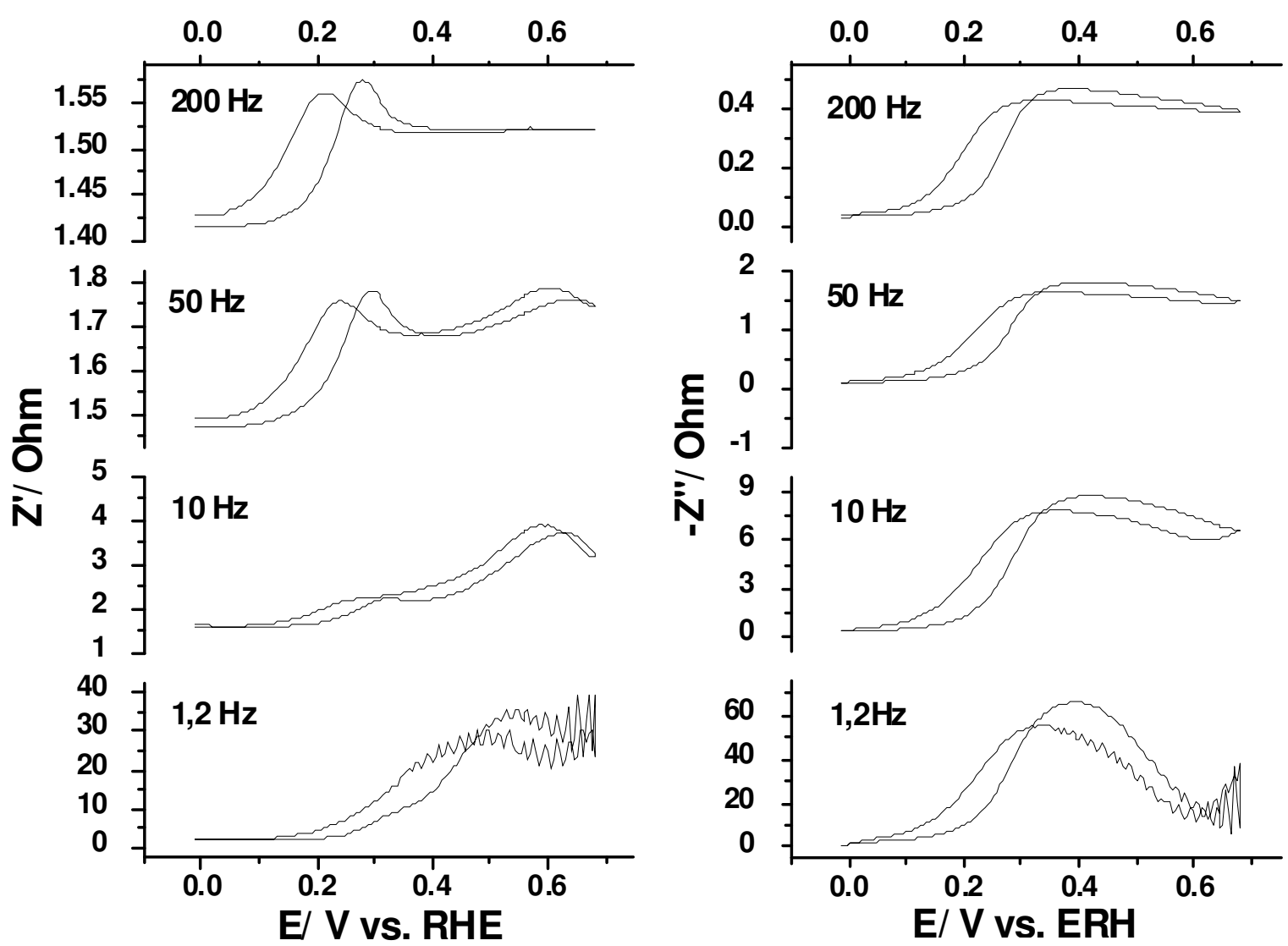

Figura 64: Z' e Z'' em função do potencial em diferentes valores de freqüência para o eletrodo de Ti/Pt, em $\mathrm{H}_{2} \mathrm{SO}_{4}$ 0,5 mol dm-3 + etanol $1 \mathrm{~mol} \mathrm{dm}^{-3}, \mathrm{~A}=5 \mathrm{mV}, \mathrm{v}=5 \mathrm{mV} / \mathrm{s}$.

Os valores de $R_{\Omega}$ podem ser observados na Figura 65. Os valores se apresentam entre 0,5 e $0,8 \Omega \mathrm{cm}^{2}$, e concordam com os valores obtidos anteriormente nos etudos de EIE com estabilização cronoamperométrica (Figura 58). Consequentemente, são próximos aos valores já apresentados na litertura [168]. 


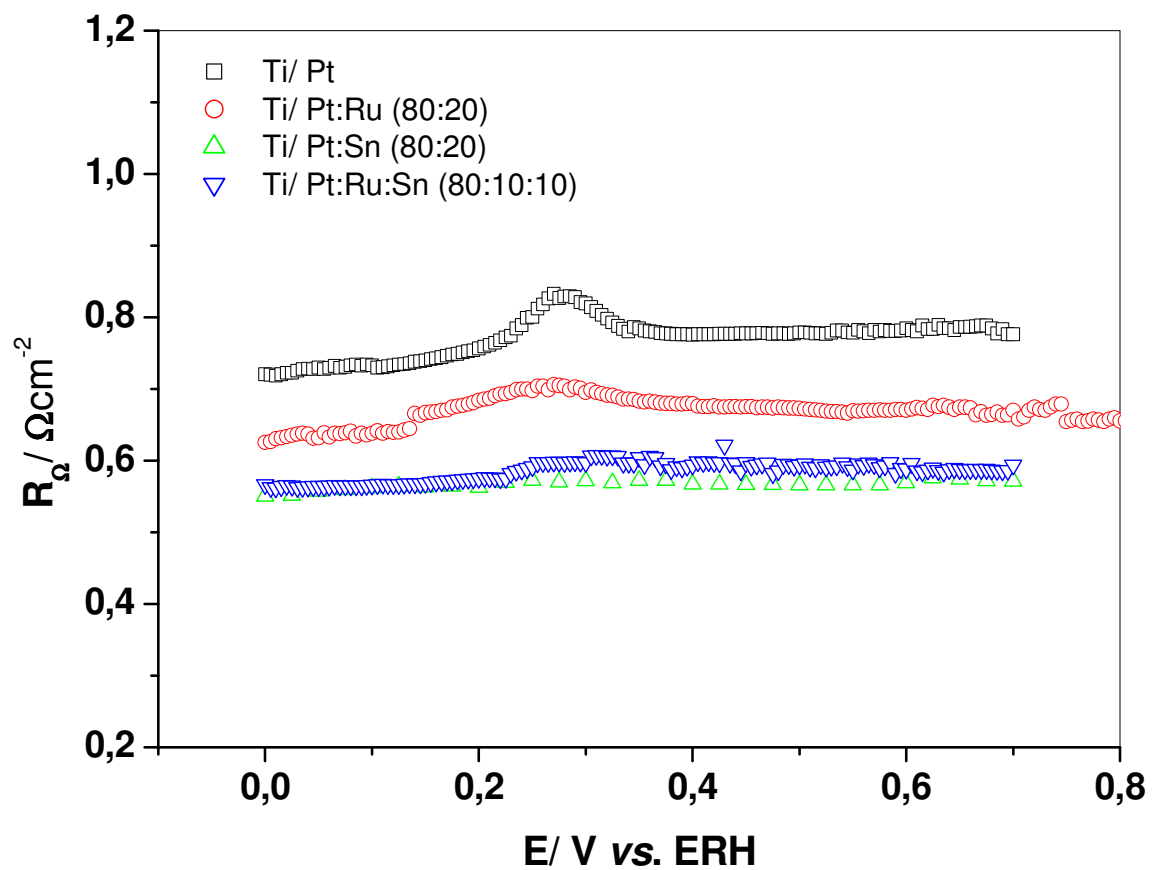

Figura 65: $R_{\Omega}$ em função do potencial para as diferentes composições eletródicas investigadas em $\mathrm{H}_{2} \mathrm{SO}_{4} 0,5 \mathrm{~mol} \mathrm{dm}^{-3}+$ etanol $1 \mathrm{~mol} \mathrm{dm}^{-3}, \mathrm{f}=200 \mathrm{~Hz}$.

Os valores de capacitância da dupla camada elétrica, $Q_{d c}$, estão apresentados na Figura 66. Nota-se, na Figura 66a, que os valores obtidos no sentido positivo e negativo de potencial apresentam o mesmo comportamento. Já na Figura 66b, pode-se observar o efeito da composição eletródica. O eletrodo de Pt apresentou novamente os menores valores de $Q_{d c}$, sendo que, as demais composições apresentam valores similares. 

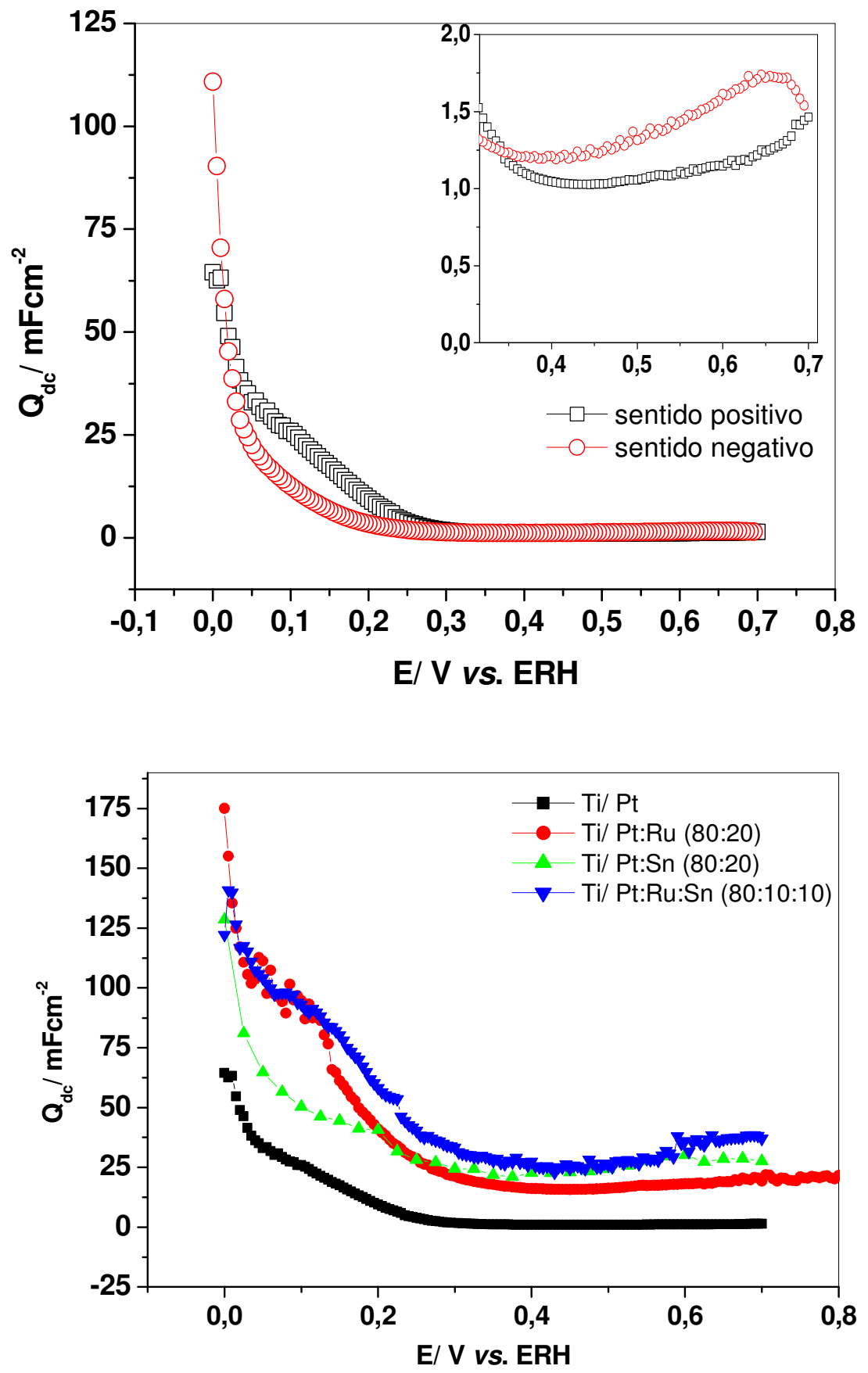

Figura 66: Os valores de $Q_{d c}$ calculados a partir da voltametria $a c$, em função do potencial: para o eletrodo de Ti/Pt nos sentidos positivo e negativo de potencial e (b) para as diferentes composições eletródicas investigadas no sentido positivo de potencial. Em $\mathrm{H}_{2} \mathrm{SO}_{4} 0,5 \mathrm{~mol} \mathrm{dm}^{-3}+$ etanol $1 \mathrm{~mol} \mathrm{dm}{ }^{-3}$. 
Na seção anterior, foram calculados os valores de $Q_{d c}$ em função do potencial, a partir de medidas de EIE obtidas após a estabilização cronoamperométrica. Na Figura 67, estão apresentados os valores de $Q_{d c}$ obtidos na seção anterior, juntamento com os valores obtidos por voltametria ac. Podemos observar que os valores são equivalentes, comprovando que ambas técnicas são eficientes para realizar medidas de EIE. Porém, a voltametria ac apresenta algumas vantagens importantes frente a estabilização cronoamperométrica seguida de EIE. Primeiramente, a obtenção de pontos em menores intervalos de potencial, que nos fornece uma discussão mais detalhada dos resultados. Além de que, as medidas de voltametria ac são realizadas em um tempo extremamente mais curto em relação à outra técnica. Entretanto, convém salientar que, com a obtenção de maior quantidade de diagramas de EIE, a análise dos resultados de voltametria ac se torna mais demorada e trabalhosa.

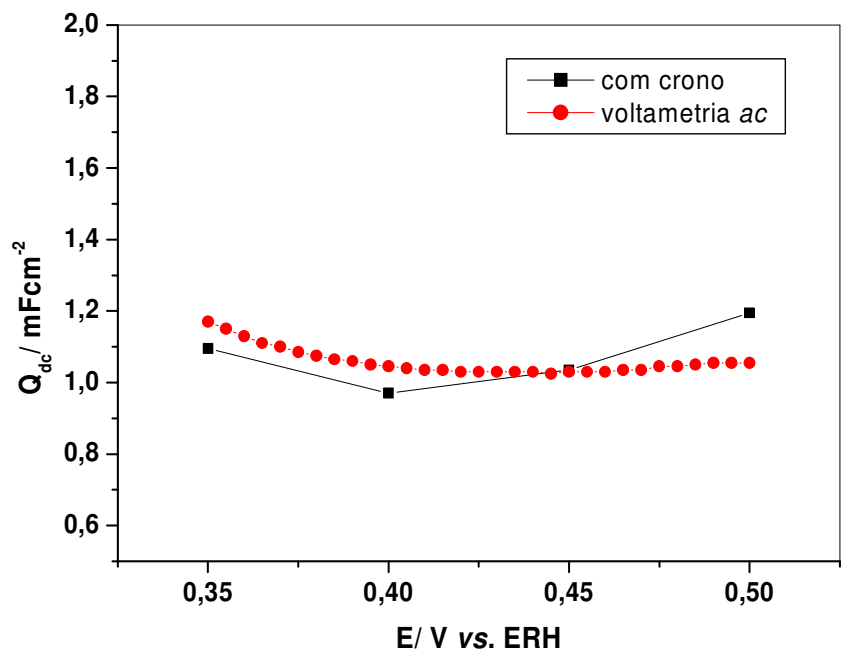

Figura 67: Os valores de $Q_{d c}$ em função do potencial, calculados a partir das medidas de EIE registras após estabilização cronoamperométrica e também obtidos a partir dos resultados de voltametria ac. Eletrodo de Ti/Pt, em $\mathrm{H}_{2} \mathrm{SO}_{4}$ 0,5 mol dm${ }^{-3}+$ etanol $1 \mathrm{~mol} \mathrm{dm}^{-3}$. 
O último elemento a ser analisado é a resitência à transferência de carga, $R_{t c}$, apresentada na Figura 68. Os valores de $R_{t c}$ para o eletrodo de Ti/ Pt obtidos nesta seção, em todo o intervalo de potencial investigado, e nos sentidos positivo e negativo de potencial, são silimares aos apresentados e discutidos anteriormente na Figura 61, quando realizada a estabilização cronoamperométria. Portanto, os valores de $R_{t c}$ obtidos nos testes de voltametria $a c$, serão apresentados apenas na região de potencial próxima ao início da oxidação do etanol, entre 0,5 e 0,7 V vs. ERH. Na Figura 68a, nota-se que os valores de $R_{t c}$ não variam no sentido positivo e negativo de potencial. Na Figura 68b, observa-se que os ânodos contendo Sn na composição (Ti/ Pt:Sn (80:20) e Ti/ Pt:Ru:Sn (80:10:10)), apresentam os melhores resultados, concordando com o observado anteriormente para a oxidação do etanol (Figura 48).

Novamente a EIE comprova os resultados obtidos por outras técnicas [180], pode-se observar que na Figura 48b, os eletrodos de Ti/ Pt e Ti/ Pt:Ru (80:20) apresentaram os maiores valores de $R_{t c}$ comprovando que: eletrodos de platina pura não apresentam boa eficiência na oxidação do etanol; ea adição de Ru em materiais aplicáveis a DEFCs não melhora a eficiência dos mesmos [178]. 

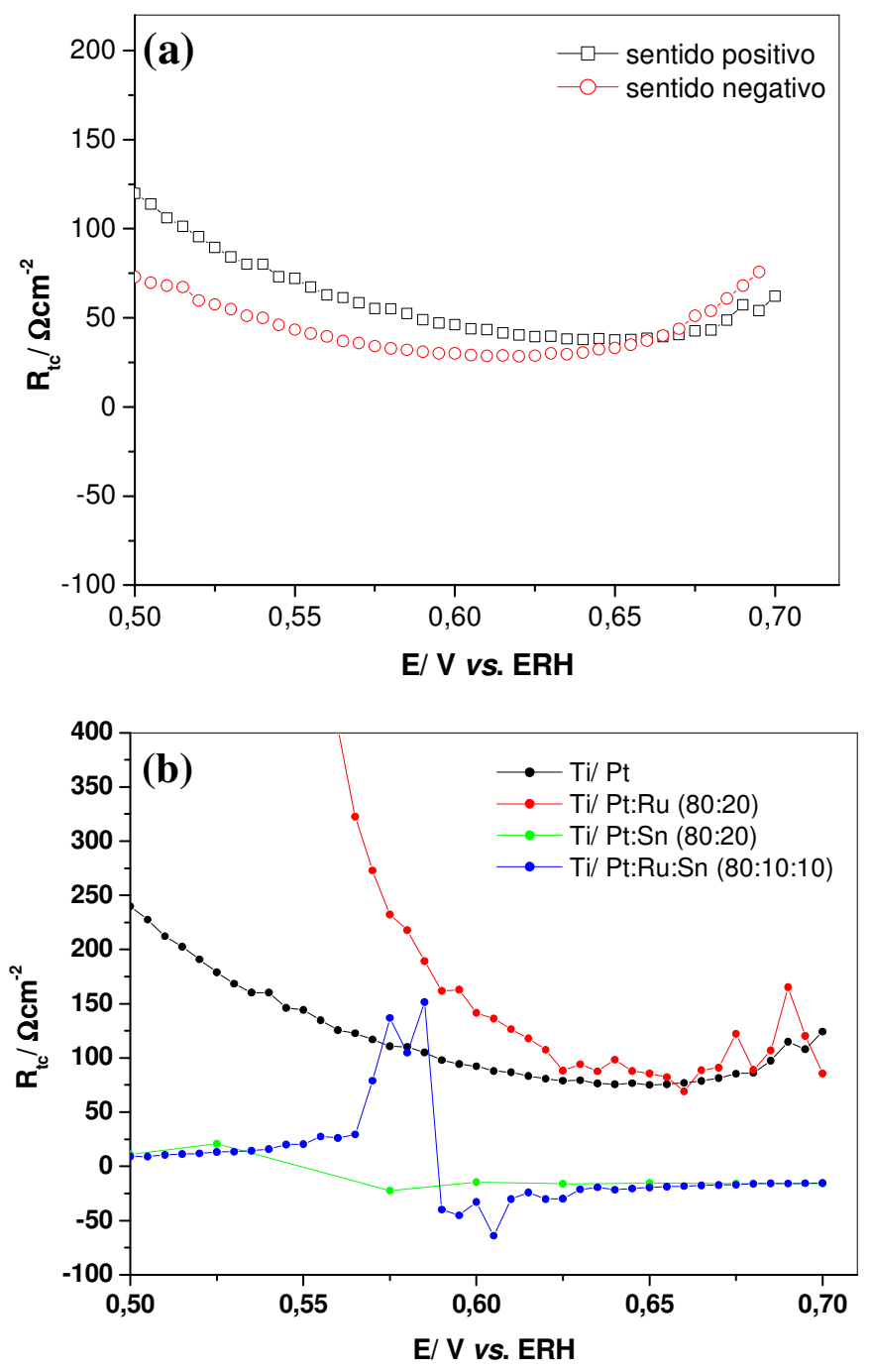

Figura 68: Os valores de $R_{t c}$ em função do potencial (a) nos sentidos anódico e catódico para o eletrodo de Ti/Pt e (b) no sentido positivo para todas composições eletródicas investigadas em $\mathrm{H}_{2} \mathrm{SO}_{4} 0,5 \mathrm{~mol} \mathrm{dm}^{-3}+$ etanol $1 \mathrm{~mol} \mathrm{dm}^{-3}$. 


\section{IV.3.5 Testes de células a combustível de etanol}

Estudos de diferentes materiais a base de Platina, para aplicação em DEFCs, vem sendo investigados no Laboratório de Eletrocatálise e Eletroquímica Ambiental de Ribeirão Preto [205]. Com o objetivo de comparar o desempenho da celula eletroquímica de etanol e os resultados apresentados anteriormente neste trabalho de EIE, foram realizadas algumas medidas de potencia de células contendo ânodos de composição: C/ Pt:Ru (80:20), C/ Pt:Sn (80:20) e C/ Pt:Ru:Sn (80:10:10). Os resultados obtidos de tensão (E/ mV) e densidade de

potência $\left(\mathrm{P} / \mathrm{mWcm}^{-2}\right)$ em função da densidade de corrente $\left(\mathrm{i} / \mathrm{mAcm}^{-2}\right)$ são apresentados na Figura 68.

Podemos observar na Figura 69 que o eletrodo de que apresenta os melhores resultados é o de composição C/ Pt:Sn (80:20). Os resultados obtidos concordam com os observados anteriormente por Ribeiro et al. [205] , onde foram obtidos valores de potência próximos a 20mWcm $\mathrm{m}^{-2}$ para o ânodo de C/ Pt:Sn (80:20). 

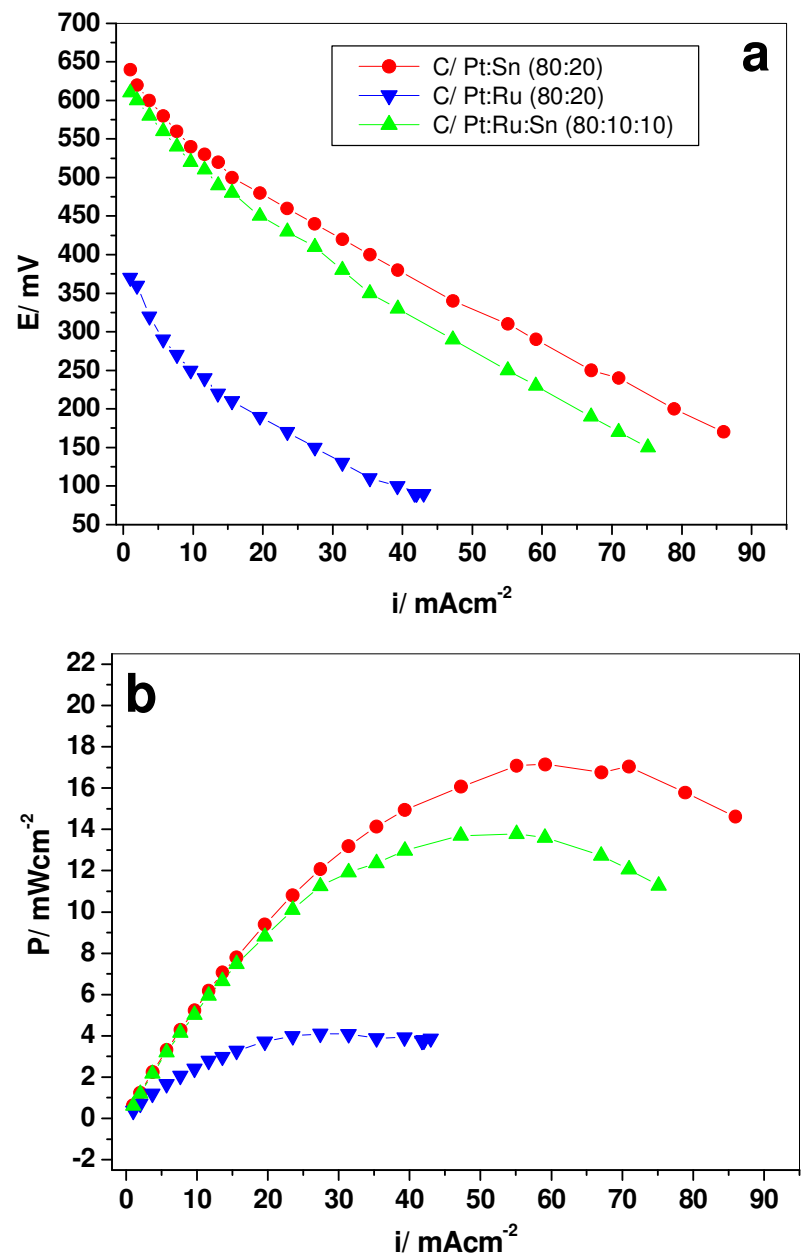

Figura 69: Valores de tensão $(\mathrm{E} / \mathrm{mV})$ e densidade de potência $\left(\mathrm{P} / \mathrm{mWcm}^{-2}\right)$ em função da densidade de corrente (i/ $\mathrm{mAcm}^{-2}$ ) para todas as composições investigadas. Medidas realizadas com etanol $2 \mathrm{M}$, a $80^{\circ} \mathrm{C}, p \mathrm{O}_{2}=1$ bar e $p_{\text {etanol }}=1$ bar, fluxo de $\mathrm{O}_{2}=150 \mathrm{mLmin}^{-1}$ e fluxo de etanol $=2 \mathrm{mlmin}^{-1}$. Cátodo de Nafion ${ }^{\circledR} 117$. Ânodo com $25 \mathrm{~cm}^{2}$ e $2 \mathrm{mg}$ de Platina na composição.

Foram realizadas também medidas com o eletrodo comercial de composição C/ Pt:Sn (75:25)-E-TEK. Na Figura 70 estão apresentados os valores obtidos deste material em comparação com o eletrodo de composição C/ Pt:Sn (80:20). Nota-se que ambas composições apresentaram praticamente o mesmo comportamento, o eletrodo comercial apresenta resultados um pouco melhores de potência, mas o eletrodo de C/ Pt:Sn (80:20) 
preparado termicamente, apresenta excelente resultado comparado ao comercial. Os valores obtidos para o eletrodo comercial $\left(\sim 20 \mathrm{mWcm}^{-2}\right)$, são inferiores aos valores geralmente relatados em outros trabalhos $[120,205]$. Este fato pode ser atribuído a problemas experimentais, pois foi observado a contaminação de cobre no reservatório de água, utilizado para humidificar o gás oxigênio proveniente da tubulação do equipamento. Outro fator importante, já discutido na literatura, é a hidratação da membrana de Nafion ${ }^{\circledR} 117$ [205].
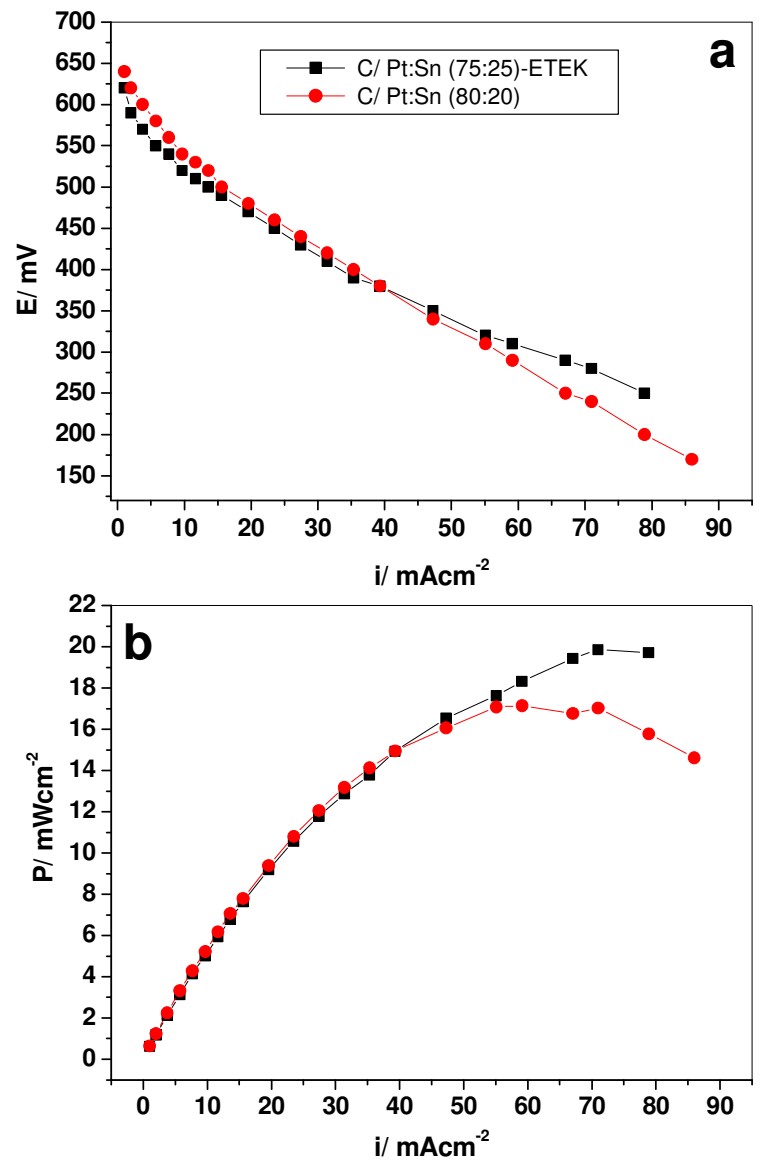

Figura 70: Valores de tensão $(\mathrm{E} / \mathrm{mV})$ e densidade de potência $\left(\mathrm{P} / \mathrm{mWcm}^{-2}\right)$ em função da densidade de corrente (i/ $\mathrm{mAcm}^{-2}$ ) para os eletrodos C/ Pt:Sn (75:25)-E-TEK e C/ Pt:Sn (80:20). Etanol $2 \mathrm{M}$, a $80^{\circ} \mathrm{C}, p \mathrm{O}_{2}=1$ bar e $p_{\text {Etanol }}=1$ bar, fluxo de $\mathrm{O}_{2}=150 \mathrm{mLmin}^{-1}$ e fluxo de etanol $=2 \mathrm{mlmin}^{-1}$. Cátodo de Nafion ${ }^{\circledR} 117$. Ânodo com $25 \mathrm{~cm}^{2}$. 


\section{IV.3.6 Conclusões}

Nos testes de voltametria $d c$, foi observado que o eletrodo de composição ternária Ti/ Pt:Ru:Sn (80:10:10), apresentou maior atividade para a oxidação do etanol, dando início a oxidação em potenciais inferiores as demais composições. Os valores de capacitância da dupla camada elétrica, $Q_{d c}$, em meio de etanol, apresentaram os menores valores para o eletrodo de Ti/Pt, devido a adsorção de moléculas de CO na superfície eletródica.

Observou-se que os eletrodos de composição Ti/ Pt:Ru:Sn (80:10:10), Ti/ Pt:Ru (80:20), Ti/ Pt:Sn (80:20), não apresentaram estabilidade quando submetidos às condições cronoamperometricas. Os valores de resistência de transferência de carga, $R_{t c}$, foram analisados de acordo com as diferentes regiões de potencial, sendo observado valores negativos de $R_{t c}$, nos potenciais entre 0,7 e $1,0 \mathrm{~V} v s$. ERH. Tais valores de $R_{t c}$ são obtidos após o pico de oxidação do etanol e atribuídos ao fato de que nesta região, a $R_{t c}$ não mais limitar a velocidade da reação.

Os estudos de voltametria $a c$ possibilitaram a análise de todas as composições de interesse, pois estas se apresentaram mais estáveis à técnica do que a estabilização cronoamperométrica. Além disso, outra vantagem foi, a obtenção de valores dos elementos do circuito em intervalos menores de potencial, possibilitanto uma visão mais detalhada dos resultados obtidos. Os valores de $Q_{d c}$ obtidos por voltametria $a c$ e também por estabilização cronoamperométrica seguida de EIE foram similiares, comprovando a equivalência entre as técnicas, que possibilitam as medidas de EIE no estado estacionário. 
Os testes de células a combustível de etanol comprovaram os resultados da EIE, obtidos pelos valores de $R_{t c}$ em função do material, indicando que o eletrodo de composição Pt:Sn (80:20) apresentou o melhor desempenho na oxidação do etanol. Deve-se salientar também que, o catalisador C/Pt:Sn (80:20), preparado por decomposição térmica de precursores poliméricos, apresentou desempenho similar ao catalisador C/Pt:Sn (75:25) - ETEK em baixas densisdades de corrente. 


\section{V- CONCLUSÕES FINAIS}

Neste trabalho, foi possível confirmar que, a técnica de EIE pode ser aplicada a diferentes materiais, com diferentes objetivos, apresentando bons resultados. No estudo da RDO de ADEs, a técnica possibilitou quantificar resultados qualitativos, apresentados na literatura utilizado-se outras técnicas eletroquímicas. Foi observado que a teoria $a c$ (EIE) e dc (Tafel) apresentam o mesmo comportamento, portanto, podem ser ditas equivalentes.

Outro fator importante é a versatilidade da técnica de EIE, diferentes procedimentos experimentais procuram ser equivalentes, permitindo que materiais diferentes possam ser investigados pela técnica de EIE. Assim, mostramos que as medidas de EIE podem ser aplicadas seguidas de estabilização cronoamperométricas ou medidas por voltametria $a c$, dependendo da estabilidade do material. Além disso, os resultados experimentais podem ser analisados adotando diferentes abordagens matemáticas tais como: circuito equivalente ou linha de transmissão. Tanto no estudo de ADEs como de ânodos de platina aplicáveis a DEFCs, a EIE apresentou-se uma técnica extremamente útil e interessante. 


\section{V- REFERÊNCIAS BIBLIOGRÁFICAS}

1. Lasia A., "Impedance of Porous-Electrodes", Journal of Electroanalytical Chemistry, 397(1-2), p. 27-33, 1995.

2. Lasia A., "Porous electrodes in the presence of a concentration gradient", Journal of Electroanalytical Chemistry, 428, p. 155-164, 1997.

3. Lasia A., "Hydrogen evolution/oxidation reactions on porous electrodes", Journal of Electroanalytical Chemistry, 454(1-2), p. 115-121, 1998.

4. Lasia A., "Nature of the two semi-circles observed on the complex plane plots on porous electrodes in the presence of a concentration gradient", Journal of Electroanalytical Chemistry, 500, p. 30-35, 2001.

5. $\quad$ Bueno P. R., Leite E. R., Giraldi T. R., Bulhoes L. O. S., Longo E., "Nanostructured Li ion insertion electrodes. 1. Discussion on Fast Transport and Short Path for Ion Diffusion", Journal of Physical Chemistry B, 107(34), p. 8868-8877, 2003.

6. Bisquert J., Garcia-Belmonte G., Fabregat-Santiago F., Ferriols N. S., Bogdanoff P., Pereira E. C., "Doubling exponent models for the analysis of porous film electrodes by impedance. Relaxation of $\mathrm{TiO} 2$ nanoporous in aqueous solution", Journal of Physical Chemistry B, 104(10), p. 2287-2298, 2000.

7. Cao F., Oskam G., Meyer G. J., Searson P. C., "Electron transport in porous nanocrystalline $\mathrm{TiO}_{2}$ photoelectrochemical cells", Journal of Physical Chemistry, 100(42), p. 17021-17027, 1996.

8. Cao F., Oskam G., Searson P. C., "Charge transport processes in nanoporous TiO2 films", Abstracts of Papers of the American Chemical Society, 211, p. 141-PHYS, 1996.

9. $\quad$ Grätzel M., "Photoelectrochemical cells", Nature, 414, p. 338-344, 2001.

10. Alves V. A., Da Silva L. A., Boodts J. F. C., "Electrochemical impedance spectroscopic study of dimensionally stable anode corrosion", Journal of Applied Electrochemistry, 28(9), p. 899-905, 1998.

11. Alves V. A., Da Silva L. A., Boodts J. F. C., "Surface characterisation of $\mathrm{IrO}_{2} / \mathrm{TiO}_{2} / \mathrm{CeO}_{2}$ oxide electrodes and Faradaic impedance investigation of the oxygen evolution reaction from alkaline solution", Electrochimica Acta, 44(8-9), p. $1525-1534,1998$.

12. Alves V. A., da Silva L. A., Boodts J. F. C., "Impedance study of the oxygen evolution on the $\mathrm{IrO} 2 / \mathrm{TiO} 2 / \mathrm{CeO} 2$ system in acidic medium", Polish Journal of Chemistry, 74(3), p. 421-428, 2000.

13. Alves V. A., Da Silva L. A., Boodts J. F. C., Trasatti S., "Kinetics and Mechanism of Oxygen Evolution on $\mathrm{IrO}_{2}$-Based Electrodes Containing $\mathrm{Ti}$ and $\mathrm{Ce}$ Acidic Solutions", Electrochimica Acta, 39(11-12), p. 1585-1589, 1994.

14. De Andrade A. R., Donate P. M., Alves P. P. D., Fidellis C. H. V., Boodts J. F. C., "Ethanol electro-oxidation in ruthenium-oxide-coated titanium electrodes", Journal of the Electrochemical Society, 145(11), p. 3839-3843, 1998. 
15. Wu J., Yuana X. Z., Wang H., Blanco M., Martin J. J., Zhang J., "Diagnostic tools in PEM fuel cell research:Part I Electrochemical techniques", International Journal of Hydrogem Energy, 33, p. 1735 - 1746, 2008.

16. Carvalho L. A., De Andrade A. R., Bueno P. R., "Espectroscopia de Impedância Eletroquímica aplicada ao estudo das reações heterogêneas em Ânodos Dimensionalmente Estáveis", Química Nova, 29(4), p. 796-804, 2006.

17. Macdonald J. R., Impedance Spectroscopy: John Wiley and Sons, 1987.

18. Bisquert J., Garcia-Belmonte G., Fabregat-Santiago F., Compte A., "Anomalous transport effects in the impedance of porous film electrodes", Electrochemistry Communications, 1, p. 429-435, 1999.

19. De Levie R., "On porous electrodes in electrolyte solutions", Electrochimica Acta, 8, p. 751-780, 1963.

20. Boukamp B. A., "Equivalent Circuit", University of Twente, the Netherlands, 1989.

21. Lasia A., "Impedance of porous electrodes", Modern Aspects of Electrochemistry. in print ed. Vol. 43, Sherbrooke, 2008.

22. Levie R., "Advances in Electrochemistry and Electrochemical Engineering", $P$. Delahay (Ed.), VI(Interscience, New York), p. 329, 1967.

23. Hitz C. \& Lasia A., "Experimental study and modeling of impedance of the her on porous Ni electrodes", Journal of Electroanalytical Chemistry, 500, p. 213-222, 2001.

24. Bueno P. R., Leite E. R., Giraldi T. R., Bulhoes L. O. S., Longo E., "Nanostructured $\mathrm{Li}$ ion insertion electrodes. 2. Tin dioxide nanocrystalline layers and discussion on "nanoscale effect"", J. Phys. Chem. B, 107(34), p. 8878, 2003.

25. Terezo A. J., Bisquert J., Pereira E. C., Garcia-Belmonte G., "Separation of transport, charge storage and reaction processes of porous electrocatalytic $\mathrm{IrO}_{2}$ and $\mathrm{IrO}_{2} / \mathrm{Nb}_{2} \mathrm{O}_{5}$ electrodes", Journal of Electroanalytical Chemistry, 508(1-2), p. 59-69, 2001.

26. Bisquert J., Garcia-Belmonte G., Fabregat-Santiago F., Ferriols N. S., Bogdanoff P., Pereira E. C., "Doubling exponent models for the analysis of porous film electrodes by impedance. Relaxation of $\mathrm{TiO}_{2}$ nanoporous in aqueous solution", J. Phys. Chem. $B, 104(10)$, p. 2287, 2000.

27. Bruce P. G., Solid State Electrochemistry, Cambridge: Cambridge University Press, 1995.

28. Harrington D. A., "Ac Voltammetry for Measurement of Surface Kinetics", Journal of Electroanalytical Chemistry, 355(1-2), p. 21-35, 1993.

29. Breiter M. W., "Isotherms for Hydrogen Adsorption on Platinum Electrodes in Sulfuric Acid Solution", Journal of Electroanalytical Chemistry, 8(6), p. 449-\&, 1964.

30. Tilak B. V., Kozlowsk.Ha, Conway B. E., Perkins R. S., "Impedance and Formation Characteristics of Electrolytically Generated Silver Oxides .1. Formation and Reduction of Surface Oxides and Role of Dissolution Processes", Electrochimica Acta, 17(8), p. 1447-\&, 1972.

31. Conway B. E. \& Gottesfe.S, "Real Condition of Oxidized Platinum-Electrodes .2. Resolution of Reversible and Irreversible Processes by Optical and Impedance 
Studies", Journal of the Chemical Society-Faraday Transactions I, 69, p. 10901107, 1973.

32. Trasatti S., "Electrocatalysis: understanding the success of DSA (R)", Electrochimica Acta, 45(15-16), p. 2377-2385, 2000.

33. Ribeiro J., De Andrade A. R., Bento C. A. S., Tremiliosi-Filho G., "Surface Morphology and Chemical composition of Thermally Prepared $\left(\mathrm{RuO}_{2}\right) \mathrm{x}\left(\mathrm{Ta}_{2} \mathrm{O}_{5}\right) \mathrm{y} / \mathrm{Ti}$ coatings", Acta Microsc., 12(1), p. 115-119, 2003.

34. Shieh D. T. \& Hwang B. J., "Morphology and Electrochemical Activity of Ru-Ti-Sn Ternary-Oxide Electrodes in $1 \mathrm{~m} \mathrm{NaCl}$ Solution", Electrochimica Acta, 38(15), p. 2239-2246, 1993.

35. Trasatti S. \& Jaksic M. M., "Special issue - Electrocatalysis: Advances and industrial applications", Electrochimica Acta, 45(25-26), p. XI-XI, 2000.

36. Trasatti S. \& Lodi G., Electrode of Conductive Metallic Oxides, part A and B. Elsevier, Amsterdam, ed. Trasatti S. 521-626, 1981.

37. Trasatti S. \& Kurzweil P., "Electrochemical Supercapacitors as Versatile Energy Stores. Potential Use for Platinum Metals", Platinum Met. Rev., 38(2), p. 46-56, 1994.

38. Kinoshita E., Ingman F., Edwall G., Glab S., "An examination of the palladiumpalladium oxide system and its utility for $\mathrm{pH}$-sensing electrode", Electrochimica Acta, 31(1), p. 29-38, 1986.

39. Amatore C., Berthou M., Hebert S., "Fundamental principles of electrochemical ohmic heating of solutions", Journal of Electroanalytical Chemistry, 457(1-2), p. 191-203, 1998.

40. Comninellis C. \& De Battisti A., "Electrocatalysis in anodic oxidation of organics with simultaneous oxygen evolution", J. Chimie Phys. Phys.-Chimie Biolog., 93(4), p. $673,1996$.

41. Fóti G., Gandini D., Comninellis C., "Anodic Oxidation of Organics on Thermally Prepared Oxide Electrodes", Curr. Top. Electrochem., 5, p. 71-91, 1997.

42. Boodts J. F. C. \& Trasatti S., "Effect of Composition on the Electrocatalytic Activity of the Ternary Oxide $\mathrm{Ru}_{0.3} \mathrm{Ti}_{(0.7-\mathrm{X})} \mathrm{Sn}_{\mathrm{x}} \mathrm{O}_{2} .1$. Oxygen Evolution from $\mathrm{HClO}_{4}$ Solutions", Journal of the Electrochemical Society, 137(12), p. 3784-3789, 1990.

43. Da Silva L. M., Boodts J. F. C., De Faria L. A., "Oxygen evolution at $\mathrm{RuO}_{2}(\mathrm{x})$ plus $\mathrm{Co}_{3} \mathrm{O}_{4}(1-\mathrm{x})$ electrodes from acid solution", Electrochim. Acta, 46(9), p. 1369, 2001.

44. Da Silva L. M., Boodts J. F. C., De Faria L. A., "Chlorine evolution reaction at $\mathrm{Ti} /\left(\mathrm{RuO}_{2}+\mathrm{Co}_{3} \mathrm{O}_{4}\right)$ electrodes", Journal of the Brazilian Chemical Society, 14(3), p. 388-395, 2003.

45. Forti J. C., Olivi P., De Andrade A. R., "Characterisation of DSA((R))-type coatings with nominal composition $\mathrm{Ti} / \mathrm{Ru}_{0.3} \mathrm{Ti}_{(0.7-\mathrm{x})} \mathrm{Sn}_{\mathrm{x}} \mathrm{O}_{2}$ prepared via a polymeric precursor", Electrochimica Acta, 47(6), p. 913-920, 2001.

46. Lassali T. A. F., Boodts J. F. C., Trasatti S., "Electrocatalytic Activity of the Ternary Oxide $\mathrm{Ru}_{0.3} \mathrm{Pt}_{\mathrm{x}} \mathrm{Ti}_{(0.7-\mathrm{X})} \mathrm{O}_{2}$ for Chlorine Evolution", Electrochim. Acta, 39(11-12), p. 1545, 1994.

47. Lassali T. A. F., Boodts J. F. C., Decastro S. C., Landers R., Trasatti S., "Uhv and Electrochemical Studies of the Surface-Properties of $\mathrm{Ru}+\mathrm{Pt}+\mathrm{Ti}$ Mixed-Oxide Electrodes", Electrochim. Acta, 39(1), p. 95, 1994. 
48. Pelegrino R. R. L., Vicentin L. C., De Andrade A. R., Bertazzoli R., "Thirty minutes laser calcination method for the preparation of DSA (R) type oxide electrodes", Electrochem. Commun., 4(2), p. 139, 2002.

49. Alves V. A., Da Silva L. A., Boodts J. F. C., "Surface characterisation of $\mathrm{IrO}_{2} / \mathrm{TiO}_{2} / \mathrm{CeO}_{2}$ oxide electrodes and Faradaic impedance investigation of the oxygen evolution reaction from alkaline solution", Electrochim. Acta, 44(8-9), p. $1525,1998$.

50. Motheo A. J., Gonzalez E. R., Tremiliosi G., Olivi P., de Andrade A. R., Kokoh B., Leger J. M., Belgsir E. M., Lamy C., "The oxidation of formaldehyde on high overvoltage DSA type electrodes", Journal of the Brazilian Chemical Society, 11(1), p. 16-21, 2000.

51. Da Silva L. A., Alves V. A., Trasatti S., Boodts J. F. C., "Surface and electrocatalytic properties of ternary oxides $\operatorname{Ir}_{0.3} \mathrm{Ti}_{(0.7-\mathrm{x})} \mathrm{Pt}_{\mathrm{x}} \mathrm{O}_{2}$. Oxygen evolution from acidic solution", J. Electroanal. Chem., 427(1-2), p. 97, 1997.

52. Da Silva L. M., Franco D. V., De Faria L. A., Boodts J. F. C., "Surface, kinetics and electrocatalytic properties of $\mathrm{Ti} /\left(\mathrm{IrO}_{2}+\mathrm{Ta}_{2} \mathrm{O}_{5}\right)$ electrodes, prepared using controlled cooling rate, for ozone production", Electrochimica Acta, 49(22-23), p. 3977-3988, 2004.

53. Da Silva L. A., Alves V. A., Da Silva M. A. P., Trasatti S., Boodts J. F. C., "Electrochemical impedance, SEM, EDX and voltammetric study of oxygen evolution on $\mathrm{Ir}+\mathrm{Ti}+\mathrm{Pt}$ ternary-oxide electrodes in alkaline solution", Electrochimica Acta, 41(7-8), p. 1279-1285, 1996.

54. Da Silva L. A., Alves V. A., Da Silva M. A. P., Trasatti S., Boodts J. F. C., "Oxygen evolution in acid solution on $\mathrm{IrO}_{2}+\mathrm{TiO}_{2}$ ceramic films. A study by impedance, voltammetry and SEM", Electrochim. Acta, 42(2), p. 271, 1997.

55. Lassali T. A. F., Boodts J. F. C., Bulhoes L. O. S., "Charging processes and electrocatalytic properties of $\mathrm{IrO}_{2} / \mathrm{TiO}_{2} / \mathrm{SnO}_{2}$ oxide films investigated by in situ AC impedance measurements", Electrochimica Acta, 44(24), p. 4203-4216, 1999.

56. Lassali T. A. F., Boodts J. F. C., Bulhoes L. O. S., "Effect of Sn-precursor on the morphology and composition of $\mathrm{Ir}_{0.3} \mathrm{Sn}_{0.7} \mathrm{O}_{2}$ oxide films prepared by sol-gel process", J. Non-Crystal. Sol., 273(1-3), p. 129, 2000.

57. Lin S. M. \& Wen T. C., "Oxygen Evolution on Ir-Ru-Sn Ternary Oxide-Coated Electrodes in $\mathrm{H}_{2} \mathrm{SO}_{4}$ Solution - an Approach Employing Statistical Experimental Strategy", Journal of the Electrochemical Society, 140(8), p. 2265-2271, 1993.

58. Hu J. M., Meng H. M., Zhang J. Q., Cao C. N., "Degradation mechanism of long service life $\mathrm{Ti} / \mathrm{IrO}_{2}-\mathrm{Ta}_{2} \mathrm{O}_{5}$ oxide anodes in sulphuric acid", Corros. Sci., 44(8), p. 1655-1668, 2002.

59. Hu J. M., Zhang J. Q., Cao C. N., "Oxygen evolution reaction on $\mathrm{IrO}_{2}$-based DSA (R) type electrodes: kinetics analysis of Tafel lines and EIS", Int. J. Hydrogen Energy, 29(8), p. 791, 2004.

60. Mahe E., Devilliers D., Groult H., Pouilleau J., "Electrochemical behaviour of platinum-coated $\mathrm{Ta} / \mathrm{Ta}_{2} \mathrm{O}_{5}$ electrodes", Electrochimica Acta, 44(13), p. 2307-2315, 1999. 
61. Ribeiro J. \& De Andrade A. R., "Characterization of $\mathrm{RuO}_{2}-\mathrm{Ta}_{2} \mathrm{O}_{5}$ Coated Titanium Electrode Microstructure, Morphology, end Electrochemical Investigation", $J$. Electrochem. Soc., 151(10), p. D106-D112, 2004.

62. Xu L. K. \& Scantlebury J. D., "A study on the deactivation of an $\mathrm{IrO}_{2}-\mathrm{Ta}_{2} \mathrm{O}_{5}$ coated titanium anode", Corros. Sci., 45(12), p. 2729-2740, 2003.

63. Terezo A. J. \& Pereira E. C., "Preparation and characterization of $\mathrm{Ti} / \mathrm{RuO} \mathrm{O}_{2}-\mathrm{Nb}_{2} \mathrm{O}_{5}$ electrodes obtained by polymeric precursor method", Electrochimica Acta, 44(25), p. 4507-4513, 1999.

64. Terezo A. J. \& Pereira E. C., "Fractional factorial design applied to investigate properties of $\mathrm{Ti} / \mathrm{IrO}_{2}-\mathrm{Nb}_{2} \mathrm{O}_{5}$ electrodes", Electrochimica Acta, 45(25-26), p. 43514358, 2000.

65. Forti J. C., Manzo-Robledo A., Kokoh K. B., De Andrade A. R., Alonso-Vante N., "Electrooxidation of acetaldehyde on platinum-modified $\mathrm{Ti} / \mathrm{Ru}_{0.3} \mathrm{Ti}_{0.7} \mathrm{O}_{2}$ electrodes", Electrochimica Acta, 51(14), p. 2800-2808, 2006.

66. Burke L. D. \& McCarthy M., "Oxygen Gas Evolution at, and Deterioration of, $\mathrm{RuO}_{2} / \mathrm{ZrO}_{2}$-Coated Titanium Anodes at Elevated-Temperature in Strong Base", Electrochimimica Acta, 29(2), p. 211-216, 1984.

67. Pelegrino R. L., Di Iglia R. A., Sanches C. G., Avaca L. A., Bertazzoli R., "Comparative study of commercial oxide electrodes performance in electrochemical degradation of organics in aqueous solutions", J. Braz. Chem. Soc., 13(1), p. 60, 2002.

68. Zanta C. L. P. S., De Andrade A. R., Boodts J. F. C., "Solvent and support electrolyte effects on the catalytic activity of $\mathrm{Ti} / \mathrm{RuO}_{2}$ and $\mathrm{Ti} / \mathrm{IrO}_{2}$ electrodes: oxidation of isosafrole as a probe model", Electrochim. Acta, 44(19), p. 3333, 1999.

69. Bertazzoli R. \& Pelegrini R., "Photoelectrochemical discoloration and degradation of organic pollutants in aqueous solutions", Quim. Nova, 25(3), p. 477, 2002.

70. Comninellis C., "Electrocatalysis in the Electrochemical Conversion/Combustion of Organic Pollutants for Waste-Water Treatment", Electrochimica Acta, 39(11-12), p. 1857-1862, 1994.

71. Savall A., "Electrochemical Treatment of Industrial Organic Effluents", Chimia, 49(1-2), p. 23-27, 1995.

72. Stucki S., Kotz R., Carcer B., Suter W., "Electrochemical Waste-Water Treatment Using High Overvoltage Anodes .2. Anode Performance and Applications", Journal of Applied Electrochemistry, 21(2), p. 99-104, 1991.

73. Pelegrini R., Reyes J., Duran N., Zamora P. P., De Andrade A. R., "Photoelectrochemical degradation of lignin", Journal of Applied Electrochemistry, 30(8), p. 953-958, 2000.

74. Lin S. M. \& Wen T. C., "Electrocatalytic Oxidation of Benzyl Alcohol in AlkalineMedium in $\mathrm{RuO}_{2}$-Coated Titanium Electrode", Journal of Applied Electrochemistry, 25(1), p. 73-79, 1995.

75. Alves V. A., Dasilva L. A., Boodts J. F. C., Trasatti S., "Kinetics and Mechanism of Oxygen Evolution on Iro2-Based Electrodes Containing $\mathrm{Ti}$ and $\mathrm{Ce}$ Acidic Solutions", Electrochimica Acta, 39(11-12), p. 1585-1589, 1994. 
76. De Andrade A. R., Donate P. M., Alves P. P. D., Fidellis C. H. V., Boodts J. F. C., "Ethanol electro-oxidation in ruthenium-oxide-coated titanium electrodes", $J$. Electrochem. Soc., 145(11), p. 3839, 1998.

77. Forti J. C., Olivi P., de Andrade A. R., "Electrochemical behavior of ethanol oxidation on a Ti/ $\mathrm{Ru}_{0.3} \mathrm{Ti}_{(0.7-\mathrm{x})} \mathrm{Sn}_{\mathrm{x}} \mathrm{O}_{2}$ electrode - The role of experimental parameters in the selectivity of the products", Journal of the Electrochemical Society, 150(4), p. E222-E226, 2003.

78. Rodrigo M. A., Michaud P. A., Duo I., Panizza M., Cerisola G., Comninellis C., "Oxidation of 4-chlorophenol at boron-doped diamond electrode for wastewater treatment", Journal of the Electrochemical Society, 148(5), p. D60-D64, 2001.

79. Zanta C., Michaud P. A., Comninellis C., De Andrade A. R., Boodts J. F. C., "Electrochemical oxidation of p-chlorophenol on $\mathrm{SnO}_{2}-\mathrm{Sb}_{2} \mathrm{O}_{5}$ based anodes for wastewater treatment", Journal of Applied Electrochemistry, 33(12), p. 1211-1215, 2003.

80. Da Silva L. A., Alves V. A., Da Silva M. A. P., Trasatti S., Boodts J. F. C., "Oxygen evolution in acid solution on $\mathrm{IrO}_{2}+\mathrm{TiO}_{2}$ ceramic films. A study by impedance, voltammetry and SEM", Electrochim. Acta, 42(2), p. 271-281, 1997.

81. Lassali T. A. F., Boodts J. F. C., Bulhoes L. O. S., "Faradaic impedance investigation of the deactivation mechanism of Ir-based ceramic oxides containing $\mathrm{TiO}_{2}$ and $\mathrm{SnO}_{2} "$, Journal of Applied Electrochemistry, 30(5), p. 625-634, 2000.

82. Borresen B., Hagen G., Tunold R., "Hydrogen evolution on $\mathrm{Ru}_{\mathrm{x}} \mathrm{Ti}_{1-\mathrm{x}} \mathrm{O} 2$ in $0.5 \mathrm{M}$ $\mathrm{H}_{2} \mathrm{SO}_{4}$ ", Electrochim. Acta, 47(11), p. 1819-1827, 2002.

83. Malpass G. R. P., Neves R. S., Motheo A. J., "A comparative study of commercial and laboratory-made $\mathrm{Ti} / \mathrm{Ru}_{0.3} \mathrm{Ti}_{0.7} \mathrm{O}_{2}$ DSA ${ }^{\circledR}$ electrodes: "In situ" and "ex situ" surface characterisation and organic oxidation activity", Electrochimica Acta, 52(3), p. 936-944, 2006.

84. Da Silva L. M., De Faria L. A., Boodts J. F. C., "Electrochemical impedance spectroscopic (EIS) investigation of the deactivation mechanism, surface and electrocatalytic properties of $\mathrm{Ti} / \mathrm{RuO}_{2(\mathrm{x})}+\mathrm{Co}_{3} \mathrm{O}_{4(1-\mathrm{x})}$ electrodes", Journal of Electroanalytical Chemistry, 532(1-2), p. 141-150, 2002.

85. Hu J. M., Zhang J. Q., Cao C. N., "Oxygen evolution reaction on $\mathrm{IrO}_{2}$-based DSA (R) type electrodes: kinetics analysis of Tafel lines and EIS", Int. J. Hydrogen Energy, 29(8), p. 791-797, 2004.

86. Liu Y., Li Z. Y., Li J. H., " $\mathrm{IrO}_{2} / \mathrm{SnO}_{2}$ electrodes: prepared by sol-gel process and their electrocatalytic for pyrocatechol", Acta Mater., 52(3), p. 721-727, 2004.

87. Miller B. \& Chen A., "Effect of concentration and temperature on electrochemical oscillations during sulfide oxidation on $\mathrm{Ti} / \mathrm{Ta}_{2} \mathrm{O}_{5}-\mathrm{IrO}_{2}$ electrodes", Electrochimica Acta, 50(11), p. 2203-2212, 2005.

88. Panic V. V., Vidakovic T. R., Dekanski A. B., Miskovic-Stankovic V. B., Nikolic B. Z., "Capacitive properties of $\mathrm{RuO}_{2}$-coated titanium electrodes prepared by the alkoxide ink procedure", Journal of Electroanalytical Chemistry, 609(2), p. 120128, 2007.

89. Castro E. B., Real S. G., Bonesi A., Visintin A., Triaca W. E., "Electrochemical impedance characterization of porous metal hydride electrodes", Electrochim. Acta, 49(22-23), p. 3879-3890, 2004. 
90. Hasbach A., Retter U., Siegler K., Kautek W., "On the impedance of porous electrodes - double-layer charging and charge transfer on an inhomogeneous inside electrode surface", J. Electroanal. Chem., 561(1-2), p. 29-35, 2004.

91. Garcia-Belmonte G., Bisquert J., Pereira E. C., Fabregat-Santiago F., "Anomalous transport on polymeric porous film electrodes in the dopant-induced insulator-toconductor tansition analyzed by electrochemical impedance", Applied Physics Letters, 78, p. 1885-1887, 2001.

92. Grove W. R., Phil. Mag., 3(14), p. 127, 1839.

93. Grove W., Phil. Mag., 3(15), p. 287, 1839.

94. Grove W. R., Phil. Mag., 3(21), p. 417, 1842.

95. Alcaide F., Cabot P. L., Brillas E., "Fuel cells for chemicals and energy cogeneration", Journal of Power Sources, 153(1), p. 47-60, 2006.

96. Rousseau S., Développement de catalyseurs plurimétalliques multifonctionnels pour l'oxydation électrocatalytique de l'éthanol dans une pile à oxydation directe (DEFC), Docteur - Faculté des Sciences Fondamentales et Appliquées, l'Université de Poitiers: Poitiers. p. 229, 2004.

97. Viol J. B., Loureiro F. A. M., Pereira R. P., Mota C. J. A., Rocco A. M. Matrizes poliméricas copósitas Nafion $\AA / Z e o ́ l i t a ~ Y$ nanomérica condutoras protônicas para aplicação em Células a Combustível. in $29^{\circ}$ Reunião Anual da Sociedade Brasileira de Química, 2006.

98. Le Ninivin C., Balland-Longeau A., Demattei D., Palmas P., Saillard J., Coutanceau C., Lamy C., Leger J. M., "Determination of the physicochemical characteristics and electrical performance of postsulfortated and grafted sulfonated derivatives of poly(para-phenylene) as new proton-conducting membranes for direct methanol fuel cell", Journal of Applied Polymer Science, 101(2), p. 944-952, 2006.

99. Aupretre F., Descorme C., Duprez D., "Catalytic steam reforming: Use for on-board hydrogen production from hydrocarbons or alcohols", Anna. De Chim.-Sci. Mat, 26(4), p. 93-106, 2001.

100. Wang J., Wasmus S., Savinell R. F., "Evaluation of Ethanol, 1-Propanol, and 2Propanol in a Direct Oxidation Polymer-Electrolyte Fuel Cell", J. Electrochem. Soc, 142(12), p. 4218-4224, 1995.

101. Song S., Wang G., Zhou W., Zhao X., Sun G., Xin Q., Kontou S., Tsiakaras P., "The effect of the MEA preparation procedure on both ethanol crossover and DEFC performance", Journal of Power Sources, 140(1), p. 103-110, 2005.

102. Wang H., Jusys Z., Behm R. J., "Ethanol electro-oxidation on carbon-supported Pt, $\mathrm{PtRu}$ and $\mathrm{Pt}_{3} \mathrm{Sn}$ catalysts: A quantitative DEMS study", Journal of Power Sources, 154(2), p. 351-359, 2006.

103. Schmidt V. M. \& Pastor E., "Electro-oxidation of propene on gold in acid solution studied by DEMS and FTIRS", Journal of Electroanalytical Chemistry, 401(1-2), p. 155-161, 1996.

104. Willsau J. \& Heitbaum J., "Elementary Steps of Ethanol Oxidation on Pt in Sulfuric-Acid as Evidenced by Isotope Labeling", Journal of Electroanalytical Chemistry, 194(1), p. 27-35, 1985.

105. Iwasita T. \& Pastor E., "A Dems and Ftir Spectroscopic Investigation of Adsorbed Ethanol on Polycrystalline Platinum", Electrochimica Acta, 39(4), p. 531-537, 1994. 
106. Bittinscattaneo B., Wilhelm S., Cattaneo E., Buschmann H. W., Vielstich W., "Intermediates and Products of Ethanol Oxidation on Platinum in Acid-Solution", Berichte Der Bunsen-Gesellschaft-Physical Chemistry Chemical Physics, 92(11), p. 1210-1218, 1988.

107. Iwasita T., Rasch B., Cattaneo E., Vielstich W., "A Sniftirs Study of Ethanol Oxidation on Platinum", Electrochimica Acta, 34(8), p. 1073-1079, 1989.

108. Schmidt V. M., Ianniello R., Pastor E., Gonzalez S., "Electrochemical reactivity of ethanol on porous Pt and PtRu: Oxidation/reduction reactions in $1 \mathrm{M} \mathrm{HClO4",}$ Journal of Physical Chemistry, 100(45), p. 17901-17908, 1996.

109. Gootzen J. F. E., Visscher W., vanVeen J. A. R., "Characterization of ethanol and 1,2-ethanediol adsorbates on platinized platinum with Fourier transform infrared spectroscopy and differential electrochemical mass spectrometry", Langmuir, 12(21), p. 5076-5082, 1996.

110. Ioannides T., "Thermodynamic analysis of ethanol processors for fuel cell applications", Journal of Power Sources, 92(1), p. 17-25, 2001.

111. Iwasita T., "Fuel cells: Spectroscopic studies in the electrocatalysis of alcohol oxidation", Journal of the Brazilian Chemical Society, 13(4), p. 401-409, 2002.

112. Perez J. M., Beden B., Hahn F., Aldaz A., Lamy C., "Insitu Infrared Reflectance Spectroscopic Study of the Early Stages of Ethanol Adsorption at a PlatinumElectrode in Acid-Medium", Journal of Electroanalytical Chemistry, 262(1-2), p. 251-261, 1989.

113. Camara G. A. \& Iwasita T., "Parallel pathways of ethanol oxidation: The effect of ethanol concentration", Journal of Electroanalytical Chemistry, 578(2), p. 315-321, 2005.

114. Rightmire R. A., Rowland R. L., Boos D. L., Beals D. L., "Ethyl Alcohol Oxidation at Platinum Electrodes", Journal of the Electrochemical Society, 111(2), p. 242-247, 1964.

115. Cases F., Lopezatalaya M., Vazquez J. L., Aldaz A., Clavilier J., "Dissociative Adsorption of Ethanol on Pt (H, K, L) Basal Surfaces", Journal of Electroanalytical Chemistry, 278(1-2), p. 433-440, 1990.

116. Pastor E. \& Iwasita T., "D/H Exchange of Ethanol at Platinum-Electrodes", Electrochimica Acta, 39(4), p. 547-551, 1994.

117. Hitmi H., Belgsir E. M., Leger J. M., Lamy C., Lezna R. O., "A Kinetic, Analysis of the Electrooxidation of Ethanol at a Platinum-Electrode in Acid-Medium", Electrochimica Acta, 39(3), p. 407-415, 1994.

118. Lamy C., Belgsir E. M., Leger J. M., "Electrocatalytic oxidation of aliphatic alcohols: Application to the direct alcohol fuel cell (DAFC)", Journal of Applied Electrochemistry, 31(7), p. 799-809, 2001.

119. De Andrade A. R. \& Boodts J. F. C., "Electrochemical behavior of 4-keto isophorone in non-aqueous medium in the presence of carbon dioxide", Journal of the Brazilian Chemical Society, 9(2), p. 157-161, 1998.

120. Simões F. C., Dos Anjos D. M., Vigier F., Leger J. M., Hahn F., Coutanceau C., Gonzalez E. R., Tremiliosi G., De Andrade A. R., Olivi P., Kokoh K. B., "Electroactivity of tin modified platinum electrodes for ethanol electrooxidation", Journal of Power Sources, 167(1), p. 1-10, 2007. 
121. Ribeiro J., Alves P. D. P., De Andrade A. R., "Effect of the preparation methodology on some physical and electrochemical properties of Ti/IrxSn(1-x)O2 materials", Journal of Materials Science, 42(22), p. 9293-9299, 2007.

122. Xia X. H., Liess H. D., Iwasita T., "Early stages in the oxidation of ethanol at low index single crystal platinum electrodes", Journal of Electroanalytical Chemistry, 437(1), p. 233-240(8), 1997.

123. Morin M. C., Lamy C., Leger J. M., Vasquez J. L., Aldaz A., "Structural Effects in Electrocatalysis - Oxidation of Ethanol on Platinum Single-Crystal Electrodes Effect of Ph", Journal of Electroanalytical Chemistry, 283(1-2), p. 287-302, 1990.

124. Lamy C., Rousseau S., Belgsir E. M., Coutanceau C., Leger J. M., "Recent progress in the direct ethanol fuel cell: development of new platinum-tin electrocatalysts", Electrochimica Acta, 49(22-23), p. 3901-3908, 2004.

125. Antolini E., "Catalysts for direct ethanol fuel cells", Journal of Power Sources, 170(1), p. 1-12, 2007.

126. Mendez E., Rodriguez J. L., Arevalo M. C., Pastor E., "Comparative study of ethanol and acetaldehyde reactivities on rhodium electrodes in acidic media", Langmuir, 18(3), p. 763-772, 2002.

127. Orozco G. \& Gutierrez C., "Adsorption and electro-oxidation of carbon monoxide, methanol, ethanol and formic acid on osmium electrodeposited on glassy carbon", Journal of Electroanalytical Chemistry, 484(1), p. 64-72, 2000.

128. Yee A., Morrison S. J., Idriss H., "A study of ethanol reactions over $\mathrm{Pt} / \mathrm{CeO}_{2}$ by temperature-programmed desorption and in situ FT-IR spectroscopy: Evidence of benzene formation", Journal of Catalysis, 191(1), p. 30-45, 2000.

129. Gotz M. \& Wendt H., "Binary and ternary anode catalyst formulations including the elements W, Sn and Mo for PEMFCs operated on methanol or reformate gas", Electrochimica Acta, 43(24), p. 3637-3644, 1998.

130. Kelley S. C., Deluga G. A., Smyrl W. H., "A miniature methanol/air polymer electrolyte fuel cell", Electrochemical and Solid State Letters, 3(9), p. 407-409, 2000.

131. He C. Z., Kunz H. R., Fenton J. M., "Evaluation of platinum-based catalysts for methanol electro-oxidation in phosphoric acid electrolyte", Journal of the Electrochemical Society, 144(3), p. 970-979, 1997.

132. Gasteiger H. A., Markovic N., Ross P. N., Cairns E. J., "Electrooxidation of Small Organic-Molecules on Well-Characterized Pt-Ru Alloys", Electrochimica Acta, 39(11-12), p. 1825-1832, 1994.

133. Hoster H., Iwasita T., Baumgartner H., Vielstich W., "Pt-Ru model catalysts for anodic methanol oxidation: Influence of structure and composition on the reactivity", Physical Chemistry Chemical Physics, 3(3), p. 337-346, 2001.

134. Lin W. F., Iwasita T., Vielstich W., "Catalysis of $\mathrm{CO}$ electrooxidation at Pt, Ru, and PtRu alloy. An in situ FTIR study", Journal of Physical Chemistry B, 103(16), p. 3250-3257, 1999.

135. Lin W. F., Zei M. S., Eiswirth M., Ertl G., Iwasita T., Vielstich W., "Electrocatalytic activity of Ru-modified Pt(111) electrodes toward CO oxidation", Journal of Physical Chemistry B, 103(33), p. 6968-6977, 1999. 
136. Camara G. A., De Lima R. B., Iwasita T., "Catalysis of ethanol electro oxidation by $\mathrm{PtRu}$ : the influence of catalyst composition", Electrochemistry Communications, 6(8), p. 812-815, 2004.

137. Spinace E. V., Neto A. O., Franco E. G., Linardi M., Gonzalez E. R., "Methods of preparation of metal nanoparticles supported on high surface area carbon as electrocatalysts in proton exchange membrane fuel cells." Quimica Nova, 27(4), p. 648-654, 2004.

138. Neto A. O., Giz M. J., Perez J., Ticianelli E. A., Gonzalez E. R., "The electrooxidation of ethanol on Pt-Ru and Pt-Mo particles supported on high-surface-area carbon", Journal of the Electrochemical Society, 149(3), p. A272-A279, 2002.

139. Spinace E. V., Neto A. O., Linardi M., "Electro-oxidation of ethanol on PtRu/C electrocatalysts prepared from (eta-C2H4) $(\mathrm{Cl}) \mathrm{Pt}(\mathrm{mu} \mathrm{Cl})(2) \mathrm{Ru}(\mathrm{Cl})(\mathrm{eta}(3)$, eta(3)C10H16)", Journal of Power Sources, 124(2), p. 426-431, 2003.

140. Watanabe M. \& Motoo S., "Electrocatalysis by Ad-Atoms .2. Enhancement of Oxidation of Methanol on Platinum by Ruthenium Ad-Atoms", Journal of Electroanalytical Chemistry, 60(3), p. 267-273, 1975.

141. Fujiwara N., Friedrich K. A., Stimming U., "Ethanol oxidation on PtRu electrodes studied by differential electrochemical mass spectrometry", Journal of Electroanalytical Chemistry, 472(2), p. 120-125, 1999.

142. Leung L. W. H., Wieckowski A., Weaver M. J., "Insitu Infrared-Spectroscopy of Well-Defined Single-Crystal Electrodes - Adsorption and Electrooxidation of CO on Pt(111)", Journal of Physical Chemistry, 92(24), p. 6985-6990, 1988.

143. Morimoto Y. \& Yeager E. B., "CO oxidation on smooth and high area Pt, Pt-Ru and Pt-Sn electrodes", Journal of Electroanalytical Chemistry, 441(1-2), p. 77-81, 1998.

144. Morimoto Y. \& Yeager E. B., "Comparison of methanol oxidations on Pt, Pt vertical bar $\mathrm{Ru}$ and $\mathrm{Pt}$ vertical bar Sn electrodes", Journal of Electroanalytical Chemistry, 444(1), p. 95-100, 1998.

145. Wang K., Gasteiger H. A., Markovic N. M., Ross P. N., "On the reaction pathway for methanol and carbon monoxide electrooxidation on Pt-Sn alloy versus Pt-Ru alloy surfaces", Electrochimica Acta, 41(16), p. 2587-2593, 1996.

146. Frelink T., Visscher W., Cox A. P., Vanveen J. A. R., "Ellipsometry and Dems Study of the Electrooxidation of Methanol at Pt and Ru-Promoted and Sn-Promoted Pt", Electrochimica Acta, 40(10), p. 1537-1543, 1995.

147. Gonzalez M. J., Hable C. T., Wrighton M. S., "Electrocatalytic oxidation of small carbohydrate fuels at Pt-Sn modified electrodes", Journal of Physical Chemistry B, 102(49), p. 9881-9890, 1998.

148. Shibata M. \& Motoo S., "Electrocatalysis by Ad-Atoms .11. Enhancement of Acetaldehyde Oxidation by Shole Control and Oxygen Adsorbing Ad-Atoms", Journal of Electroanalytical Chemistry, 187(1), p. 151-159, 1985.

149. Zhao X. S., Jiang L. H., Sun G. Q., Yang S. H., Yi B. L., Xin Q., "Electrocatalytic property of Pt-Sn anode catalyst for electro-oxidation of ethanol", Chinese Journal of Catalysis, 25(12), p. 983-988, 2004.

150. Neto A. O., Giz M. J., Perez J., Ticianelli E. A., Gonzalez E. R., J. Electrochem. Soc., 149, p. A272, 2002. 
151. $\mathrm{Xu}$ C. W. \& Shen P. K., "Electrochemical oxidation of ethanol on $\mathrm{Pt}-\mathrm{CeO}_{2} / \mathrm{C}$ catalysts", Journal of Power Sources, 142(1-2), p. 27-29, 2005.

152. Goetz M. \& Wendt H., "1998", Electrochim. Acta, 43, p. 3637.

153. De Oliveira-Sousa A., Da Silva M. A. S., Machado S. A. S., Avaca L. A., De LimaNeto P., "Influence of the preparation method on the morphological and electrochemical properties of $\mathrm{Ti} / \mathrm{IrO}_{2}$-coated electrodes", Electrochim. Acta, 45(27), p. 4467-4473, 2000.

154. Kwak J. H., Herrera J. E., Hu J. Z., Wang Y., Peden C. H. F., "A new class of highly dispersed VOx catalysts on mesoporous silica: Synthesis, characterization, and catalytic activity in the partial oxidation of ethanol", Applied Catalysis aGeneral, 300(2), p. 109-119, 2006.

155. Easton E. B. \& Pickup P. G., "An electrochemical impedance spectroscopy study of fuel cell electrodes", Electrochimica Acta, 50(12), p. 2469-2474, 2005.

156. Makharia R., Mathias M. F., Baker D. R., "Measurement of catalyst layer electrolyte resistance in PEFCs using electrochemical impedance spectroscopy", Journal of the Electrochemical Society, 152(5), p. A970-A977, 2005.

157. Mueller J. T. \& Urban P. M., "Characterization of direct methanol fuel cells by AC impedance spectroscopy", Journal of Power Sources, 75(1), p. 139-143, 1998.

158. Sen Gupta S., Mahapatra S. S., Datta J., "A potential anode material for the direct alcohol fuel cell", Journal of Power Sources, 131(1-2), p. 169-174, 2004.

159. Wang Z. B., Yin G. P., Shao Y. Y., Yang B. Q., Shi P. F., Feng P. X., "Electrochemical impedance studies on carbon supported PtRuNi and PtRu anode catalysts in acid medium for direct methanol fuel cell", Journal of Power Sources, 165(1), p. 9-15, 2007.

160. Seo S. H. \& Lee C. S., "Impedance characteristics of the direct methanol fuel cell under various operating conditions", Energy \& Fuels, 22(2), p. 1204-1211, 2008.

161. Seo S. H. \& Lee C. S., "Effect of operating parameters on the direct methanol fuel cell using air or oxygen as an oxidant gas", Energy \& Fuels, 22(2), p. 1212-1219, 2008.

162. Mazurek M., Benker N., Roth C., Buhrmester T., Fuess H., "Electrochemical impedance and x-ray absorption spectroscopy (EXAFS) as in-situ methods to study the PEMFC anode", Fuel Cells, 6(1), p. 16-20, 2006.

163. Wagner N. \& Gulzow E., "Change of electrochemical impedance spectra (EIS) with time during CO-poisoning of the Pt-anode in a membrane fuel cell", Journal of Power Sources, 127(1-2), p. 341-347, 2004.

164. Schiller C. A., Richter F., Gulow E., Wagner N., "Relaxation impedance as a model for the deactivation mechanism of fuel cells due to carbon monoxide poisoning", Physical Chemistry Chemical Physics, 3(11), p. 2113-2116, 2001.

165. Leng Y. J., Wang X., Hsing I. M., "Assessment of CO-tolerance for different Ptalloy anode catalysts in a polymer electrolyte fuel cell using ac impedance spectroscopy", Journal of Electroanalytical Chemistry, 528(1-2), p. 145-152, 2002.

166. Bai Y. X., Wu J. J., Xi J. Y., Wang J. S., Zhu W. T., Chen L. Q., Qiu X. P., "Electrochemical oxidation of ethanol on $\mathrm{Pt}-\mathrm{ZrO}_{2} / \mathrm{C}$ catalyst", Electrochemistry Communications, 7(11), p. 1087-1090, 2005. 
167. Bai Y. X., Li J. F., Qiu X. P., Wu J. J., Wang J. S., Xi J. Y., Zhu W. T., Chen L. Q., "Mesocarbon microbeads supported PtSn catalysts for electrochemical oxidation of ethanol", Journal of Materials Science, 42(12), p. 4508-4512, 2007.

168. Sen Gupta S. \& Datta J., "A comparative study on ethanol oxidation behavior at Pt and PtRh electrodeposits", Journal of Electroanalytical Chemistry, 594(1), p. 65-72, 2006.

169. Bommersbach P., Mohamedi M., Guay D., "Electro-oxidation of ethanol at sputterdeposited platinum-tin catalysts", Journal of the Electrochemical Society, 154(8), p. B876-B882, 2007.

170. Wiezell K., Gode P., Lindbergh G., "Steady-state and EIS investigations of hydrogen electrodes and membranes in polymer electrolyte fuel cells I. Modeling", Journal of the Electrochemical Society, 153(4), p. A749-A758, 2006.

171. Wiezell K., Gode P., Lindbergh G., "Steady-state and EIS investigations of hydrogen electrodes and membranes in polymer electrolyte fuel cells II. Experimental", Journal of the Electrochemical Society, 153(4), p. A759-A764, 2006.

172. Parthasarathy A., Dave B., Srinivasan S., Appleby A. J., Martin C. R., "The Platinum Microelectrode Nafion Interface - an Electrochemical Impedance Spectroscopic Analysis of Oxygen Reduction Kinetics and Nafion Characteristics", Journal of the Electrochemical Society, 139(6), p. 1634-1641, 1992.

173. Kurzweil P. \& Fischle H. J., "A new monitoring method for electrochemical aggregates by impedance spectroscopy", Journal of Power Sources, 127(1-2), p. 331-340, 2004.

174. Diard J. P., Glandut N., Landaud P., Le Gorrec B., Montella C., "A method for determining anode and cathode impedances of a direct methanol fuel cell running on a load", Electrochimica Acta, 48(5), p. 555-562, 2003.

175. Mazurek M., Benker N., Roth C., Fuess H., "Binary mixtures of carbon supported Pt and Ru catalysts for PEM fuel cells", Fuel Cells, 6(3-4), p. 208-213, 2006.

176. Sen Gupta S. \& Datta J., "Electrode kinetics of ethanol oxidation on novel CuNi alloy supported catalysts synthesized from PTFE suspension", Journal of Power Sources, 145(2), p. 124-132, 2005.

177. Sen Gupta S. \& Datta J., "An investigation into the electro-oxidation of ethanol and 2-propanol for application in direct alcohol fuel cells (DAFCs)", Journal of Chemical Sciences, 117(4), p. 337-344, 2005.

178. Van der Geest M. E., Dangerfield N. J., Harrington D. A., "An AC voltammetry study of Pt oxide growth", Journal of Electroanalytical Chemistry, 420(1-2), p. 89$100,1997$.

179. Seland F., Tunold R., Harrington D. A., "Impedance study of methanol oxidation on platinum electrodes", Electrochimica Acta, 51(18), p. 3827-3840, 2006.

180. Seland F., Tunold R., Harrington D. A., "Impedance study of formic acid oxidation on platinum electrodes", Electrochimica Acta, 53(23), p. 6851-6864, 2008.

181. Pechini M. P. \& Adams N., "Method of preparing lead and alkaline earth Titanates and Niobates and coated method using the same to form a capacitor", US Patent, 3, 330, 697, p. 1-6, 1967. 
182. Lassali T. A. F., De Castro S. C., Boodts J. F. C., "Structural, morphological and surface properties as a function of composition of $\mathrm{Ru}+\mathrm{Ti}+\mathrm{Pt}$ mixed-oxide electrodes", Electrochimica Acta, 43(16-17), p. 2515-2525, 1998.

183. Garavaglia R., Mari C. M., Trasatti S., "Physicochemical Characterization of $\mathrm{CO}_{3} \mathrm{O}_{4}$ Prepared by Thermal-Decomposition .2. Response to Solution Ph", Surface Technology, 23(1), p. 41-47, 1984.

184. Bard A. J. \& Falkner L. R., Electrochemical Methods: Fundamentals and Applications, N. Y: John Wiley \& Sons Inc, 1980.

185. Macdonald D. D., "Reflections on the history of electrochemical impedance spectroscopy", Electrochimica Acta, Electrochemical Impedance Spectroscopy Selection of papers from the 6th International Symposium (EIS 2004) 16-21 May 2004, Cocoa Beach, FL, USA, 51(8-9), p. 1376-1388, 2006.

186. Ribeiro J. \& De Andrade A. R., "Investigation of the electrical properties, charging process, and passivation of $\mathrm{RuO}_{2}-\mathrm{Ta}_{2} \mathrm{O}_{5}$ oxide films." Electrochimica Acta, 592, p. 153-162, 2006.

187. DaSilva L. A., Alves V. A., DaSilva M. A. P., Trasatti S., Boodts J. F. C., "Oxygen evolution in acid solution on $\mathrm{IrO}_{2}+\mathrm{TiO}_{2}$ ceramic films. A study by impedance, voltammetry and SEM", Electrochimica Acta, 42(2), p. 271-281, 1997.

188. Leiva E., Iwasita T., Herrero E., Feliu J. M., "Effect of adatoms in the electrocatalysis of $\mathrm{HCOOH}$ oxidation. A theoretical model", Langmuir, 13(23), p. 6287-6293, 1997.

189. Horvat-Radosevic V., Kvastek K., Vukovic M., Marijan D., "Impedance of ruthenium electrodes in sulphuric acid solution", Journal of Electroanalytical Chemistry, 463(1), p. 29-44, 1999.

190. Forti J. C., Novos materiais para eletrooxidação de substratos orgânicos: o uso de óxidos ternários de composição $\mathrm{Ti} / \mathrm{R} u_{0,3} \mathrm{R} u_{(0,7-x)} \mathrm{Sn}_{x} \mathrm{O}_{2}$ na investigação da oxidação do etanol,Dissertação de mestrado, Departamento de Química, Universidade de São Paulo: Ribeirão Preto -SP. p. 102, 2000.

191. Shub D. M. \& M.F. R., Elektrokmiya, 21, p. 855-937, 1985.

192. Bockris J. O. M. \& Conway B. E., Modern Aspects of Electrochemistry, ed. Butterworths. Vol. 5, London. 369, 1969.

193. Elumalai P., Vasan H. N., Munichandraiah N., "A note on overpotential dependence of AC impedance data", Journal of Solid State Electrochemistry, 3(7-8), p. 470-473, 1999.

194. Forti J. C., Aplicação de eletrodos óxidos ativados em eletrooxidação orgânica: oxidação de formaldeído,acetaldeído e ácido oxálico.,Tese de doutoramento, Departamento de Química,FFCLRP., Universidade de São Paulo: Ribeirão Preto. p. $110,2005$.

195. Ticianelli E. A. \& E.R. G., Eletroquímica: Princípios e Aplicações, ed. Edusp, 1998.

196. Ribeiro J., Estudo da atividade do sistema binário $\mathrm{RuO}_{2}-\mathrm{Ta}_{2} \mathrm{O}_{5}$ preparado por dois métodos de decomposição térmica na oxidação do Etanol,Tese de doutorado, Departamento de Química, Universidade de São Paulo: Ribeirão Preto - SP. p. 129, 2006. 
197. Comninellis C. \& Vervesi G. P., "Characterization of DSA®-type oxygen evolving electrodes: Choice of a coating ", Journal of Applied Electrochemistry, 21(4), p. 335-345, 1991.

198. Lassali T. A. F., Bulhoes L. O. S., Abeid L. M. C., Boodts J. F. C., "Surface characterization of thermally prepared, Ti-supported, Ir-based electrocatalysts containing Ti and Sn", Journal of the Electrochemical Society, 144(10), p. 33483354, 1997.

199. Ticanelli E., Beery J. G., Paffett M. T., Gottesfeld S., "An Electrochemical, Ellipsometric, and Surface Science Investigation of the Ptru Bulk Alloy Surface", Journal of Electroanalytical Chemistry, 258(1), p. 61-77, 1989.

200. Perez J., Gonzalez E. R., Ticianelli E. A., "Oxygen electrocatalysis on thin porous coating rotating platinum electrodes", Electrochimica Acta, 44, p. 1329-1339, 1998.

201. Cunha E. M., Dissertação de Mestrado, Departamento de Química, Universidade de São Paulo: Ribeirão Preto. p. 77, 2007.

202. Carvalho L. A., Investigação das propriedades eletroquímicas do sistema $\mathrm{Ti} / \mathrm{Ru}_{0,3} \mathrm{Ti}_{(0,7-x)} \mathrm{Sn}_{x} \mathrm{O}_{2}$ utilizando a Espectroscopia de Impedância Eletroquímica, Ribeirão Preto, Dissertação de mestrado, Departamento de Química-FFCLRP, Universidade de São Paulo. p. 1-102, 2004.

203. Giner J., "The anodic oxidation of methanol and formic acid and the reductive adsorption of $\mathrm{CO}_{2} "$, Electrochimica Acta, 9, p. 63, 1964.

204. Iwasita T., "Electrocatalysis of methanol oxidation", Electrochimica Acta, 47(2223), p. 3663-3674, 2002.

205. Ribeiro J., Dos Anjos D. M., Léger J. M., Hahn F., Olivi P., De Andrade A. R., Tremiliosi-Filho G., K.B. K., "Effect of $\mathrm{W}$ on $\mathrm{PtSn} / \mathrm{C}$ catalysts for ethanol electrooxidation", Journal of Applied Electrochemical, 38, p. 653-662, 2008. 